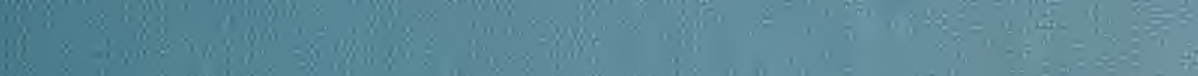
;is

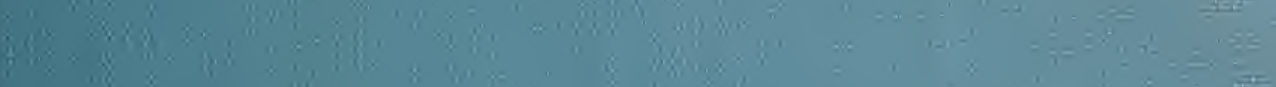

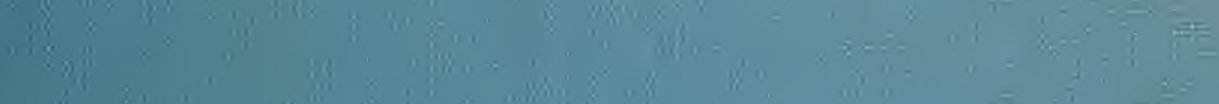

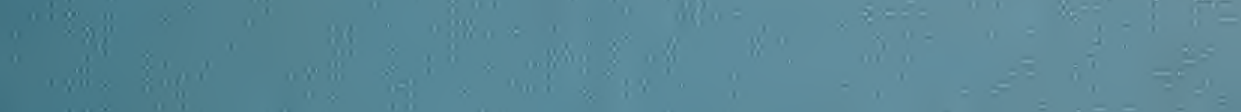

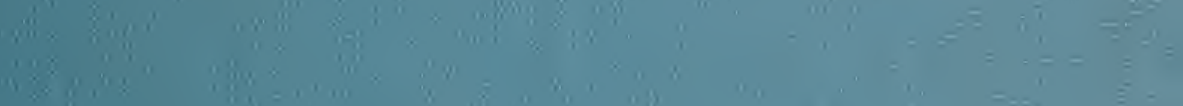

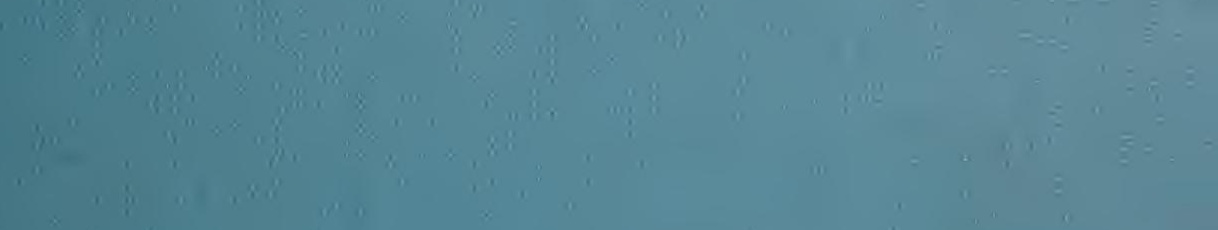

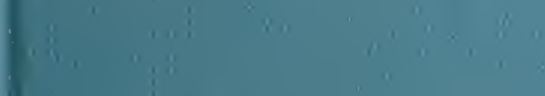

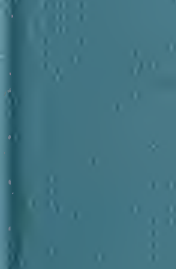

8 $\ddot{y}$

$x^{\prime}$ in $1, \ln$

ins $\sin _{i=1}$ $3 \quad a^{n}$ $\therefore \ddot{x}$ 30

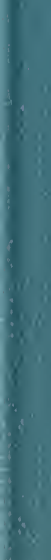

30

1.

$8 X$

$0 \%$

$\therefore i n$

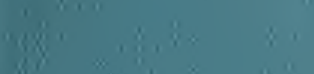
W'
$\mathrm{Y}_{\mathrm{s}}$

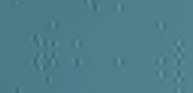

$\operatorname{cis} 2$

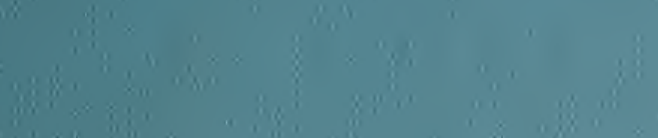

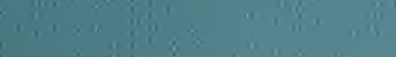

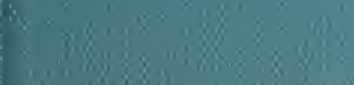

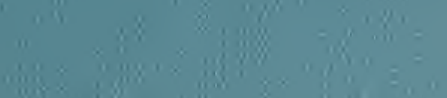
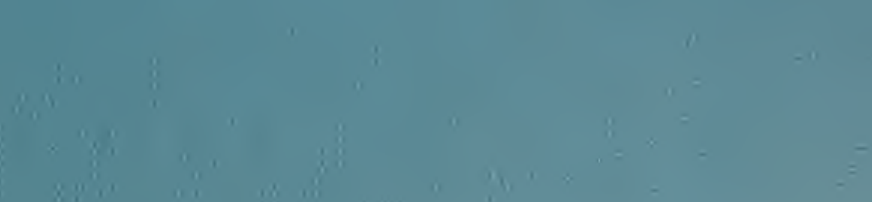


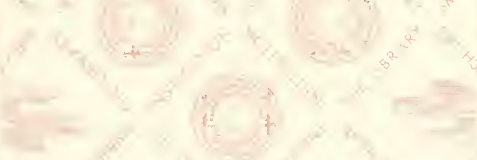

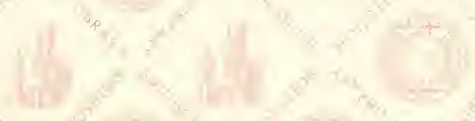

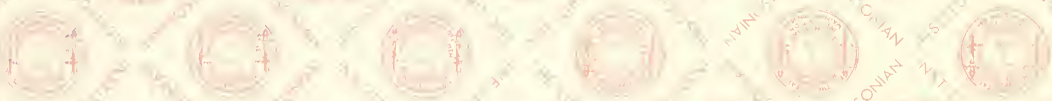

(1) of a

$\Rightarrow$

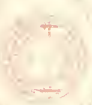

$-9$
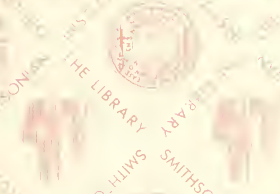

f. It

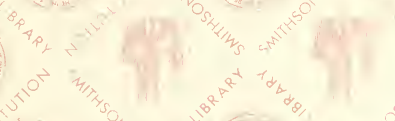

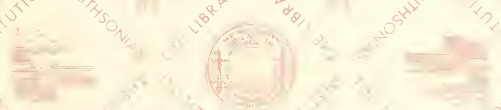

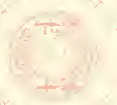

T-
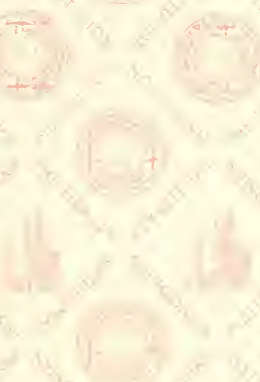

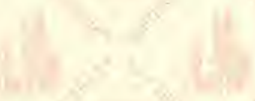
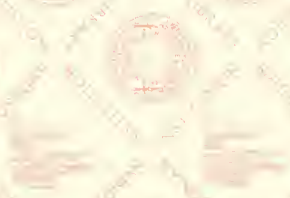

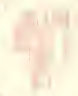
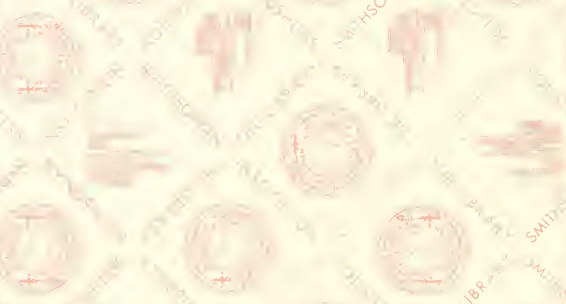

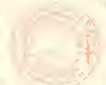<smiles>CC1CCC1[13CH]</smiles>
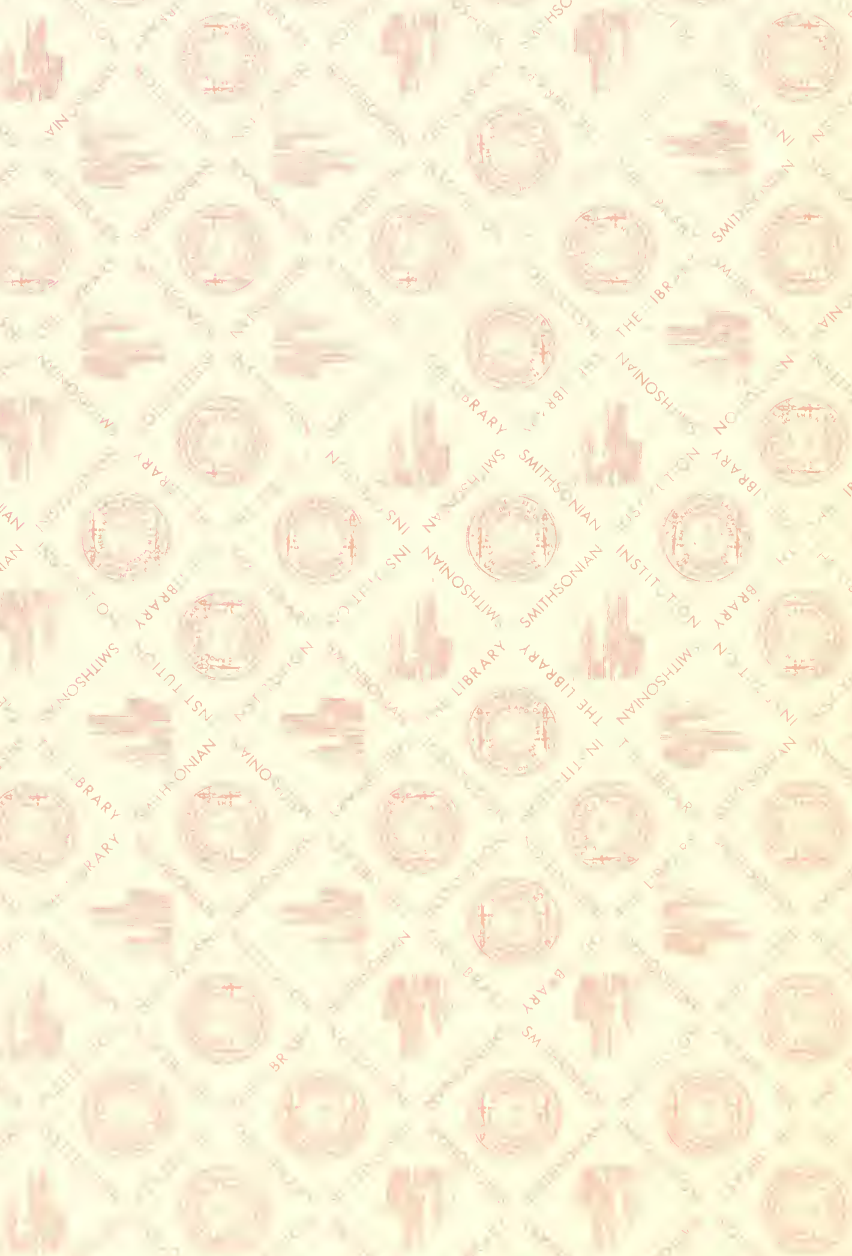

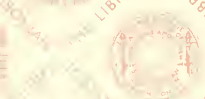



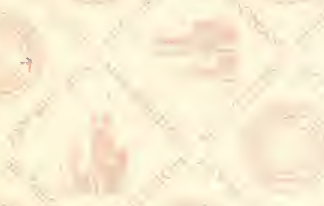

1)
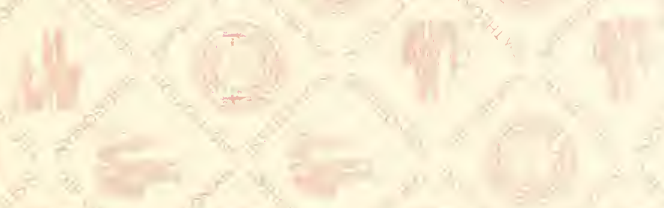

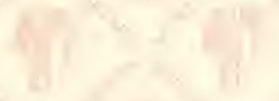

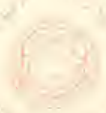

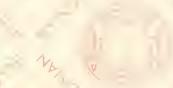

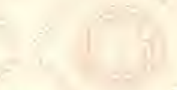






$$
\begin{aligned}
& =\quad \\
& = \\
& = \\
& =
\end{aligned}
$$




\title{
INFORME OFICIAL
}

\author{
DE LA
}

COMXSXON CYENTYKICA

AGREGADA AL ESTADO MAYOR GENERAL DE LA

\section{EXPEDICION AL RIO NEGRO (PATAGONIA)}

\author{
realizada en los meses de Abril, Mayo y Junio de 1879, \\ bajo las órdenes del
}

\section{GENERAL D. JULIO A. ROCA}

(con 16 Láminas.)

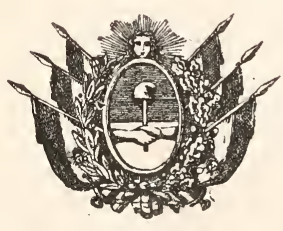

\section{BUENOS AIRES}

Imprenta de Ostwald y Martinez, calle Florida Núm. i 36.

$$
1 \overline{881} \text {. }
$$



EXPEDICION AL RIO NEGRO 



\section{INTRODUGGION}

E1 año I879 tcndrá en los anales de la Rcpública Argentina una importancia mucho mas considerable que la que le han atribuido los contemporáneos. Ha visto realizarse un acontecimiento cuyas consecuencias sobre la historia nacional obligan más la gratitud de las generaciones venidcras que la de la presente, y cuyo alcance, desconocido hoy, por transitorias cuestioncs de personas y de partido, necesita, para rcvelarse en toda su magnitud, la imparcial perspectiva del porvenir. Ese acontecimiento es la supresion de los indios ladrones que ocupaban el Sur de nuestro territorio y asolaban sus distritos fronterizos: es la campaña llevada á cabo con acierto y energía, que ha dado por resultado la ocupacion de la línea del Rio Negro y del Neuquen.

Al hablar del pasado, seremos parcos de consideraciones, y sobre todo de recrimina-

ciones que, á mas de ser inoficiosas, se volverian fácilmente irritantes. Sin embargo, hay que estudiar, á lo ménos con el fin de aprovechar las lecciones que encierra para el futuro, ese fenómeno de una nacion vigorosa, pronta para todos los patrióticos sacrificios, provista de un ejército aguerrido, de medios de accion relativamente poderosos, y sin embargo tenida en jaque, cruelmente herida en su desarrollo y su fortuna, por un puñado de malvados.

No se ha hecho nunca una estadística exacta de las depredaciones de los salvajes, de los valiosos intereses destruidos anualmente por ellos, sin contar las vidas sacrificadas. No es el momento de reunir á ese respecto guarismos desconsoladores. No tendrian ya interés práctico, y su triste elocuencia desaparece en presencia de esta consideracion: que las pérdidas matcriales eran poca cosa en comparacion de los perjuicios de mayor trascendencia política y moral que esas impunes corrcrías infligian á la República.

No solamente atacaban en sus fucntes la principal industria del país y el más rico 
elemento de su prospcridad: la ganadería; no solamente contribuian á disminuir á la entrada ó, despues de entrada, á estancar inútilmente en las ciudades la corriente de la inmigracion estrangera; comprometian el crédito esterior del Gobierno Nacional, por la impotencia de que parecía convicto frente á un ejército de chuzas, por los humillantes tributos que eran la consagracion oficial y el irrisorio rescate de esa impotencia. Cuando el emperador del Brasil preguntaba con fingido interés á un plenipotenciario argentino, en el acto de presentarle éste sus credencialés, si eran ciertas las noticias que le habian llegado de una invasion india en el Sur de Buenos Aires, dejaba ver á las claras con qué peso, en la opinion de los estadistas vccinos, la cucstion indios debía gravitar sobre la política esterior de la Confedcracion Argentina.

En cuanto á Chile, su gobierno contenía tambien, á duras penas, á los salvajes quae ocupaban sus sierras meridionales, pero cierto gremio de sus comerciantes mantenia con los indios de este lado de los Andes relaciones de entrañable amistad. Es permitido suponer que la periódica llegada de inmensos rebaños de hacienda, que los soldados de una república rival no habian podido defender, no ha dejado de tener influencia sobre la opinion que las clases poco ilustradas de la poblacion se formaban de la organizacion militar dcl pueblo argentino. Es más que probable que ha contribuido á desvirtuar, hasta en los hombres más encumbrados de la administracion chilena, mcjor enterados, sin embargo, de las condiciones de esa ingrata lucha, el buen efecto de la conciliadora actitud que el Gobierno Nacional de nuestro pais había adoptado en la cuestion límites. Tendrémos ocasion, al estudiar los valles del Rio Negro y del Neuquen, de mostrar, con la satisfac* cion que se esperimenta en señalar un peligro ya conjurado, la deplorable situacion en que hubiera colocado militarmente á los Argentinos, la presencia del indio en el inmenso territorio que ayer no más dominaba.

Hemos abreviado cuanto ha sido posible la esposicion de los elevados intereses de progreso interior $\mathrm{y}$ de influencia esterior que se encontraban ligados con las cabalgatas de unos cuantos nómades resueltos á no pedir sinó al robo sus medios de subsistencia, y consideramos inútil estendernos en pruebas. No hay argentino á cuyo espíritu no se hayan presentado, y con más fuerza que la con que las presentamos, idénticas consideraciones. Todos los gobiernos, desde que hay una República Argentina, han demostrado, por sus actos, de qué importancia les parecía esa intrincada cuestion indios, y han tratado, si no de resolverla, á lo menos de adelantar su solucion.

Para tributar á todos la merecida justicia, creemos que pocas son las ideas, aún entre las que han dado tan brillante resultado en estos últimos tiempos, que no hayan sido an. teriormente propuestas, discutidas, ensayadas. Sobre la ocupacion de puntos estratégicos á vanguardia y á gran distancia de los establecimicntos, para operar de ahí en todos los rumbos por medio de columnas ligeras, se conocen las opiniones del Coronel Don Pedro García, consignadas en el notable informe que redactó en los primeros alborcs de la guerra de la Independencia; en tiempos menos remotos, no se han olvidado la espedicion dcl Coronel 
Granada á Salinas-Grandes, los proyectos presentados por el general Rivas durante la administracion Sarmiento. Sobre la conveniencia de la guerra ofensiva, en vez de la defensiva, sin hablar de Rauch, que la erigió en sistema, basta recordar la larga série de gol. pes de mano sobre los toldos, afortunados unos, desgraciados otros, lo que no importa nada para la clara percepcion del principio que los motivaba, que han sucesivamente dirigido los más conspícuos gefes de la época de Rosas, y más tarde los dos generales Mitre y el general Arredondo. Sobre la misma espedicion al Rio Negro, tenemos un antecedente: la espedicion del general Pacheco, hecha en combinacion con fuerzas venidas de Mendoza.

En este sentido, había cierto viso de verdad en las afirmaciones de los que declaraban, al ver los acontecinientos tomar otro giro, que eso no era novedad, que idea análoga se había puesto en ejecucion en tal fecha. Onitimos hablar de la variedad numerosa, y siempre ingénuamente convencida, de los que esclaman, con cándida solemnidad, despues de cada nuevo triunfo alcanzado: que el éxito no les sorprende, puesto que era la consecuencia de lo que han proyectado y predicado en otros tiempos.

Sin embargo, algo nuevo habia de haber en las teorias recien aplicadas á la guerra fronteriza, pues sería difícil comprender de otro modo lo inesperado de los resultados. Una concepcion militar, lo mismo que el árbol del Evangelio, debe juzgarse por sus frutos. Había algo nuevo, en efecto, en el plan del general Roca, y de ese conjunto de ideas, parcial y aisladamente aplicadas al acaso de las inspiraciones de cada gefe y de las variables fases de la guerra, había llegado á formar un sistema completo, eminentemente ori. ginal y propio. Se valió, para coordinar y fecundar esos varios, conocidos y hasta entonces estériles medios de accion, de un estudio cuya utilidad en la guerra no era tampoco un descubrimiento, $\mathrm{y}$ que desde algunos años ha, sobre todo, se ha vuelto el alma $\mathrm{y}$ el nervio de las grandes campañas europeas, pero que nunca se había aplicado á la guerra pampeana con tanta paciencia en las pesquisas y con tanta perspicacia en las deducciones. Ese estudio, es el estudio topográfice del futuro teatro de las operaciones.

El general Roca se ha inspirado en los modernos adelantos de la ciencia de la guerra, pues la guerra ha dejado de ser un arte sometido á los caprichos del instinto marcial y de la inspiracion, $y$ obedese á las reglas fijas $y$ al método severo de la ciencia esperimental. Ha comprendido que la llave del asunto se encontraba en la configuracion del terreno, y que, mientras no se hubiera arrancado á la misteriosa pampa sus últimos secretos, habría que prescindir de sistemas. Ha dedicado á ese estudio los largos ratos desocupados que le dejaba la guardia que estaba montando en las fronteras de Cuyo. No se ha dejado desanimar por las oscuridades del problema, la incertidumbre de los datos, las contradicciones de los vaqueanos, ni tampoco, lo que es más meritorio todavía, por la radical diferencia que notaba entre las opiniones universalmente aceptadas sobre la guerra de indios y las consecuencias á que lo llevaban sus laboriosos y paulatinos descubrimientos. En fin, apoyado en un acopio de conocimientos que se servian de mútuo control, posesionado en espíritu de todas las peculiaridades de su campo de accion, ha podido for. 
mular su plan, vasto cn el conjunto, minueioso en los detalles, elaborado eon tanta preeision que la eampaña se ha realizado en eompleta conformidad eon. las instrueeiones distribuidas, y más bien con la tranquila regularidad de un esperimento de físiea, organizado en un laboratorio, para poner de manifiesto lcyes eonoeidas, que con las eontingeneias de una empresa de guerra. Las operaeiones abareaban, sin embargo, una estension de quinee mil leguas euadradas. Tales son los títulos del general Roea. Ha puesto al servieio de un espíritu sagaz un método aeertado, verdaderamente eientífico.

No tenemos la inteneion, y nadie sospechará que ni remotamente la tengamos, de deseonoeer en esa apreciaeion de la última eampaña el inmenso paso que habia heeho dar á la euestion frontcras el ilustre Dr. Alsina. Se rebelarian eontra tal apreeiaeion, si llegase alguna vez á formularse, no solamente la equidad de la historia, sinó los mas íntimos y más sagrados sentimientos de la concieneia públiea de su patria. En el eneadenamiento lógieo de los sueesos, la obra del Dr. Alsina debía preeeder á la del general Roea para hacerla posible. A fin de formarse una idea de lo que ha importado su eorto pasaje en el Ministerio de la Guerra para la solueion definitiva de la euestion, basta indicar lo que cran los indios euando se reeibió de la cartera, y en qué estado los dejó. Los eneontró dueños en la eampaña,-ensoberbeeidos por los recientes golpes que las discordias eiviles les habian permitido inferir á la fortuna pastoril de la República, eonfiados cn euanto á impunidad en las vacilaeiones de una administraeion apenas instalada y rodeada de amenazas; ora dietando eondieiones, ora atreviéndose á ofreeer batallas campales; rieos en eaballos, campos y audacia, burlando la vijilaneia y riéndose de la perseeueion.

Los dejó pobres, fugitivos, errantes por estériles eampañas, sin eaballos, sin víveres, dominados por todas partes, desalojados de sus mejores invernadas, esearmentados en sus desesperadas tentativas de invasion, temblando en sus própios toldos á eada ráfaga de viento, y recibiendo, en los sueesivos eampamentos de fortuna en que se venian á refugiar, golpe tras golpe, de las fuerzas de la nueva frontera. Los que han preseneiado las rápidas peripeeias de la guerra del desierto, durante ese período, dirán_si exageramos un solo rasgo en ese breve euadro de los resultados obtenidos en tres años por la robusta inteligeneia, la ardiente actividad, el aeendrado patriotismo del Dr. Alsina. Su intervencion en los asuntos fronterizos marea, en la historia de la frontera, algo más que un momento deeisivo: una era nueva.

Pero euando desapareeió, euando esa alma de fuego y esa voluntad de hierro vinieron á deseansar en la muerte, si bien debido á sus esfuerzos, las tropas fronterizas estaban sobre el eamino del Rio Negro, nada autorizaba á creer que estuviesen en sus orillas, y que de un salto franquearian la distancia que las separaba de esa frontera natural. Estaba en la eonvieeion de todos que la terminaeion de la guerra india cra euestion de tiempo, la opinion públiea se resistía á creer que fuese cuestion de dias, La vigorosa mano del Dr. Alsina, sus triunfos, habian abierto una brecha en preoeupaciones seculares; aparccía á todas las inteligencias la posibilidad de resolver el problcma, pero jeuántas divergencias so- 
bre el tiempo neccsario para la ejecucion! Una voz autorizada habló de centenares de años; los mas intrépidos pedian veinte años para coronar el edificio. Un solo hombre afirmó que bastaba un año, y probó, del modo más á propósito para abreviar la discusion, quc lo que había dicho era realizable: Lo probó, realizándolo.

Nadie ha olvidado el sentimiento de sorpresa y de incredulidad que acogió la primera indicacion de esa idea cn el mensajc al Congreso del I4 de Agosto de 1878. Esa circunstancia revcla bien que ese mensaje cambiaba en algo la faz de la cuestion, quc mo. dificaba de cierto modo las ideas reinantes. En otros términos, el general Roca, á más de los elementos de solucion que había recibido, por decirlo así, en herencia, á más de los fecundos ejemplos y de los brillantes resultados prácticos que cran cl glorioso lcgado del Dr. Alsina á su sucesor, traía tambien al debate algun contingente propio, algun descubrimiento personal, algun argumento que se ofrecía por primera vez al fuego de la discusion.

$\mathrm{Y}$ verdaderamente, en presencia de ese documento, cuyas incicaciones, sin cmbargo, sc han cumplido tan al pié de la letra, que hoy parece escrito despues de la campaña y no antes, se comprende la escitacion de la opinion, y entendemos por csa palabra la opinion ilustrada, la de los hombres mas compctentes en la materia: la opinion de los demás no es opinion. Se trataba de conquistar una área de I 5,000 leguas cuadradas, ocupadas cuando menos por unas I 5,000 almas, pues pasa de 14,000 el número de muertos y prisio. neros que ha reportado la campaña. Se trataba de conquistarlas cn el scntido mas lato de la espresion. No era cuestion de recorrerlas y de dominar con gran aparato, pero transitoriamente, como lo había hecho la cspedicion del general Pacheco al Neuquen, el espacio que pisaban los cascos de los caballos del ejército y el círculo donde alcanzaban las balas de sus fusiles. Tal espedicion, por la dcsigualdad cntrc los sacrificios que hubicra exijido y el resultado material quc hubiera proporcionado, habría constituido mas bien un retroceso sobre lo que existía. Era necesario conquistar rcal y eficazmcntc csas I 5,000 leguas, limpiarlas de indios de un modo tan absoluto, tan incuestionable, que la mas asustadiza de las asustadizas cosas del mundo, cl capital destinado a vivificar las cmpresas de ganadería y agricultura, tuviera él mismo que tributar homenaje á la evidencia, quc no esperimentase rccelo en lanzarse sobre las huellas del ejército espedicionario y sellar la toma de poscsion por $\mathrm{cl}$ hombre civilizado de tan dilatadas comarcas.

Había una consideracion mas que csa conquista hacía surgir. La administracion supcrior, por el hecho mismo de apodcrarsc de csas regiones y declararlas sometidas á su autoridad, aceptaba todas las consecuencias y todos los cargos que csa autoridad acarrcaba. Afirmaba que ella cra cn adelante la encargada de la policía de sus nuevos dominios; contraía la obligacion de hacer sentir, en todos los rincones de éstos, su accion previsora y protcctora. Pues bien, csos dominios representaban casi otra República Argentina anexada á la antcriormente constituida, y formada de territorios indefinidos, dondc la soledad, las distancias, los montes, oponian obstáculos gravísimos tanto á la vijilancia como á la 
represion. Los deberes que venían aparejados con la gloria del triunfo, empeñaban de un modo bastante sério la palabra del Gobierno Nacional para provocar las meditaciones de los hombres de estado. Se podía dudar, y se dudó efectivamente con mucha generalidad, si esa empresa no era una imprudencia análoga á la de las familias que se arruinan por haber comprado una casa demasiado grande, no á consecuencia del precio que les costó, sinó de las erogaciones contínuas para amueblarla y mantenerla en buen estado y en buen pié. Esas dudas respondian á sanas teorias de gobierno, y las significativas palabras: «se necesitarán diez generaciones y trescientos años para llegar al Rio Negro, s por mas cruelmente que hayan sido desmentidas por los hechos, indicaban una elevada comprchension de las leyes generales que rigen el desarrollo de las sociedades, al mismo tiempo que revelaban un conocimiento incompleto de las condiciones físicas de la pampa. Esa frase era la espresion exagerada, la reproduccion abultada, porque se miraba la cuestion con el espíritu de partido, que lo engrosa todo como un microscopio, pero, con todo, la reproduccion de ideas que compartian entonces muchos espíritus escelentes.

No insistimos sobre esa consideracion solamente con el objeto de mostrar que el general Roca, en vez de ser llevado por la opinion á la consumacion de una empresa con. siderada como fácil y madura, tuvo que remontar la corriente para hacerse autorizar á llevar adelante sus proyectos. Insistimos sobre todo, porque tendrémos que volver, cuando se trate de la esplotacion de las tierras arrancadas á los indios, sobre esos problemas de administracion que se imponen al estudio en el momento mismo en que quedan re. sueltos los problemas militares.

De todos modos, el resultado ha probado que era hacedero, y aun fácil, el estirpar los indios, hasta el último, de la zona que se quería agregar á las posesiones de la República, y se puede ver ya que, una vez limpia aquella de salvajes, es posible proporcionarle las garantias de seguridad $y$ de vigilancia adninistrativa que reclama un territorio para entrar de frente en el movimiento de la civilizacion y de la produccion. Tal fenómeno es debido á esta circunstancia: que, en esa inmensa superficie, contados son los puntos donde podian encontrar abrigo y subsistencia los indios. Contados son por el mismo motivo los puntos donde podrian, si la desidia del gobierno les permitiera aparecer en la pampa, albergarse los cuatreros. Desalojados los indios de esas guaridas conocidas, ya no tenian donde meterse, y les era forzoso rendirse ó emigrar. Ocupando permanentemente los mismos lugares, ó visitándolos con frecuencia, no hay cómo temer que los cuatreros se posesionen del nido abandonado de los salvajes.

Esa consecuencia, que el general Roca había sacado de sus largas investigaciones sobre la topografía de la pampa interior, era la base de todo su plan. Constituía seguramente, por lo fecundo de los resultados que naturalmente han dimanado de esas premisas, una novedad no despreciable en la guerra india.

Parecerá estraordinario que campos casi ilimitados no brinden por todas partes á sus moradores refugios y escondites, donde puedan diseminarse y evitar la persecucion. Así 
sucede sin embargo. No hay que demostrarlo hoy: no se demuestra la evidencia. Los resultados anunciados por el general Roca se han realizado de modo á dar satisfaccion á los más exigentes sobre lo acertado de la conviccion que manifestaba á ese respecto.

Para esplicar cómo esos resultados debian necesariamente producirse, hay que indicar la composicion del suelo de la pampa en las diversas zonas en que está dividida. No entraremos en enumeraciones de puntos geográficos, que eran de palpitante interés para el militar en el momento de la campaña, pero que podrian fácilmente fastidiar al lector. A fin de dar más claridad $y$, en cuanto el asunto lo permita, más animacion á esta esposicion, veamos de qué modo se ha formado ese suelo, y busquemos los elementos de la conquista y las condiciones de la futura esplotacion en el juego de las fuerzas geológicas que, mucho ántes de la aparicion del hombre, preparaban un campo á su actividad, á sus pasiones y á sus luchas.

En una época que es difícil fijar, en el estado actual de nuestros conocimientos geológicos de la pampa, pero que se puede colocar aproximadamente á fines de la edad terciaria, ó á principios del período cuaternario, probablemente toda la zona que se estiende á inmediaciones y á vanguardia de la antigua línea de fronteras, del Océano al pié de los Andes, era ocupada por el mar. Sólo aparecian sobre las olas los cerros, mucho más altos que lo que son ahora, de las sierras de Currumalan, y unos cuantos islotes de terreno primitivo-granito $\mathrm{y}$ asperon colorado-testigos de convulsiones anteriores del globo, piedra de arranque de la construccion de un continente nuevo.

En el transcurso del tiempo, de la evolucion geológica, inmensas capas de materia calcárea se depositaron alrededor de cada uno de los cerros. Deponian sus despojos sobre las orillas, en un agua poco honda, y el incesante trabajo de esas fuerzas misteriosas, durante una innumerable sucesion de años, iba alejando paulatinamente las costas del mar de los distintos islotes de terreno primitivo que constituían otros tantos centros de irradiacion. Los islotes se volvieron islas; las islas se ensancharon y llegaron á unirse pirra constituir una gran tierra.

Otro fenómeno se había unido á la formacion de los sedimentos de materia calcárea para acelerar ese resultado. Era la desagregacion de las rocas primitivas, bajo la influencia de los agentes atmosféricos, y su trasporte á gran distancia bajo la forma de piedras rodadas, de piedritas, de arena gruesa, luego de arena muy ténue, por las corrientes de agua que surcaban sus flancos y se deslizaban sobre los bancos calizos que se estendian á sus piés. Algunas de esas corrientes se han perdido, ntras existen todavía:-son los arroyos que, del lado del Atlántico especialmente, estan en actividad y, puede decirse, á la obra. Estan ocupados en rellenar, con el contingente de sus arenas y de su barro, lo que fué en otros tiempos sus imponentes estuarios, y que, por lo general, no pasa hoy de cangrejales que van solidificándose á nuestra vista.

Sobre la superficie de las capas sedimentarias, á medida que los elementos calizos depositados le dan un poco de firmeza, la accion del viento eleva la caprichosa ar- 
quitectura de los médanos. Estos son una especie de construccion hibrida entre la tierra firme de que son la vanguardia por un lado, y por otro lado las olas que vienen á reemplazar, cuyas formas reproducen, cuya movilidad al ímpetu del viento imitan imperfectamente y de lejos. Son algo parecidos en eso á aquellos seres fantásticos, hijos de la imaginacion griega, que han seducido tantas veces el talento de los pintores, y que, condenados á una lenta petrificacion por la venganza de algun dios, conservaban largo tiempo en medio de la invasion creciente de la rigidez mineral, el aspecto, el instinto ó el impoten. te esfuerzo de la vida, Los médanos, orientados con notable regularidad, segun la direccion de los vientos, dominantes, dibujan con su línea ondulada las orillas sucesivas de los antiguos mares, hoy secos, y presentan un dobladillo continuo y como la línea tendida de un ejército de invasion en marcha, á lo largo de la costa del Altántico.

Los arroyos actuales, sea que vayan á perderse en el Océano, sea que mueran en algun inmenso hueco, que queda como la representacion en miniatura del mar que las arenas han terraplenado, ofrecen todavía una série de fenómenos perfectamente caracterizados, y patentizan los métodos de que se ha valido la naturaleza para hacer emergir este continente del seno de las aguas.

Se comprende, por la distancia é irregular colocacion de los puntos graníticos que servian de centro á los círculos de solevantamiento del suelo, que varias deben ser las porciones de cauce del antíguo mar que han quedado prisioneras entre los levantamientos surjidos de centros diferentes. Esos trozos de cauce de mar siguen desempeñando, en pequeña escala, sus funciones de océano reducido. Reciben los arroyos que las montañas les mandan; se rodean de médanos, cuyos materiales les son brindados por esos mismos arroyos. Pero los dos vestigios de mar interior, los mas notables que ofrezca toda la pampa, son, á lo largo de la sierra de Currumalan, la gran laguna Alsina con sus dependencias, las lagunas de Guaminí y Epecuen, y á lo largo de los últimos contrafuertes de los Andes, la laguna Urre-Lafquen, con la larga depresion, orientada de Norte á Sur, que la pone en comunicacion con las aguas saladas de San Luis, por medio del Rio Salado.

Ahí tenemos patente, aunque en via de desaparecer y de unirse con la pampa inmediata, el cauce del antíguo mar, cauce muy arriba, sin embargo, como es natural, del nivel anterior, y bastante elevado ya sobre el Atlántico para que lo sobrante de las aguas que recibe, lo que la evaporacion espontánea no disipa, pueda dirigirse al Océano. Las aguas de la laguna Alsina, despues de una infinidad de vueltas, de culebreos y de estancamientos debidos á la ausencia de declive, vienen á engrosar el Saladillo y el Salado de la provincia de Buenos Aires y se dirigen perezosamente á la Ensenada de San Borombon. A medida que se regularice la parte superior de su cauce, por los aluviones contínuos que recibe, se levantará la marcha de las aguas, y el antíguo mar tendrá una corriente fija: es un rio en estado embrionario. Las aguas del Bebedero, en la parte occidental del continente, y las que trae el Atuel, van con un declive mas marcado á engrosar el Rio Colorado, despues de atravesar la laguna Urre-Lafquen, por mełio del Cura-Có. Son rios no 
perfectos todavía, pero que han salido del estado cmbrionario, y de que el hombrc podrá quizá sacar partido, aprovechando el movimiento que la gravedad imprime á sus aguas y la rclativa regularidad de su caucc.

Tal es el aspecto de toda la comarca hasta el Rio Colorado. Al Sur de este rio, la formacion calcárea desaparece, el suelo está compuesto dc espesos depósitos de matcrias de aluvion que descansan directamente sobre cascajos, $y$ todo despierta la idea de una forma. cion mucho mas reciente, probablemente de un Estrecho de Magallanes cuaternario, que marcaba por ese lado la estremidad meridional del continente.

Del análisis geológico que acabamos de hacer, se deduce toda la economía del plan militar adoptado y se hacen palpables los motives del éxito que ha coronado las operacioncs de guerra. Esto no ha de sorprender á los que hayan estudiado con alguna detencion los estrechos lazos que unen la composicion del suelo y su topografia con los problemas que presenta su conquista. Diremos mas: hay una necesaria correlacion entre la geo. logía de una comarca y las facilidades que ofrece para el desarrollo de una floreciente civilizacion; podremos sacar de lo que antecede consideraciones importantes sobre el porvenir de esas tierras. Hablemos primero de las cuestiones militares.

Siendo la formacion de la pampa lo que hemos dicho, resulta que presenta cuatro clases de terrenos con caracteres perfectamente definidos y aptitudes de produccion muy distintas. Esas cuatro clases son: $I^{\circ}$ los terrenos primitivos, antiguas islas del mar americano; $2^{\circ}$ inmensos depósitos calcáreos estratificados al rededor de ćstas, terrenos mas altos que los siguientes; 3 formacion arenácea, líncas sucesivas y paralelas de médanos que han sucedido inmediatamente á los bancos calizos y rellenan los claros que dejan entre sí; 4 en fin, lagunas y bajos formando dos grandes sistemas principales, ora sali. trosos, ora salados, que son el caucc actual é intermitcnte de un mar casi completamente terraplenado por la accion niveladora de las aguas llovedizas. Ahora ¿qué recurso ofrecía á los indios cada clase de terrcno?

El terreno primitivo forma á veces sierras de cierta importancia, como la de Currumalan, perdida hace tiempo para ellos, generalmonte grupos aislados de una á tres leguas de estension. La tierra vegetal es escasa; la que hay es admirable. El agua dulce es su. ministrada por manantiales y arroyuelos. La caza es difícil, así como la custodia del ganado yeguarizo y vacuno por lo escabroso del suelo. Hemos visto en Lihué-Calel, á dos pasos de una tribu que se moría literalmente de hambre, bandas de guanacos arrimarse con curiosidad á tiro de fusil, como animales que no han sido molestados, y confiados completamente en las pendientes á pique de sus cerros para preservarse de cualquicra tentativa de cazadores salvajcs. En resumidas cuentas, hay cn cada sierrita elementos cie vida para una familia, no los hay para una tribu cn posesion de unos cuantos animales. Cuando se han encontrado tolderias en las sierritas, eran gente de pasage, dcscansando algunos dias en su retirada, ó si eran habitantes permancntes, componian agrupaciones muy reducidas, de vcinte á treinta indivíduos. 
El terreno calcáreo, que viene despues, forma planicies tendidas, de una sustancia sumamente dura y generalmente escasa de agua. Cuando tiene abundaneia de líquido, es muy á propósito, merced á los elementos calizos que contiene, tanto para la cria como para el engorde. Dá animales mas robustos para el trabajo y mas sabrosos para comer que los que se mantienen en las campañas, formadas de puro barro, del Norte de Buenos Aires. Pero no es posible tener agua dulce en abundancia sinó á lo largo de los arroyos, ó en los valles interiores formados por antiguos arroyos, hoy obstruidos por amontona mientos de tierravegetal $\mathrm{y}$ de arena. La region de los arroyos de agua dulce habia sido quitada á los indios, al mismo tiempo que las bajantes meridionales de la Sierra de Currumalan, por el acertado trazado de la línea avanzada del Dr. Alsina. Los valles no contienen siempre lagunas dulces, pero en la materia de aluvion que forma su fondo, es fácil cavar jagüeles que dan agua potable si se baldean incesantenıente, agua salitrosa, cargada de materias orgánicas, y á veces verdaderamente venenosa para los caballos, si se deja algunos dias en contaeto con el aire. Allí se obstinaron en vivir de privaciones hasta el último momento, $\mathrm{y}$ se aniquilaron del todo, hasta tener que presentarse sin condiciones, los últimos restos de las tribus de Catriel y de Cañumil, arrinconadas en esos poco hospitalarios valles, á consecuencia de: la tenaz persecucion de que fueron objeto.

El terreno arenáceo presenta zonas nuy distintas segun su altura sobre el nivel del mar. Las partes más elevadas, las más distantes de los vestigios del cauce primitivo de que hemos hablado, son áridas. No carecen completamente de agua, pero la tienen guardada en la arena, á una profundidad que hace difícil para indios su estraccion. En las partes intermedias, es fácil la escavacion de jagüeles y algo más difíeil para indios preservar del desmoronamiento sus desmenuzables orillas.

No hubiera sido posible á salvajes, en esas regiones, abastecer de agua por medio de jagüeles un regular número de haciendas.

Pero las regiones inmediatas al antiguo mar interior reciben una cantidad de agua estraordinaria, no solamente de los arroyos sinó de la filtracion natural del líquido por entre las capas de arena que las dominan. Cuando esa agua no es salada por la abundancia de cloruro de sodio contenido en $\mathrm{el}$ suelo, cuando tiene en disolucion solamente los nitratos y los sulfatos que la descomposicion de las plantas origina espontáneamente en las grandes lagunas, esa zona es la más fértil de la comarca. Notable ejemplo de esa favorable condicion presenta la línea divisoria entre la formacion caleárea y la arenácea que, pasando por las lagunas Alsina, Guaminí, Epecuen, sigue por Salinas Grandes, „Chiloé y una cadena no interrumpida de lagos hasta Traru-Lafquen. Los deelives de las dos formaciones vienen á converger en el centro del estrecho valle que les sirve de límite comun y que rebosa de agua. Los médanos se hallan tan impregnados de líquido que brotan por todas partes manantiales de agua ligera, pura, cristalina, filtrada por el inmejorable filtro natural que forma la arena silíceo-calcárea del médano. Ese valle, por su feracidad escepcional, permitió á la tribu de Namuncurá el quedar una de las últimas en pié, hasta que le hubieron quitado 
esa joya de la pampa. Cuando, de retirada en retirada, llegó á su estremidad, tenia que desaparecer, y desapareció.

Otros bajos, más ó ménos estensos, ofrecen el mismo carácter de mostrar en la superficie cl agua filtrada por médanos más clcvados que su nivel y que van incílnándose hácia ellos desde larga distancia. Dcscuella entre ellos, tanto por su importancia, cuanto por su ventajosa situacion á buena distancia de las tolderías de Namuncurá y de los establecimientos cristianos, sobre uno de los caminos generales mas importantes que llevan á Chile, el valle de Leufu-Có, morada de la principal aglomeracion de los Ranqueles.

Unas cuantas lagunas más, conocidas hoy y visitadas una por una por las tropas nacionales, rcpresentan en toda la region arenácea los únicos puntos donde el salvaje pueda vivir. Sus migraciones, que tanto han intrigado á los gefes fronterizos al principio de las espediciones, por falta de vaqueanos y de ideas fijas sobre el aspecto general de la comarca, se limitaban á mudarse de una á otra en la region elegida por cada tribu. Agotada para ellos la série de esas posibles moradas y perseguidos en su marcha con constancia, llegó el momento en que les faltó cl agua cn ese mar de arena. Es exactamente como si les hubiese faltado la tierra bajo los piés.

En cuanto á la línea de grandes lagunas qne quedan del mar antiguo, están rodeadas del lado del Oeste, de la laguna Alsina á Epecuen, de bajos muy fértiles; pero del lado del Este, de Urre-Lafquen al Bebedero, la sal de que está cargado el suelo lo ha esterilizado á larga distancia de las lagunas y de los rios que las alimentan. Es una region desolada tendida á lo largo de la pampa central como una natural barrera que la separa de la region andina, y cruzada de pocos caminos que van á Chile.

Se comprende bien, despues de la breve enumeracion de las grandes zonas en que está dividida la pampa, de qué modo y por cuales motivos la consideracion de esos característicos accidentes topográficos, aplicada por vez primera á esa vasta y poco conocida estension de desierto por un cspíritu metódico y generalizador, debía cambiar del todo la faz de la guerra. La abundancia de terrenos inhabitables para nómades, que es ahora fácil describir, despues de conquistados, había sido revelada poco á poco al General Roca, recogiendo y comparando datos. El dia en que la conviccion se formó en su espíritu á ese respecto, pudo csclamar: "La pampa es nuestra!" La direccion á imprimir á la campaña, aparecía, por esa sola circunstancia, clara como un teorema.

Y efectivamente, el resultado final se pronunció mas pronto aun de lo que se suponía. Antes de determinar los últimos detalles del plan de operaciones que debian ser coronadas por la ocupacion del Rio Negro, era indispensable despejar algunas incógnitas geográficas, al mismo tiempo que tantear el verdadero estado, el actual poder de resistencia de los indios. Se lanzaron varias columnas con mision de hacer grandes reconocimientos, dándoles por objetivo los puntos mas lejanos donde podian guarecerse los salvages.

$\mathrm{Y}$ eran tan eficaces los nuevos principios de guerra fronteriza que habian dictado estas medidas, que hemos asistido á un cspectáculo inesperado. Esas maniobras prclimina- 
res, que no cran sinó la preparaeion de la campaña, fueron en el aeto decisivas. Quebraron el poder de los indios de un modo tan eompleto, que la espedieion al Rio Negro se eneontró casi hecha antes de ser principiada. No hubo una sola de esas columnas de es* ploracion que no volviese eon una tribu cntera prisionera, y euando llegó cl momento scnalado para el golpe final, no existian en toda la pampa ecntral sinó grupos de fugitivos $\sin$ eohesion $y$ sin gefes.

Se eneontrará, en el eurso de este libro, la marcha de los aeonteeimientos, deserita, paso por paso, por los gefes mismos que les imprimieron tan vigorosa impulsion. Sería para nosotros una grata tarea, si estos no hubiesen gloriosamente eonquistado el derccho de reservárscla, contar esas espedieiones que son un timbre de honor para los ofieiales que las mandaron y para los sufridos soldados que las ejeeutaron.

Hemos tratado de espliear, apoyándonos en una minueiosa deseripeion topográfiea, eómo la eonquista de 15000 leguas era posible eon los redueidos elcmentos de que se disponía. Entre la posibilidad y la realizaeion, había sin embargo todo euanto el desierto puede aeumular de obstáculos, de penurias, de marehas forzadas por entre travesías, en defensa de sus seeretos $\mathrm{y}$ cn defensa de sus moradores salvages. Para sobrcllevar tantas difieultades, se neeesitaba acierto en la direecion superior, ardor y pcricia en los gefes de columna, en las tropas, enfin, un esforzado sentimiento de la diseiplina y del deber, una inquebrantable abnegacion. No queremos disminuir, analizándolas, $t 1$ efeeto de las paginas donde se desarrollan las te naees eorrerias y los heehos de armas que han dado cn tierra en poeos meses con el po. der seeular de los indios.

En el punto á que hemos llegado, no hay salvages sinó allende el Rio Negro y el Neuquen. Ahora hay que esplotar las tierras eonquistadas. No hemos disimulado las eondiciones desfavorables que presentan muehos parages, $y$ que han sido preeisamente la causa determinante de su eonquista. Sin embargo, hay que tener presente que los medios de que dispone el hombre eivilizado para fertilizar sus dominios no tienen eomparaeion eon los que están al aleanec de una tribu nómade. Consideremos otra vez las grandes divisiones en que se divide la pampa, y prescindamos por un momento de los valles de los grandes rios $y$ de la region andina, que brindando al hombre una feraeidad asombrosa, merceen un estudio á parte.

En la zona ealeárea, hcmos señalado ya grandes depresiones donde cl líquido está á la mano, y la execlente ealidad del pasto, la preseneia de numerosos y corpulentos algarrobos, dán á esos bajos un mérito eseepeional para atraer la poblaeion. Los eampos altos y tendidos que presenta en abundaneia la misma zona no se abasteeerán de agua con facilidad, pero la cmpresa de ir á buscarla á unos 20 ó 30 metros de profundidad no es tampoeo eomo para desanimar á un estaneiero inteligente. Esta eireunstaneia lo ha de obligar á erogaeiones de alguna consideracion al prineipio, $y$, lo que es más difícil, scguramente conseguir, á la adopeion de aparatos perfeeeionados. En eambio, el propietario será bien recompensado de sus gastos, y del esfucrzo intelcetual y moral que sc neecsita para sepa- 
rarse de rutinas tradicionales, por el vigor de su rebaño, la estatura de los animales, y las notables propiedades de la carne, como carne de consumo. Esto vale la pena de rcemplazar la patriarcal manga de cuero por un malacate y una bomba.

Es probable que el modelo de pozos que ofrezca más ventajas consistirá cn perforar, á pequeña seccion, como si se tratase de un sondage, la piedra dura que forma el suelo, hasta encontrar la segunda capa acuifera, que es inagotable. Esta capa, que ha sido reconocida, debajo de la tosca, en toda la provincia de Bucnos Aires y en la de Entre-Rios, se prolonga probablcmente hasta el Colorado. Suministra un agua muy pura y de igual temperatura en todos los tiempos, esto es fresca en vcrano, tíbia en invierno. Esto basta para recomendarla. Evitaría para las haciendas una porcion de enfermedades que les comunican las malas condiciones higiénicas de las aguas de charco que gcneralmente beben. Su uso no se ha generalizado en razon de la resistencia que oponen sicnpre á toda novedad las costumbres arraigadas. La toma de posesion de una comarca donde escasean los depósitos naturales de aguas llovedizas, hará aprovechar esta reserva de líquido, que presenta la abundancia indispensable á una ganadería adelantada. No será la primera vez que, bajo la presion de la necesidad, los métodos progresistas hayan sido puestos en práctica, primero en rincones remotos y que no parecian destinados, por su grado de desarrollo, á dar el bucn ejemplo á distritos mas prósperos. Es escusado agregar que el dia en que la República Argentina, saliendo paulatinamente del pcriodo pastoril, se trasforme en país agricultor, los terrenos calizos y abundantes en fosfatos de que se trata conquistarán una rápida superioridad sobre los terrenos gordos, pero casi desprovistos de sales minerales, donde la agricultura se ha implantado primero. Ciertos cultivos, la viña por cjemplo, cncontrarán en los declives setentrionales de las colinas, una tierra de promision.

La zona de las arenas presenta, como hemos dicho, caracteres distintos segun su altura. Muy húmeda y cubierta de una exuberante vegetacion cn las partes bajas, es estéril en las partes altas, por las propiedades filtrantes del terreno, que deja al líquido sepultarse en sus entrañas. Pcro aqui su estraccion es más fácil que en la piedra de cal, y no hay siquicra que hacer pozos, trabajo para cuya realizacion la tendencia de la arena á desmoronarse ocasionaría tanta incomodidad como la dureza del suelo en los campos anteriores. Hay que notar, en efecto, que el ccntro de los médanos, empapado de líquido, se encuentra á menudo á un nivel más alto que las partes adyacentes. Si se va á buscar el líquido con un tubo de sonda oblícuo, el agua correrá por la salida que se le efrece. El aparato constituiría una especie de pozo abisinio horizontal, ó más bien ligeramente inclinado de arriba abajo, lo que evita el empleo de una bomba. La gravedad cs suficiente para hacer salir el agua. Es un manantial artificial dispuesto exactamcnte del mismo modo que los manantiales naturales.

Como para los sondajes de que se acaba de hablar, esta idea naturalmente no podía ocurrir á indios, y tenemos ahí una de las mil consideraciones que demucstran en qué error se incurriría al declarar que campos donde éstos no podian mantenerse han de ser de difi- 
cíl esplotaeion para los Argentinos del siglo XIX. Es evidente que en una gran parte de las llanuras reeien abiertas al trabajo humano, la naturaleza no lo ha hecho todo, y que d arte y la ciencia deben intervenir en su eultivo, como han tenido parte en su conquista. Pero se dcbe considerar, por una parte, que los esfuerzos que habría que haeer para transformar estos campos en valiosos elementos de riqueza y de progreso, no están fuera de proporeion con las aspiraeiones de una raza jóven y emprendedora; por otra parte, que la superioridad inteleetual, la aetividad y la ilustraeion, que ensanehan los horizontes dcl porvenir y hacen brotar nuevas fuentes de produccion para la humanidad, son los mejores títulos para el dominio de las tierras nuevas. Preeisamente al amparo de estos prineipios, se han quitado éstas á la raza estéril que las oeupaba.

No apareee con menos evidencia la neeesidad de eorrejir por medio del arte y de la ciencia, lo que la naturaleza ha dejado imperfeeto; euando se eonsidera el valle del Rio Negro, y de todos los puntos de la Pampa éste es quizá donde eon poeo esfuerzo se pueden realizar las mas traseendentales mejoras.

El valle, ancho de unas dos leguas en eiertas partes, estreehado en otras entre altas barrancas que llegan hasta la misma ribera del rio, está formado de un suelo liviano de aluvion, eompuesto espeeialmente de arena. Las barrancas, y los terrenos altos que se estienden á derecha é izquierda, están formados tambien de arena, mcdio solidifieada en las eapas inferiores, hasta formar un asperon tierno y permeable, y suelta en la parte superior.

La feraeidad del valle es admirable, su elima templado, aún en invierno, porque las barraneas inmediatas lo preservan en parte de la accion de los vientos. La naturaleza silicoealearea del suelo proporeiona á los produetos agríeolas ealidades de que daremos una idéa dieiendo que, de toda la Provincia de Buenos Aires, es cl solo punto donde se puede obtener eebada propia para la fabrieaeion de la cerveza, é igual á la de Chile. El trigo, las frutas de aquellos parajes, son ya eélebres; la eomposicion del suelo es análoga á la del suelo de Mendoza. Esto basta para indicar qué reeursos ofrece para una ganaderia adelantada.

Otra provineia de Mendoza, pero una provincia regada por un majestuoso rio navcgable, y en eontaeto con cste camino que comunica eon el Océano, se formará segứamente con el tiempo á orillas del Rio Negro.

Para obtener este resultado, hay que preservar las primetas colonias que se formen de los efeetos de las inundaeiones, y que perfeeeionar las eondieiones del Rio Negro como arteria navegable.

Las inundaciones son debidas á las grandes erecientes que sobrevienen en el momento del derretimiento de las nieves en los Andes. El agua llena entonees todos los brazos falsos que ocupaba antiguamente el rio en el fondo del valle, $y$ todas las partes invadidas se vuelven en el aeto muy pantanosas, por la misma lijerezadle terreno, ineomunicando las partes intermedias que no están cubiertas por el liquido. 
Sería demasiada ambicion, al mismo tiempo que una medida poco acertada, tratar de suprimir del todo las inundaciones. Son un elemento indispensable de la fertilidad del valle, pues el rio le suministra un riego y un iolmatage parecidos á los que han dado su reputacion benéfica al Nilo, cuando sus inundaciones son moderadas, si bien destruye las cosechas en las crecientes extraordinarias. Pero hay que reducirlas á proporciones menos desastrosas, eon algunas obras de defensa en la ribera, en las partes donde ésta presenta grandes depresiones por donde se engolfa el caudal de agua..

Hay otra consideracion más importante todavía. Como el valle no presenta bastante superficie cultivable para el porvenir á que parece llamado, es indispensable que el hombre se posesione de los campos mas altos y estremadamente secos que lo rodean, y los obli. gue, por medio del riego, á volverse fértiles. La navegacion del Rio Negro, para ser práetica, regular y barata, necesita la supresion de canales inútiles, la concentracion de las aguas, en varios puntos de su curso. La corriente irregular y fuerte, las curvas muy pronuneiadas que forma el cauce, son eircunstaneias que el arte debe combatir. Por otra parte, el puerto de San Antonio, cuyas ventajas maritimas son verdaderamente admirables, está cireunvalado y separado del Rio Negro por campos donde el agua dulce no aparece á la superficie, y no brotará de tierra sino á costa de sondages bien dirigidos.

Sería una puerilidad tratar de ocultar cstos inconvenientes, y es preciso considerarlos resueltamente con ánimo de vencerlos. Los esfuerzos que se harán en ese sentido tenđrán resultados bastante importantes para que no sea permitido desmayar en tan trascendental empresa. El Rio Negro es para la poblacion de la parte meridional del continente lo que ha sido el Rio Paraná para la ocupacion y el desarrollo de las comarcas mas centrales. Hay dos diferencias que mas bien están en favor del Rio Negro. La primera es que si éste tiene una entrada más dificil y un caudal menor de agua, posce á inmediaciones de su embocadura un puerto como la bahía de San Antonio, que es capaz de responder á las exigencias de la navegacion de ultramar la más activa. ¿Quien podrá calcular qué entorpecimiento ha producido para el desarrollo de las provincias litorales del Paraná la falta de un buen puerto en Buenos Aires? La segunda diferencia entre el Paraná y el Rio Negro, es que los afluentes del primero se internan en comarcas tropicales, dejando á un lado las regiones templadas donde la poblacion tiene mas probabilidades de multiplicarse, mientra; que los afluentes del Rio Negro y este mismo, en su direccion general, cortan cl continente casi segun una direccion normal á su línea media, y representan el camino mas corto, no solamente entre los ricos valles andinos y el Atlántico, sinó tambien entre los pueblos ribereños de los dos oceános que bañan ambos lados de América. Si los Americanos del Sur deben dar algun dia al universo el grandioso espectáculo que le han dado los Es. tados-Unidos, ligando el Pacífico con el Atlántico por medio de un ferro-carril, es indiscutible que, sinó la única, á lo menos la más corta y menos costosa via ferrea que realizará el pensamiento arrancará del Pucrto San Antonio y se alejará poco en su trayecto del valle del Rio Negro, cuyos elementos de prosperidad aprovcchará decuplandolos. 
Tales proyectos perteneccn á un porvenir muy lejano, convenido; pero la configuracion topográfica que permitc ya sentarlos como probables tiene consecuencias inmediatas que es conveniente estudiar. Lo que debe hacer considcrar csc trecho de continente como un camino natural, mas ó menos concurrido y periecciona lo segun los progresos sucesivos de csos territorios, del comercio interoceinico, cs el conjunto de circunstancias siguientes: existencia de un puerto de ultramar escelente, disminucion del ancho de la tierra firme que reduce á un minimum el trayccto por tierra, disminucion de la clevacion de la Cordillera en esa latitud, revelada por la disposicion de las corrientes de agua á la primera inspeccion del mapa, indicada esperimentalmente por la frecuencia y la antiguiedal de las rclaciones entre los pobladores de ambos lados de los Andes cn esas alturas.

Todo esto debe hacer de la region del Rio Negro el objeto de la preferente atencion del gobierno argentino. Lo que sc deduce de estas consideraciones es que cn ningun pun. to la Cordillera of rece á los pobladores ventajas mus decididas que en el País de las Man zanas, ocupado todavía por los últimos restos de los salvajes, pero cuya conquista es una consecuencia obligada, un corolario indispensable de la ocupacion dcl Rio Negro. Menos elevado que las partes culminantes de los Andes, abrigado por éstas, participando de la feracidad y diversidad de suelo que ofrecen las montanas al poblador industrioso, preservado de las severidades de clima que las montañas originan, á corta distancia del mar, está, como topografia y climatologia, en condiciones muy supcriores á las que presenta Suiza, y que han contribuido tanto á hacer figurar á los habitantes de la Confederacion Helvética entre los mas adclantados y los mas felices de Europá.

De ese punto favorecido, la poblacion podrá estenderse al Sur, sobre las vertientes de la Cordillera, y avanzar paso á paso en los valles que de ella se desprenden y se adelantan mas ó menos en los desiertos patagónicos. Es el solo modo de derramarla sobre esa vasta y poco hospitalaria comarca, defendida por el lado del mar por la aridez de sus mesetas mas recientes, apenas emerjidas del oceano. Por mas estraordinario que esto parezca, á primera vista, un siglo de dolorosas esperiencias y la opinion unánime de todos los esploradores, obliga á llegar á la conviccion que, para penetrar en Patagonia, hay que dar la vuelta por el valle del Negro y embestirla por las espaldas. Atacarla de frente es esponerse seguramente á estrellarse contra la mas terrible de las defensas naturales, un desierto árido, en que ninguna colonia ha podido todavía tomar pié.

¡Qué diferencia en el porvenir de la colonizacion si se le dá por base de operaciones en vez de un punto desolado de la costa cn que ni agua potable se encuentra, cl País de las Manzanas, cuyo solo nombre dice la natural feracidad, y cuyos bosques de robles, de araucarias, de pinos, han despertado en los mismos indios la idea de una region escepcional, cuna y último refugio de su raza, centro y llave de sus antiguas posesiones!

No se puede pensar sin sorpresa y sin una retrospectiva emocion, en las fatales conse. cuencias que hubiera podido tener $\mathrm{cl}$ abandono en que tan valiosos territorios yacian abandonados desde hace un siglo. Los Chilenos se habian seguramente fijado en el provecho 
que, dado el caso de una guerra, podian sacar del admirable camino del Rio Negro, abierto de par en pará sus tropas. Hasta la expedicion, les hubiera bastado, en el momento de romper las hostilidades, lanzar un cuerpo de ejército por los pasos relativamente fáciles de la Cordillera, entre el Nauquen y el Limay, ocultar sus movimientos detrás de un telon de ginetes salvajes, que tenian entonces á su discrecion, y que dominaban toda la Pampa Central, y de seguir tranquilamente el cómodo valle del Negro, para posesionar. se de todo su curso, sin que fuese posible á los ejércitos de Buenos Aires impedir su ocupacion, ni operar eficazmente contra ellos.

Es casi indudable que este plan, sumamente peligroso para los Argentinos y que hubiera puesto el objeto del litigio en manos del enemigo antes que se hubiese podido empeñar combate, ha sido acariciado por el Estado Mayor chileno. No sería muy difícil encontrar en los reconocimientos hechos, en la política adoptada con los indios, traza de semejantes proyectos. Probablemente respondía á las mismas miras la indicacion del Rio Negro como frontera posible, que el gobierno chileno se atrevió á dejar deslizarse en uno de los documentos de su diplomacia.

La ocupacion del Rio Negro y del Neuquen ha tenido como consecuencia inmediata el cambio completo de las situaciones estratégicas de ambos pueblos. Las facilidades que presenta el valle del Rio Negro para la marcha de un ejército no es ya un peligro para la República Argentina, y sería todo lo contrario para Chile que presentaria un flanco abierto, si la cuestion de límites tuviera que ventilarse á cañonazos. No queremos extendernos sobre la posibilidad de un conflicto. El buen sentido práctico del gobierno de Santiago y la perspectiva de tener un ejército de invasion á dos pasos de una de las puertas mas accesibles de Chile, dan fundadas esperanzas de que se podrá conjurar la calamidad de una guerra. Pero podemos indicar que las consideraciones militares se unen en esta ocasion con las previsoras tendencias de una política de paz y de progreso económico para incitar á realizar lo mas pronto posible la poblacion del Rio Negro y el desarrollo de todo el territorio adyacente. Es asegurar al ejército una base de operaciones sólida y poner á su inmediato alcance recursos inmensos para expedicionar, al mismo tiempo que tiende, y nos es mas grato insistir sobre este tópico, á enriquecer la República con una nueva provincia, que figuraría entre sus mas prósperas posesiones.

La creacion de centros de poblacion á orillas del Rio Negro concuerda igualmente con las sanas teorias de buena administracion. Para hacerse sentir con facilidad y provecho á tanta distancia, la accion del Gobierno central debe ejercerse sobre aglomeraciones compactas cuya índole y cuyas ocupaciones ordinarias sean exactamente lo contrario de las costumbres vagabundas de los nómades que vendrán á reemplazar. Importa establecer colonias, cuya existencia sea una garantía de paz y de exacta policía, en todos los puntos donde tengan elementos de vida. Es el mejor y quizá el solo modo, de dominar un tan dilatado territorio.

¿Se deduce de esto que todo el Rio Negro debe formar un solo cordon de colonias? 
De ningun modo. En primer lugar, porque no hay bastantes colonos para rellenar todo el trecho $\mathrm{y}$ porque, mientras se tengan los necesarios, mas vale poblar una porcion del terreno en cstancias que decretar el vacío alrededor de las colonias primeramente formadas. En segundo lugar, porque ni toda la tierra del Rio Ncgro se presta para cultivo, ni se pueden hacer de golpe los gastos necesarios para convertir en tierras de cultivo, por medio del riego, las partes altas que pueden utilizarse desdc luego en ganadería. Enfin, porque no es solo el Rio Negro el punto que necesita colonias para la perfccta seguridad y debida explotacion del tcrreno conquistado, y que es preferible diseminarlas sobre tan inmensa superficie. Algunas colonias colocadas en los puntos mas favorables, separadas por terrenos de estancia, pero vigorizadas por trabajos de irrigacion cjccutados bajo la direccion del gobierno, obras tendentes á facilitar la navegacion del rio, y á poner en servicio y en relacion fácil con el valle del Negro el puerto de San Antonio, tales son las medidas quc parecen las más aparentes para sacar por ahora partido de las ventajas que el vallc ofrece, y para preparar el brillante destino que le está indudablemente reservado.

No hemos podido tocar sinó los puntos más culminantes de una cuestion que para la República Argentina es de vida ó muerte, que lia pesado de un modo ruinoso en el pasado, sobre su fortuna y sus relaciones exteriores, y que está estrechamente ligada con las esperanzas que inspira su porvenir como nacion. Lo poco que hemos dicho servirá á lo menos para mostrar la importancia de los resultados obtenidos y lo árduo de las tareas que quedan por hacer afin de completar la jornada. Dentro de muy poco, la empresa militar que era como el primer acto de la apropiacion del desierto a las galas de la civilizacion, habrá concluido, despues de haberse desarrollado de triunfos en triunfos, con la conquista del País de las Manzanas y la captura de los últimos caciques que lo habitan. La obra de la administracion va á principiar, no menos dificil, no menos gloriosa. Estamos en frente de un continente virgen. ¿Será la morada de un gran pueblo cosmopolita, formará los Estados Unidos del Sur? ó bien languidecerá mucho tiempo en los limbos de la civlizacion, apenas notado en el concierto de los pueblos por el envio de algunos cueros á los mercados extrangeros? De la solucion que se dć á los problemas gubernativos que ofrecen á nuestras meditaciones la reciente conquista del desierto y la organizacion de nuestras nuevas posesiones depende, en parte, la respuesta á tan grave cuestion. 
PRIMERA PARTE

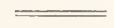

Z O O O G I A

CON 4 LAMINAS

$=$ 



\section{ZOOLOGIA}

POR EL

\section{D. ${ }^{R} \quad$ D. A D OLFO D OERING \\ con la colaboracion del}

D. ${ }^{R}$ D. CARLOS BERG Y DE D. EDUARDO L. HOLMBERG 

Debido á la circunstancia de ser los territorios litorales del Sur de la Provincia de Buenos Aires y de la Patagonia setentrional, de fácil acceso á los esploradores, su fauna ha sido, relativamente, bien estudiada, siendo conocida ésta particularmente por los viajes de esploracion de Alcide D’Orbigny (1828-29) y de Charles DARwin (i833).

Ambos han hecho sus escursiones desde Bahía Blanca hácia el interior de la pampa meridional y han recorrido las riberas litorales del Rio Negro. Los respectivos trabajos de estos sábios viajeros se hallan incluidos en sus obras clásicas, universalmente conocidas, y sus colecciones, especialmente las de vertebrados, han sido tan completas, que casi náda nuevo ha quedado posteriormente por descubrir.

GERMAN BURMEISTER ${ }^{1}$,en la parte zoológica de su obra general sobre la República Argentina, y en varias publicaciones zoológicas en los periódicos del ramo, suministra numerosos datos acerca de la fauna de la Patagonia setentrional y de la pampa meridional.

Uno de los más eminentes observadores ornitólogos de esta República, IV. H. HuDSoN, recorrió las márgenes del Rio Negro (1870-71), publicándose algo de sus observaciones por P. L. Sclater 2, cuyo trabajo hemos podido utilizar para completar nuestra lista de las especies pertenecientes á las márgenes del Rio Negro.

Deben mencionarse tambien los numerosos datos, relativos á la fauna de aquellas regiones, consignados en las importantes obras de Pellegrino Strobel ${ }^{3}, y$, además, los viajes de F. P. Moreno 4. El último visitó las inmediaciones de Bahía Blanca, entró hácia el interior, hasta cerca de Salinas Chicas, y recorrió el antiguo camino de los Indios, á lo largo de los Rios Negro y Limay, hasta el lago Nahuel-Huapí en la falda oriental de la Cordillera; pero es de deplorar que este muy apreciado antropólogo no haya viajado en

(1) G, Burmeister, Descripcion física de la República Argentina, T. V. Lepidoptera. Buenos Aires 1878. (El único tomo de la parte zoológica aparecido hasta ahora.) Numerosas pulflicaciones zoológicas en la "Stettineri Entomol. Zeit.", y en otros periúdicos del ramo.

(2) P. L. Sclater, On the birds of the Rio Negro of Patagonia. By W. Hudson, Proc, Zool. Soe. 1872 , p. 534 ss.

(3) P. Sтroвel, Materiali per una malacostatica di terra e d'acqua dolce dell' Argentinia Meritio. nale. Pisa, 1874. Varias publieaciones antropolígicas del mismo y diversas entomológicas relativas it la coleccion de Strober, por Mayr, Rostasi, ete. en las "Atti della Soc. di St. Nat. di Medena", ete.

(4) F. P. Monexo, Viaje á la Patagonia anstral. T. I. Buenos Aires, 1879. 
calidad de zoólogo especialista, siendo muy incompletos los datos zoológicos que en el primer tomo de su obra suministra acerca de aquellas regiones, por ćl recorridas.

Algunos datos relativos á especies patagónicas se hallan cn las publicacioncs de E. LYNCH ${ }^{1}$ $y$ de E. L. Holmberg ${ }^{2}$. A este último naturalista, autor de la parte aracnológica y de las láminas zoológicas de esta obra, debemos tambien nuestras gracias por la participacion activa que ha tomado en la redaccion de esta publicacion.

Con la prolijidad con que D ORBIGNy y DARwin observaron la fauna de los vertebrados, moluscos, etc., ha estudiado CÁRlos BLRG 3 , en varias escursiones por las sierras de la pampa mericlional y por las márgenes litorales del Rio Negro, etc., la fauna entomólogica de una gran parte de las mismas regiones. Es sensible que este naturalista no haya publicado un resúmen general compieto de sus observaciones, las cuales se hallan esparcidas en sus diversas publicaciones especiales sobre lá entomología argentina. Le agradecemos el interés que ha tomado en esta publicacion, dedicándose al penoso trabajo de clasificar la coleccion entomológica recojida durante nuestra campaña.

Despues de cstas lijeras indicaciones, conviene recordar aquí algunos datos relativos á los antecedentes de las siguientes contribuciones al estudio de la Zoología de las mencionadas regioncs, debićndose consultar, para mejor conocimiento del caso, la parte histórica de esta obra 4 .

Acaba de realizarse, á principios de este año, uno de los más importantes acontecimientos en la historia moderna de los Paises del Plata.

Los vastos territorios del Sud-ocste de la República Argentina central, con un área de más de I5.000 leguas cuadradas, estaban abandonados, hasta los últimos tieınos, al dominio de los salvages de la Pampa. Las comarcas limitrofes de las provincias de Buenos Aires, Córdoba, San Luis, etc. gemían, desdc há siglos, bajo la presion de las invasiones de csos hijos del desierto y cada iniciativa civilizadora, cada paso progresivo hácia el límite de estas regiones, era inscrito en la historia con la sangre de innumera. bles víctimas, sacrificadas á la inclemencia del salvage.

La espcriencia obtenida en el sistema defensivo de las sucesivas fronteras militares, dcmostró la insuficiencia de aquel, y la conquista definitiva de todos cstos territorios, su sometimiento á la mano fecunda del agricultor, fué un problcma, nn proyecto ventilado seriamente en varias ocasiones, desde el comienzo de este siglo. Pero la falta de la suficiente práctica y de conocimientos exactos, respecto de las condicioncs de aqucllas regioncs y

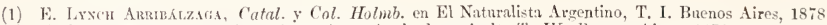

(2) E. L. Hotvisent, Aricnitos Argentinos, Anal. d. agvicult. 'T. IV, Buenos Aires, 1876.

(3) (' Brat, Veber cine Erpelition na.h Patagonien. Petermann's Geogr. Mitthil., T. XXI, p. 364

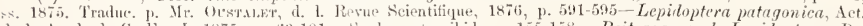
a. t. Acul. d. C. E. I. 1875, p. 63-101. Suplemento, ihid. p. 155-158.-Beitraege z. d. Lepidopteren Patagoniens. Bull Soe. Imper. Sit. de Hoseon, 1877, T. III, p. 122.-Contribucion al cstudio de la fiana entomológica de Patagonia. Au. d. 1. Soc. Cientifien Argentina, 'T. III, p. 87-102 y 199-211, Buenos Aires, 1877 , ote.

(4) Ina muy buena veopilacion $y^{*}$ resumen general sobe los acoutecimientos prévios á la expedicion del

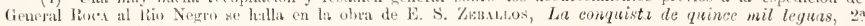
edieion, Buenos Aires, 1878 . 
del número y poder de sus habitantes, algo misteriosos por su vida nómade y peregrina, no ayudaban siempre á los iniciadorcs de scmejantcs proyectos, no pudiendo, por esto, elevarse su, iniciativa sobre el nivel dc csfuerzos infructuosos de una buena voluntad;hasta que, por fin, uno de los gefes militares dc esta República, prominente por su conocida circunspeccion y su esperimcntado tino práctico, utilizó bien su permanencia en las fronteras del Sur, recopilando los datos nccesarios para el cstudio fundamental de dicho proyecto. El General D. Julio A. RocA, conscjero constante en cl ministerio de guerra del Dr. Alsivi y finalmente succsor de cste conocido patriota Argentino, había preparado así las condiciones necesarias para el éxito completo de dicho proyecto.

Los indios residentes en estas vastas llanuras estaban presos, en su mayor parte, á consecuencia de preliminares operaciones militares de una estratégia bien calculada $y$ hábilmente ejecutada, y se trataba de coronar la obra con una espedicion militar definitiva, que recorriera simultáneamente, en difercntes subdivisiones, todas las comarcas del territorio hoy sometid', para desparramar los últimos restos de la poblacion indiana y para trasladar definitivamente una nueva línea militar á lo largo de los Rios Negro y Neuquen, ctc., frontcra bien limitada y resistente por el auxilio dc las ventajosas condiciones naturales de las mismas regienes. Esta espedicion, ejecutada durante los meses de Abril, Mayo y Junio de 1879 , fuć dirigida por el mismo General RocA, que se puso á la cabeza del ejército en campaña.

Este distinguido Argentino, deseando que la espedicion, además de su ilimitado alcanre práctico, contribuyera al mismo tiempo al conocimiento exacto de la naturaleza de aquellas comarcas, invitó á diferentes naturalistas de este pais, para acompañar, como comision científica, al ejército espcciicionario, incorporandose á la comitiva del General en gefe y del Estado Mayor.

Tomaron parte en la comision aludida, para la confeccion del diario y para cl estudio botánico, el Dr. P. G. Lorentz, acompañado por su ayudante Gustavo Niederlein; y para el estudio zoológico y á la vez para reunir datos sobre las condiciones geológicas y agrícolas de aquellas regiones, el autor, acompanado por el inspcctor del Museo Zoológico de Córdoba, FED. Schulz.

La cruzada de nuestra division se hizo, desde el Azul, en direccion á la línea de la antigua frontera, llegando á Carhué y pasando á largo de la misma línca, hasta Nueva Roma, y cruzando el Rio Colorado hácia el Rincon Grande, antigua residencia de los caciques Gueupé y Melicura. Hemos pasado por la ribera meridional del Rio Colorado hasta enfrentar los cerros graníticos de Choique-Mahuida, cruzando el territorio entreriano por el antiguo camino de los indios, hácia la isla de Choelechoel, cn el Rio Negro, donde pcrmanecimos varios dias. El reconocimiento del Rio Negro, hácia arriba, nos llcvó hasta la embocadura del Rio Neuquen, volviendo (rio abajo) á lo largo del Rio Negro, hasta cl Fortin Conesa, donde nos esperaba cl vapor destinado para nuestro regreso por el Cármen de Patagones.

La estacion invernal y la rapidcz con que debía realizarse la cspedicion militar, no 
eran muy favorables á las observaciones zoológicas. Cuando llegábamos al Rio Negro, en los últimos dias del mes de Mayo, la Naturaleza estaba ya bajo la influencia de los frios hiemales: desde luego las colecciones, particularmente las entomológicas, no podian hacerse con el éxito que se hubiera deseado. Si, á pesar de estos inconvenientes, no fueron completamente infructuosos nuestros esfuerzos, ello es debido, en gran parte, al precavido gefe de nuestra especiicion, que nos ayudaba en todo sentido, interrumpiendo tambien, á veces, las marchas rápidas, para dar tiempo á que la Comision Científica hiciera sus esploraciones.

Finalizada nuestra obra, séanos permitido depositarla sobre el altar de la ciencia, como una lumilde corona de siempre-vivas, que sirva de conmemorativo del transcendental acontecimiento con que ella se liga. Será un eslabon más de la cadena que vincula á los pueblos verdaderamente cultos, frente á ese altar sagrado de la verdad, á donde no llega el espíritu airado de las pasiones políticas y sobre el cual se desvanecen fatalmente todas las nubes que pueden empañar el brillante astro que guia á la humanidad á la realizacion de sus más grandes y nobles aspiraciones. 
SORRE LA

\title{
FAUNA DEL TERRITORIO CONQUISTADO.
}

POR EL

\author{
D. ${ }^{r}$ D. ADOLFO DOERING
}

El carácter general de la fauna de un territorio siempre depende íntimamente de sus condiciones físicas, su hicirografía, formacion geológica, etc., y, sobre todo, dc la vegetacion correspondiente. Así, por ejemplo, los campos llanos de la pampa tienen sus organismos característicos; pero su fauna se modifica instantáneamente, así que llega á cambiar su fisonomía, v. gr., con la entrada de una vegetacion arbórca.

Para el propósito de nuestras observaciones y con el objeto de dar una lijera revista general, podemos dividir cl territorio conquistado en las siguientes zonas zoogeográficas:

I. REGION DE LA PAMPA MERIDIONAL.

I. El campo llano de la pampa.

2. Las sierras de la pampa moridional.

3. Los esteros y lagunas dulces.

4. Las lagunas saladas.

II. REGION ENTRERIANA DE LA PATAGONIA SETENTRIONAL.

I. El territorio de las matas y arbustos patagónicos.

2. Los rios y lagunas adyacentes.

III. REGION CENTRAL DEL MONTE.

IV. REGION DE LAS FALDAS ORIENTALES DE LA CORDILLERA.

Como las dos últimas regiones limitrofes de la Cordillera no son conocidas aún pór observaciones directas (esceptuando unos datos incompletos de MoLiNA), debemos prescindir de entrar aquí en una descripcion zoológica de ellas. Se conoce bien, en cambio, $r^{b}$ e los territorios litorales, la fauna de los moluscos y vertebrados, siendo estas divisir, nes 
aquellas sobre las cuales, con una base más autorizada por observaciones propias, podemos, tambien nosotros, estendernos cn las siguientes consideraciones generales sobre la fauna del territorio conquistado.

Es de suponerse que la fauna de la region central del monte, es decir, de las densas selvas de espinares, sea más ó menos idéntica con la de las provincias de Cuyo, como v. gr. la de Mendoza, la cual es perfectamente conocida, y, segun lo ha comprobado ya Sclater, muy análoga á la del Rio Negro. Scguramente no existe una difercncia notable entre ambas, como tampoco existe $\mathrm{cn} \mathrm{cl}$ carácter de su vegetacion, quedando solamente por esperar la cntrada de muchos elementos zoológicos que habitan las sclvas de espinares (con árboles altos) en las provincias centralcs de la República.

En ia fauna de la region andina, indudablemente, hay que encontrar muchos de los elementos bien conocidos de la fauna chilena.

\section{REGION DE LA PLIPA MERIDIONLL.}

Nos referimos aquí á la pampa situada al Sur del $37^{\circ}$ de latitud. Ella se estiende desde la costa atlántica hasta el $65^{\circ}$ longitud $\mathrm{O}$. Greenv. más ó ménos, hallándose allí limitada, al $\mathrm{O}$, por la region central de las densas selvas de espinarcs y hácia el Sur (aproximativamente como unas quince leguas al Norte de las ribcras del Rio Colorado) por la region patagónica de los arbustos.

Su conexion con la pampa setentrional constituye la identidad con la fauna de esta. Las especies principales, en ambas, son por lo general las mismas; pero existe, sin enbargo, una diferencia caracterizada por la disminucion del número de ellas en las regio. nes mas templadas de la parrpa meridional. Muchos elementos zoológicos que, en la pampa vecina de Bucnos Aires, etc., son apariciones frecuentes y constantes, faltan ya en los territorios meridionales ó no pertenecen á las normales características.

El caracter general, monótono y estercotípico de las pampas sud-americanas no deja de reflejarse támbien en esta pampa del Sur. Sin embargo, ya ofrece alli una diferencia notable con la del Norte, constituyéndose alguna variabilidad por la ondulacion pronunciada de su superficic. Se nota facilmente quc esta ondulacion y formacion de colinas poco elevadas va acompanada de una configuracion análoga en la planicic superior de la intcresantc formacion dc tosca, que constituye cl csquelcto, el verdadcro fondo, ó sub-suclo, de todo este tcrritorio de la paspa meridional. La zanja fronteriza que, con una estension de So lcguas, atravicsa esta pampa de Sur á Norte, mucstra la no interrumpida conexion ale la formacion tobácca, en $\mathrm{cl}$ fondo del terreno, y la mayor parte de las numcrosas colinas que cxisten ccrca de Carhuć, Puan, etc., generalmente designadas como médanos no son médanos en su acepcion cstricta, sinó mas bien colnas de tosca, cubiertas, como todas las otras comarcas vecinas de la pampa, por una capa de ti rra suclta, vestida de vegetacion gramínea. 
Esta eapa de ticrra fina, que constituye el suelo eultivablc ascntado sobre la formaeion tobácea, es de $\frac{1}{2}$ á 3 metros de altura. Su ealidad algo arenosa es característica y casi general en todos estos terrenos del Sur, a diferencia de los del Norte, donde predo. nina un terreno más eompacto y gredoso, no existicndo, por lo demás, ese fondo sólido tobáceo en las capas superiozes del suelo. Esta formacion de tosca jucga un im. portante papel sobre las condiciones hidrográficas de la pampa meridional, dependiendo de su existencia la abundancia de lagunas y esteros en la misma, produciéndose en igual grado alguna modifieacion insignificante en el carácter esterior de la vegetacion pampeana. No obstante, puede decirse, en gencral, que la region aludida sc halla enteramente eubierta por una vegctaeion graminosa, mas ó menos análoga a la de la pampa setentrional con las modificaciones que produeen los numerosos parajes con aguas estancadas y eon su vegetacion mas vigorosa, pero siempre desprovista de árboles.

Recien, más al Ocste, aproximandose á la verdadera formacion eentral de las selvas de espinares, eerea de Trenel, Loan, Salinas, ete., prineipian á entrar, en esta formaeion, grupos de árboles ó de arbustos, que luego dan paso á la formaeion de las selvas cen. trales.

\section{EL CAMPO LLANO DE LA PAMPA.}

Los vertebrados que caracterizan esta region pertenecen at las siguientes especies:

\section{MAMMALIA}

Dysopes hrasiliensis, Is, ficof:

(anis A zarae, Wat.

Galictis vittata, 1 .

Mephites patagonicus, Licht.

Lagestomns trichedactylus, $\mathrm{Br}$.

Ctenomy̨s (magellanicus, Benn)

Caria leteopyga, Br.

Mus elegans, Wat.

Anthis correndera, Vieill. " furcatus, D'Orb.

Troglodytes furves, fim.

Progne purpurea, Boje.

Attienara cyanolenea, Vieill.

Hirunde leneorrhoa, Vieill.

Zonotrichia pileata, Bodtl.

Clirysomitris barbata, Mol.

Sycalis arrensis, Kittl.

Wolothrus bonariensis, (im.

Stmolla Defilippii, Bly.

Taenioptera dominietua, $\mathrm{V}$.

( variegata, $[\%(\mathrm{~m})$.)

( * nengeta, Vieill.)

( " coronata, Vieill.)

rubetra, Burm.

(iensita cumicularia, Vicill.

Lineerthia dumeteria, Gifi, $1 \mathrm{O}^{\circ} \mathrm{l}$.

Cinclodes fusens, Vieill.
Mns graeilipes, Wat.

a bimaeulatus, Wat.

a brasilientis, Wat.

Cervus campestris, Cuv.

Dasypus villosus, Desm.

" minutus, Desin.

" conurus, lieotfi:

Praopus hybridus, Desm.

ATES

Colaptes agrieola, Malh.

fonures patagonns, Tieill.

Noctua cunicularia, $\mathrm{X}[\mathrm{ol}$.

Strix perlata, Licht.

(Cirens macroptcmis, Vieill.)

(Buteo erythronotus, Kiny.)

(Elanus lencmrs, Vieilı.)

Jinnuneulus sparverius, L.

Nilvago thimango, Vieill.

(Polyborns therris, Mol.)

(Cathartes atratus, Bartr.)

Theristiens melanopis, Gm.

(o)lumba picazuro, Temm.

Aetitnrus longieauda, Bechst.

Thinteorus rumicisorts, E*ch.

Budromias molesta, licht.

Phynehotus rufesens, Temm.

Xothura maculosa, Temm.

Rhea americana, Lth. 
A.PРHIBI.

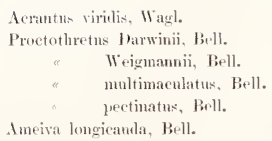

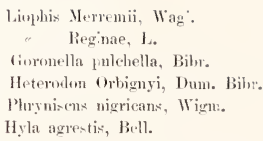

En el cuadro de la vida animal que se imprime en la momoria del viajero durantc sus cruzadas diurnas por la pampa meridional, los mamiferos hacen un papel muy insignificante. En su mayor parte, ellos viven retirados y ocultos, generalmente en los densos pajonales de las regiones palustres.

Una figura caracteristica, frecuentemente observada, es el Canis Azarae. Practica sus cacerias de noche $y$ de dia, y se le encuentra ocupado con preferencia en rastrear las perdices. Las persigue tan tenazmente, que, como nosotros lo hemos observado una vez, er: el momento en que la perrada lo tenía acosado, viendo una perdiz que se levantaba delante de él, dió un salto al aire en persecucion de la misma, movimiento cuya demora lo entregó en un instante á su trájico destino. Su carrcra no es lo mas rápida, y, léjos de su cueva, casi siempre perece, huyendo de los perros.

Una manada del Cervus campestris ofrece siempre, á ia vista de los viajeros, un cambio de perspectiva muy agradable. Pero es un fenómeno poco frecuente en el vcrdadero campo llano, siendo mas abundante en los territorios ondulosos, como particularmente en las inmediaciones de las Sicras del Azul, Currumalan, etc. El pálido color gredoso plateado de su cuerpo, forma un agradable contraste sobre la verdc alfombra del suelo; pero sus movimientos, lo mismo que su cuerpo algo pesado, quitan al animal csa gallarda figura que observamos en los venados del viejo mundo.

En la pampa neridional, se nota visiblemente la escasez de la vizcacha (Lagostomns trichodactylus), como tambien la de su compañera, la Voctna cunicularia. La primera, cuyo limite de distribucion alcanza hasta el Rio Colorado, se observa aún frecuentemente en el Norte de la pampa meridional, pero deja ya de ser una aparicion diaria en las comarcas del Sur.

En el Sur de la Sierra de la Ventana, llamon mucho la atencion del viajcro los abundantes montoncitos de tierra, procedentes de las cuevas del "oculto" (Ctenomys magellanicus), recordandonos este animal, con su vida subterránea, los topos del viejo mundo. Es menester aún comprobar si la especie de la pampa meridional es realmente idéntica con el Ct. magellanicus de la formacion patagónica, cuya voz, segun DAkwrs, ofrece alguna difercncia con la de aquella.

De los murcićlagos, abunda mucho en Bahia Blanca, segun ei Sr. Hol.Miberi, el Dysopes brasiliensis.

Entre lás diversas especics de Desdentados, la "mulita" (Iracpus hybridus) es indudablemente la más frecuente en la pampa mcridional, encontrándosela, a veces, recorriendo los caminos y los sitios algo quebrados. En los mismos lugares se encuentran 
tambien las dentás especies del referido grupo, las cuales han ofrecido siempre un recurso esquisito á los indios antiguos y á los aetuales habitantes de la pampa.

Entre las aves de rapiña, el Miliago Chimango es indudablemente la aparicion más vulgar en la pampa meridional, mueho más abundante que el Polyborzs tharzs, que generalmente se observa reeien al aproximarse el viajero á alguna laguna, de la misma manera que el Elanus lcacurns, el Circus macropterus, el Butco crythronotus, ctc. El último abunda durante la estacion de invierno, en que se le observa en todos los estados de edad $\mathrm{y}$ de colorido. Los ejemplares viejos, eon el blanco de nieve de la parte inferior, suelen llamar mueho la atencion de los que recorren esta comarea.

El Conurus patagonus: la Strix perlata y, entre los eantores, el Troglodytes furvus, la Atticora cyanoleuca, la Cotyle leucorrhoa y la Progne purpurea, sólo se hallan en los sitios barraneosos, y los últimos, á veces, en las habitaeiones támbien. Se observan las dos especies de Anthus: el A. furcatus y el A. correndera, pero siempre en escaso nú mero de individuos, levantándose uno que otro casi de entre las patas de las cabalgaduras;--son mucho menos abundantes que en la pampa del Norte.

De la Zonotrichia pileata se observa una que otra pareja en la pampa llana, pero con mayor frecuencia en los lugares algo quebrados, donde anida en las matas de paja. Las bandadas de Sycalis ariensis y de Chrysomitris barbata son probablemente huéspedes de la estacion hiemal. Las especies de Taenioptera las he observado en las localidades próximas á las sierras pampeanas y algunas de ellas en el Sur tambien, al presentarse los precursores de una vegetaeion arbórea.

En bandadas esparcidas sobre todo el vasto territorio de la pampa, se halla con frecuencia la hermosa Sturnclla Defilippii, una de las aves más vivas y abundantes de estas regiones. Numerosos individuos lastimados se reeojieron á lo largo de la línea telegráfiea, en euyo estado eaen generalmente víetimas de las aves de rapiña. Con la aproximaeion á las regiones de la formacion patagóniea y de las selvas de espinares, al S. O. de Carhué, esta espeeie esta sustituida por la cloica. (Sturnella militaris) espeeie sumamente parecida á la otra, diferenciándose sólo por el color blaneo de sus cubiertas axilares interiores.

Una de las especies mas frecuentemente observadas es la Gcositta cunicularia. Donde hay algun sitio desnudo de vegetaeion, por ej., en aquellos en que abundan los vizeaeherales y partieularmente á lo largo de los eaminos pisados, se hallan algunas parejas de esta especie, una de las alondras mas vivas y alegres, corriendo con rapidez sobre el suelo desnudo, ó volando otras veees, persiguiéndose uno á otro y ostentando el pronuneiado color ferrugíneo de la base de sus alas. En el verano se oye á menudo su canto particular, que nos reeuerda la risas alegres de una criatura.

Como huéspedes estraños se presentan de vez en cuando, en la verdadera pampa, algunos indivíduos asoeiados de la bandurria mora (Ibis mclanopis). En realidad, ellos pertenecen más bien á los sitios paludosos, pero tambien suelen andar buscando inseetos en el eampo seco, volviendo de noche á su palustre domicilio. 
Entre las especies pertenccientes a la familia de los Limicolac, hay dos verdaderos habitantes característicos de la pampa, aunque prefieren siempre los sítios algo húmedos. El Thinoconts municiorus, que casi parece, por la configuracion de su pico y de sus patas, intermedio cntre la paloma y la perdiz, se halla sicmprc en sociedades de 5 á 50 indivíduos, durante la estacion hiemal, particularmente en los lugares donde abundan yuyos con semillas y una granilla corta en vez de paja larga. Son animalitos mansos y confiados, que corren por la alfombra del suelo, completamente con las costumbres de la paloma. Nos accrcamos y el individuo más próximo deja oir un suave silbido de alarma. Al instante todos los compañeros vecinos se dan por avisados, agazapándose momentáneamente entre la paja; cl primcro se levanta emitiendo un grito particular y toda la bandada le siguc al instante, mostrando luego en el vuclo su figura particular, completamente parcida a la ce los chorlitos. Gencralmente no vueliun léjos; sólo dan unas cuanta ; vueltas y descienden otra vez à la playa vecina.

Semcjante en todas sus costumbres es el batitú (Aotiturus longicauda); pero me ha sorprendido su escasez cu los territorios de la pampa meridional, sea esto ocasionado por la circunstancia de que prefiere mas bien los lugares con alguna vegetacion de arbustos, ó porque durante la estacion hiemal abandona dichas comarcas. Sólo alguna vez he oido su grito sonoro y penetrante, en las noches claras, mientras daba ćl sus vueltas en el aire. Es un animal algo mas arisco que la especie anterior, particularmente en la estacion en que no anida, y corre por el suelo con la habilidad de la perdiz, escapándose con vuclo de zig-zag así que se acerca cl cazador.

Lo más característico del territorio llano de la pampa, entie todas las aves que habitan en ella, son, indudablemente, los dos representantes de la familia de los Tinamidae.

La Nothura maculosa, "perdiz chica," se halla propagada en esta region como en la pampa setentrional y no falta en ningun lugar apropiado. Es un habitante de las verdaderas planicies con paja alta (Stipa), donde á cada instante la encuentra en parejas el viajero que cruza estas regiones. Cuando se la rodea un cierto número de veces, se agacha y entónces es fácil cazarla con cualquier arma primitiva. Durante las marchas cansadoras, nos soliamos entretener en cazar docenas enteras, sin emplear otra arma que cl latigo, y los indios quc nos acompañaron recogieron otras tantas con sus lanzas.

Mucho ménos frecuente es la especic grande, el Rhynchotus rufisicns. Esta prefiere los lugares algo más húmedos, donde abundan las yerbas y pastos altos, particularmentc en la vecindad de los csteros ó lagunas tcmporales. En invicrno se encuentra generalmente en pequeñas familias. lis mucho mas arisca que la especie chica. Espantada, sc aleja generalmente d distancias retiradas, formando en su vuelo ondulaciones serenas y muy hermosas, ostentando así el intenso color ferruginoso de sus alas. Hemos notado su presencia en el Sur, hasta en los alrededores de la Sierra de la Ventana.

El cazador apasionado que deja las comodidades de la ciudad para buscar sus diversiunes en los lejanos campos de la pampa meridional, se siente tristemente sorprendido por la escasez de los grandes animales de caza, como la del venado y particularmente la de la Rlea americana. 
Este verdadero habitante indigena y característico de los territorios de la pampa, propagado indudablemente en bandadas numerosas en los tiempos antiguos, ha sido diezmado por las cacerias inclementes de los indios, de tal manera quc, en la actualidad, pertenece á los fenómenos raros. Sic puede cruzar por dias entcros estos vastos campos, $\sin$ que un solo ejemplar ó rastro se ofrezca á la vista. Los úricos lugarcs donde abunda todavía son los distritos ondulados en los alrededores de las sierras pampeanas, como v. gr., cerca de Puan, etc. y de los distritos limitrofes de la region silvestre, como, por ejemplo, al Norte del Rio Colorado.

Entre los anfibios, hay algunas especies, en escaso número de ejemplares, quc de cuando en cuando llaman la atcncion del viajero.

De los lagartos hay el Acrantus viridis, especie ágil, de color verde oscuro con manchas negras. Se halla tambien en los verdaderos campos llano', en ciertos lugares con estipales, encontrándosele á veces parado, tomando el sol en los caminos y sitios desnudos.

En los parajes ondulosos se observa tambicn el Proctothretus pectinatus y cerca de Bahía Blanca descubrió DARwiN el Proct. Wézgnanniiz, el Pr. Dariviniz, cl Pr. multzmaculatus y la Anciva longicauda.

De las serpientes, las especies mas abundantes en los estipales, particularmente en la vecindad de las lagunas ó aguas corrientes, son: el Liophis Merrcmiz, de un color gris verduzco, bastante uniforne y una vivora vencnosa, el Hctcrodon D'Orbignzyi, de color oscuro con pintas blancas y algunas coloradas y con cabeza hocicuda. En las grietas de las barrancas tobáceas de los arroyos, se halla, en lugares adecuados, uno que otro ejemplar del Lioplis reginac, y en los territorios ondulosos y quebrados, la hermosa Coronclla pulchella, fácil de reconoccr por la línea roja que prescnta sobre el espinazo.

Entre los batrácios se halla, en ciertos lugares, ana espccie de Bufo, cerca de la costa el Phrynixcus nigricans y, en los valles de los rios, la Hyla agrestis.

De las especies de moluscos, no hay ninguna que sea realmente habitante de la vasta llanura. En los territorios vecinos de las sierras pampeanas y aún cn la llanura misma, hay uno que otro ejemplar del Borms Oróignyi y del Plagiodontes patagonicns; en los sítios algo palustres y $\mathrm{cn}$ las riberas de los arroyos, se encuentran las especies dc Saccinea, la $S$. meridionalis, la S. rosarincnsis, $y$, en el Sur, la S. magcllanica tambien.

\section{LAS SIERRAS DE LA PAMPA MERIDIONAL.}

Las dos cadenas de sierras que, desde la costa atlántica, en direccion al N. O., surgen hácia el interior de la pampa meridional, la Sicrra del Tandil desde cl Cabo Corricntes y la de la Ventana desde cerca de Bahía Blanca, ambas con sus prolongaciones hácia el N. O. y sus demás ramificaciones sccundarias, no se distinguen por una vegctacion arbórea. Donde en ellas no sale á la superficie la roca cuarcitica desnuda, se ven cu- 
biertas sus faldas por la misma especie de Stifa que viste la pampa vecina, aunque en las quebradas y lugares sombrios se nota la prescncia de una vegetacion particular, escasa, pero completamente diversa de la de la pampa. Algunos arbustitos pequeños del género Himosa, por ej. la hermosa M. Rorac, Nied. nov. sp., no se encuentran en suficiente abundancia, ni son tan exuberantes para que puedan desempeñar papel alguno en la modificacion del carácter general de la vegetacion de estas regiones.

Por csto es que la influencia y modificacion que aquellas sierras ejercen sobre la fauna de los vertebrados, no cs muy importante. Seguramcnte se nota, por ej., al entrar en ellas, la prescncia y mayor abundancia de los venados, avestruces etc, y de muchos animalcs de rapiña, principalmente de las aves que no pueden habitar constantemente la pampa llana por la falta de sitios apropiados para sus nidadas.

El Gcranoä̈tns mclanolcucns es una aparicion perpétua en estas sierras, durante túdo el año; abunda mucho el Buteo crythronotus, el Cathattes atratus, ei Timnunculns sparrerius y otras especies más. Algunas aves, que son muy raras en la pampa, se hallan en mayor abundancia en estas sierras, como v. gr. el Colaptes agricola, la Upucerthia dume. toria, la Muscisaxicola mbetra, la Tacnioptera dominicana, el Troglodytes furws, etc.

Mucho más notable es la modificacion que sufre la fauna de moluscos y demás animales inferiores. Hay mayor abundancia de especies é indivíduos de insectos y de arác. nidos, y la presencia de lugares sombrios produce una fauna particular de moluscos.

En los sítios húmedos, alrededor de los ojos de agua, etc., se halla abundantemente el Limax argentinus y la Succinca meridionalis y, en la Sierra de la Ventana, encontró Strobel la Scolodonta argentina, Strob.

En todas las colinas próximas á esta última sierra abundan el Plagiedontes patagonicus y el Borzs Orbignyi, en la Sicrra de Currumalan se agrega el Plagiodontes Rocac, n. esp., forma típica de la sierra. Una variedad del Fudioptus menáozanus, Strob., puebla, en sociedades considerables, las paredes húmedas de la arenisca cuarcitica de los Cerros Bayos del Azul, y otra nueva especie, el Eudioptns Aicllancedac, nob., se halla cn la Sierra de Currumalan. Estas especics son formas características de las respectivas sicras y se las buscaría en vano en los vastos campos llanos de la pampa.

\section{LOS ESTEROS Y LAGUNAS DULCES Y LOS LUGARES PALUSTRES ADYACENTES.}

\section{MANMALLI}

Felis concolor, L.

Felis jajeros, A\%.

I'anis Azarne, Wat.

Anthus correndera, Vieill. furcatus, D'orh.

('istothorus plateusis, Latl. Poospiza nigromena, Lafr., 1$)^{\circ}\left(\mathrm{O}_{1} \mathrm{~b}\right.$. Jonacospiza allifions, Vieill. Embrragra platensis, (im.
Canis jubatus, Desm. Myopotamus coypus, Cux.

AVES

Agelajus thilius, Mol.

Canthosomus flaves, (im.

Preudoleistes virescens, Yiuill.

Lichenops perepicillatus, Giu.

Centrites niger, Bodd.

Pivomura capisirata, Burm. 
Serpophaga nigricans, Vieill.

Hapalocereus taviventris, Lafr Do Orth.

Cyanotis Azarac, Licht.

Cinclodes fuseus, Vieill.

Phloeocryptus melaneps, Vicill.

Symallaxis sulfurifera, Burm.

"6 anthoides, King.

( " Havogularis, (rould).

Cireus macropterus, Vicill.

Elams lencurus, Vieill.

Otus brachyotus, Forst.

Ardea cocoi, L.

" egretta, Gu.

Nyeticorax Gardeni, Gm.

Theristicus melanopis, fim.

Faleinellus igneus, Gm.

Phoenicopterus ignipalliatus, Gfr.

Chamna chavaria, L.

(Chloepluga magellanica, Gm.)

( " poliocephtala, (ir.)

(Cygnus nigricollis, (rim.)

" coscoroba, Mol.

Hyla agrestis, Bell.

Planorbis peregrinus, J'Orb.

Succinea meridionalis, Dort.

* rosarinensis, Toer.
Querquedula eyanoptera, Vieill.

is flavirostris, Vieill.

" versicolor, Vieill.

Spatula platalea, Vieill.

batila spinicauda, Vicill.

"6 balamensis, I.

Mareca sibilatrix, P.

Rallus rythyrhynchus, Vieill.

Fuliet armillata, Vieill. lencoptera, Vieill.

Vamellus cayanensis, $\mathrm{fm}$.

Eudromias modesta, Licht.

Oreophilus totanirostris, Jard.

Thinocorus rumicivorus, Esch.

Himantopus nigrieollis, Vieill.

Gallinago paraguaine, Vieill.

Gambetta melanolenea, Gm.

Tringa dorsalis, Licht.

Limosa hudsonica, Lath.

Larus cirrhocephalus, Vieill.

Podiceps dominicus, L.

AMPHIBIL

Pyxicephalus americamus, D Otb.

MOLLESCA

Chilina Parchappii, D'Orb.

Paludestrina Parchapii, D Orb.

Al llegar el viajero á las regiones palustres y acuáticas, observa el rápido y agradable cambio que sufre la fastidiosa monotonia de la pampa. Matas altas y aisladas de cortadera (Gyncrium), esparcidas sobre la planicie, indican ya la presencia de aguas en el fondo del terreno; estas matas de cortadera pronto aumentan en cantidad, hasta que forman, á veces, densos pajonales en las inmediaciones de las lagunas. Fácilmente se nota la mayor exuberancia de la vegetacion graminosa y herbacea en toda su circunferencia.

Las lagunas mismas, en su orilla, se presentan cubiertas de una vegetacion de totoras, juncos, etc.; en su interior se hallan suspendidas las especies de Potanogcton, Ccratopliyllum, etc. y á veces, en la superficie, flotan la Azolla ó la Lemna.

Mucho antes de llegar à la orilla de las lagunas, ya se observa, con agrado, una vida animal más agitada.

Bandadas del Falcincllıs ignens, Vancllns cayanensis, y, de vez en cuando, algunos indivíduos de la Channa chavaria, acusan desde léjos su presencia por sus gritos resonantes. Pero estas dos últimas especies mencionadas, representantes muy característicos y numerosos en las regiones acuáticas de la panapa setentrional, desaparecen más y más hácia el Sur de la pampa meridional, donde la última especie apénas se encuentra.

Entre las aves de rapiña hay algunas que son realmente características de las regiones palustres, sobre todo el Circus macropteris, el Elanus leucurus (sólo en escasos 
ejemplares, en el Norte de la pampa meridional) y el Otus braihyotus, aunque estas especies estienden sus escursiones hasta el interior de la pampa.

Desde muy léjos, se conoce por su particular vuelo pesado y por lo grosero de su figura, el mochuelo de los pantanos. Practica sus escursiones de dia y de noche, volando con vucltas particulares para arriba $y$ abajo, descendiendo casi á tierra, elevándose otra vez, y deteniéndose por instantes en el aire con pesados aleteos.

Mucho mayor elegancia en su figura y en su vuelo muestra el Circus macroptcrus, que se acerea á observar con curiosidad á los nuevos huéspedes, para alejarse otra vez y continuar volando y cerniéndose sobre los pajonales, en busea de sus presas. Tocas las demás aves de rapiña, habitantes de la pampa, se hallan, por lo general, en mayor número de indivíduos, en la vecindad de les esteros y lagumas, por las mayores ventajas quc estas ofrecen á sus cacerias.

Al entrar en el distrito de los pajonales de Gyncrium, se nota luego la presencia de algunos pequeños habitantes muy característicos. El Cistothorus platensis, muy parecido en sus costumbres á los representantes del aliado género Trogledytes, se levanta repentínamente de una densa mata de Gynctimm, huyendo unos veinte pasos hácia otra vecina, emitiendo alaridos penetrantes. Algunos individuos de la Synallaris anthoides corren con mucha habilidad por la tierra húmeda. Al observar al cazador, esta avecilla se agacha y queda immóril por un instante $y$, huyendo de él, vuela cortas distancias, descendiendo otra vez directamente sebrc los espacios desnudos de los pajonales. Uno de los más frecuentes habitantes de éstos es la Embcrnagra platinsis, ave poco arisca que, desde la eima de un penacho de Gynerinun, nos observa con euriosidad, acompanándonos y re. pitiendo constantemente sus cortos silbidos insignificantes.

La Poospisa nigromufa nos deja sentir su presencia, aunque vive bastante oculta entre los pajonales; pero pronto sale á la superficie así que observa algun ruido estraño en su vecindad. La Donacospiza albifrons, en cambio, vive más bien libre, eneima de las matas ó de los manojos de Gyncrizm, teniendo la costumbre particular de lcvantarse perpendieularmente de tiempo en tiempo unos to metros, bajando otra vez hasta posarse sobre algun vástago sobresaliente. Esta especie sólo se lialla en los pajonales grandes y estensos, como tambien otra de Synallaxis, la Synallaxis sulfurifera, la cual, en sus costumbres, se asemeja á la Synallaris anthoides.

El Pscudoleistes vircscens, hermosa ave de color amarillo intenso, con la cabeza y las alas oseuras, vive en alegres bandadas. Durante el dia estiende sus escursiones hasta el interior de la pampa, volviendo las bandadas á la noche, para pernoctar en los pajonales y cañaverales de las lagunas. Asociada á él se halla alguna vez, en el Norte de la panipa meridional, una espceie semejante y aún más hermosa, por tener tambien el cuello y la cabeza de intenso color amarillo, el Tanthoscmus facus; pero parece que no es muy abundante en aquellas regiones.

En las loealidades falustres de la pempa, donde, en vez de los pajonales y canaverales hay sitios inundados, de naturaleza algo pantanosa $y$ con corta vegetacion graminosa 
y herbácea, se encuentra generalmente alguna bandada del Falcinellus igneus, la sbandurrias, y, frecuentemente, en su vecindad, una pequeña familia, de indíviduos esparcidos, del Gallinago paraguaia, la becacina. Se levanta produciendo un grito precipitado, dando en el aire vueltas en zig-zag, haciendo en seguida otras vueltas largas, y descendiendo sobre el pantano vecino. Durante la estacion de primavera puede observársele un hábito particular: haciendo el macho sus escursiones muy arriba en el aire desciende repentinamente algunos metros, produciendo un sonido cstraño y emitiendo tonos como la voz de una cabra. En esta costumbre, nuestra especie presenta una analogía completa con la muy conocida especie aliada de Europa.

Rara vez se observa tambien, en los mismos sítios medio inundados, la imponente Limosa Inudsonica, ave escasa y bastante arisca, que vuela en el instante mismo en que se acerca el cazador y que practica á una altura considerable sus largas y estensas vueltas, acompañada alguna vez de la Tringa dorsalis y de una ó dos especies aliadas de este género, que tienen la misma costumbre. Además, hay tambien otras dos interesantes especies en estos sítios paludosos, las que, como el Thinoconus nuicivorus (el que rara vez falta allí) tienen el hábito de cstender sus escursiones hasta el interior de la verdadera pampa: son la Eudromias modesta y el Oreophilus totanirostris, especie de Tringa, de regular tamaño, fácilmente reconocible por su mancha bermeja en la garganta.

Ambas especies viven siempre asociadas en bandadas durante la estacion fria; la primera la hemos encontrado abundantemente en el Norte, la segunda con mayor frecuencia en el Sur de la pampa nieridional. En sus costumbres, vuelo, etc. se asemejan completamente á los representantes del género Tringa.

Sobre los sítios desnudos de vegetacion, como principalmente en las riberas inmediatas de los arroyos y lagunas, corre con habilidad el Centrites niger, pequeña avecita negra con el dorso de color canela, acompañada siempre del muy abundante Cinclodes fuscus y una que otra vez de algun indivíduo del Anthus correndera y, en cl invierno, á veces, de la Mnscisaxicola capistrata.

En las lagunas mismas, sobre la superficie del agua, se desplega una vida muy agitada é interesante; particularmente aquellas rodeadas de totoras, juncales, ctc., son las que hospedan un número considerable de especies y de indivíduos.

Una bandada de aves acuáticas, compuesta de elementos muy heterogéneos, como p. ej, la Fulica armillata (y de vez en cuando la F. lencoptera), asociada á especies de Anas y de Podiceps, á saber: Querquedula cyanoptera, Querquedula flavirostris, Qnerquedula verszcolor, Mareca sibilatrix, Podiceps dominicus, etc., pronto empieza á huir, nadando á toda prisa hácia la opuesta orilla. Cuando se la ha sorprendido y espantado de cerca, generalmente la bandada se disuelve, dando lugar á la separacion de los diversos elementos que la componian, empezando cada uno de estos su fuga segun su costumbre particular: los representantes de Podiccps aléjanse sumergidos bajo la superficie del agua; los patos se detienen á observar, durante algunos momentos, al cazador, precipítanse luego en los aires y dan estensas vueltas en torno de la laguna; las gallaretas, levantándose como á una señal 
toda la bandada, huyen medio corriendo, medio volando, sobre la superficic de aquella háeia la márgen opuesta de la laguna, donde generalmente, despucs de un rato, toda la bandada primitiva torna á reunirse.

En toda lagına de eicrta estcnsion, raro es el que falte la agradable figura del eisne blanco ó ganso (Cygnus coscoroba). Menos frecuente pareee ser, en la pampa meridional, la cspecie aliada, el hermoso Cygmus nigricollis.

Una bandada de la Marcca sibilatrix, el mas clegante de los patos del país, por el hermoso eontraste que ofrece el delicado dibujo blanco y oscuro de su esbelto cuerpo, ofrece siempre durante su vuelo, un hermoso espectáculo.

En los pajonales, eañaverales, juneales, ete., que bordean las lagunas, sobrc el suelo algo inundado corre eon mucha habilidad una hermosa gallineta, el Rallus rythyr/hynchus, animal bastante vivo é inquicto. En invicrno, eomo en verano, sobre todo durante la noche, se oye fiecuentemcnte su grito partieular, bastante fuerte y sonoro. De las demas especies aliadas de la misma familia existe indudablemente una que otra en la pampa meridional, pero durante nuestro rápido paseo no hemos tenido oeasion eneontrarlas.

En los mismos sitios, en la espesura de los juncales, eañavcrales, etc., donde el suelo está eubierto aun por una capa delgada de agua, hay ocasion de observar tres pequeñas aves muy característieas para estas regiones. El Phlococryptus molanops, aveeita de pobre aspeeto, llama la ateneion por su agilidad. Es activa, durante todo el dia, saltando de hoja en hoja ó de tallo á tallo siempre ecrca de la superficie del suelo inundado, ó andando con habilidad sobre las hojas flotantes dc esta misma. Un poeo mas arriba, en los tallos de los juneales y eañaverales, se mueve, volando ineansablemente de tallo en tallo, otro pajarito ehieo reeonoeible desde léjos por el amarillo intenso de la parte inferior de su cuerpo, eon faja transversal de color oseuro sobre el peeho: el aseado Cyanotis Azarac, uno de las avecitas mas hermosas de Sud-América. Vive siempre bastante oeulta en la espesura de los eañaverales y raras veees se le observa fuera de ellos; lo mismo que tambien el Hapaloccras favivcntris, espeeie muy aliada por sus hábitos.

Entre las garzas la espeeie mas abundante en los arroyos y lagunas es la Ardea corrtta reeonoeible á larga distaneia por el blaneo puro de su plumage. Esta especie sa halla tambien en las lagunas ehieas ć insignifieantes, las que, seguramente, no encierran peces, debiendo suponerse que en tales oeasiones su alimento eonsiste de amfibios $\hat{c}$ inseetos.

Los rios y arroyos que cruzan la pampa meridional no son de mucha importaneia. Sus riberas son generalmente desnudas ú orilladas de densos pajonales de Gyncrium como v. gr. cl Arroyo Salado.

Hay algunas especies que prefieren estas aguas corrientes ó se hallan allá con mayor freeuencia; eomo p. ej. la Ardea cocoi, el Larus cirrhoccphalus y sobre todo el Phalacrocorax brasilianus, ete.

Por lo demas, su fauna y la de sus alrededores, es análoga á la de las lagunas. 
De las especies de moluscos, el Planorbis peregrinzs se encuentra en abundancia en las lagunas, y, en los contornos húmedos, la Snccinea meridionalis y la $S$. Rosarinensis. Estas especies, en ejemplares numerosos, blanqueados, cubren los aníiguos sitios paludosos' p. ej. entre los fuertes Lavalle y Carhué.

En los arroyos, con agua de poca corriente, de todo el territorio, se halla la Palntdestrina Parchappii y casi en cada uno de los que nacen en la Sierra de lát Ventana se presenta en millares de individuos una especie de Chilina, la $C$. Parchappii bajo sus diversas y numerosas variedacles.

\section{LAS LAGUNAS SALADAS.}

A VES

Larns dominicanus, Licht. Aegialitis falklandicns, Lath. Himantopus nigricollis, Vieill. Dafila bahamensis, Lin.
Querqnednla flavirostris, Vieill. eyanoptera, Vieill.

Spatula platalea, Vieill.

Phoenicopterus ignipalliatus, Geof. D Orb,

Las lagunas saládas de la pampa carecen de cañaverales, juncales ó pajonales en su orilla. Sus riberas inmediatas, son desnudas y en la estacion seca, cubiertas de eflorescencias salitrosas. A alguna distancia de la orilla, abundan los vegetales halófitos, como son los representantes del género Salicomia, Szeda, etc.; pero en los sitios donde hay entradas de agua dulce, la vegetacion presenta una transicion gradual á la de los esteras y lagunas dulces.

No se puede decir, en un sentido estricto, que las lagunas con agua salada tengan una fauna ornitológica, que les pertenezca esclusivamente. Pero algunas especies prefieren para su domicilio las lagunas saladas y son apariciones escepcionales ó poco frecuentes en las dulces.

El Larns dominicanus se observa en la vecindad de todas las grandes lagunas saladas del Sur, y casi nunca se lo encuentra sobre las dulces.

La orilla inmediata del agua de estas lagunas, durante la estacion hiemal, está ocupada por una especie de Charatrins, el Aegialitis falklandicus, ave viva y muy corredora, que se observa cazando en la márgen de estas lagunas, sobre el barro húmedo y en los sítios inundados por una delgada capa de agua salada. Pocas veces se encuentra en su sociedad el Himantopus nigricollis.

Las grandes bandadas, hasta de mil y más individuos, del flamenco (Phonicoptorns ignipalliatus) que se encuentran en las lagunas saladas de Carhué, Marra-Có, Salinas Chicas, etc, ofrecen un hermoso espectáculo, particularmente durante su vuelo. D'Orbigny observó una colonia de esta especie anidando igualmente en una laguna salada del Sur. Durante nuestro viaje no hemos tenido ocasion de observarlas en las lagunas dulces de la pampa meridional.

De las especies de patos, la Dafila Bahamcnsis, Spatula platalca visitan particular- 
mente las lagunas saladas. Las dos especies de Querquedula se hallan con la misma frecuencia en las saladas que en las dulces $y$ en las aguas corrientes.

\section{REGION ENTRERLANA DE LA PATAGONIA SETENTRIONAL.}

Nos referimos aqui al territorio situado entre el Rio Colorado, el Rio Negro y el Rio Neuquen, con los precursores y parages de vegetacion análoga al N. y N. O. del Rio Colorado, siendo limitada esta region, en el N. E., por la pampa meridional que se estiende hasta una distancia de diez leguas más ó menos de la orilla del Rio Colorado y en el N. y N. O. por la region central de las densas selvas de espinares; y en fin, en el O. por la region andina.

\section{EL TERRITORIO DE LAS MATAS Y ARBUSTOS PATAGONICOS.}

MAMMALIA

Nycticejus bonariensis, Less.

Felis concolor, L.

- Geoffroyi, Guér.

" pajeros, Az.

Canis Azarae, Wat.

Lyncodon patagoniens, Blainv.

Galictis vittata, Schreib.

* barbara, Wagn.

Mephites patagouicus, Licht.

Troglodytes furvus, Gim.

Anthus furcatus, D Orb.

" correndera, Vieill.

Mimus triurus, Vieill.

" patagonicus, Lafr. D'Orb.

Atticora cyanolenca, Vieill.

Progne purpurea, Vieill.

Hirundo leucorrhoa, Viell.

Anumbius acuticaudatus, Less.

Synallaxis patagonica, D Orb.

- sordida, Less.

- modesta, Eyt.

( \& lencocephala, D'Orb.)

* striaticeps, Lafr. D'Orb.

Leptasthenura aegithaloides, Kittl.

Homorus gutturalis, Lafr. WOrb.

Rhynocrypta lanceolata, Lafr. D'Orb.

Pteroptochus sp., (Tarnii, King.?)

Geositta cunicularia, Vieill.

Upucerthia dumctoria, Gicoffr.

Sturnella loica, Mol.

Molothrus bonariensis, Gm.

Chrysomitris barbata, Mol.

Sycalis arvensis, Kittl.
Didelphys elegans, Wat.

Cervus campestris, Cuv.

Auchenia llama, Schreb.

Dicotyles torquatus, Cuv,

Dolichotis patagonica, Wagu.

Cavia australis, Geoffr.

Ctenomys magellanicus, King.

Hesperomys griscoflarus, Wat.

Dasypus minutus, Desm.

A V E S

Zouotrichia pileata, Bodd.

var. canicapilla, Gld.

Embernagra platensis, Lafi. DO Orb. olivascens, D'Orb.

Phrygilus fruticeti, Kittl.

* carbonarius, Lafr. D'Orb.

Coturniculns manimbe, Licht.

Diuca minor, Bp.

Poospiza torquata, $\mathrm{B}_{1}$.

Gubernatrix cristatella, Vieill.

Agriornis striatus, Gld.

Taeuioptera coronata, Vieill. * ribetra, Bum.

* irupero, Vieill.

Pyrope murina, Lafr. D'Orb.

Cnipolegus anthracinus, Cab.

Yuscisaxicola mentalis, Lafr D Orb.

Anaeretes parulus, Kittl.

Stigmatura flavo-cinerea, Burm.

Phytotoma rutila, Vieill.

Conurus patagonus, Vieill.

Colaptes agricola, Malh.

Geranoaetus melanoleueus, Vieill.

Buteo (pterocles, Temm?) 
Harpyhalcaetus coronatus, Vieill.

Polyborus tharns, Mol.

Milvago chimango, Vieill.

Hypotriorehis femoralis, Temm.

Tiununculus sparverius, Lin.

Circus einerens, Vieill.

Sarcorhamphus gryphus, Lin.

Cathartes atratus, Btr.

Strix perlata, Temm.

Bubo virginianus, Gm.
Glaucidium nanum, King.

Noctna eunicularia, Hol.

Columba maculosa, Tenum.

Zenaida maculata, Vieill.

Eudromia elegans, D'Orb.

(Nothura maculosa, Temm.)

" Darwini, Gld.

Rhea americana, Lth.

* Darwini, Gld.

Testudo chilensis, W.

Leiosaurus fasciatus, D'Orb.

Acrantus viridis, Wagl.

Proctothretns Weigmamii, Dum. Bbr. pectinatus, Bell.

AMPHIBIA

Ameiva longicauda, Bell.

Liophis Merremii, Wagl.

Coronella pulchella, Bibr.

Heterodon D'Orbignyi, Dum. Bbr.

Elaps frontalis, Dum. Bbr.

MOLLUSCA

Pupa oblonga, Pf.

Succinea Magellanica, Gld.

Atravezando el territorio situado entre Bahia Blanca y el Rio Colorado, á unas cinco leguas al S. O. de las riberas del Sauce Chico, ya principian á mostrarse los primeros arbustos, en los bajos del terreno ondulado.

Estos arbustos son precursores tanto de la formacion patagónica por una parte, como tambien, por otra, de la region central de los montes de espinares. Algunos grupos de árboles altos de una especie de Prosopis (algarrobo), sin duda componente importante característico del monte espinar del Sur, se mezclan aquí con los demas arbustos bajos.

A unas cinco leguas al $\mathrm{N}$. del Rio Colorado, en el instante en que se notan las primeras piedritas rodadas del suelo patagónico, mezcladas con la tierra, recien cambia completamente el carácter de la vegetacion, tomando el de la formacion patagónica, con sus constituyentes principales, lus representantes de los géneros Larrea (jarilla), Cordalia, Chuquiraga, y otras numerosas Sinantéreas leñosas. Esta vejetacion de matorrales es mas densa en las inmediaciones de los rios y valles, disminuyendo su espesor en el interior de la entreriana meseta, donde no faltan trozos y playas semejantes á los campos llanos de la pampa meridional. Fuera de los hermosos sauces, que orillan el rio, y de los grupos de Chañares en los valles, no existen árboles elevados en esta formacion, llegando, sólo alguna que otra vez, la fodina rhombifolía, con una hermosa corona cupuliforme y en todo el año de verde fresco, hasta las dimensiones de pequeños árboles.

Apenas habíamos dejado las riberas del Rio Sauce Chico, en direccion al Rio Colorado, durante nuestra cruzada, cuando ya se nos presentó el primer habitante característico de la formacion del monte: eran unos grandes individuos de la Dolichotis patagónica, especie que abunda en toda la formacion, particularmente en los bajos y en los valles del Rio Negro y Rio Colorado. 
Muy frecuente en los últimos es tambien el Ctenomys magellanicus cuya voz particular, se siente cada instante, haciéndose ademas muy desagradable esta especie á las cabalgaduras, por sus galerias subterráneas, con las que, en algunos sitios, el suelo se halla perforado en todas direcciones.

En los mismos parajes se encuentra abundantenente tambien la Cavia australis. E1 Hesperomys griseo-flavns puebla en infinito número los valles del Rio Negro y del Rio Colorado. Algunas otras especies del mismo género no hemos aun determinado.

Uno de los animales mas interesantes de esta formacion es el Lyncodon patagonicus. Es un animalito sumamente ágil y mordaz con movimientos mucho más hábiles y rápidos que los de su aliado, el huron (Galictis vittata), teniendo, como este, la costumbre de acompañar cada asalto de defensa por furiosos gritos. Se diferencia de él por su figura mucho menor y mas elegante, siendo su color principal el rojo-oscuro, salpicado de blanco.

A mas de la aliada especie vulgar, Galictis vittata, se encuentra cerca de Patagones segun el Sr. Moreno tambien la G. barbara.

De las especies de Murcielagos, se halla, en los bosques de sauces del Rio Negro, segun el mismo autor, el Nycticcjus bonariensis, especie que tiene la costumbre durante la estacion de verano, de vivir colgada entre el denso follage de los árboles.

De las aves, se sintieron, así que hubimos llegado á los primeros arbustos, los chirridos del Anumbius acuticaudatus, especie que realmente abunda mas bien en la orilla que en la espesura ó en el interior de los montes y matorrales.

En segruida se presentaron: la «martineta», Eudromia clegans, el Mimus patagonicus, la calandria del Sur, casi la única especie que nos alegraba con su canto durante nuestras marchas en la estacion hiemal; la Synallaxis aegithaloides, la Zonotrichia canicapilla, el Plirygilus carbonarius, etc. Del género Mimus se encuentra allí, ademas de la mencionada especie, el $\mathrm{H}$. triums, algo más grande que aquella, con anchas fajas blancas en la cola y en las alas. La primera es abundante en estremo durante todo el año, pero la segunda es un ave bastante escasa en estas regiones, teniendo su centro de distribucion en las selvas de espinares de las provincias centrales de la República y abandonando su domicilio frio en la Patagonia para trasladarse al Norte durante la estacion hiemal. Ambas especies son cantoras muy animados, durante todas las estaciones de año; y tiene sobre todo la primera una fama bien merecida por lo lleno de su voz y lo corricnte de su canto mixto y compuesto, que imita la voz de todos los animales que se encuentran en la vecindad de su domicilio. El del M. patagonicus es análogo, pero ménos interesante, siendo siempre mas interrumpido é incompleto y la voz ménos fuerte.

En los valles del Rio Negro y Rio Colorado ademas se siente la voz de dos especies cantoras, huéspedes de la estacion de verano; el cardenal amarillo, Gubcrnatrix cris. tatclla, con su cantoagradable y sus alegres movimientos, y el hermoso Ilyytotoma rutila, 
con su curioso vuelo ondeado, y su chirrido cansador que emite á cada instante descle la corona de algun arbusto.

Un interesante cantor, durante la estacion de verano, es el Phrygilus fraticti. Este animal, con su color pronunciado, mcdio negro, comienza á producir sus chirridos encima de un arbusto, levántase luego al aire y dcscendiendo suavemente, sostenido por sus alas desplegadas é inmóviles corta su canto con dos silbidos altos de agradable contraste. El viagero que conoce ciertos distritos traquiticos cn la Sierra alta de Tucuman con sus breñales de especies de Chuquiraga y demas Sinantércas leñosos, vegetacion completamente análoga á la de la Patagonia Setentrional, se siente no poco sorprendido al encontrar en la misma vegetacion análoga tambien el mismo habitante cantor. Durante la estacion hiemal vive asociado en grandes bandadas, y reunido á ellos ó por enjambres aislados se halla tambien con frecuencia la otra especie del mismo género el Ph. carbonarius, siendo acompanado estc generalmente, por la Zonotriclia canicapilla, Diuca mizor, y alguua que otra vez por la Poospisa torquata.

E. 1 mas turbulento de todos los habitantns de esta region es indudablemente el Homorus gutturalis. Lo mismo que su aliado del Norte, el "cachalote", ambos sexos en union, gritando desde la cima de un arbusto, hacen un concierto cuyo ruido estruendoso se puede sentir claramente hasta la distancia de una media legua.

Durante el invierno viven mas bien algo separadas tomando cada individuo su rum. bo para buscar alimentos, moviéndose en el suelo con la misma habilidad que en la cspesura de los arbustos. Pero tambien en este tiempo se siente con frecuencia la voz de uno que otro individuo. Las especies de Synallaxis la S. sordida y particularmente, la S. patagonica tienen costumbres muy análogas. Ambas sc distinguen por una voz fuerte y un trinado muy resonante.

Son animalitos muy ágiles y vivos que vuelan incansablemente de arbusto en arbusto, ó, bajando á veces á tierra, dejan oir durante todo el dia su canto particular. Asociada á ellos durante la estacion hiemal, se hallan algunas otras cspecies no menos características para estas regiones. El Anacretes parulus, uno de los pígmeos de su familia, se presenta con voz suave aleteando de arbusto en arbusto, siempre reunido en sociedad de varios individuos.

Muy análoga en sus costumbres, es la Stigmatura flavosinerea; avecita muy alegre y sociable. Ambos sexos, unidos en el mismo arbusto, son incansables de su canto par. ticular, que emita un martillcteo en cuyos golpes se alternan los sexos, grito que tambicn recuerda el ruido de un molino; este canto se oye tambien con frecuencia durante la estacion fria. La Leptastlucnura aegithaloides se mueve con la mayor habilidad en el ramaje de los arbustitos mas densos; andando tambien con frecuencia, á ticrra, entre la paja. La Synallaxis modesta anda casi constantemente por el suelo, entre los matorrales; pero es una especie bastante rara que habita las rocas, hallándose sólo en los sitios quebrados y peñascosos.

Una de las especies mas interesantes es la Rlzynomía lanceolata, el "gallito ave con 
alas bastante débiles y poco activas, pero sumamente hábil para correr con rapidez sobre el terreno desnudo entre los grupos de arbustos, saltando á uno de estos tan pronto como se prescnta un accidente estraño, bajando luego otra vez $\mathrm{cn}$ la huida $\mathrm{y}$ corriendo rápidamente á largas distancias. Completamente idéntica en todo sus hábitos es una especie de Pteroptocluus, que allí se encuentra y la que se presenta escasamente en los terrenos algo arenosos, como p. ej. entre los jarillares del Chichinal, etc.

Entre los aliados de la familia de los Tyrannidae hay una especie muy interesante' el Cnipolegus anthracinus, Cab. ${ }^{1}$. Aparece en aquellas regiones á fines de Setiembre, emigrando al Norte al principio del otoño. Es un ave muy solitaria que por lo general vive muy retirada y oculta, moviéndose incansablemente con vuelo duro y ruidoso y que cruza como errante en los matorrales densos, cerca del suelo. Recien en la primavera el hermoso macho de un color negro intenso, casi uniforme, sale de su escondite, presentándose sobre una rama ó en la punta seca de un arbusto, para cmitir su canto corto, compuesto en su parte esencial, sólo de dos silbidos melancólicos, pero de un agradable tono aflautado, y vuela siempre dejándolo oir, elevándose unos piés en el aire y descendiendo sobre el mismo sitio. Durantc esta maniobra particular hay ocasion de observar el agradable contraste que produce la faja blanca de sus alas. Muy semejante á esta especie, en su esterior y sus hábitos es el Lichcnops perspicillatus. Pero es una especie mas bien propia de los pajonales, sítios húmcdos de la orilla del rio, que anida entre las matas de Gyncrium,

Entre las especies de aves de rapiña, el Buteo crythronotus es la más abundante, alimentándose con preferencia de los numerosos individuos de Ctcnomys, etc., que pueblan estas regiones. Frecuentemente hemos encontrado su nido en algun arbusto alto sobre la cuchilla y barranca que limita el valle de los rios.

El Hypotriorclis femoralis, el que no se halla en la verdadera pampa, encuentra aquí con abundancia su recurso preferido, la Zenaida maculata.

En el valle del Rio Negro, particularmente sobre los altos sauces, se observa con frecuencia una especie de Buteo de gran tamaño que probablemente es el B. ptcroclcs.

Un pequeño alcon que tambien menciona HuDSON, medio blanco por debajo, con gris por arriba, no es muy raro en el valle del Rio Negro, pero no lo he conseguido para la determinacion sistemática.

El majestuoso Geranoaitus mclanolcucus, el "aguilucho *, anida sobre las prominencias de las paredes de la arcnisca terciaria, en las cuchillas que limitan los valles, como p. ej. en la del Balcheta, etc. Mucho mas raro debe ser el Harpyhalcaítus coronatus, que menciona HUDSON sin que nosotros hayamos tenido ocasion de observarlo.

Las diferentes cspecies de lechuzas pueblan con preferencia á la meseta entreriana, los bosques ribereños de sauccs $\mathrm{y}$ las islas.

Era un concierto estraño el de la voz baja y misteriosa del Bubo virginianus, emi-

(1) Schater ha deserito del Rio Negro una variedad no muy rara de ésta especie, cou plumas blancas en los costados, como nueva: Cnipol. Hulsoni, Sel. Proc. Zool. Soe. 1872, p. 439. 
tida por media docena de indivíduos, que se contestaban el uno al otro cual eco repetido, como teníamos ocasion de observarlo durante nuestra pasada hiemal en la isla de Choe-

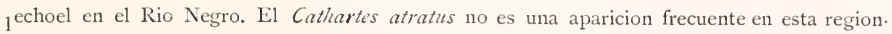
Hemos observado algunos individuos en el valle del Rio Negro asociados al Polyborus tharus, al Milvago chimango, etc.

Las dos especies de palomas, la Columba maculosa y la Zenaida maculata se hallan ambas con frecuencia. Durante la estacion hiemal la primera visita en grandes bandadas ios verdes trebolares silvestres de los valles del Rio Colorado y Rio Negro. Existen ademas, dos especies de palomitas rupestres, del género Orcopila ó sus aliados, especies que no hemos podido conseguir para determinar.

Entre los Tinamidae hay dos especies lo más características para estas regiones.

La Eudromia clcgans ó «martineta se encuentra exclusivamente en territorios que no carecen de nna vejetacion de breñales ó arbustos bajos. En el momento de nuestra entrada en la formacion correspondiente, cerca de Salinas Chicas, se presentó esta especie en abundancia, lo mismo que mas tarde, particularmente en estos valles de los Rios Negro y Colorado. Su vuelo es ruidoso y rápido, pero no tan ondulado como el de la perdiz grande.

Acercándose á las márgenes del Rio Colorado, se nota luego que la Nothura maculosa, perdiz comun. que nos acompañaba por todo el territorio de la pampa, está sustituida por una especie semejante á ella en todo su esterior y en sus hábitos. Al principio, ambas especies se encuentran con la misma frecuencia, hasta que mas tarde, al acercarse al centro de esta formacion, sólo se halla la segunda, Nothura Darwini. Es un animal de un color ménos amarillento y algo mas gris; en sus hábitos se nota que es mucho más arisco que la $N$. macnlosa, corre ménos, pero vuela con mayor persistencia, cuando se le persigue. Durante el vuelo se la reconoce y distingue por la cabeza relativamente mas grande y redonda, pero su voz apenas se diferencia de la otra.

Las dos especies de avestruces se hallan ambas al Norte del Rio Niegro, pero la Rhea Darwini es muy escasa, comenzando á ser muy abundante al Sur del mismo rio.

De los amfibios se halla, particularmente sobre la meseta, el Elaps frontalis, lo mismo que el Proctothretus pectinatus. Las demás especies habitan mas bien los bajos y valles de los rios. La Testudo Chilensis es seguramente una aparicion bastante escasa en estas regiones.

Entre los arácnidos, llama mucho la atencion una especie de Mygale (Eurypelmas. $s t r$.) que se halla con abundancia estraordinaria en algunos sítios arenosos, sobre la meseta, entre los matorrales de jarilla. Vive en tubos verticales construidos en el suelo, de 2 á 5 decímetros de hondura. Ellos están tapizados por un tejido sedoso y llevan una tapa ó puerta móvil, resistente, un poco convexa en la parte inferior y fija al tubo por uno de los puntos del borde, por medio de cierta cantidad ne hiles, tal cual se observa en la $M$. caementaria de Europa y otras muchas especies de la misma familia. En algunos sitios el 
suelo parece perforado por estas habitaciones, que tienen desde un diámetro reducido hasta el de dos centímetros ó mas.

De las especies de moluscos, ninguna es verdadero habitante de la meseta; pero en los lugares húmedos en los valles, vive escasamente la Succinea meridionalis y la $S$. maScllanica, y en los Cerritos de Pichi Mahuida he hallado, bajo los troncos de una Opuntia, la Pupa oblonga.

\section{LOS RIOS Y LAGUNAS ADYACENTES Y SUS RIBERAS INMEDIATAS.}

\section{MIMMALA}

Felis onça, L.

" pajeros, Az.

Canis jubatus, Dsm.
Myopotamus eoypns, Cuv.

Lutra ehilensis, Nol.

Hesperomys (Glongiendatus Benn.?),

IVES

Turdus falklandieus, Q. et fram. rufiventris, Vieill.

Cistothorus platensis, Lath.

Centrites niger, Bodd.

Synallaxis sulfurifera, Burm.

" flavognlaris, Gld.

Phloeocryptus melanops, Vieill.

Cyanotis Azarae, Vieill.

Hapalocercus flaviventris, Lafr. D Orb.

(Ptyonma capistrata, Bum.)

Lichenops perspicillatns, Vieill.

Psendoleistes virescens, Vieill.

Agelaius thilius, Mol.

Emberuagra platensis, Gm. olivascens, D'Orb.

Ceryle torquata, Lin.

Ardea cocoi, L.

" egretta, Gm.

Nyeticorax (iardeni, Gm.

Hyla agrestis, Bell.

Perichtys laevis, Jen.

Thio patagonicns, $D^{\prime}$ Orb. Anodonta juelchana, D'Orb.

Chilina fluminea, Mat. * tehuelcha, D'Orh.

Suecinea meridionalis, $\mathrm{D}^{\mathrm{O}} \mathrm{r}$.

\section{AMPHIBIA}

Pyxicephalns americans, Dum. Bbr.

PISCES

(Pejeríy. Spee. dub.)

IOLLESCA

Falcinellus ignens, Gm.

Theristiens melanopis, (im.

Phoenicopterus ignipalliatns, Geofr. D'Orb.

Querquednla flavirostris, Vieill.

$$
\text { " cyanoptera, Vieill. }
$$

Dafila spinieauda, Vieill.

Erismatura feruginea, Eyt.

Mareea sibilatrix, Poepp.

Phalaerocorax brasilianus, Gm.

Podiceps major, Bodd.

\& Rollandi, Q. et Gaim

Rallus rythyrhynchus, Vieill.

Oreophins totanirostris, Jard.

Eudromias modesta, Licht.

Aegialatis falklandica, Lath.

Gallinago paraguaiae, Vieill.

Gambetta melanolenea, Gm.

Himantopus nigricollis, Vieill.

Larus cirrhoeephalus, Vieill.

\footnotetext{
Sucinea magellaniea, King.

Agriolimax arcentims, Strob.

Planorbis peregrinus, Dorb.

" auatims, borb.

Incylus eoneentricus, 1) On.
}

Los dos grandes rios, el Colorado y el Negro (con su afluente el Neuquen) que forman el límite de la region aludida, corren por anchos valles de crosion, limitados á cada 
lado por los declives de la meseta vecina, siendo formados estos por cuchillas de arenisca calcárea, de una altura de 20 á 50 metros. Estos valles, el del Rio Colorado de I á 2 y el del Rio Negro de 4 á 5 leguas de ancho, forman generalmente una ancha playa llana, cubierto con una vegetacion mas fresca $y$ mas exuberante que la que cubre la meseta entreriana.

El caudal de los rios mencionados serpentea en estos anchos valles, formando nume rosas curvas, acercándose unas veces á la cuchilla del Norte, y otras á la del Sur, siendo fijado su curso, durante la altura norma! de sus aguas, por una barranca ó ribera inmediata de algunos metros de altura.

Aquellas curvas limitan rincones estensos, dotados de una vegetacion vigorosa y verde durante todas las estaciones del año, á consecuencia de la humedad natural del suelo ribererio.

Pronto se descubre en la superflcie turbulenta del agua cristalina, en medio de la corriente del rio, la suelta figura del Phalacrocorax brasilianus, el cuervo del agua, especie conocida en casi toda Sud-América. Es un pescador incansable en las aguas corrientes. Con su cuerpo sumerjido entre las olas hasta la base del esbelto cuello, desapareciendo completamente en el agua á veces y saliendo por otra parte á la superficie, se le vé arrastrado por la corriente rio abajo; no sin observarle algun tiempo despues volando, siempre cerca de la superficie del agua, rio arriba, siguiendo el curso de este, hasta el sitio de su anterior parada, para comenzar de nuevo el mismo paseo.

El Larus cirrhocephalus se observa con frecuencia, haciendo, á lo largo del rio, susestensas curvas en el aire ó fluctuando por cima de la laguna; pero baja tambien á las playas vecinas, en busca de alimento.

Las riberas inmediatas del rio bajo, á veces son arenosas ó térreas, pero generalmente están formadas por bancos de cascajo ó cantos rodados. El vulgar Cinclodes fuscus, el Contrites niger, y, á veces la Plyonura capistrata, son huéspedes constantes en estos bancos durante la estacion hiemal.

La escarpa de estas riberas inmediatas está generalmente orillada por una angosta faja de cañaverales de una especie de Arundo, seguiéndola otra faja mas ó menos densa ó estensa de hermosos bosques de sauces. Ellos son, à veces, muy densos y de una estension considerable, particularmente en las islas, y llaman además la atencion por lo derecho $\mathrm{y}$ esbelto de sus hermosos y grandes árboles, fenómeno que resulta de su crecimiento en grupos muy densos y cerrados. Su follaje, que se remueve cada año, y que cae en el otoño, forma gradualmente una verdadera capa de seroja y de humo en el suelo de estos sauzales. Un ejército de insectos, coleópteros y particularmente carabicineos, corre en todas direcciones cuando se remueve esta capa de hojarasca depositada sobre el suelo, donde tambien buscan escondite, en los huecos húmedos del fondo, centenares de individuos del Limax argentimus.

Estos bosques son el verdadero clíseo para el alegre Turdus falklanäicus, especie 
que abunda mucho, corriendo en numerosos individuos, con preferencia sobre el suelo húmedo, y anidando en las mísmos saucedales durante la estacion de la primavera. Segun DARIvin se ha!la tambien, cerca de Patagones, el aliado Turdus rufiventris, especie cuya presencia no hemos tenido ocasion de observar durante nuestra escursion.

En una rama inclinada sobre el agua se observa la hermosa Coryle torquata, el - Martin-pescador», la mas grande de las tres especies americanas, propagadas por casi toda Sud-América.

Estos bosques son, además, la habitacion predilecta de muchas aves de rapiña, de la Columba maculosa, de la Zcnaida maculata y de varias otras especies.

Fuera de los bosquez de sauces se estiende el terreno bajo de la playa ribereña, inundado hasta cierto límite, en la estacion de las crecientes del rio, dando orígen esta abundante humedad á la formacion de considerables y espesos pajona!es de Gynerium, mientras que al mismo tiempo varios brazos ciegos ó cañadas secundarias del rio, existentes allí sólo durante la creciente, dejan, en la época de la bajante, una série de lagunas orladas de Gynerium, carrizó, tija y juncos, etc.

Esta zona de pajonales de Gynerium es á veccs muy ancha y estensa ó bien angosta, pero siempre mas densa en las inmediaciones del agua, donde generalmente se mezcla á los cañaverales de Arundo, Typha, etc. que ultrapasa.

El Cistothorus platensis es una de las especies que pronto descubren su presencia en estos carrizales, lo mismo que la Embernagra platcnsis, y, en las márgenes del Rio Colorado la Embernagra olivascens. Sólo en los pajonales estensos, en ciertcs sitios, tiene oca. sion de reconocer, el observador instruido, la presencia de la interesante Synallaxis sulfurifora, ave rara $\mathrm{y}$ de vida muy retirada.

Penetramos, no sin resistencia y dificultad, en estos densos pajonales de Gyncrium, siguiendo la direccion de los grupos de sauces que nos hacen sospechar la presencia del agua.

Al llegar, pronto nos convencemos de que no se trata de un verdadero brazo del rio, sinó una de esas numerosas cañadas ó charcos, con agua estancada en la época de la bajante. Allí se nos presenta una sorpresa en estremo agradable. El Myopotamus coypus, ocupado en sociedades en la orilla de la laguna, se lanza al agua al instante. Media docena de individuos del magestuoso Cygnts nigricollis, nada con serenidad á poca dis. tancia, en el centro de aqnella, y, al observar que nuestra presencia no los incita a volar, recordamos que esto no les es posible durante la muda de su plumage.

Una precavida Ardea cocoi ya ha levantado el vuelo, mientras que otros ejemplares de la garza blanca (A. egretta) parecen dudar aún si han de seguir ó nó el cjemplo de su compañera. De las especies de patos, rara vez faltan la Qucrquedula cyanoptcra y Q. favirostris, la Erismatura ferruginea, y la Mareca sibilatrix. Una sociedad de Fulica armillata, frecuentemente acompañada por la F. lcucoptera y el Podiccps Rollandi, corta pronto la lisa superficie del agua, para ir á buscar nadando el sítio más lejáno de la laguna. 
La orilla inmediata de estas lagunas, hasta en cl interior del agua. está bordeada generalmente por cañaveralcs de Typha y á veces de juncales, en cuya espesura se puede notar la abundancia del Rallus rythyrliynchus del Phloeocryptus melanops, y á veces, del hermoso Cyanotis Azarae. En los juncales se eneuentra, en escaso número de indivíduos, el Agelaius Thilius.

En la espesura de los pajonales de Gyncrium y Typha, cerca de la orilla del agua, se observa no muy raro y formado de hojas de la misma cortadera, el nido ingenioso, cerrado, de un roedor, segun las observaciones dcl Sr. Schulz, probablemente el Hesperomys longicaudatus, ó una especie muy aliada.

Fn todos aquellos sitios cn que el rio toca con una de sus ancas el escarpe de las barrancas, que lo limitan entonces, se observa frecucntemente una faja de matorrales de Baccharis lanceolata $\mathrm{y}$ de otras compuestas, arbustitos leñosos sin espinas.

Estos matorrales son domicilios preferidos de la Synallaxis flavogularis de cuya cspecie, no muy abundante, queda, en aquellas regiones, durante la estacion hiemal, uno que otro indivíduo, descubriendo su presencia por el suave silbido característico de está especie.

Estos matorrales de Baccharis forman gradualmente allá el tránsito á la region del los arbustos patagónicos, predominando ya estos por completo en los sitios qucbratos y escarpadss de la cuchilla tcrciaria que limita el valle.

Todas las especies de esta formacion de arbustos patagónicos, se presentan en ma. yor número en estas faldas de los valles que en el interior de la meseta entreriana.

En las márgenes del rio donde se estienden las grandes playas ribereñas, hay uno que otro sitio de naturaleza paludosa, donde abundan, particularmente en cl Rio Colorado, el Gallinago paraguaiac, var. magellanica, el Falcincllus igneus, la Eudromias modesta, y, á veces, el Theristicus melanopis, raientras que numerosas bandadas de "abutardas» (Chlocphaga magcllanica, Ch. polioccphala), pueblan la fresca y verde alfombra de las playas vecinas, durante la estacion hicmal.

De los batracios no es rara, en las lagunas una especie de rana, el Pyxiccphalus antricanus.

De los peces, recordaremos que el Rio Colorado está poblado por el Pcrichtys lacvis, especie que DARWIN descubrió en el Rio Santa-Cruz, estando ella acompañada frecuentemente por una especie no determinada aún, de «Pejerey . Ademas del último, abunda, en el Rio.Negro, una mcrluza ó bacalao, que no hemos podido traer para determinar, tenicndo los indivíduos recojidos un largo de más de dos á cuatro decímetros.

Durante el período de la bajante del Rio Negro se nota, en los bancos de arena, á la orilla del agua, la presencia de varios moluscos importantes y característicos de este rio, como son el Unio patagonicus, la Anodonta puclchana y la Chilina tehuelcha. No hemos tenido ocasion de encontrar, en el Rio Negro, la Chilina Morcníi, nueva especie coleccionada por el Sr. Moreno en el Rio Limay.

Examinando el interior de las lagunas, se ve su fondo ocupado generalmente por el tejido verde de plantas acuáticas del género Ceratophyllum, etc. Una alegre poblacion de 
insectos, coleopteros acuáticos, notonectineos, gamarídeos, larvas de dípteros y de neurópteros, etc., se mueven con habilidad y lijereza dentro de esta vegetaeion acuática.

De los moluscos, es abundante, en estas lagunas, el Planorbis peregrinus, en ejemplares bastante grandes, $y$, en escaso número de indivíduos, se halla alguna vez, en el follaje del Coratophyllum, el pigmeo de la misma familia, el Phanorbis anatinus, especie cuyo domicilio no se conocía hasta ahora, habiendo sido descubierto por D'Orbigny en el estómago de los patos. El Ancylus concentricus, especie que abunda en muchos sítios, vive son prefereneia adherido á las hojas de la Typha que flotan en la orilla de las aguas estancadas de aquellas lagunas. 


\title{
II
}

\section{ENUMERACION SISTEMẢTICA}

DE LAS

\section{ESPECIES OBSERVADAS DURANTE LA ESPEDICION.}

\section{VERTEBRADOS}

POR EL

\author{
D. ${ }^{r}$ D. ADOLFO DOERING
}

I. M A MI M LIA.

\section{FELIS ONÇA L.}

Bermerster, Reise dwch die La Plata-Staaten, Bd. II, p. 397. (1)

En todos los distritos algo poblados, el tigre se presenta ya como una aparicion muy rara. Parece hallarse con más frecuencia en los pajonales de las grandes lagunas, en el interior de la region del monte, es decir en el centro del territorio conquistado, donde muchos parajes llevan su nombre en la lengua indígena.

Durante nuestra campaña se presentó por primera vez cerca de la laguna de Marra-Có, distante como iz leguas de la costa atlántica de la Bahia Blanca.

(1) Para no aumentar innecesariamente el número de citas, no recordaremos, para las especies mís conocidas, sino las principales obras sobre la fauna del pais, donde ya se enenentran consignadas, haciendo escepcion para aquellas especies ménos conocidas. 
En las orillas del Rio Colorado, generalmente en la proximidad de los grandes pajonales de Gynerium, se encontraron muchos rastros de este animal feroz. En los primeros dias de nuestra llegada, durante la noche desapareció un caballo, víctima de aquel terrible enemigo, que, en otras ocasiones diversas, causó la huida cie las caballadas. Más hácia el alto Rio Colorado parece ser mucho más escaso. En el Rio Negro no hemos observado sus rastros.

\section{FELIS CONCOLOR L.}

Bг'rм., Reise, Bd. II, p. 398.

Hallándose ésta especie mucho más propagada que la anterior, es probable que exista en todo el territorio.- Hemos visto cueros de este animal en los fuertes Lavalle y Carhué.

\section{FELIS PAJEROS Az.}

Bırм. Reise, Bd. II. p. 398.

Los soldados mataron un ejemplar durante la cruzada entre el Rio Sauce clico y el Rio Colorado.

\section{CANIS AZARAE Waterl.}

Векм. Reise, II. p. 405.

Es una de las especies que se ven mas frecuentemente en todo el territorio aludido, tanto en la llanura y la pampa abierta como en las márgenes del Rio Colorado y del Rio Negro. Es un perseguidor muy dañino de las perdices.

\section{LYNCODON PATAGONICUS Blainv.}

BLAIxr., Osteogr., genre Mustela. p. 42.-Mustela patagonica Bl., ibid. p. 81. pl. 13.

Gervais, Dict. univ. d'hist. nat. de Ch. dOrbigny, T. IV. p. 685. (Lyncodon).

D'Orbigny, Toyage d. l'Amer. Mer. T. IV. p. 20. pl. NIII, fig. 4.

MACHO. El pelage de toda la partesuperior, desde el cuello hasta la punta de la cola, color de canela oscuro, salpicado y cubierto de blanco, por ser las puntas de todos los pelos largos de un blanco plateado. La frente con las orejas $y$ una faja ancha que parte desde las orejas, á lo largo del cuello, hasta el pecho, y la punta de la cola de un blanco completo. Una mancha sobre la nuca, la gargante, el pecho, y las cuatro piernas, de un color brúneo de umbra.

Longitud total (desde la punta de la nariz hasta ia de la cola): 35-36 centímetros; desde la nuca hasta la raiz de la cola: 23. centímetros. Cola; $9 \mathrm{~cm}$. Circusferencia más grande del cuerpo (vientre): I I cmts. 
Esta interesante y rara especie, que ha dado orígen á la formacion del sub-género Lyncodon, se diferencia de todas las aliadas por lo anormal de su sistema dentario, teniendo sólo tres muelas arriba y tres abajo, á diferencia de las demás, que están armadas con cuatro arriba y cinco abajo.

Este hermoso animal vive en las colinas ó barrancas calcáreas de la formacion patagónica, entre el Rio Colorado y el Rio Negro. El Capitan Silva tomó un ejemplar vivo en la cuchilla de la márgen derecha del Rio Colorado, un poco más arriba del Rincon Grande.

Segun las comunicaciones del Sr. Coronel Guerrico, la especie no es rara en las inmediaciones de Patagones, de donde tambien consiguió el Dr. BERG un ejemplar, miéntras que D'ORBigny tuvo que contentarse con un viejo cráneo de la mencionada especie.

Es probable que la que BURMeister ${ }^{1}$ menciona como existente en la Sierra de Mendoza sea idéntica con ésta, habiendo en dicha sierra, tanto por su fauna, como por su vegetarion, muchas analogias con las de la Patagonia setentrional. En cambio, la Mlustelir Quiqui de Molina, segun PhilipPI, ${ }^{2}$ debe ser idéntica con la Galictis vittata y no con esta especie del Rio Negro.

\section{MEPIITES PATAGONICUS Licht.}

Burm. Reise, II, p. 409.

Hemos notado la presencia de este animal en todas las regiones de nuestra cruzada hasta el R. Neuquen.

En Carhué hemos visto preciosas alfombras trabajadas por los indios y formadas de pieles de esta especie.

\section{DIDELPIYS ELEGANS Waterh.}

Bткм. Reise, II, p. 412.

De esta hermosa especie nos fué entregado un ejemplar por el señor Coronel GuerRICO, quien lo había cazado cerca de las barrancas de la Balcheta, en el yalle del Rio Negro. Parece tener una propagacion bastante extensa en la República, siendo ya conocida procedente de Córdoba y Mendoza.

\section{MYOPOTAMUS COYPUS Cuv.}

Bгrм. Reise, II, p. 416.

Abundante en los sítios acuáticos de todo el territorio de nuestra cruzada, hasta el Rio Negro inclusive.

(1) Burm. Reise, II, p. 408

(2) Anal. de la Úniv. de Chile, XXIX, p. 798, 1867. 
9. HESPEROMYS GRISEOFLAVUS Waterh.

Proc. Zool. Soc. 1837 , p. 28.

Zool. of the Beagle. Mamm. p. 62, T. XXI.

Esta especie se halla abundantemente cn las playas ribereñas del Rio Colorado y del R. Negro. En el Rincon Grande del primero, el Dr. LoRENTz cazó un ejemplar jóven, vivo, el que apénas podía correr, á causa de estar atacado por las larvas de un díptero. la Rogenhofera grandis Guér. 1 Todo el muslo posterior se había hinchado hasta tomar un tamaño doble del normal, saliendo luego por una abertura de la piel una larva desarrollada de dicho grande insecto, la que dentro de un dia se había trasformado en crisálida.

En cl Rio Negro la hemos recogido cerca de Choelechoel y más tarde cerca del fortin Conesa.

\section{CTENOMIS MAGELLANiUUS Benn.}

Transact. Zool. Soc., Vol. II, p. 84, pl, 17.-Proc. Zool. Soc. 1885, p. 190. G.AY, Fanna Chil. I, p. 10.5 .

El oculto, cuyas cuevas ya habiamos observado con frecuencia en el valle del Rio Sauce Chico, se nos presentó primero en las márgenes del Rio Colorado, donde se encuentra en abundancia. Hemos tenido frecuentemente ocasion de oir el ruido característico que produce su grito particular, imitando perfectamente cl que se produce cuando se dān dos golpes secos é inmediatos con un martillo sobre un palo parado.

En el Rio Negro no la hemos observado con tanta frecuencia; pero abunda ccrca de Choelechoel.

\section{CAVTA AUSTRALIS Geoff.}

Brrm. Reisc, II, p. 420 .

Kerodon Kingii Bexx. Proc. Zool. Soc. 1835, p. 190.

DARw., Zool. of Beagle. Mamm. p. 88.

En los sítios análogos á los en que se encuentra la especie anterior, y bastante abundante en las riberas del Rio Colorado y del Rio Negro.

\section{DOLICHOTIS PATAGONICA Wagn.}

Bнтм. Reise, II, p. 422.

Los primeros ejemplares que hallamos en el viaje, se presentaron cntre el Rio Sauce Chico y el R. Colorado, en la entrada de la formacion de arbustos cerca de Salinas Chicas, al Nortc dcl Rio Colorado.

(1) C. Berci, Nuturgesch. der Rogenh. grandis. Stcttin. Entomolog. Zeit., 1876, p. 268-272. 
Es muy abundante en las playas ribereñas del último rio, y se la enctentra tambien, con frecuencia, en las del Rio Negro.

\section{LAGOSTOMUS TRICHODACTYLUS Brook.}

Burs. Reise, II, p. 422.

En todo el territorio de la pampa; pero más abundante en el Norte que en el Sur, desapareciendo al empezar la formacion de arbustos, al Norte del Rio Colorado.

\section{CERVUS CAMPESTRIS Cuv.}

Bекм. Reise, II, p. 430.

Abundantemente $\mathrm{y}$ en pequeños tropeles hemos observado la gama en las colinas vecinas de las Sierras del Azul y Currumalan. Más rara en la verdadera llanura, y ménos aún en los distritos dominados, hasta los últimos tiempos, por las cacerias destructoras de los indios. En los fuertes Lavalle, Carhué, etc., las pieles de este animal forman un artículo mercantil muy importante.

En una que otra ocasion hemos notado su presencia en el valle del Rio Colorado y del Rio Negro, donde tambien, en mayor número, se halla en la isla de Choelechoel.

\section{DASYPUS CONURUS Geoffr.}

Вспм. Reise, II, p. 426.

Hemos encontrado esta especie cerca del fuerte Lavalle, y más tarde cerca del Rio Colorado.

\section{DASYPUS MINUTUS Desm.}

Burm. Reise, II, p. 428.

Encontrado en diferentes ocasiones entre Olavarría y Carhué, y tambien un ejemplar en el valle del Rio Negro, cerca de la embocadura del Neuquen.

\section{PRAOPUS HYBRIDUS Desm.}

Векм. Reise, II, p. 428.

Muy abundantemente se observó esta especie en la pampa meridional, sobre todo en las inmediaciones del Arroyo Salado del fortin Iniciativa. 


\section{I. A V ES.}

1. TURDUS FALKLANDICUS Q. et Gaim.

Qtor et G.um. Zool. de l' Trane, p. 104. D'Orb. Toy. IV, p. 202. Gould, Zool. of Bagle, III.-G.x, Faun. Chil., I, p. 331.-Sclat. et Hodsux, Proc. Zool. Soc., 1872. p. $584 \mathrm{f}$.

Turd. magellanicus Kixe, Proc. Zool. Soc., 1831, p. 14.

La primera vez que se nos presentó esta especie meridional, fué en las márgenes del Rio Colorado, en un cañaveral, á la orilla de una laguna. Abunda mucho en las riberas del Rio Negro.

Vive siempre en los territorios vecinos al agua, busca los alimentos en el suelo húmedo, en los cañaverales, y particularmente en los bosques de sauce, donde tambien anida en la primavera. Es un animalito arisco, pero más silencioso que las especies aliadas, principalmente en la estacion de invierno.

\section{MiniUs PATAgONICUS Lafr. D’Orb.}

Mag. Zool., 1836, p. 19. D'Ors. Toy. IV, p. 210, pl. II, fig. 2.

Sclit. Proc. Zool. Soc., 1859, p. 345.-Sclat. et Hedsox, ibid., 1872, p. 534, ss.

A nuestra llegada á los territorios del Sur, al Sud-oeste de Nueva Roma, y con los primeros arbustos, ya apareció esta especie, la cual es abundante en toda la formacion de arbustos patagónicos. Aún en los primeros dias de Ilayo se encontraron pichones de nido en las riberas del Rio Colorado.

Esta especie parece haberse propagado bastante hácia el Norte de la República, y se la encuentra aún en la sierra alta de Córdoba, en cierta region, á I,200 metros de altura.

\section{TROGLODITES FURVUS Gm.}

Ti. platensis, D'Onв, Foy. Ois., p. 231.

Bгrм., Syst. Lebers., III, 1. 137. Reisc, П, p. 476.

Tar. pallida:

Trogl. pallidus Lafr, D'Oar. Mag. Zool., 1836, p. 25. D'Orb. Toy. Ois., p. 284.

Tr. magellanicus Gotwd, Proc. Zool. Soc., 1836, p. 88. Toy. Beagle, III, p. 74.

Tr. magellanicue Gid. Secat., Proc. Zool. Soc., 1867, p. 21.

Ti. homonsis Les. GaY, Faun. Chil., I, p. 313.

En lugares adecuados, en todo el territorio que hemos recorrido: Azul, Carhué, N. Roma, R. Colorado, R. Negro. 
Segun Sclater, el Tr. magellanicus de las regiones meridionalcs, no es, probablemente, más que una variedad de color pálido de la misma especie.

\section{CISTOTHORUS PLATENSIS Lath.}

Troglodytes platensis Gould, Zool. Beagle, III. p. 75 .

Cistothorus fasciolatus Buri, Journ. Oin., VII, p. 252. Reise, II, p. 476.

Observada primeramente entre F. Lavalle y Carhué, es muy abundante en la ribera del Rio Sauce (Chico), Rio Colorado, Rio Negro, etc. Frecuenta los pajonales de $G^{\prime}$ nerium, etc.

En sus costumbres, se asemeja mucho á algunas especies de Synallaxis. Vive siempre deslizándose en los densos copos de la paja ó de la cortaderä, bajando á veces á tierra. Suele generalmente huir, dando un fuerte grito alarmante, á corta distancia, á otro copo vecino. Tambien anida en estos pajonales, formando dc hoja de paja y de cortadera un nido redondo, cerrado, con la abertura al laco.

\section{ANTHUS CORRENDERA Vieill.}

D'Orbigny, Voy. Ois., p. 225.

Gocld, Zool. of Beagle, III, p. 85. Proc. Zool. Soc., 1859, p. 95.

Sclat. et Hedson, Proc. Zool. Soc., 1872, p. 584. Huds., Proce Zool. Soc., 1873, p. 77.

Fácilmente reconocible por el color oscuro de la parte superior de su plumage, y las hermosas pintas medio doradas.

En sitios desnudos y en la orilla de una laguna cerca del Azul.

\section{ANTHUS FURCATUS Lafr. D'Orb.}

Lafr. D Orb., Synops., p. 27. D'Orb, Voy. Ois. p. 227.

Gould, Zool. of Beagle, III, p. 85.

A. breviunguis Strix, Av. Bras., p. 75 , T. 76, f. 1 .

Fácil de reconocer por su color más pálido, su tamaño mayor, con la cabeza relativamcnte más gruesa y redonda, las máculas muy finas y más numerosas, y particularmente por la uña posterior, que es muy corta.

Se diferencia tambien, notablemente, por sus costumbres, su voz, canto, etc., y es quizá la especie más comun en el territorio Argentino, encontrándose tambien con abundancia en las provincias centrales. Prefiere los lugares algo más secos y cubiertos densamente de paja y grama.

Durante la expedicion, hemos tenido frccuentes ocasiones de observarla, p. ej., cerca del Azul, Carhué, Nueva Roma, etc. 
7. POOSPIZA NigRoRUFA Lafi., Dorb.

Brrm., Reise, II, 1. 484 .

Observada por última vez en los pajonales de Gyncrium del R. Sauce (Chico), cerca del F. Argentino. En el R. Colorado y en el R. Negro, donde, segun Hudson, se encuentra esta especie, no la hemos hallado: es probable que ella desaparezca con la entrada de la estacion hiemal.

8. Poospiza Torguta Lafr. DOrb.

Burv., Reise, II, p. 484 .

Observada una sola vez en los jarillares del R. Colorado, donde parece tener el límite meridional de su propagacion.

\section{DONACOSPIZA ALBIFRONS Vieill.}

Btru. Reise, II, p. 484 .

Entre los pajonales de Gyncrium del Arroyo Salado, cerca del fortin Iniciativa.

Difiere bastante, en sus costumbres, de los representantes de Poospizct.

\section{FIITGILUS CARBONARILS D'Orb.}

Burm, Reise, II, p. 487.

El plumaje nuevo de invierno es, en toda la parte superior del cuerpo, de un colorido pardo pálido, estriado de un color más oscuro, teniendo cada pluma una estria oscura en su centro, sobre el escapulario. La base de todas las plumas, en su arranque, es de un gris negruzco. Las pequeñas cubiertas alares y la orilla externa de los remos, son bordadas de un gris pálido hasta gris blanquecino; los remos secundarios, como tambien, aunque en menor grado, las rectrices internas, son bordadas en la parte superior de un gris-pardo pálido. Toda la parte inferior es de un negro intenso en el fondo, pero salpicado de gris-blanco encima del plumaje, por tener las plumas, particularmente las cubiertas inferiores de la cola, lo mismo que las plumas de la parte posterior del vientre, en los flancos, en el pecho, el cogote y alrededor de los ojos, las puntas ó barbas blanquecinas.

En la estacion fria, vive generalmente en bandadas, asociada á la Zonotrichia canicapilla, en los jarillares y demás arbustos de la formacion patagónica.

Por primera vez la he encontrado cerca de la laguna de Marra-Có, es decir, donde empieza la vegetacion de arbustos. Parece ser muy abundante en las colinas de los valles del Rio Negro y del Rio Colorado, lo mismo que en el interior de la travesía. Al volar, se la reconoce fácilmente por las plumas negras de la cola y de las alas. 


\section{PIIRYGILUS FRUTICETI Kittl.}

Burs. Reise, II, p. 487. Darw. Zool. of Beagle, III.

GaY, Faun. Chil. I, p. 357 .

Sclat. et Hudsox, Proc. Zool. Soc., 1872, p. 534, ss.

El plumaje nuevo de invierno ofrece particularidades, como la especie anterior, á saber: aparece de un color gris, por el gris blanquecino de las puntas ó barbas de las plumas. Desgastándose gradualmente las barbas extremas de las plumas, el macho adquiere cada vez más aquel color negruzco que lo caracteriza durante la estacion de verano.

En el invierno se la observa generalmente en bandadas de á 40-50 indivíduos, (pocas veces de á 1000 y más, como la encontré cerca del Neuquen) en los jarillares, entre el Rio Colorado y el Rio Negro, donde tambien anida en el verano. Espantados, se levantan generalmente muy alto, formando en su vuelo grandes curvas á distancias considerables. Se diferencia fácilmente, á lo léjos, de la especie anterior, por su tamaño casi doble.

Observé las primeras bandadas en el R. Colorado, cerca de Pichi-Mahuida. Es interesante esta especie por la circunstancia, digna de mencionar, de que en la Patagonia setentrional ella habita sítios en que abunda una Compuesta del género Chuquiraga, la misma que abunda tambien en los parajes serranos donde encontré este animalito, en el Infiernillo» de la Sierra de Tucuman, á una altura de 3,000 metros.

\section{DICCA MINOR Bon.}

Веrм. Reise, II, p. 483 .

Sccat. et Heds. P. Z. S., 1872, p. 584, ss.

En sociedad de la Zonotr. canicapilla, pero no muy abundante, entre el R. Colorado y R. Negro (Pichi-Mahuida, Choelechoel, etc.); Gould (Zool. of t. Beagle, III) considera esta especie del Rio Negro como la D. grisea LEss. de Chile.

\section{ZONOTRICIIA PILEATA Bodd.}

Zonotr. matutina, L., Burk. Reise, II, p. 486. GAY, Faun. Chil. I, p. 360.

En todos los lugares adecuados de la pampa. Desaparece más y más hácia el Sur, remplazándola la siguiente forma:

Var. canicapilla, GotwD, Zool. Beagle, III, p. 91.

Dejemos aquí pendiente la cuestion acerca de la separacion de esta forma como cspecie ó como variedad geográfica. En su voz, canto y costumbres no hemos podido observar ninguna diferencia fundamental entre ambas. Pero se reconoce fácilmente la última, desde léjos, por el gris uniforme de la cabeza.

Se presenta este animal con la aparicion de los primeros arbustos precursores de la 
formacion patagónica. La encontré por primera vez cerca de la laguna de Marra-Có, entre el R. Sauce (Chico) y el R. Colorado, y hasta el R. Negro ella ha sido, de ambas, la única que hemos observado.

Vive por lo general en bandadas, asociada al P/r. carbonarizs D'Orb.

\section{EMBERAAGRA PLATENSIS Gm.}

Burm. Reise, II, p. 485.

En los pajonales de Gynerinm, etc., cerca de las lagunas y aguas corrientes, casi en todo el territorio de la pampa, como tambien en el valle del R. Negro. No la hemos observado en el valle del R. Colorado, donde predomina la siguiente especie.

\section{EMBERNAGRA OLIVASCENS D'Orb.}

Berm. Reise, II, p. 485.

Habitante más bien de la vegetacior de arbustos de las provincias centrales, que de los pajonales de la pampa, (como ya lo dice D'Orbigny,) apareció la vez primera cerca de la laguna de Carhué, y se la encontró en abundancia en el valle del Rio Colorado; pero no hemos notado su presencia en el valle del R. Negro, donde abunda la $E$. platensis.

\section{CHRYSOMITRIS BARBATA Molina.}

Chr. campestris, Gax, Faun. Chil., p. 352.

Numerosa en bandadas, cerca del R. Sauce, R. Colorado, R. Negro, etc.

\section{SYCALIS ARVENSIS Kittl.}

ScLAT. P. Z. S., 1867, p. 323. 1868, p. 140.

Sycalis luteiventris, BurM. Reise, II, p. 489.

Siempre en grandes bandadas. Cerca de Carhué, R. Sauce, R. Colorado, etc.

\section{COTURNICULUS MANIMBE Vieiil.}

Burm. Reise, II, p. 486 .

He cazado ejemplares de esta especie en el valle del Rio Colorado; pero parece que no es muy abundante.

\section{AGELAJUS THILIUS Mol.}

Burm. Reise, II, p. 492.

En una laguna de la orilla del R. Colorado. 


\section{XANTHOSOMUS FLAVUS Gm.}

Guez. Syst. Nat. I, 389.

Gould, Voy. Beagle, III, T. 45.

Сав, Mus. Hein., I, p. 189.

Cassix, Proc. Acad. Phil., 1866, p. 14.

Numerosos individuos asociados á una gran bandada de la subsiguiente especie, en la pampa, entre Lavalle y Carhué. Mas hácia el Sud no la he observado ya.

\section{PSEUDOLEISTES VIRESCENS Vieill.}

Leistes anticus, Burm. Reise, II, p. 491.

Siempre en bandadas considerables por su número, generalmente en los pajonales de Gynerium, ó sus alrededores, etc. Cerca de Guamini, en el valle del R. Sauce y del R. Colorado.

\section{MOLOTIIRUS BONARIENSIS Gm.}

Cass. Proc. Acal. Phil., 1866, p. 28.

Sclat. Proc. Zool. Soc., 1868 , p. 140.

M. sericens Btru. Reise, II, p. 494.

Fué observada por última vez en una bandada cerca de Carluué, pero sin la sociedad del M. mufaxillaris, lo que en cambio por regla general, se observa en los distritos del Norte.

\section{STURNELLA DEFILIPPII Bp.}

Trupialis militaris, BurM. Reise, II, p. 490.

Abundante en bandadas en la pampa-donde se recogieron en frecuentes ocasiones individuos lastimados, á lo largo de la línea telegráfica.

\section{STURNELLA LOICA Mol.}

Sturnella militaris Lix., autor. plur.

Trupialis loica Вгвм., Reise, II, p. 496.

Esta especie sustituye la anterior en el Sud-Oeste del territorio, siendo observado por nosotros primeramente cerca de Carhué, Nueva Roma, etc. Es muy abundante en las orillas del R. Colorado y R. Negro.

\section{AGRIORNIS STRIATUS Gonld.}

A. striatus Gocld, Zool. Beagle, III, p. 56.

A. micropterus GovLD, ibid, T. XII.

A. striatus Bскм., Reisc, II, p. 459.

Ejemplares escasos en los jarillales, cerca del R. Colorado y R. Negro. 
26. TAENIOPTERA DOMINICANA Vieill.

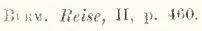

Sc han observado algunos ejemplares en las Sierras de Azul y de Currumalan.

27. TAENIOPTERA IRI PERO Vieill.

T. moesta, Buns., Reise, II, 2). 460.

Observada una vez en las barrancas coloradas", al Norte del R. Colorado, donde había un grupo de árboles de algarrobo.

28. TAENIOPTERA CORONATA Vieill.

Brrm. Reise, II, p. 459.

Al Norte del Rio Colorado.

29. PTIONIRA CAPISTRATA Burm.

Brn., Joum. Orn., VII, 1. 80 . Reise, II, p. 462.

Hemos observado en diferentes ocasiones, en escasos ejemplares, un representante de este género, de un color gris predominante, con frente negra, etc., por lo que debe ser la mencionada especie de Burmeister.

Azul, Carhué, R. Colorado, R. Negro.

El animal corre con mucha destreza por el terreno húmedo, en la orilla de las aguas. Indudablemente es un luésped del invierno. El Museo públıco de Buenos Aires tiene la misma especic del Cármen de Patagones.

\section{CENTRITES NIGER Bodd.}

$$
\text { Burv., Reise, 11, 1. 4.5. }
$$

Hastante abundante en sítios húmedos y abiertos de la pampa, desde el Azul hasta el Rio Colorado.

31. PIILLOSCARTES FLAVOCINEREUS limm.

Bгти, Rieise, II, p. 455.

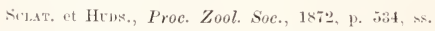

fis una aparicion constante en los farillares del R. Negro $y$ del R. Colorado, aunque no se halla con frecuencia. Los ejemplares de allí son de un color algo más oscuro que los de Córoba. 


\section{ANAERETES PARULUS Kittl}

Berm., Reise, II, p. 455.

Abundante en los jarillares y arbustos espinosos del R. Negro y del R. Colorado. Ge. neralmente en sociedad con la especie anterior y las diferentes de Synallaxis.

\section{CYANOTIS AZARAE Licht.}

Sclat., Proc. Zool. Soc., 1867, p. 327. 1869, p. 159.

Tachuris omnicolor, LFr. DORB, Syn. p. 55.

T. rubigastra, D’Orв., Toy. Ois., p. 383.

En las lagunas dulces rodeadas de juncales y cañaverales, en la pampa y en las márgenes del R. Colorado y del R. Negro (Choelechoel). Vive generalmente asociada á la Synallaxis melanops.

34. GEOSITTA CUNICULARIA Vieill.

Вивм., Reise, II, 1. 465 .

Abundante en sítios de suelo desnudo, en todo el territorio, hasta el Rio Negro.

35. UPUCERTIIA DUMETORIA Geoffr norb.

Bтвм., Reise, II, p. 468.

La observamos por vez primera entre Carhué y Puan, en las murallas de los fortınes y en las rocas de la Sierra de Currumalan.

Muy abundante en las colinas del Rio Colorado, ménos en las del R. Negro.

\section{CINCLODES FUSCUS Vieill.}

C. vulgaris D'Orв., Borм., Reise, II, p, 468.

Abundante en todo el territorio, hasta el Rio Negro, particularmente en las riberas desnudas de las lagunas y rios de agua dulce.

\section{PIILOEOCRYPTUS MELANOPS Vieill.}

Burm., Reise, II, p. 470.

Abundante en los juncales y totorales de las lagunas dulces, hasta en los del Rio Colorado, R. Negro y R. Neuquen. Vive siempre en el suelo medio inundado, y rara vez sube á la punta de las espigas.

\section{LEPTASTIENURA AEGITIIALOIDES Kittl.}

DOre., Voy. Ois., p. 243.

Esta especie, que en los espinares del Norte de la República se halla sustituida por 
la L. platensis Reich. (ó sea la L. aegithaloides BURM. Reise, II. p. 469), la hemos observado con la aparicion de los primeros arbustos patagónicos al Norte del R. Colorado, como cuatro leguas al Sud-oeste de Nueva Roma.

Ella se halla con alguna frecuencia en los jarillares entre el R. Negro y el R. Colorado.

\section{SYNALLAXIS PATAGONICA D'Orb.}

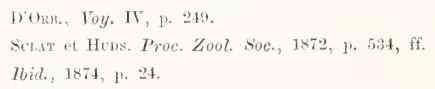

Hemos encontrado recien los primeros individuos de esta especie á nuestra llegada á las márgenes del R. Colorado. Frecuenta los jarillares de la meseta, asociándose generalmente á la subsiguiente especie, con la cual tiene remarcables analogias en sus hábitos y su modo de vivir.

\section{STNALLAXIS SORDIDA Less.}

Syn. humicola Kiтть., Векм. Reise, II, p. 468.

syn. brumea, Gotup, Zool. Beagle, III, P. is (juv.)

Esta especie es algo variable, segun la edad de los indivíduos y las localidades donde se hallan.

Los indivíduos del Rio Colorado, en su mayor parte, y más pronunciadamente aún los de Córdoba, tienen en la base de la mácula gular ferrugínea una mantilla negruzca, formada por dos ó más plumitas escamosas, de color negro-brúneo, cuyas barbas finas extremas, lo mismo que en la mácula ferrugínea, en estado fresco, son blanquecinas seríceas.

En una variedad del Sud de Corrientes la mácula gular es mucho más grande, apareciendo compuesta como de blanco (en el ángulo maxilar), y rojo bermejo en el gargante, sin tener las mencionadas plumitas negruzcas en la base de la mácula.

De los rectrices, siempre los tres primeros, externos, á cada lado, son de un rojo bermejo uniforme, pero en los ejemplares jóvenes la tercera ya está orillada de negro en su barba interior, en su extremo, y alguna vez tambien en la barba exterior. La cuarta rectrice es de color oscuro solo en su extremo, pero la $5^{\text {a }}$ y $6^{\text {a }}$ enteramente de un negro pardo uniforme.

En los ejemplares viejos la cuarta rectriz tiene generalmente toda la barba exterior hasta el extremo, y alguna vez, tambien, una faja á lo largo de la quilla en la barba interior, de color ferrugíneo, siendo oscura generalmente la punta de la pluma. La 5: y 6: rectrices tienen vestigios de este color solo en la orilla mas extrema de las barba, y solo cuando el plumaje está nuevo.

Los remos, en su base, y su barba interior, son de un color rojizo bermejo pálido, más pálido que las cubiertas axilares interiores de la ala; y tambien las barbas exteriores 
de los remos, cerca de la base, son algo orilladas del mismo color, poco más intenso.

El pico y los piés de esta especie son bastante robustos, y la cabeza igualmente, en comparacion con la siguiente especie. En los ejemplares jóvenes la mácula gular es muy pálida, casi blanca.

Toda la configuracion de esta especie, que es más robusta, su cola más corta, y lo insignificante del color gris ferrugíneo, en la parte exterior del ala, la diferencia á primera vista de la sub-siguiente, á la cual es casi súmamente parecida.

Ella es un habitante exclusivo de los espinares, y no se halla donde éstos faltan. Vive con preferencia en las ramas de los arbustos y árboles, saltando y volando de un arbusto á otro, y no baja con frecuencia al suelo, como la especie siguiente. Cási durante todo el dia se oye su canto especial—un trinado fuerte y resonante.

\section{STNALLAXIS rLAVIgLtaRis Gid.}

Gocis, Zool. of Beagle, III, p. 78, pl, 24.

Syn. Orbignii Reieh. Selat, Proc. Zool. Soe., 1879.

En su colorido, esta especie se asemeja mucho á la anterior, aunque difiere considerablemente en todas sus costumbres y modo de vivir.

Las diferencias más notables consisten en la figura mucho más esbelta y graciliforme del pico y de todo el cuerpo. Tambien la cola es mucho más prolongada y escalonada, aunque en la distribucion del color rojo hay poca diferencia.

Las tres rectrices externas, á cada lado, son de un rojizo bermejo uniforme. La siguiente $\left(4^{n}\right)$ tiene la base y toda la barba exterior de color rojizo, la $5^{n}$ y $6^{\text {a con la base }}$ del mismo color, y en ejemplares frescos, está bordada tambien del mismo color, pero más cargado, la orilla de la barba externa.

Los remos secundarios tienen un lunar completo rojizo-bermejo, más dilatado y en su colorido algo más cargado que en la otra especie, formando una verdadera faja transversal en el ala, que se nota cuando ésta se abre. Las rectrices y las barbas exteriores de los remos son mejor y más claramente bordadas de color rojizo, de modo que casi toda la base, en el exterior de las alas, parece algo rojiza, á diferencia de la especie anterior.

Toda la parte inferior del cuerpo parece algo más oscura, es decir, cargada de grisbermejo.

La mácula gular es pequeña y de un amarillo puro, algo anaranjado. Las plumitas amarillas que la forman son blancas en su base y la barba extrema, y cada una tiene generalmente una manchita negra cerca de la punta. En los ejemplares jóvenes la mácula gular falta por lo comun, siendo generalmente la garganta de color amarillento-blanquecino.

Las dimensiones de ambas especies son las siguientes: 


\begin{tabular}{|c|c|c|c|c|c|c|c|c|}
\hline & & סיניו & & & & HTRE LA L & $\begin{array}{l}\text { HFEREACTAS } \\
\text { ETTEID DE LAS }\end{array}$ & REctericts \\
\hline Long. & total. & Longitud. & Altura. & Ala. & Colit. & $\begin{array}{l}\text { Eutre la } 1^{\text {a }} \\
\text { y la última. }\end{array}$ & $\begin{array}{l}\text { Entre la } \\
\text { 1? y la } 2 \text { ? }\end{array}$ & $\begin{array}{c}\text { Eutre la } 1: \\
\text { y la } 3:\end{array}$ \\
\hline sordida. & $\mathrm{I} 5^{\mathrm{em} .}$ & $9^{\mathrm{mm} .}$ & $3 \frac{1}{2} \mathrm{~mm}$. & $60-62^{\mathrm{mm}}$ & $65^{\mathrm{mm} .}$ & $25^{\mathrm{mm} .}$ & I $2^{\mathrm{mm}}$. & $5^{\text {mm. }}$ \\
\hline S. flavigularis. & $16^{\mathrm{em}}$ & $9^{\mathbf{n m} .}$ & $2 \frac{8}{4} \mathrm{~mm}$. & $60^{\mathrm{mm}}$ & $75^{\mathrm{mm} .}$ & $35 \cdot 40^{\mathrm{mm} .}$ & I I $\mathrm{mm}$ & $\mathrm{IO} \mathrm{mw}$. \\
\hline
\end{tabular}

La longitud total de la $S$. fazigularis es mayor, por la cola mucho más larga, que la de la $S$. sordida, mientras que el tanaño del cuerpo es menor. La diferencia más fácilmente mensurable existe en la distinta longitud de la $2^{\text {? }}$ y $3^{\text {: }}$ rectrices externas rojizas.

Esta especie vive con preferencia en los lugares algo húmedos, á lo largo de las riberas de los rios y lagunas, particularmente donde abundan los bosquecillos de Baccharis lanccolata cubiertos con enredaderas. Anda frecuentemente en cl suelo húmedo, y vive siempre medio oculta entre las yerbas y los arbustillos, cuando los hay. Es sumamente arisca y fugitiva, volando generalmente á grandes distancias, y bajando otra vez á tierra, $o$ al centro de un arbusto. Su cola larga y medio rojiza puede fácilmente reconocerse ciurante el vuelo. Su voz consiste en un silbido muy suave, casi idéntico al del $l / h y^{\prime} l$ lopneuste rufa de Europa, á diferencia, muy notable por cierto, de la especie antcrior.

Tiene una propagacion bastante estensa, hallándose á lo largo de los rios, desde la Cordillera hasta las embocaduras de éstos, por cuya razon se encuentra tambien en regiones donde faltan las verdaderas selvas de espinares.

He tenido ocasion de observar esta especie cerca de Córdoba y de Tucuman (Tafí), en los valles del R. Colorado y del R. Negro hasta cerca de la cmbocadura del Neuquen.

Observacion.-He enviado ejemplares de esta espeeie a los SS. Drs. Jean Cabanis en Berlin y P. L. Scliter en Londres.

El Dr. Cab.uxs la cousidera eomo S. sordida Less., aunque crec diferente de ésta, la especie anterior, de la cual le habia mandado ejemplares bajo el nombre de $S$. sordila Less.

En eambio, Mr. Schter considera nuestra especie idéntica con la S. crassirostris L.avos. de Meudoza, la que, segun él, debe ser la S. Orbignii Reıch. (1), mieutras que, tanto la S. flarigularis, como la S. brunnea de Goct.D, debian ser individuos jóvenes de una mismísima espeeie, la S. sordida LEss. (2), lo que difieilmente se entiende.

La gran semejanza de ambas especies indudablemente ha dado origen, muchas veces, a dudas y equivocaciones. El observador que no ha examinado nn bueu número de ejemplares de anbas especies, no las diferencia al primer golpe de vista, $y$ se halla aún mís perplejo, euando se le presentan ejemplares con plumaje viejo $y$ algo desgastado, á pesar de lo earaeterístieo que se ofreee por lo delgado y graciliforme de su pieo y por el tinte rojizo en la parte exterior de las alas, de la S. flavigularis, á cliterenvia de la S. sordida.

No podemos inclinarnos i ercer que nna especie que nosotros, al principio, quisimos nombrar $S . g r a-$ cilirostris", nombre bien propio y mereeido por ella, sea idéntiea eon una espeeie llamada por t.sxn-

(1) Cf. Proc. Zool. Soc., 1879.

(2) Cf. Proc. Zool. Soe., 1874, p. 22 y 24. 
вЕск "S. crassirostris". De los pocos datos que el último snministra acerea de los hábitos de su especie. se deduce instantúneamente que ella no puede ser idéntica con la nnestra, en cnestion, sinó mús bien det la anterior ó de una especie muy análoga í ella, que podría ser la S. Orbignii Reich., que no conoremos por observaciones propias, pero que, segun las del sr. Schulz en Corrieutes, debe ser una especie algo mís grande y robusta.

La figura de la $S$, flavogularis Gocus, en el Toy. of the Beagle, representa indudablemente un inlividuo jóven de nuestra especie, y no de la anterior, como pretende Sctater. Fsas manehitas oscuras esparcidas, en la garganta, formadas por un puntito oscuro en el extremo de cada plumita, sou sumamente earacterísticos para mestra especie, y nunea se hallan, en una agrupacion análoga, en la especie anterior.

Muy earaeteristicamente tambien diferencia Gocto de ella su S. brmmea, la cual debe ser nu individuo de la anterior especie, y que, como él lo recuerda mu bien, se diferencia de la s. flavigularis por su pieo nús grneso.

\section{SYXALLAXIS MODESTA Eyt.}

S. flacogularis, Buru., Reise, II, p. 468.

S. modesta Exт., Contr. Orn., 1851, p. 159. Scist., Proc. Zool. Soc. 1867, 1. 3204. Itrid. 1874 , p. 23. Sclat, et Hers. Ibid, 1872, p. 544 s8.

S. sordida, Phin, et Lasp., Cat. ae. Chil., p. 18.

Un verdadero habitante de las rocas y piedras; sólo en invierno se le halla tambien en otras regiones. La hemos observado recien, en ejemplares escasos, á nuestra llegada á los cerros graníticos de Pichi-Mahuida, en el R. Colorado, y en la travesía de la balcheto en el R. Negro. Tienc una propagacion estensa hácia ei Norte de la República, encontrándose aún en la Sierra de Córdoba y en la de Tucuman.

\section{STNALLAXIS ANTIIOIDES King.}

S. anthoides Kisg., Proc. Zool. Soc., 1830-31, p. 30. Sctat., Ibid. 1859, Pp. 193, 196. Hhisl. 1867 , p. 324 . Ibid. 1874 , p. 25.

S. mufogularis, Golsd, Zool. Beagle, III, p. 77, T. 28. CАвмx., Mus. Hein., II, p. 28.

Se ha encontrado, con bastante frecuencia, esta especie, en las regiones palustres de la pampa, entre Azul y Carhué, en los pajonales de Gynerium, etc., como p. ej. en las riberas del Arroyo Salado, en las inmediaciones de la laguna de Epecuen, etc. Prefierc la vida en tierrá, corriendo sobre el suelo.

En los ejemplares jóvenes, la mácula gular es poco pronunciada.

\section{SYNALLAXIS STRIATICEPS Lafr. D`Orb.}

Brาu, Reise, II, p. 4isy.

Esta especic se halla, aunque no muy abundantemente, en los arbustos espinosos situados entre el R. Colorado y el R. Negro, donde tambien encontramos varias veces aquellos nidos particulares que construye esta especie, con el único objeto de pernoctar en ellos. 
43. ANUMBIUS ACUTICATDATIS Less.

Burm., Reise, II, p. 467.

Es una especie que se encuentra frecuentemente y que es caracteristica de las regiones con selvas espinares. Pero vive más bien en la orilla que en el centro de los montes densos, ó á lo ménos en lugares abiertos, con pocos árboles ó arbustos.

Hemos notado su presencia en la pampa, así que se ofrecieron á la vista algunos arbustos, como p. ej. cerca de Carhué, y más tarde, algunas leguas al Sud-Oeste de Nueva Roma. Se halla, aunque no en tanta abundancia, en los valles del R. Colorado y del R. Negro.

\section{ANABATES GUTURALIS Lafr. D'Orb.}

Bгпм. Reise, II, p. 467.

Es una de las aves más características de la formacion patagónica de arbustos: alli se siente con frecuencia su voz, un trinado muy fuerte y resonante, pues se le puede oir á una distancia de $2-3$ kilómetros y más.

Hemos encontrado por primera vez esta especie en las inmediaciones del R. Colorado, lo mismo que en todo el territorio entreriano hasta el R. Negro.

\section{RHYNOCRYPTA LANCEOLATA (ieofir. D'Or.} BurM., Reise, II, p. 471 .

Se halla, aunque no en mucha abundancia, en los valles del $\mathrm{R}$. Colorado y del $\mathrm{R}$. Negro.

\section{PTEROPTOCIIUS [TARNIL King.!] \\ Gir., Faun. Chil., I, p. 304 .}

He observado en los jarillares del chichinal», en el R. Negro, una especie de este género, con la frente de color canela, y la cola oscura en su estremo. Probablemente es ésta especie la indicada, conocida de las regiones meridionales de Chile.

\section{COLAPTES AgRICULA Malh.}

C. australis, Вивм. Journ. Orn., VII, p. 244. Reise, IJ, 1. 445.

Parece qne esta especie no abunda en el Sur de la República Argentina. La he observado por primera vez en la Sierra de Currumalan, y más tarde en los sauces del R. Negro, cerca de la travesía de la Balcheta.

4. MEGACERYLE TURQUATA linn.

Burm., Reise, II. p. 446 .

La hemos observado algunas veces en el R. Negro, cerca de Choelechoel, y en la travesía de la Balcheta. Parece ser escasa en aquellas regiones. 
49. CONURUS PATAGONUS Vieill.

Burm., Reise, II. p. $4+1$.

R. Colorado y R. Negro, en bandadas.

\section{STRIX PERLATA Licht.}

Bunм., Rcise, II, p. 440 .

Un ejemplar muerto, pero suficientemente conservado, he encontrado en las riberas del R. Negro, cerca de la embocadura del Neuquen.

\section{BUBO VIRGINIANUS Gm.}

B. erassirostris Buru., Reise, II, p 439.

Abunda bastante en las islas del R. Negro, principalmente en Choelechoel, donde, en las noches frias de Junio, diferentes indivíduos nos divirtieron con su lúgubre canto nocturno, que recuerda la voz humana.

\section{OTUS BRACIIYOTUS Forst.}

Bunм., Reise, II, p. 489.

Muy abundante en todas las regiones palustres de la pampa. Vuela tambien en el dia, y entónces se la reconoce fácilmente por su particular aleteo pesado.

\section{GLAUCIDIUM NANUM King.}

Burm., Reise, II, p. 441.

Observado cerca de Choelechoel.

\section{5.. NOCTUA CUNICULARIA Mol.}

Burm., Reise, II, p. 440.

Esta especie parece seguir, respecto á su propagacion, á su compañera, la vizcacha. Es mucho más escasa en el Sur que en las partes centrales de la República.

En las inmediaciones del R. Colorado ya es una aparicion rara, y en el valle del R. Negro no recuerdo haberla visto.

\section{CIRCUS CINEREUS Vieill.}

Burm., Reise, II, p. 439.

Rio Colorado. Rio Negro. 
56. CIRCUS MACROPTERUS Vieill.

C. macropterus Susat., Proc. Zool. Soc. 1868, p. 143.

C. superciliosus Lass. Tr. Oin., p. 87., T. III. f. 1.

C. megaspilus GocL. Proc. Z. S., 1837., p. 10.

Muchas veces hemos observado esta especie en el territorio de la pampa, hasta en las inmediaciones del R. Colorado.

\section{ELANUS LEUCURUS King.}

Selat. Proc, Zool. Soc., 1869. p. 159.

Faleo melanopterus Boxar. Am. Orn., II. T. II. f. 1.

E. dispar Less. Tr. Orne, p. 72.

Observada alguna vez cn el territorio de la pampa.

\section{BUTEO ERYTHRONOTUS King.}

Kise, Zool. Journ., 1827.

(isi, Faun. Chil., I, p. 215.

B. braccatus Lafr., Rev. Zool., 100.

B. tricolor D'()в,., Voy. Amer. mer. Ois., p. 106, T. III, f. 1-3.

B. tricolor D'Окв., Векм., Reise, II, p. 490.

No nos atrevemos á ventilar aquí la cuestion de si el B. polyosoma Q. et Garm. representa una especie distinta de ésta, ó si debe considerarse como el macho viejo de la misma, como la reputó D'OrbignY. Hemos observado ambas formas durante nuestro viaje, á veces en parejas, la una con la otra. No he podido cazar hasta ahora un macho quc tuviese el colorido característico del verdadero $B$. erythronotus s. str.

El ave de ménos edad, en su color, se diferencia notablemente del viejo.

Toda la parte inferior del cuerpo, con inclusion de los calzones y cubiertas inferiores de la cola, y con exclusion de la garganta, la cual es de color amarillo-blanquecino, está pintada de fajas transversales de color bermejo-oscuro. La parte superior del cuerpo es de color pardo-rojizo, con las quillas y algunas manchas transversales en cada pluma de color cargado. Las puntas de las plumas encima de la cabeza, como igualmente las cubiertas de las orejas y los frenos, son de color oscuro negruzco. Las rectrices, en su parte superior y en la barba exterior, son de color gris; la barba interior es de color blanquecino, con manchas angostas oscuras en forma de zigzag. Una faja transversal, más oscura, en el extremo de la cola, la cual, en los ejemplares viejos, es muy pronunciadamente marcada, casi no es ostensible en los ejemplares jóvenes.

Con el avance de la edad desaparecen gradualmente las líncas transversales de la parte infcrior, conservandose siempre vestigios de ellas en los calzones y en la cola, hasta que en la vejez toda la parte infcrior cs de un blanco puro

Esta especie ha sido, durantc nucstra cruzada, una de las apariciones más frecuentes, 
tanto en la pampa, como en la Patagonia setentrional Con mucha frecuencia la hemos cazado en todos los diferentes estados de edad y colorido, entre Azul y Carhué, á lo largo de la línea telegráfica, donde se posaba sobre los palos.

En las inmediaciones del R. Colorado hemos observado frecucntemente su nido, encima de los árboles, y tambien en arbustos altos y densos. Entre los restos de ratones, etc., tambien se han encontrado los del Lyncodon patagonicus, bajo su nido.

\title{
59. BUTEO PTEROCLES Temm.
}

B. acuticaudatus, lewcures, ViEnL. Encylc. meth., $1223,1257$.

Abundante en el valle del R. Negro, cerca de Choelechoel, en el Chinchinal, ctc.

\section{GERANOAETUS MELANOLEUCUS Vieill.}

Burm. Reise, II, p. 435.

Sierra de Azul y Currumalan. Abundante en el valle del R. Negro, donde anida arriba de las barrancas de arenisca terciaria, formando su nido de palitos encima de las terrazas prominentes, p. ej. en las colinas de la travesía de la balcheta .

\section{HYPOTRIORCIIS FEMORALIS Temm.}

Burm. Reise, II, p. 437 .

Muy abundante en los valles del R. Negro y R. Colorado.

\section{TINNUYCULUS SPARVERIUS Lin.}

Burм. Reise, II, p. 437.

Abundante en todo el territorio expiorado.

\section{MILVAGO CHIMANGO Vieill.}

M. pezoporus M․ Вегм. Reise, II, p. 434.

Muy comun en toda la pampa, pero en mayor número en los distritos del Norte que en los del Sur.

\section{POLYBORUS THARUS Mol.}

\author{
P. vulgaris Vieml. Burm. Reise, II, p. 434.
}

Ménos abundante en la pampa que la especie anterior; pcro se la observa con más frecuencia en las regiones con vegetacion arbórea, como en el Rio Colorado, Rio Negro, etc. 
65. CATHARTES ATRATUS Bart.

C. foetens It... Bırx. Reise, II, 1) 438.

En el valle del Rio Negro.

66. PIIALACROCORAX BRASILIANUS Gm.

Burм., Reise, II, 1. 520.

Es abundante en el Rio Colorado y en el Rio Negro.

67. ARDEA COCOI Lin.

Bстм., Reise, II, 1. 508.

Observada en las lagunas ribereñas del R. Colorado y del R. Negro.

6s. ARDEA EGRETTA Gm.

A. lenee Bum., Reise, 1) 509 .

En los mismos sítios y tambien en muchas lagunas dulces de la pampa.

69. NYCTICORAX GARDENI (imel.

Burm. Reise, II, p. 508 .

En los pajonales del R. Negro, cerca de Choelechoel.

\section{TIIERISTICUS MELANOPIS Gm.}

BtrM., Reise, II, p. 510.

Observada en diferentes lugares de la pampa, y por última vez en las lagunas de las riberas del Rio Colorado.

\section{FALCINELLUS IGNEUS $(\mathrm{im}$.}

lbis ehaleoptera Tнмм., Bunм., Reise, II, p. 511.

Abundante en las regiones palustres de la pampa. Observada por última vez en las lagunas de las riberas del Rio Colorado.

\section{PHOENICOPTERUS IGNIPALLIATUS Geoff. D’Orb.}

Burk., Reise, II, p. 512.

En grandes bandadas en las lagunas de agua salada de la parnpa, p. ej. cerca de Carhué (Lag. Epecuen), Puan, Laguna de Marra-Có, Salinas Chicas, etc. 
73. CHAUNA CIIAVARIA Lin.

Berm. Reise, II, 1. 506.

Observada sólo en aigunos esteros y lagunas dulces, entre Olavarría y Lavalle.

7. Cilloepitaga Magel.lanica $\mathrm{im}$.

Sclat., Proc. Zool. Soc., 1860, p. 387. Berm. ibid, 1872, p. 364, ss. Sclat. et Salv, ibid. 1876, p. 368 .

Ch. dispar Phil. Laxdв. Ann. Univ. Chil. 1862, XXI, p. 427.

Sclat. Proe. Zool. Soc. 1867 , p. 334 .

Vulg. "Avutarda".

En bandadas considerables en las riberas de la laguna de Epecuen (Carhué) y en las del R. Colorado y R. Negro.

\section{CILLEPIAGA POLIOCEPIALA Gray.}

Sclat. Proc. Zool. Soc., 1867, p. 128. Scl. et Saly., Ibid. 1876, p. 366. Burar. Ibid, 1872, p. 364 , ss.

Anser inornatus, Kisa., Proc. Zool. Soc., 18:1, p. 15.

Bernicla chiloensis, PHiL., An. Univ. Chil., XXI, p. 427.

Asociada á la especie anterior.

\section{CYGNUS NIGRICOLLIS Gm.}

Bсr.s., Reise, II, p. 512.

Observada en algunas lagunas de la pampa y en las del R. Negro. En el último rio esta especie abunda, en pequeñas sociedades, en los brazos secundarios de agua parada, p. ej. cerca de Choelechoel, y más hácia abajo. En la parte de arriba del mismo rio no la hemos observado.

\section{CYGNUS COSCOROBA Hul.}

Beri. Reise, II, p. 512.

Abundante en todas las mayores lagunas dulces de la pampa.

\section{S. QUERQUEDULA CTANOPTERA Vieill.}

Burm., Reise, II, p. 516 .

Esta especie es indudablemente una de las más propagadas en la pampa Sur, hasta el Rio Colorado, encontrándose lo mismo en las lagunas que en las aguas corrientes. 
79. QUERQTEDULA FLAVIROSTRIS Vieill.

Burm. Reise, II, p. 516.

Lo mismo que la especie anterior, es decir, universalmente propagada en el territorio explorado. Abundante tambien en el R. Colorado y en el R. Negro.

80. (QUERQUEDULA VERSICOLOR Vieill.

Scuat. et Sirita, Proe. Zool. Soc., 1876, p. 388.

Anas maculirostris, Bıвм. Reise, II, p. 516.

Sobre casi todas las aguas dulces de la pampa.

81. DAFILA SPINICAUDA Vieill.

Bстм. cisc, 11. p. 515 .

Asociada á la $Q$. flavirostris, hemos cazado un ejemplar en el R. Negro, cerca de la embocadura del Neuquen.

\section{DAFILA BAIIANEYSIS Lin.}

Berm. Reise, 11, p. 245 .

Laguna de Carhué.

\section{S3. MARECA SIBILATRIX Poepp。}

Anas. Chiloensis Kixa. Brrm. Reise, II, p. 516.

Este hermoso pato no es una rara aparicion en los territorios meridionales de nuestra cruzada.

R. Sauce (Chico). R Colorado. R. Negro.

\section{s. ERISMATURA FERRUGINEA Eyt.}

Gis. Faun. Chil., p. 4.58 .

Burm. Proc. Zool. Soc., 1872, p. 369.

Sclat. et Silu, Proc. Zool. Soc., 1876, p. 404.

En las lagunas de las riberas del R. Negro.

\section{COLUMIBA PICAZURO Temm.}

Texs. Pig. gallin., I, p. 111. Selit. Proc. Zool. Soc., 1868, p. 143.

C. Reichenbachi Box., Consp. At. II, p. 55.

Sólo en la pampa septentrional. 
S6. COLUMTA MACULOSA Temm.

Вегм. Reise, II, p. 496.

Esta especie se nos presentó á nuestra llegada á las regiones próximas á la vegetacion arbórea; como p. ej. cerca de Carhué. Ella abunda en el valle del R. Colorado y del R. Negro. reuniéndose en bandadas numerosas en los trebolares de los bajos húmedos.

\section{ZENAIDA MACULATA Vieill.}

BсRм. Reise, II, p. 497 .

En los territorios con vegetacion arbórea. Abundante en cl valle del $\mathrm{R}$. Colorado y de! R. Negro.

\section{RALLUS RYTHYRHYXCHUS Vieill.}

Bсrм. Reise, II, p. 504.

En todo el territorio de nuestra excursion, en las lagunas dulces rodeadas de totoras, etc. Abundante tambien en las lagunas ribereñas y los brazos secundarios del R. Colorado y R. Negro, hasta el Neuquen.

\section{FULICA ARMILLATA Vieill.}

Bcrm. Reise, II, p. 505. Sclat et Salv., Proc. Zool. Soc., 1868, p. 465.

Abundante en las lagunas de agua dulce, en todo el territorio de la pampa, y en las márgenes del R. Colorado y del R. Negro.

90. FULICA LEUCOPTERA Vieill.

Sclat. et Saly., Proc. Zool. Soc, 1868, p. 468.

Asociada á la especie anterior en algunas lagunas ribereñas del R. Colorado y dcl Rio Negro. Pero mucho más escasa que aquella. Se diferencia fácilmente por el escudo frontal de color amarillo. El tamaño puede ser algo mayor.

\section{VANELLUS CAYANENSIS Gm.}

Вскм. Reise, II, p. 562.

Observado con frecuencia solo en los territorios scptentrionales de la pampa mcridional, siendo muy escasa en los del Sur. 
92. ELDROMIAS IIODESTA Licht.

Tanell. modestus Berm. Reise, II, p. 502.

En bandadas cerca del Azul y de Puan y en las playas de Choelechoel.

93. OREOPIILUS TOTANIROSTRIS Jard.

T. ruficollis Wage., Bunm., Syst. Uebers, III, p. 361.

En pequeñas sociedades cerca de F. Argentino, y en Nueva Roma, y tambien en el Rincon Grande en el Rio Colorado.

94. THINOCORUS RUMiCIVORUS Esch.

Buњм., Reise, II, p. 500 .

Abundante en pequeñas bandadas en las regiones húmedas de toda la pampa meridional.

Observada desde el Azul hasta el R. Sauce (Chico).

\section{AEGIALITIS FALKLANDICLS Latl.}

Scuat. Proe. Zool. Soe., 1860, p. 386. Ibid. 1868, p. 144.

Charadrius trifasciatus Licнт. Bun. Syst. Uebers., III, 1. 361.

En las orillas de las lagunas saladas, en la parte Sur de la pampa. Carhué, Puan, Salinas Chicas, etc.

\section{IIIIANTOPUS NIGRICOLLIS Vieill.}

Bunм. Reise, II, p. 502 .

En diferentes lagunas dulces y saladas de la pampa. Algunos ejemplares, tambien, en una laguna del R. Colorado.

\section{GALLINAGO PARAGUAIAE Vieill.}

Seolopax frenatu Burm., Reise, II, p. 503.

La variedad pallida (Scol. magcllanica K.) en las orillas del R. Colorado y del R. Negro.

98. GAMBETTA MELANOLEUCA Gim.

Вегм. Reise, II, р. 503.

Por última vez en las lagunas del R. Colorado. 
94. ACTITURUS LONGICAUDA Behst.

Totanus bartramia WiLs. Brrm,, Reise, II, p. 503.

Parece bastante rara en la parte meridional de la pampa, á lo ménos en el otoño $\mathrm{y}$ el invierno.

100. LIMOSA HUDSOXICA Latl.

LАтн. Ind. Om., II, p. 720 .

L. australis Gr.tx, List. Scolop., p. 95.

Un ejemplar cazado cerca del Azul.

\section{LARLS DOMINICANES Licht}

L. vociferus Gr., Btra., Reise, II, p. 518 .

En las grandes lagunas saladas de la pampa. Laguna Epecuen (Carhué), Puan, y Salinas Chicas.

\section{LARUS CIRRHOCEPIALUS Vieill.}

L. maculipennis L., Buru., Reise, II, p. 518.

En todo el territorio cruzado, desde Azul hasta el R. Negro; siempre en la vecindad de las aguas corrientes.

103. PODICEPS DOMINICUS Lath.

Burm. Reise, II, p. 521.

En las aguas dulces de la pampa.

104. PODICEPS ROLLANDII Quoy et Gaim.

Q. et Garm., Toy. de l'Uran. lam. 36.

GaY, Faun. Chil., I, p. 463.

En el R. Sauce Chico y en las lagunas ribereñas del Rio Colorado y del Rio Negro.

\section{RINCIIOTUS RUFESCENS Temm.}

Btrm. Reise, II, p. 498.

Abundante en la pampa, entre Lavalle y Carhué. 
106. NOTHURA MACULOSA Temm.

BtrM. Reise, II, p. 499.

En todo el territorio de la pampa hasta as inmediaciones del Rio Colorado.

\section{NOTHURA DARWINI Gray.}

Grax. List. gallin., p. 104.

Noth. minor GLv. Zool. Beagle, III.

Tinn. adspersus Texм. DOORв, Voy. Pt. hist, III, p. 302.

Nothera Darwini Glo., Sclat. et Hutos. Proc. Zool. Soc. 1879, p. 534.

En las inmediaciones del R. Colorado, así que se presentan los arbustos Patagónicos empiezan á mezclarse indíviduos de esta especie con los de la anterior, siendo la única existente en el Rio Negro. En todas sus costumbres, ambas se asemejan enteramente.

\section{EUDROMIA ELEGANS Lafr. D'Orb.}

Bиям. Reise, II, p. 49k.

Aparece con los primeros arbustos espinosos. Observada primeramente cerca de Salinas Chicas, y muy abundante en las inmediaciones del Rio Colorado y del Rio Negro.

\section{RHEA AMERICANA Lth.}

Burn. Reise, II, p. 500 .

En los distritos de la antigua dominacion de los indios no es una aparicion frecuente.

Hemos observado muchos individuos en las inmediaciones de la Sierra de Currumalan.

Los indígenas conocen tambien el a avestruz blanco s, del que se encuentra, en raras ocasiones uno que otro individuo. Nos parece casi indudable que se trata de una liar. albinea, descrita por E. LyNCH y E. L. HoLmberG, como nueva especie.

\section{RHEA DARWINI Gould.}

Govlid, Zool. of Beagle, III. Selat et Hudsox, Proc. Zool. Soc., 18ite, p. 534, sh. Rhea pennata D'Orв., Voy. P. hist., II, P, 67.

Se considera el Rio Negro como límite de propagacion de esta especie hácia el Norte, y son en realidad estraviados los ejemplares que se hallan más allá de este rio, en el rumbo espresado, como lo confirma tambien el señor coronel GUERRICo. 


\section{AMTPIIBIA.}

\section{TESTLDO CIILENSIS Aut.}

T. sulcata G., D ORb. Berm. Reise, II, p. 521.

T. maritima Desm.

Hemos encontrado una coraza de esta especie en los fogones de los antiguos indios habitantes del R. Negro, cerca del Neuquen.

\section{ACRANTL'S VIRIDIS Wagl.}

BurM. Reise, II, p. 526.

Cazado cerca del R. Sauce Chico, Choelechoel, etc.

\section{PROCTOTHRETUS PECTINATLS Beil.}

Zool. of Beagle, V, p. 18. Tb. IX, fig. 2.

En las playas de choelechoel.

\section{AMEIVA LONGICAUDA Bell.}

Zool. of Beagle, V, p. 18. Tb. XV, fig. 1.

Una hermosa especie fácilmente reconocible por su figura muy estirada, las características lineas longitudinales de la parte superior, el color rojo del vientre, y la cola armada de escamas grandes $y$ ásperas.

En las playas de Choelechoel.

\section{LIOPIIS MERREMH Wagl.}

Bгrм. Reise, II, p. 528.

Cazado en nuestro campamento cerca del R. de Lavalle, y en Choelechoel, etc.

\section{LIOPIIIS REGINAE Lin.}

Вевм. Reise, II, P. 528.

Esta especie, que se halla frecuentemente entre los pedazos de tosca del R. Paraná, la hemos encontrado en sítios muy análogos cn las barrancas del Arroyo Vcnado, entre el Fucrtc Lavalle y Carhué. 
7. CORONELLA PULCIELLA Jan.

Вгви. Reise, II, p. 528.

Hemos encontrado esta hermosísima especie en un bajo, á unas cuatro leguas al Sud-oeste de Nueva Roma.

\section{S. HETERODON DORIBIGNYI Dum. Bibr.}

Dumer. Bibr. Herpet. génèr.

Pintada de negro, blanco y colorado en el vientre de la hembra adulta. La hemos hallado cn diferentes ocasiones, primero en nuestro campamento en las inárgenes del Arroyo Lavalle, y más tarde en las colinas de la barranca del F. Argentino.

\section{ELAPS FRONTALIS Dum. Bbr.}

Un ejemplar en la cuchilla del R. Colorado, cerca de Pichi-Mahuida.

\section{HILA AGRESTIS Bell.}

Buтм. Reise, II, p. 531.

Cerca del F. Argentino y en el valle del R. Colorado.

IV. PISCFS.

\section{PERICITHIS LAEVIS Jen.}

Bспм. Reise, II. p. 538.

Esta especie, descubierta por DARIviN en el R. Sta. Cruz de Patagonia y encontrada por BURMeister cerca de Mendoza, es la más abundante en el R. Colorado, como igualmente en las lagunas ribereñas del Rio Negro.

Su carne es muy sabrosa. 


\title{
M O L U S C O S
}

POR EL

\author{
D*. D. ADOLFO DOERING.
}

\section{PULMONATA STYLOMMATOPHORA.}

\section{AGRIOLIMAX ARGENTINUS strob.}

Limax argentimus StroвеL, Mater. p. u. Malacost. d. Argent. Mer., p. 6.

Agriolimax merilionalis Doering, Periódico Zoolog. I, p. 181, L. III, fig. 2-6.

Agriolimax argentines ऽтвов, Doвr. Bol. de la Acad. Nac. de Cienc. Ex. II, p. 311.

La propagacion muy estensa de esta especie, en el territorio de la República Argentina, se ha confirmado nuevamente. Se halla en todas las localidades adecuadas para las necesidades de su vida, aunque no siempre en abundancia. La encontré por primera vez en las faldas de los cerros del Azul, cerca de Olavarria, en lugares húmedos, al pié de las rocas; más tarde en sítios análogos en la Sierra de Currumalan.

Se encuentra muy abundantemente en las márgenes del Rio Colorado y del Rio Negro, particularmente en las riberas inmediatas del rio, en los bosques de sauces, viviendo allí en el terreno húmedo, bajo la capa de hojas secas, reunida alguna vez en sociedades, en las cavidades húmedas del suelo, entre las raices de los árboles, etc.

Respecto á su color, hay la misma variabilidad, desde el claro hasta el negro, como en los territorios setentrionales del pais; pero el tamaño parece ser constantemente más reducido comparativamente con los ejemplares de la Sierra de Córdoba. 


\section{SUTCINEA MAGELLANTCA Gould.}

S. aequinoctialis DORn., Strob., Mat., p. 81 .

S. magellanica Goch, Doer. Bol. de la Acat. Nae. de Cienc. Ex. II, 1) 305.

Esta especie, fácil de reconocer por las grandes dimensiones de la abertura, se encuentra en abundantes ejemplares blanqueades, en algunos lugares, al pié de los cerros de la Sierra de la Ventana, cerca del Fuerte Argentino. En las riberas del Rio Negro, en la parte de arriba, parece ser demasiado rara, pues no la he podido encontrar. Strobel ${ }^{1}$ y Berg ${ }^{2}$ la recojieron en las riberas del Rio Negro, cerca de Patagones.

\section{STCCINEA MERIDIUNALIS D\%rb.}

DoEr. Bolet. Acad. Cienc., II, p. 807 .

Esta especie fué coleccionada en los cerros de los Hermanos cerca de Olavarría, en las ribcras del Arroyo del Venado, próximo á Carhué, en los del Rı Sauce Chico; en los cerritos de Pichi-Mahuida, en la márgen del R. Colorado, etc. El señor Aguirke tambien la recogió durante su última excursion por la Sierra del Tandil.

La var. cornea Nob. es abundante en las regiones palustres de la pampa. Junto con el Planorbis peregrinus D'ORB. se halla nuestra especie, en abundantes ejemplares blanqueados, en muchos sítios de la pampa, que, durante las lluvias, están parcialmente inundados.

Fntre los ejemplares recogidos se halla uno que otro de la siguiente especie.

\section{SUCCINEA RosARINENSIS Doer.}

S. rosarinensis Doer., Malac. B1. XXI, p. 64. T. III, fig. 224. Doer., Bol. Acad. Cienc., II, p. 308.

S. meridionalis D'Orв., Sтroв., Mater. Malae, p. 29.

Hallé ejemplares vivos en las barrancas del Arroyo Venado cerca de Carhué. Este sítio es muy análogo á aquel en que recogí la misma especie cerca del Rosario. Crecidas yerbas cubren densamente la pequeña barranca del Arroyo, produciéndose uno que otro rincon, sombrio y húmedo, donde se ve el animal caminando sobre el suelo gredoso. Asociada á esta se halla tambien hasta muy abajo en la capa de la tierra fina, seguramente atraida por el viento, en el trascurso del tiempo, de encima de la formacion de tosca de la referida barranca la especie anterior. Parece tener, lo mismo que ésta, una propagacion nuy estensa, pero se halla generalmente en reducido número de indivíduos.

\section{EUDIOPTUS MENIOZANES Strob.}

VAR. Las. I, Fig. 1.

Sтroв. Materiali, ete, p. 28, T. I, fig. 4.

Segun la diagnósis de Strobel, no pueden hallarse diferencias suficientes para sepa-

(1) Materiali, etc. 1, 81.

(") Bol. de la Acal. de Cienc., II, P. 306. 
rar esta forma ce la de Mendoza. Los caractéres spira clongata, apice obtuso, no convienen mucho á nuestros ejemplares. Pero no teniendo á mi disposicion ni ejemplares típicos de la especie de Strobel, ni las láminas correspondientes de su Materiali, " etc., no estoy bien preparado para resolver definitivamente la cuestion.

Los ejemplares recogidos tienen las siguientes dimensiones:

\begin{tabular}{|c|c|c|c|c|}
\hline & LOXGITUD. & LATITUD. & ABERT. LOXG. & ABERT. LAT. \\
\hline a. & $24 \mathrm{~mm}$ & $12 \mathrm{~mm}$. & $15 \mathrm{~mm}$. & smm. \\
\hline b. & $25 \mathrm{~mm}$. & $14 \frac{1}{5 m}$. & $16 \mathrm{~mm}$. & $9 \mathrm{~mm}$. \\
\hline c. & $27 \mathrm{~mm}$ & $14 \mathrm{~mm}$. & $17 \omega \mathrm{m}$. & $9 \mathrm{~mm}$. \\
\hline 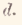 & $28 \mathrm{~mm}$ & $15 \mathrm{~mm}$. & $161 \mathrm{~mm}$ & $10 \frac{1}{3} \mathrm{~mm}$. \\
\hline e. & $2 \mathrm{~mm}$. & $16 \mathbf{m} \mathbf{m}$. & $17 \mathrm{~mm}$. & $10 \mathrm{~mm}$. \\
\hline
\end{tabular}

El color es oscuro de ámbar-oliváceo, con estriās longitudinales, irregulares, de un tinic algo más oscuro. La concha es muy delgada y algo flexible, con muchos pliegues ó fuertes arrugas y con algun lustre en la superficie. En el interior es lisa y algo nacarada.

Aliadas á esta especie sor, además de la subsiguiente, el Bulimul. tortoranus NoB., el Bül. cordillerae Strob., el Bul. monticola NoB., é indudablemente el análogo de éste en la Cordillera alta, el Bul. nivalis D'ORB.

Se diferencia del primero por la figura más recogida y ventricosa, particularmente la espira, y por el color oscuro y el tamaño mayor; del B. monticola por el tamaño mucho mayor y por la figura más prolongada.

La maxila es bastante encorvada en forma de herradura y compuesta de iz gruesas costillas. La última costilla de cado estremo es un poco dilatada y medio redondeada en su periferia. Las intermedias son bastante iguales entre sí, relativamente al ancho; las dos centrales un poco más angostas y cónicas. Hay bastante semejanza con el Bulimulus tor toranus NoB. Pero de ninguna manera pueden clasificarse los representantes de este grupo en el género Otostomus.

Encontré esta especie en los primeros cerros (de Sotoya) que toca el camino que va del Azul hasta la Sierra de Olavarría. Dichos cerros, formadas por una arenisca cuarcítica, regularmente estratificada, tienen las cabezas de sus capas, que son de poca inclinacion, dirigidas hácia el Norte. En las quebradas y grietas de estos, muy arriba en las paredes de las rocas, en lugares en que el agua de las lluvias suele buscar su camino hácia abajo, se encuentran numerosos ejemplares de esta especie, pegados en montones á las paredes de la roca. El animal está adherido tenazmente á la piedra, y hasta llega á romperse muchas veces la concha, al despegarlo.

No he podido encontrarla en los cerros de los «dos Hermanos », sin embargo de ser éstos completamente análogos, en su estructura geognóstica y demás condiciones, á los de Sotoya. 


\section{$-61-$ \\ 6. ETIOPTL'S AVELLANEDAE nor. spec.}

LAM. I, Fig. 2 y 3.

T. rimata, conico-oblonga, subfusiformis, striatula, pellucida, lacrigata, fusco-cornea, striis fulvescentibus, irregularibus aliquot ornata; anfi. 7 parm convexiusculi, ultimus non descendens, $2 / 5$ longitudinis subaequans: sutura planiuscula, impressa; apertura oblongo-ovalis, intus margaritacea; peristoma simplex, acutum, margine basali breve expanso, dextro superne recto, columellari reflexo, marginibus callo tenui junctis.

Long. 22mm.; lat. $9 \mathrm{~mm} . ;$ long. apert. $9 \mathrm{~mm} \cdot ;$ lat. $5-5 \frac{1}{2} \mathrm{~mm}$.

Esta hermosa especie tiene muchas analogias en su forma exterior con el Bul. tortoramus Nов., y difiere algo de los aliados del mismo género por su figura gracilifurme.

El tamaño es menor que en la especie mencionada, la abertura relativamente mucho más pequeña, las vueltas más aplanadas, la sutura ménos honda, la cáscara ménos delgada $\mathrm{y}$ algo más lisa $\mathrm{y}$ el color algo más cargado.

La callosidad de la pared de la abertura es, alguna vez, bastante gruesa, en forma de un pequeño liston.

Del Bul. Mendozanus STroв. se diferencia notablemente por su tannaño mucho menor.y su figura prolongada, con mayor número de vueltas. La superficie es mucho más lisa, la cáscara es relativamente muy sólida, la abertura nucho más pequeña.

Se halla esta especie en lugares semejantes á los que la anterior, aunque no en tanta sociabilidad, como por ejemplo, en las rocas cuarcíticas de la Sierra de Currumalan. Vive allí asociada al Plagiodont. Rocae Nob. Más tarde la encontré tambien en uno de los cerros ó promontorios de la Sierra de la Ventana, cerca del Fuerte Argentino.

\section{EORLS DORBIGNYI Doer.}

L.x. I, Fig. 4 .

Bul. mucleus Sow., DOORв. (neque Sow.) Syn. Mag. Zool. 1535, p. 14. Voy. p. 305.

Borns nuclens D'Orв., Stroв., Mater. Malac. Arg. Mer., p. 29.

Bonts D'Orbignyi Doer., Bol. Acad. Cienc. Ex. II, p. 336.

Ejemplares frescos ó vivos de esta especie son muy escasos y hasta ahora muy desconocidos, de manera que ni D'Orbigny ni Strobel pudieron conseguirlos. Pero yo he tenido la ocasion cle encontrar más de media docena, frescos, en la barranca del Rio Sauce Chico, cerca del Fuerte Argentino.

No son enteramente blancos, sinó algo transparentes; las primeras vueltas de la punta tienen un color rojizo-gredoso pálido, las demás son blanquecinas con un débil tinte rojizo pálido, y una que otra faja longitudinal del mismo color. El borde interior de la abertura, lo mismo que la callosidad de encima de la pared, es brillante y liso y de un hermoso color anaranjado pálido. El carácter de la diagnósis de D'ORBIGNY "sutura levigata" debe cambiarse con relacion á nuestros ejemplares, en sutura laevigata vel subcrenulata, " pues casi la mitad de ellos tienen la sutura visiblemente denticulada. En ninguno he no- 
tado las líneas espirales características del B. lutescens $\mathrm{K}$ y del B. pachychilus PF. especies con las que, sin embargo, la nuestra es indudablemente una estrecha aliada.

La maxila ofrece muchas analogias con la del $B$. lutescens var. Cordillerae Nob: está formada por un solo pedazo, sin verdadera articulacion y division en costillas. Es de forma de herradura, pero mucho ménos curva y más corta que la de la especie indicada. Con facilidad se nota una fina estria transvcrsal. En el centro de la márgen interior hay un diente, ó más bien dicho, una pequeña convexidad sobresaliente.

Esta especie parece tener más ó ménos la misma distribucion que el Plag. patagonicus DORB., con el cual se halla generalmente asociada en los mismos lugares. Ejemplares blanqueados se ven en todos los lugares medanosos y barrancosos situados entre la Sierra de la Ventana hasta Bahia Blanca.

Abunda en el estremo occidental de la Sierra de Currumalan, y en todos los cerritos ó prominencias, allí donde tambien encontré los primeros ejemplares Los indivíduos de la Sierra son generalmente de un tamaño más reducido.

Los ejemplares vivos se hallaban en las pendientes de las barrancas, bajo los grandes terrones de piedra tosca, pcgados sicmpre con la abertura hácia abajo, de modo que el animal suele cavarse con su pié un pequeño hueco en la tierra húmeda. Nunca se le halla pegado á las caras de las piedras. El animal sabe proveerse, con el auxilio de su manto ó de sus pulmones, de un buen depósito de agua, ántes de hundirse en su escondite. En tal estado, el pié parece hinchado y convexo; recojido el animal, deja salir al instante su provision de agua, mientras que el pié se relaja.

Donde no hay bancos de tosca, en la superficie inmediata del suelo, es fuera de duda que el animal hace hondas escavaciones en el terreno arenoso: por esto son tan raros los ejemplares frescos. Cuando el animal muere así enterrado, puede suceder que, recien despues de muchos años, cuando está ya blanqueada la concha, llegue ésta á la superficie, haciéndose entonces visible á los ojos de los esploradores.

D'ORbignv; aludiendo á la reducida propagacion de esta especie, dice que, fuera de Bahía Blanca, él no la ha encontrado, ni en la Patagonia, ni en los territorios del Rio de la Plata, observacion que viene á confirmarse completamente ahora.

Durante nuestra cruzada desde el Rio Sauce (chico) hasta el Rio Colorado, ella apareció en ejemplares escasos, sólo los primeros dias, aún hasta en lugares donde el Plagiodontes patagonicus ya había desaparecido. Pero con las entradas de los precursores de la verdadcra formacion patagónica de arbustos y malezas, desapareció tambien ella, no llegando el límite de su distribucion meridional hasta el márgen del Rio Colorado.

\section{PLAGIODONTES ROCAE Doer nov. espe.}

LAM. I, Fig. 5 y 6

T. rimata, ovato-oblonga, solidula, fusca, opaca, vix nitens; striis confertis sub-regularibus ornata; spiva ovato-subcylindrica, apice conica, sutura impressa; anfr. \& vix concexiusenti: primi dno sublaevi- 
gati, huteo-connci, eaeteri fiesci, striis confertis subcostulosis (interlum albescentibus) regulariter sculpti; ultimus $\frac{7}{3}$ longitudinis subacquans, eirea aperturam albido-calearea; apertura subertiealis, ovata, ealcarea, plicis s-10 jere elausa: dentibus 3 erassis lamelliformibus: primo angulato, tortroso, suleato, in paricte apert.; secundo maximo lingracformi in colemelia; tertio tortuoso in medio marginis dextri: plicis 3-5 mimutis, parallelis, in partc basali, 2 minutis in parte supero marginis dextri; lamella tiansversa, valida, in fundo aperturac; peristoma crpansum, labiosum, marginibus callo junctis.

Long. 21-2tmm.; lat. 8-9mm. Long. apert. $7-9 m m . ;$ lat. $6 \frac{1}{7}-7 \mathrm{~mm}$.

Esta especie se diferencia fácilmente de todas las demás, conocidas hasta ahora, por el color oscuro pardo uniforme de la concha, siendo blanca solamente la última vuelta en circunferencia de la abertura, lo misnı que el perístoma y el interior de ella. Tambien la escultura es muy característica y diferente de las especies conocidas. Las estrias son bastante elevadas y gruesas, formando así pequeñas costillitas, muy densamente agrupadas y dando á la concha una superficie algo áspera.

Las estrias scn más densas y finas en los anfractos superiores, faltando en los dos embrionales, los cuales se diferencian tambien por lo general por su color más claro. Sólo conozco, de este grupo, una especie no descrita aún, proccdente del Norte de la Pro. vincia de Córdoba, que tiene la estria tan pronunciadamente desarrollada como la presente, asemejándose tambien á ella por su tamaño y su configuracion prolongada, pero diferenciándose por su falta de colorido.

La figura de nuestra especie puede recordarnos, en algo, el B. multiplicatus NoB. aunque el tamaño es mucho menor.

La dentadura es bien desarrollada, lo mismo que en la mayor parte de las especies de este grupo, estando cerrada casi por completo la abertura por los numerosos dientes. La gran laminilla parietal forma un fuerte diente torcido, con las márgenes elevadas en forma de liston $\mathrm{y}$ bordeando una pequeña excavacion. Su apéndice hácia arriba, el cual en la mayor parte de las especies aliadas está agregado á él sin interrupcion, parece generalmente en nuestra especie, un poco separado, formando un pequeño diente aislado á su lado. El pliegue columelar es de la forma conocida, y parece: bastante torcido. En la parte basal de la abertura hay generalmente cuatro pequeños pliegues, poco divergentes. El primero, el cual, al mismo tiempo, es el más considerable, se halla acercado al lado del pliegue columelar; los demás, más próximos á al márgen derecha, están generalmente acercados entre sí. Alguna vez son dos, pero generalmente son tres, y á veces cuatro, siendo entónces el primero de ellos (el cual se halla situado más ó ménos en el centro de la base de la abertura) formado por dos plieguecitos diminutos, muy acercados entre sí, el primero de cllos un poco más retirado que los otros hácia el fondo de la abertura.

En la parte superior del borde derecho, encima del gran pliegue marginal, hay dos pequeños dientes, lo mismo que en la mayor parte de las especies de este grupo. Toda la dentadura de esta especie, comparativamente con las demás, parece demasiado retirada 
hácia el interior de la abertura, lo que tambien, y principalmente, pucde referirse al gran pliegue transversal cn el fondo de la abertura, el cual, aunque no es muy alto, es en alto grado dilatado lateralmente, y se halla á una distancia algo considerable por detrás de los dientes pequeños de la base de la abertura, siendo visible tambien exteriormente sobre el dorso de la última vuelta ó de la abertura, trasluciendo como una línea blanca semilunar.

Las vueltas de la espira son muy poco convexas, es decir, casi aplanadas, siendo por consiguiente la sutura muy poco escavada, casi filiforme.

Estos últimos caractéres, como tambien la figura algo cilindrica, su color pronunciado, la punta coneiforme, y particularmente su modo de vivir, clasifican esta especie al lado de las dos especies con vueltas llanas que hemos descrito en otra ocasion 1, y las que están acostumbradas á vivir exciusivamente en los lugares sombríos y húmedos, en las quebradas de las sierras.

Precisamente nuestra especic fué encontrada tambien en sítios completamente análogos, en las pequeñas quebradas će la falda meridional de la sierra de Currumalan, en lugares húmedos, privados de los rayos directos del sol. Vive allí en ejemplares bastan. te numerosos dentro de las rajaduras y hendiduras de las rocas, pegada á las piedras y á las plantas, asociada con uno que otro ejcmplar de la subsiguiente especie, cuya propagacion se desarrolla más bien en los sítios asoleados al pié de la misma sierra. Ya de léjos se diferencian fácilmente las dos especies, no solamente por el colorido y la estria gruesa de la primera, sino tambien por su figura cilíndrica (á difercncia de la otra que es más ventruda) y por su dentadura muy desarrollada, siendo la de la otra muy fragmentada.

\begin{tabular}{|c|c|c|c|c|}
\hline DIMEXSIONES: & LOXGITCD. & LATITID. & LOXG. ABERT. & IAT. ABERT. \\
\hline a. & $21 \mathrm{~mm}$. & $8 \frac{1}{2} \mathrm{~mm}$. & $8 \mathrm{~mm}$. & $7 \mathrm{~mm}$. \\
\hline$b$. & $22 \mathrm{~mm}$. & $8 \sin$. & $7 \frac{1}{3} \mathrm{~mm}$. & $6 \frac{1}{3} \mathrm{~mm}$. \\
\hline$c$. & $28 \mathrm{~mm}$. & $9 \mathrm{~mm}$. & $9 \mathrm{~mm}$. & 7 t nm. \\
\hline$d$. & $24 \mathrm{~mm}$. & $8 \mathrm{~mm}$. & $8 \pm \mathrm{mm}$. & 7 เ $\mathrm{mm}$. \\
\hline
\end{tabular}

El animal es de un color blanco-amarillento, la cabeza con los tcntáculos superiores, y la parte situada arriba de los inferiores, son de color oscuro, gris-negro. La punta dcl pié bastante redonda. En estado de accion, el animal tiene $20 \mathrm{~mm}$. de longitud, por 10 $\mathrm{mm}$. de ancho; los tentáculos superiores $5 \mathrm{~mm}$.

La maxila es análoga á las de las demás especies del grupo: gruesa, oscura y muy encorvada en forma de herradura, compuesta de once costillas gruesas. Estas son sobre. salientes en el borde interior como fuertes dientes en forma de sierra. El último artículo

(1) Bol. de la Acal. de Cienc., II, p. 321 y 322. 
de cada extremo es el más grande de todos, casi tiene un doble ancho relativamente á los subsiguientes. Los miembros centrales son los más angostos y más cortos, siendo la maxila, en su parte media, un poco enangostada.

\section{PLAGIODONTES PATAGONICUS D'Orb.}

Lam. I. Fig. 7 y 8.

Pupa patagonica DO ORB. Syn., MLag. Zool., ps. 22 y 35.

Pupa sowerbiana var. patagonica, D'ORB., Voy., P. 321, H. XL bis, fig. 17 y 18.

Bul. patagonicus D'Orв., Pfi. Mon. hel. viv. IT, p. 438.

Bul. dentatus var. patagonica \$тков., Mat., p. 18, ff.

Las opiniones sobre la separacion de esta especie han discrepado tanto entre los diferentes naturalistas, que creemos necesario hacer algunas referencias á este respecto.

Habiendo descrito primeramente D'OkBIGNy esta especie cn el Magazin de Zoologie segun ejemplares que Mr. PARchAppe había coleccionado cerca de Bahía Blanca, la reunió él más tarde en su voyage con su Pupa sozverbiana de Entre Rios, la cual es el B. dentatus Woov., habiéndose inclinado á considerar la especie meridional como una varicdad geográfica de la primera, por encontrarse á veccs ejemplares de ella, gue, por un mayor desarrollo de la dentadura, se asemejan superficialınente al Bul. dentatus, el cual posee siempre una dentadura muy desarrollada.

Strobel, sin ciuda, por no tener á su disposicion ejemplares del verdadero $B$. dentatus, para poder compararlos, ha aceptado en su obra, últimamente publicada, la idea de D'Orbigny, mientras que el ojo esperimentado de L. PFeiffer, que comparó los ejemplares del Museo Británico, había reconocido al instante la independencia de esta especie. Despues de una ninuciosa comparacion de ambas, me veo en la necesidad de declararme de. cididamente en favor de la opinion de PFEIFFER.

Verdad es que, scgun el estado de las consideraciones que actualmente rijen las ciencias descriptivas acerca de las definiciones de «ppecie, variedad, etc. la diferencia entre los dos conceptos parece puramente relativa, debiéndose suponer que todas las especies de un grupo con un determinado centro de distribuicion, como p. ej., el grupo Plagiodontes, deben probablemente su orígen á una misma forma típica, formándose las diversas especies por las diferentes influencias geográficas, locales, ó particulares etc., las que, con el trans. curso del tiempo, en el desarrollo de las generaciones, adoptaron sus particularidades cor respondientes. Pero es costumbre considerar una especie como separada, cuando ciertos y determinados caractéres se presentan constantemente, aún en todas las variedades, pero sin que ellos den orígen á un verdadero traspaso á una forma ó especie aliada.

Las analogías que esta especie parece ofrecer alguna vez con el B. dentatus WVoD. no son fundamentales, y sólo un exámen superficial puede confundir una y otra. Con igual razon se la debia reunir con el $P$. daedaleus DEsh. de las sierras centrales, ó considerar, por ej., el B. Orbignyi como una variedad geográfica del B. oblongus, ó del $B$. lutescens. 
Entre todas las especies del grupo, ésta es la mas incompleta respecto al desarrollo de su dentadura, en tal grado, que el gran pliegue transversal situado en el fondo de la abertura, y el cual nos ha servido de base para la formacion del grupo Plagiodontes , no llega generalmente á desarrollarse en esta especie, y falta en la mayor parte de sus indivíduos, de manera que esta particularidad, en ocasiones frccucntes, puecie servir para diferenciar fácilmente la susodicha especie de todos las demás del grupo. Son muy escasos los ejemplares en que, sin embargo, esta señal característica de todo cl grupo, se halla desarrollada en forma de un pliegue delgado de poca altura, compuesto ai principio de algunos dientes reunidos entre sí, como se nota, por ej., en un indivíduo de la car. major, encontrado cerca del Fuerte Argentino. Pero este pliegue, lo mismo que los demás dientes de la abertura, comparativamente con las otras especies del grupo, tiene tambien un tamaño muy reducido.

Por lo general sc hallan desarrollados sólo los tres pliegues ó dientes principalcs de la abertura, á saber: el pliegue parietal, el columelar y el principal del borde derecho. El diente de la pared es, lo mismo que en las demás especies, bífido, bordeado, y tiene una forma parecida á gancho; pero es siempre relativamente muy delgado y comprimido. A su lado se halla muchas veces un diente pequeño é insignificante cerca de la insercion del perístoma. El pliegue principal del borde derecho es aún ménos desarrollado, y nunca torcido como se nota sin excepcion en las demás especies.

Además de estos ejemplares con tres dientes, abundan otros con cuatro. El cuarto se halla desarrollado siempre en la base de la abertura, un poco al lado izquierdo. Los dientes $5^{\circ}$ y $6^{\circ}$, hallándose desarrollados, tienen su colocacion encima del pliegue peristo. mático, en la parte superior del borde derecho. Raros son los ejemplares en que tambien los dientes $7^{\circ}$ y $8^{\circ}$ se desarrollan en la base de la abertura; esto se nota sólo en una lar. major, la misma en que, alguna vez, se observa tambien un principio del gran pliegue transversal cn el fondo de la abertura.

Del Plagiodontes dentatus Wood., del cual tenemos, fara la correspondiente comparacion, ejemplares de Concordia (Entre-Rios) y Buenos Aires, se diferencia nuestra especie por los caracteres principales siguientes: La posicion de la abcrtura muy distinta. En el $P$. patagonicus, ésta se encuentra colocada más ó ménos verticalmente ó en direccion paralela al eje longitudinal de la concha, mientras que en el $B$. dentatus clla forma con el referido eje un ángulo obtuso hácia atras; de manera que, en la primera, la abertura aparece estendida más hácia adelante, al mismo tiempo que la dentadura se halla distanciada más hácia el fondo dc la abertura. El pliegue columelar del $B$. dentatus tiene una direccion casi vertical con el eje de la concha; el del $P$. patagonicus forma un ángulo algo inclinado transversalmente. El pliegue principal del borde derecho, en el $B$. den-

(1) Bol. de la Acal. de Cienc., II, p. 318. 
tatus, forma un diente fuerte y repentinamente torcido ó doblado; en nuestra especie un liston derecho, apénas con vestigios de torcimiento.

Los dos dientes chicos, en la parte superior de la márgen derecha, cerca de la insercion del borde, se hallan acercados y reunidos cntre sí, formando un diente bífido, en el B. dentatus; en nuestra cspecie, cuando los dos llegan á desarrollarse, cstán situados muy distantes entre sí, sin tener conexion el uno con el otro. Esta última señal es quizas una de las más caracteristiças.

Otros caracteres secundarios para diferenciar ambas especies son, enfin, el muy completo desarrollo de la dentadura en el B. dentatus y el ircompleto en nuestra especie. En la primera, la abertura está cerrada casi totalmente por los abundantes dientes fuertemente desarrollados. El número talvez no baja nunca de 6 y llega hasta io, siendo siempre, por otra parte, tambicn, bien desarrollado el pliegue transversal (que falta por regla general en nuestra especie) y siendo en clla el número normal de dientes 3-4, llegando muy raras veces hasta 7 ú 8. El tamaño en la última es un poco mayor, normalmente entre $20-23^{\mathrm{mm}}$. (en la otra $19-2 \mathrm{~mm}$.) y la configuracion algo más ventruda.

El indivíduo más grande de nucstra especie, desarrollado con cl pliegue transversal y 7 dientes, tiene $27^{\mathrm{mm}}$. de longitud con $12^{\mathrm{mm}}$. de latitud.

La maxila en su forma general cs análoga á la de la cspecie anterior. Es bastantc encorvada en forma de herradura, compuesta de 1 i costillas muy gruesas, y con el borde interior denticulado.

Puede considerarse como centro de distribucion de esta especie el sistema de la Sierra de la Ventana. En los territorios de la Sierra del Azul, etc. no la he encontrado, sinó recien á nuestra llegada á los cerros promontorios de la Sierra de Currumalan, es decir, á la continuacion occidental de dicha sierra.

Es muy abundante en los barrancos de tosca de todos los rios y arroyos que tienen sus fuentes en aquella sierra, como el Rio Napostá, el Rio Sauce-Chico, etc., cubriéndose las colinas ribereñas con numerosas cáscaras blanqueadas. Ella desaparece ya á io leguas hácia el Sud-Oeste, no llegando su propagacion hasta las riberas del Kio Colorado.

\section{PUPILLA OBLONGA Pfir.}

Pfeiff. Proc. Zool. Soc. 1852, p. 69. Mon. hel. viv. HI, p. 536. IV, p. 685. Hibale, Mol. al. viag. al Pacif. 1, p. $1+1$.

Doerixa, Bol. Acad. Cienc., III, p. 81.

Sierra de Pichi-Mahuida á la márgen derecha del Rio Colorado. Vive allí en la capa de tierra vegetal, entre las materias vegctales medio descompucstas, debajo de las piedras, y particularmente en los troncos viejos de las pencas.

Los ejenılares recojidos no se diferencian en forma y tamaño de los del Kosaío. Como se ve, csta especie, en su considerable propagacion geográfica, forma analogía comun con algunos del mismo género en el viejo mundo. Ha sido ahora encontrada en 
Sud-América en un espacio de 26 grados de latitud: primeramente en el Brasil, cerca de Bahía, y despues cerca de Montevideo. Yo la hallé cerca del Rosario, y de Córdoba; ahora en las riberas del Rio Colorado. Es probable que ella se extienda aún más hácia el Sur del continente, á lo largo de las Sierras Andinas.

\section{PUIMONATA AGUATIOA.}

\section{ANCYLUS CONCENTRICUS D'Orb.}

D'Orв., Toy., p. 354. Pl. 42, flg. 18 y 21.

Var. Bonaeriensis Sтroв., Mat, P. 5, T. II, fig, 4.

Fácilmente reconocible por la punta estrecha de la concha. La estría concéntrica es muy débil y no es siempre visible en todos los ejemplares.

Esta especie se halla no muy raras veces á lo largo de los bordes del Rio Negro, en las lugunas, en cuya orilla no faltan las Totoras y particularmente la Typlea, en cuyas hojas flotantes ó paradas se halla el animal tenazmente pegado, cuando se le recoge del agua. Mis ejemplares fueron coleccionados cerca de la embocadura del Rio Neuquen.

\section{CIILINA PARCHAPPII DOrb.}

D'Orв. Toy., p. 388 , pl. 43, fig. 4 y 5.

Esta especie bien caracterizada parece tener mucha analogía con la Ch. fluctuosa de Chile, á la vez que, cuando jóven, las fajas pintadas tienen tambien la misma figura en zig-zag que se observa en aquella.

Segun el volúmen del caudal de los rios y arroyos en que ella vive, su tamaño normal es muy diferente, y tambien la forma algo variable. En el Rio Sauce, cerca de NuevaRoma, rio con caudal bastante hondo, he recogido la Var. major, con cáscara muy tenue y pálida, y las fajas pintadas de color más claro y modificadas en las vueltas nuevas en forma de zig-zag. La figura es bastante prolongada, y la punta muy delgada $y$ ajustada. La longitud llega hasta 26 ó $27^{\mathrm{mm}}$. El liston sobre la columnilla es bien desarrollado en algunos ejemplares, desapareciendo casi por completo en otros.

La variedad que recogí en el camino á Carhué, en el arroyo Guaminí, arroyo con caudal reducido y bajo, tiene una figura mucho más corta y recogida, un color más oscuro y las fajas ó manchas oscuras mas gruesas y enredadas. Los ejemplares más grandes no llegan sino á 22 ó $23^{\mathrm{mm}}$, y éstos no son abundantes.

En ambos lugares el animal se halla en numerosos ejemplares, viviendo principalmente en las orillas de las aguas, caminando sobre el fondo gredoso. 
13. CIILLINA FLUMINEA Mat.

D'OrB. Toy., Moll., p. 337, pl. 48, fig. 19 y 20.

Esta especie, fácilmente reconocible por sus dos pliegues sobre la pared de la abertura, la he coleccionado en el Rio Colorado, frente á los Cerros de Choique-Mahuida.

Ella se halla, como siempre, con poca frecuencia. Hc conseguido tres ejemplarcs, llevados por la corriente del rio, en una rinconada de las rocas. Estos últimos no tiencn pintura claramente pronunciada, y el largo del ejemplar más grande no pasa de 16 mm.

\section{CIIILINA TEIIUELCIIA D’Orb.}

D’Ork., Toy. Moll., p. 336, pl. 43, fig. 8-12.

He colcccionado esta especie en unos brazos secundarios del Rio Negro, ccrca de Choelechocl y arriba del Chichinal. De la primera localidad, los ejcmplares son sumamentc fuertes, con concha pesada; los jóvenes generalmente con 4 ó 5 fajas formadas por manchas aisladas $\mathrm{y}$ algunas en forma de zigzag. El ejemplar más grande ticne $30^{\mathrm{mm}}$. de largo, con $20^{\mathrm{mm}}$. de ancho. Ellos pueden acercarse quizás cn algo á la var. Mcndozana de Strobel 1. Los ejemplares de arriba del Chinchinal, no muy léjos de la cmbocadura del Rio Neuquen, tienen una cáscara mucho más ténuc, y un color fusco de olivo y uniforme. Llegan á un tamaño considerable: el ejemplar más grande tienc $40^{m m}$ dc largo por $25^{\mathrm{mm}}$. dc ancho.

\section{FLANORBIS PEREGRLNT'S D'Orb.}

$$
\text { J'Orв., Voy. Woll., p. 336, pl. 44, fig. 13-16. }
$$

Teniendo esta especie una distribucion muy extensa sobre una gran parte de la América Meridional, ella cs á la vez la más frccuente en los territorios meridionales de la República. Se halla con mucha abundancia en las lagunas y cañadas, en las márgenes del Rio Negro, lo mismo que casi en todas las aguas dulces estancadas de la pampa. Los de los últimos lugares son generalmente de una escultura más lisa, un color mucho más pálido, y á veces hasta de una transparencia pronunciada y una concha más tenue, cn comparacion con los de los printeros sítios mencionados.

\section{PlaNorbis aNATINUS Dorb.}

D'Ors. Toy. Moll., p. 351, pl. 44, fig. 17-20.

Este pigmeo entre las especies sud-americanas, $y$ bien caracterizado por su configuracion, lo encontré en una de las lagunas situadas al lado del Rio Negro, cerca de la embo-

(1) Mat. Malacost. Arg. Mer. I, p. 47. 
cadura del Neuquen. La laguna, que se encuentra en una cañada ciega, estaba rodeada de Typha, y el interior lleno de una especie de Ceratophyllum. Entre las hojas finamente ramificadas de esta planta, se la halló en escasos ejemplares.

\section{PECTINIBRANCHIA}

\section{PALUDESTRINA PARCHAPPII D'Orb.}

D’Ozв. Voy. Moll., p. 383, pl, 48. fig. 1-3.

Esta especie, abundante segun D'Oreigny, en la mayor parte de los arroyos del Sur de la Provincia de Buenos Aires, fué coleccionada en grandes ejemplares en el Arroyo Sauce cerca del Fuerte Fé. Los ejemplares de mayor dimension tienen $9^{\text {mm. }}$ de largo con $4^{\text {ma. }}$ de ancho.

\section{LAMELLIBIRANOHIA.}

\section{UNIO PATAGONICUS D'Orb.}

D'Ore. Voy., P. 310, pl. 70, fig. 1-6.

La variabilidad de esta especie no es insignificante, pero siempre se conservan bien los caracteres determinantes.

En los ejemplares muy crecidos, la punta de la concha es prolongada en forma de pico, alguna vez algo encorvada. Los umbones, por regla general, son alfo corroidcs, hasta en los ejemplares muy jóvenes. Conservados, estos umbones son rugosos, y la zona circundante de un color algo más claro, amarillento.

El color de la concha es generalmente de un café oscuro uniforme, á vcces, encima de la convexidad de ella de un color verdc-oliváceo oscuro, sobre el cual, hácia la márgen, se muda en café. Fajas de radiacion no se observan, ni en los ejemplares limpiadcs con el ácido clorhídrico. El interior de la concha, en la parte más concava, es teñido generalmente de un morado pálido. Los más grandes miden: Long. 88mm.; Lat.45-46mm.; Diám. $30^{\text {mm }}$.

La especie es abundante en el Rio Negro, en todos los sítios donde el lecho del rio tiene un fondo arenoso. Cuando la llegada del ejército á Choelechoel, el rio estaba relativamente muy bajo, y en el brazo principal (izquierdo) que separa la isla, se encontraron numerosos indivíduos de esta especie, en la orilla del agua, en un fondo formado de arena fina y pesada, conteniendo crecidas cantidades de granitos finos de hierro magné- 
tico. El animal vive siempre enterrado completamente en la arena, dirigida la concha con su punta prolongada oblicuamente hácia la corriente del agua. Lo único que señalaba su presencia era una rajadura fina en la superficie de la arena, formada por la márgen posterior aplanada del pico de la concha.

Hervido en agúa ó asado directamente en el fuego, este animal constituia un alimento predilecto para los soldados. Por su modo de vivir en la arena limpia y en el agua pura del Rio Negro, su carne apénas tiene gusto á fango, como sucede por lo general con las especies de este género.

La hemos encontrado en el Rio Negro, rio arriba, hasta cerca del Neuquen.

\section{ANODONTA PUELCHANA D'Orb.}

D ORв. Toy. Moll., p. 620, pl. 79 , fig. 4-9.

Esta especie, del mismo Rio Negro, es mucho más escasa que la anterior.

E1 tamaño de los adultos es generalmente de $80^{\mathrm{mm}}$. de largo con $45^{\mathrm{mm}}$. de ancho y 28-30mm. de diámctro. Pero existen individuos hasta de 90mm. de largo. En la region de los umbones, los que casi siempre están corroidos, el color es generalmente más pálido, verduzco, y café en la márgen. Los ejemplares limpiados por el ácido tienen generalmente un número de fajas radiales de color mas oscuro.

La hemos encontrado unas 12 leguas arriba del Chichinal, en unos de los brazos del rio, en ejemplares antiguos, junto con los de la especie anterior.

\section{SUBFOSSILIA.}

\section{PALUDESTRINA AUSTRALIS D'Orb.}

D' Овв. Toy. Moll., p. 384, pl. 48, fig. 4-6.

Los ejemplares subfósiles de una especie de Paludestrina, que recogí, junto con otras conchillas marítimas de orígen antiguo, en las orillas de la laguna salada de Marra-Có, no me ha sido posible diferenciarlos de la especie marítima de Bahía Blanca.

\section{MYTILUS SPEC.}

Talvez el M. Darwinianus ó el M. Patagonicus de D'Orbigny. Junto con la especie anterior en las orillas de la Laguna de Marra-Có. Long. 30mm. lat. $40^{\mathrm{mm}}$. diám. Iomm. Aun cónserva algun tinte morado en la parte concava de la concha. 


\section{$-75-$ \\ 22. SOLEN SCALPRUM Brod.}

D'Orв. Toy. Moll., p. 505, pl. 77, fig. 22.

Procedente del mismo sítio, de las orillas de la laguna de Marra-Có. La configuracion parece completamente conforme con la de los ejemplares oriundos de la costa patagónica; pero por falta de ejemplares frescos de esta especie no se puede resolver definitivamente la cuestion sobre su identidad.

Los ejemplares recojidos son de orígen muy antiguo, careciendo completamente de la pintura y siendo muy quebradizos. Tienen las siguientes dimensiones: Long, 40-60mm. lat. $17-20^{\mathrm{mm}}$. diam. $12-\mathrm{I} 3^{\mathrm{mm}}$. 



\title{
I N S E T O S
}

POR EL

\author{
D. ${ }^{R}$ D. CÁRLOS BERG.
}

\section{ORTIIOPTERA.}

Fam. Blattidae.

1. ANAPLECTA LATERALIS Burm.

Sauss., Miss. Cient. VI, p. 19. 7 (1870).

Un individuo muy mutilado dcl Rio Colorado.

Esta especie tiene una distribucion gcográfica muy vasta, encontrándose en Colombia, Guatemala, Méjico, Misiones y Bucnos Aircs. En cstos dos últimos lugares fué observada por mí.

\section{BLATTA (PHYLLODROMIA) FUSCA SAUSS.}

SAUSS., Niss. Cient. VI, p. 28. 4 (1870).

Una larva, originaria del mismo lugar que la anterior, pertencce á esta especie, la que SAUSSURE habia recibido de Corrientes.

3. ISCHNOPTERA BRASILIENSIS Brenn.

Satss., Miss. Cient. VI, p. 55.3 (1870).

Una larva del Cármen de Patagones y un macho de la Sierra de Currumalan.

La especie es muy comun. Se encuentra en cl Brasil, cn la Banda Oricntal del Uru- 
guay y en muchas partes de la República Argentina. Los cuatros individuos que sirvieron á SAUSSURE para la descripcion, fueron recojidos en Bahía Blanca. Yo observé esta especie tambien en el Cármen de Patagones, en el año I874.

Fam. ACRIDIIDAE.

4. CEPHALOCOENA COSTULATA Burm.

Beru., Zeitschr. der Naturf. Gesell. Halle (1880).

Varias larvas del Rio Colorado, de Salinas Chicas, etc.

Esta especie es muy comun en toda la República Argentina.

\section{TRUXALIS BREVICORNIS (L.) BurM.}

STí, Rec. Orth. I, p. 104 (1878).

Un individuo de Nueva Roma. Abunda en todas partes, como la anterior.

\section{STENOBOTHRUS SIGNATIPENNIS (BLANC1.)}

Oedipoda signatipennis BuAxeн. en Gax, Hist. de Chile. Zool. VI, p. 79. o (1851).

Varios individuos del Cerro Blanco (F. Argentino), Nueva Roma y de Naran-Choyqué entre el R. Sauce y el Rio Colorado.

Se halla con frecuencia en Chile, en la Provincia de Buenos Aires, en la Banda Oriental del Uruguay, etc.

\section{LEPTYSML FILIFORMIS (SERV.) STAL.}

Stō., Rec. Orth. I, P. 85 (1873).

Una larva del Rio Colorado.

Tambien esta especie tiene una distribucion geográfica bastante vasta.

\section{DICHROPLUS VITTIGER (Blanen.)}

Acridiun vittigerum BLAxcu, en GaY, Hist. de Chile. Zool. VI, p. 78. 3 (1851).

Del Rio Colorado (Rincon Grande) y de Nueva Roma.

Abunda en toda la República Argentina, en Chile y en la Banda Oriental del Uruguay.

9. PEZOTETTIX (TRIGONOPIIMUUS) PUNCTULATUS (THLNB). STAL. STil, Rec, Orth. I, P. 77 (1873).

Del Rio Colorado. 
Se halla tambien en Buenos Aires y en el Cármen de Patagones, donde la observé en el año 1874 .

\section{ACRIdium (Schistocerca) Peregrindm (Olw.) Stal.} STí. Ree. Orth. I, p. 65 (1873).

Un individuo de Salinas Chicas.

Es nuestra Langosta migratoria, que se halla en muchísimas partes del globo terrestre, y que despues de Olivier (I794) ha sido descrita de nuevo varias veces.

Trataré detalladamente de esta cuestion en breve, en los "Anales de la Sociedad Científica Argentina".

\section{OMMEXECHA HORRIDA (Phir.)}

Graea horrida Phil. en Greb. et Siew. Zeitsch. f, d. gesammt. Naturwiss. XXI, p. 444 (1863).

Dos pequeñas larvas de los médanos de Salinas Chicas.

Se halla con frecuencia en las Provincias de San Luis y Mendoza; la he recibido tambien de Córdoba y de Catamarca.

Fam. LOCUSTIDAE.

\section{CONOCEPHALUS DISSIMILIS SERv.}

Serv., Orth. p. 518.4 (1889).

Una hembra del Cerro Nato (Rio Sauce Chico).

Lo poseo tambien de Chascomús. Los individuos corresponden bastante bien á la descripcion que da Serville, siendo de una coloracion testácea impura y verdosa. La faja negra del cono frontal es variable en cuanto á su extension.

Fam. GRYLLIDAE.

13. GRYLLOTALPA ClARAZIANA SaUss.

Sauss., Miss. Cient. VT, p. 346. 9 (1870) et Mé1. Orth. V, p. 193 (1877).

Una larva de Salinas Chicas.

SAUSSURE hizo su descripcion por individuos que había recibido de Bahía Blanca.

\section{GRYLLUS NITIDULUS STÁ.}

Sauss., Mél. Orth. V, p. 364.53 (1877).

Una larva, originaria del Cerro de Sotoya.

El ejemplar típico fué recojido por la Expedicion Sueca de la fragata "Eugenia", en Buenos Aires, donde la he observado tambien. 


\section{GRYLLODES PATAGONUS SAUSS.}

Sads, Miss. Cieot. IV, p. 421.15 (1870) ew Mel. Orth. V, p. 686. 21 (1877).

Dos individuos mutilados del Rio Colorado.

SAUssure se sirvió de cjemplarcs que le fueron enviados de Bahía Blanca.

\section{NEUROPTERA. \\ Fam. PAPHIDIADAE.}

16. MANTISPA DECORATA ERichs.

Hagev, Sya. Nearopi. p. 822 (1861).

Un macho del Rio Colorado.

El individuo típico es originario del Brasil.

Esta especie se halla tambien en las inmediaciones de Buenos Aircs y en Chascomús, pero es bastante rara.

\section{IIL. HEMIPTFIRA.}

Fam. PENTATOMIDAE.

\section{CIRTOMENUS CILIATUS Berg.}

L4 4. JI. Fig. 1.

Berri, Anal. Soc. Cient. Arg. V, 1. 234. 4 (1878) et Hem. A.g. p. 10. 4 (1879).

De esta especie fueron encontrados muchos individuos cerca del Rio Colorado, en la orilla de la laguna de Salinas Chicas, ctc., en parte ya mucrtos y descoloridos por cl sol. Apesar de habcr perdido muchos las espinas de la márgen anterior de la cabcza, han conservado, sin embargo, la mayor parte de las cerdas de las márgenes dcl pronoto $\mathbf{y}$ abdómen.

\section{CTRTOMENUS' CONSTRICTUS BerG.}

Mas: Sut latus, planiusculus, niivdus, nigro-piccus, antennis multo pedibusque nomihil pallidioribus; capite angusto, subconvexo, raliaim subrugoso, fylo medio sat elcvato, apice rolundato, jugis nonniluil brexiore, sulco ante marginem anticun valde spinoso et sctoso; antemis rostroque rufescenti- 
fuscis, illis articulis tribus terminalibus fere acque longis, hoc coxas modias vix attingentc; pronoto lcvissime convexo, transiersim haul impresso, antice laevi, pone medium et ad latera valde punctato, marginibus lateralibus pone melium anguste profunlissimeque sinuatis; seutello rude punctato; clavo corioque dense punctulatis; membrana sordida, subluyalina; margine abdominis longe setoso; ventre lacviusculo; pedibus rufesconti-fuscis, tibiis posticis obscurioribus, tarsis omnibus sordide testaceis. - Long. corp. 5; lat. cap. 1 1/4, pron. ant. $21 / 2$, post. $313 \mathrm{~mm}$.

Berg, Hem. Arg. p. 277. 358 (1879) et Anal. Soc. Cient. Arg. IX, p. 5. 358 (1880).

El macho, quc me sirvió para establecer esta especie característica por la escotadura dc la márgen latcral del pronoto, ha sido rccojido cerca del Rio Colorado.

\title{
19. MACROSCYTUS UMBONATUS Berg.
}

Bfrg, Anal. Soc. Cient. Arg. V, p. 288. 9 (1878) et Hem. Arg. p. 14. 9 (1879).

Un individuo descolorido de Salinas Chicas.

Es dc mucho intcrés saber, que esta e-pecie, que tenia solo de Catamarca y de Tucuman, se halla tambien en las regiones australes.

\section{THYREOCORIS PAMPEANUS BERG.}

\author{
LAM. II, Fig. 2.
}

Fem.: Ovalis, sat convexa, supra subtusque nigra, nitida, ubiquc grosse denseque punctata; capite perparum producto, rotuldato, ante oculos levissime simato, tylo antice et postice angustato, jugis vix breviore; rostro sordide testaceo, coxas posticas non attingente; pronoto subtransverso, marginibus lateralibus sat rotundatis, prope wargincm posticum anguste simuato; scutcllo apicem abdominis attingente; parte coriacca hemelytronem etiam punctata, ultra latera scutelli prominula et retrorsum fere acuminata; pectore meuloso, opaco; pedibus nigro-piceis.- Long. corp. 312 ; lat. $2 \mathrm{~mm}$.

Berg, Hem. Arg. p. 277. 359 (1879) et Anal. Soe. Cient. Arg. LX, p. 5.359 (1880).

Una hembra del Rio Colorado.

Esta especie, descubierta por el Dr. D. Adolfo Doering, es bien característica por el color negro uniforme y la abundancia de puntos muy undidos en todos los órganos.

\section{ACLEDRA MODESTA STAL.}

Berg, Anal. Soc. Cient. Arg. V, p 312. $60(1858)$ et IX, p. 9 (1880) et Hem. Arg. p. 51. 60 et $281(1879)$.

Fué encontrada cn muchos cjcmplarcs cerca dcl Rio Colorado, Salinas Chicas, ctc.

Se hallaba con frecuencia, segun el Dr. Doering, cn numerosos individuos mucrtos, en las orillas de la gran laguna de Salinas Chicas, donde habian sido juntados por las olas del agua salada. 
Fam. COREIDAE.

\section{LEPTOGLOSSUS INPICTUS StaL.}

Berg, Anal. Soc. Cient. Arg. VI, 1. $88.88(1878)$ et Hem. Arg. p. 72. 88 (1879).

Un individuo del Paso de Alsina cerca del Rio Colorado, que es bastante claro en su coloracion.

\section{MARGUS PALLESCENS Sín.}

Berg, Anal. Soc. Cient. Arg. VI, 1. 137. 101 (1878) et Hem. Arg. p. 81.101 (1879).

Un individuo de la laguna de Salinas Chicas, que no ofrece ninguna particularidad.

\section{IIARMOSTES PROCERUS BERG.}

Berg, Anal. Soc. (ient. Arg. HI, 1. 185. 116 (1878) et Hem. Arg. p. 91. 116 (1879).

Dos individuos de Salinas Chicas y del Fuerte Argentino.

He recibido últimamente ejemplares de esta especie de Chacabuco, que son de color fusco-rojizo claro, teniendo la parte anterior del pronoto, el escudillo y la márgen costal de los hemélitros de un verde manzano.

\section{Fam. LYGAẼIDAE.}

\section{ISCHNODEMUS STALII SIGN.}

Berg, Anal. Sor. Cient. Arg. VI, 227. 130 (1878) et Hem. Arg. p. 104. 130 (1879).

La hembra originaria del Rio Sauce Chico (Nueva Roma), es mas oscura en la coloracion general, que los individuos bonaerenses.

\section{Fam. CAPSIDAE}

25. CAPSUS (DERAEOCORIS) FRALDULENTUS (S'TAL) BERt. Berg, Anal. Soc. Cient. Arg. VI, p. 270. 149 (1868) et Hem. Arg. P. 120. 149 (1879).

Del mismo lugar que la especie anterior y observado en un solo individuo.

\section{CAPSUS (DERAEOCORIS) FRATIRUELIS BER.}

$$
\text { L.is. II, Fig. } 3 .
$$

Ias et Fem.: Laeta unt obscure picei, subopaci, puberuli, subtilissime punctulati, antennis sordide pedibusque pallide flavescenti-testeccis; capite postice trauseersin depresso et medio longitrorsum subtiliter sulcato; antenuarem articulo secundo primo plus quam duplo vel triplo fore longiore, articulo tertio primo vix dimidio longiore; rostro mejo, eaxas posticas paenc attingente; pronoto an- 
tice quam postice dimidio angustiore, subdeclivi; scutello hemelytrisque concoloribus, horum appendice nigricanti, membrana fuscescenti; pectore ventrcque piceis; pedibus flavidis, tibiis tarsisque nonnitil obscurioribus. - Long. 4-4 12; lat. $11 / 2 \mathrm{~mm}$.

Berg, Hem. Arg. p. 289. 372 (18r9) et Anal. Soc. Cient. Arg. LX, p. 17. 372 (1880).

Los dos individuos, que me sirvieron para establecer esta especie, fueron encontrados cerca del Rio Colorado.

\section{RESTIIENIA PALLIDA BERG.}

Lís. II, Fïg. 4 .

Mas et Fem.: Elongati, sordide flavescenti-testacei, pubcruli, vitta modia capitis vittisque tribus subobsoletis pronoti et scutelli virescenti-flavidis, pectore abdomineque saepissime fuscis; capite sat magno, antice obtuse rotundato; antennis corpore multo longioribus, articulo primo longiusculo, incrassato, fusco-tuberculato, articulo secundo primo quasi duplo longiore, articulo ultimo tertio quarta parte breviore; rostro coxas posticas valde superante; pronoto antice quam postice dimidio angustiore, margine postico vix sinuato; vitta media scutelli distincta; corio al suturam obsolete fuscescenti-adsperso, apice ipso in medio maculis duabus parvis obsolete fuscis ornato; membrance femoribuspue postieis fusco-adspersis vel irroratis.-Long. 4-5; lat. $113-112 \mathrm{~mm}$.

Berg, Hem. Arg. p. 291.375 (1879) et Anal. Soc. Cient. Arg. IX, p. 19. 375 (1880).

Tambien esta especie fué fundada valiéndome de individuos, que recojió el Dr. DoERING en el Rio Colorado y Salinas Chicas.

\section{RESTHENIA UNIVITTATA BER.}

Ias et Fem.: Atri, vix sericei, dense ct obsolete punctulati, vitta pronoti et scutelli marginibusque partis anticae pectoris saturate arrantiacis; capite brevi, declivi; articulo primo antennarum capite pronotoque ad unum aequilongo, articulo secundo primo plus quam dimidio longiore; rostro coxas intermedias vix superante; pronoto antice quam postice tertia parte angustiore, nargine postico angulato-sinuato; scutello transversim rugoso.-Long. 6-7; lat. $11 / 2-134 \mathrm{~mm}$.

Berg, Hem. Arg. p. 291. $876(1379)$ et Anal. Soc. Cient. Arg. IX, p. 19. 376 (1880).

De los mismos lugares como la especie anterior y traida por la misma persona.

Esta especie es bien característica por la línea media amarilla, que se extíende desde la parte anterior del pronoto hasta el ápice del escudillo.

\section{Fam. SaldidaE.}

\section{SALDA ARGENTINA BERG.}

Mas et Fem.: Oblongo-ovales, nigricantes, subuitidi, flavo-sericei, antcnnis femoribusque rufcsccntibus, aul partem obscure fuscovaricgatis, hemelytris tibiisque maximam partem albidis, his clavo maculisque tribus costalibus nigris, aut apice capitis, antennis, apice articuli secundi antennarum excepto, oculis ad partem, margine laterali mellio pronoti, macula apicali clavi, corii dimidio exteriore, maculis tibus costae exceptis, membrana pedibusque magnam ad partem, nec non apicc abdominis, rufescenti-albidis vel lutesconti-testaccis; articulo tertio antennarum articulo secundo tertia parte 
longiore, fusco, parum incrassato: rostro nigro, basi luteo; pronoto medio anguste transversim impresso, margine postico late sinuato; maculis tribus nigris costae hemelytrorum maculaque subapicali membranae distinetis; membrana fisco-venosa, areolis medio infiescatis, areola intermedia cellula minuta apicali instructa; pectore ventreque, hoe apice excepto, nigris; pedibus sordide testaceis, al partem offuscatis aut sordide albilis, fusco-maculatis $v$ cl subfaseiatis, tibiis basi apiceque et articulis primo basi terminalique apice nigris.--Long. 3 1,2-4; lat. 1 1,3-1 1,2 mm.

Berg, Hem. Arg. p. $293.879(1879)$ et Anal. Soc. Cient. Arg. IX, p. 21. 379 (1880).

Del Valle del Rio Colorado.-El individuo traido es algo mas claro que los que poseo de la Provincia de Buenos Aires.

\section{Fam. NABIDAE,}

\section{CORISCL'S PUNCTIPENNIS (BLANCH.) STÅL.}

Berg, Anal. Suc. Cient. Arg. VII, p. 86. 175 et Hem. Arg. p. 143.175 (1879).

Este hemíptero, que abunda mucho en la República Argentina y en Chile, sobre todo en Valdivia, fué traido de Salinas Chicas y del Fuerte Argentino.

\section{Fam. REDUVIIDAE.}

\section{Conorinnds infestans (Kugg) Phir.}

Berg, Aual. Soc. Cient. Arg. III, P. 266. et Hem. Arg. p. 165. 202 (1879).

Esta especie, conocida de todos bajo el nombre vulgar de Tinchuca, fuć recojida en la barranca cerca del Fuerte Argentino y en el Rio Colorado, donde vivia bajo piedras, viejos troncos, etc.

Una de las larvas traidas se conservaba viva durante ocho meses en el cartucho de papel, sin recibir alimento de alguna clase, teniendo pues una resistencia vital, análoga á la de la chinche lectularia.

\section{Fam. BELOSTOMIDAE.}

32. ZAITIIA ELEGANS MATr.

Berg, Anal. Soc. Cient. Arg. VIII, p. 31. 230 et Hem. Arg. p. 191. 280 (1879).

Un individuo de esta especie fué traido de Salinas Chicas-.Este hemíptero acuático es muy comun en la República Argentina.

\section{Fam. Notoncetidae.}

\section{NOTONECTA VARIABILIS FIEB.}

Berg, Anal. Soc. Cient. Arg. ITII, p. 75. 288 et Hem. Arg. p. 197. 238 (1879).

Esta especie fué encontrada en los brazos del Rio Negro, con agua estancada, cerca de Chocl-Choel. 


\title{
$-85$ \\ Fam. CORISIDAE.
}

34. CORISA FORCICEPS Sin.

Berc, Anal. Soc. Cient. Arg. VIII, p. 78. 242 et Hem. Arg. p. 201. 242 (1879).

De este hemíptero acuático fué observado un indivíduo en el mismo lugar, que la especie precedente.

Fam. JASSIDAE.

\section{TETTIGONIA DOERINGII Berg.}

LAM. II, Fig. 5.

Nas et Fem.: Nigri, punctulati, capitc, pronoto, lateribus pectoris scutelloque flavo-maculatis, abdomine flavo-marginato, ventre flavo-lineato, tegminibus pedibusque rubro, nigro flavoque varicgatis; capite obtuse producto, rotundato, lineis plurimis ct maculis nonnullis sulphureis ormato; fronte tu mida cum genis maculis sulphureis parvis ornata (naculis disci intcrdun minutis vel obsoletis); clypeo subgibbo, flavo-maculato; pronoto antice subfoveolato, flavo marginato et maculato, maculis ceteris in series qunque longitudinales irregularcs dispositis; scutello flavo quinquemaculato, apice ipso quoquc flavo: tegminibus variegatis: venis magnam ad partem flavidis, areolis clavi ct disci nigris, areolis reliquis margineque costali rubris, limbo hyalino, mecscenti-vcnoso; alis fuscescen. tibus, apice subhyalinis; dorso abdominis nigro, late sulphureo-marginato; ventrc flavo-qualrilincat femoribus nigro flavoque lineatis, posterioribus apicc rubris; tibiis mbris, interdum flavo-lincatis, anterioribus supra planiusoulis; tarsis rubris.-Long. $7-8$; lat. cap. 2 , pron. $13 / 4 \mathrm{~mm}$.

Berg, Anal Soc. Cient. Arg. VIII, p. 248. 317 et Hem. Arg. p. 252. 317 (1879).

Esta especie descubierta por el Dr. Doering en la Sierra de Córdoba, fué encontrada de nuevo por el mismo en el valle del Rio Colorado.

\section{TETTIGONIA CAPITANEA BERG.}

\author{
LaM. II, Fig. 6.
}

Mas et Fem.: Obscure fusci aut nigro-picei, grosse punctati, capitc, pronoto scutclloquc crebrc flaro-maculatis, pectore abdonineque flavo-marginatis, tegminibus sordide et dilute rubris, albido-conspersis vel punctatis, pedibus rubro, flavo nigroque variegatis; capite sat producto, apice subrotundato, medio transversim impresso, maculcolis plurimis flavis lineaqne mcdia subobsolcta ornato; fronte crebre flavo-maculata, apice nigra; clypeo parum gibbo, nigro, ad basin utrimque flavo-maculato; pronoto anticc foveolato, rude punctato et densc flavo-maculato; scutello medio impresso, flavo-maculato; tcgminibus apice subhyalinis; alis fuscescentibus aut nigricantibus; abdomine piceo, flavomarginato, segmento ultimo flavo-adsperso; femoribus rubris, nigro flavoque lincatis; tibiis mifs, saepissime flavo-lincatis; tibiis anticis supra lovissime et angustc sulcatis.-Long. 10-11; lat. cap. 3 , pron. $21 / 2 \mathrm{~mm}$.

Berg, Anal Soc. Cient. Arg. VIII, p. 250. 320 et Hem. Arg. p. 255.320 (1879).

Esta Tettigonia se encuentra tambien en Buenos Aires y en Chacabuco; fué observada en el último lugar por el Sr. D. FÉLIX LiNCH. 
37. ATIITSANUS DESERTORUM Berg.

IAM, II, Fig, 7.

Mas: Densissime punctulatus, capite, fronte, pronoto tegminibusque sordide flavillis, obsolete fusco-irroratis, maculatis vel indistincte fasciatis, genis, pectore, dorso abdominis ventreque coerulescentinigris, pedibus-fuseis, flavido-naculatis; capite pronoto vix latiore, modicc rotundato, postice infuscato, antice utrimque linea marginali fusca ornato; fronte obsoletissime infuscata; loris medio impressis; pronoto capite vix dimidio longiore, transversim striolato, fere fusco, flavido maeulato; seutello punctulato, pone medium impresso, vittis duabus apieeque flavescentibus; tegminibus rugulosis, fluvidis, clavo discoque infuscatis, apicem versus imegulariter fusco-fasciatis; alis hyalinis.Long. coip. cum tegm. $21 / 4$; lat. $2 / 3 \mathrm{~mm}$.

Berg, Anal. Soe. Cient. Arg. VIII, 1. 262. 342 et Hem. Arg. p. 267. 342 (1879).

Es la especie mas pequeña de esto género que conozco y un solo individuo de la cual fué traida de Salinas Chicas.

\title{
38. DELTOCEPIIALUS VARIEGATUS BEIG.
}

\author{
LAM. II, Fig. 8 .
}

Mas et Fem.: Testacei, sat nitidi, capite, fronte, pronoto, scutello tegminibusque fiesco alboque variegatis, dorso abdominis, connexivo marginibusque exceptis, nigro, ventre sordide tistaceo, ad partem infuscato; capite pronotoque ante nedium modice transwersin impresso, illo apice subangulato-rotuntato, apice ipso albido, utrimque linea angulata nigra ornato, medio utrimque fusco-maculato, disco albido-bivittato, margine postico medio macula nigra praedito, hoc capite paullo longiore, indistincte ruguloso-punctulato, fuscescenti, albido-irrorato, antice interlum fusco-limaculato, margine postico leviter late sinuato; seutello luteo, obsolete albido-bivittato, apice saepissime ftacescenti vel albido, medio nonnumqum fusco-bimaculato; venis areolisquc clavi et disci tegminum fuscis, his albo-maculatis, maculis tribus partis posterioris costae nigricantibus; tibiis posticis nigro-tuberculatis. Long. corp. cum tegm. 4-5; lat. pron. 1-1 $14 \mathrm{~mm}$.

Berca, Anal. Soc. Cient. Arg. VIII, p. 264. 345 et Hem. Arg. p. 269. 345 (1879).

Los individuos que poseo de esta especie son originarios de Buenos Aires, del Baradero y del Rio Colorado. Del último lugar la trajo el Dr. DoERING.

\section{DELTOCEPIIALUS GENTILIS BERG.}

$$
\text { LAM. II, Fig. 9. }
$$

Mas: Sordide vel dilute rufescenti-testacens, meulis dubub basalibus capitis, lineolis transversis lateralibus frontis, maculis nonullis subobsoletis partis anticae pronoti, unbraculis seutelli, areolis tegminum maximam ad parten, pectore, abdomine ad partem, femoribus anticis et mediis basin versus, nec non vittis obsoletissimis femorum posticorum, fuscis vel vigricantibus, marginibus vittisque tribus scutelli et venis tegminum flarido-albidis, areolis tegminum omnibus fore albido-maculatis; capite brevi, vix producto, wargine antico postico fere parallclo, ante apicem subtilissime transversim impresso, toto subtiliter ruguloso-punetulato; fronte dense punetulata, flarida ntrimque fusco-lineata; pronoto capite dimidio longiore, transversim ruguloso, antice indistincte punctato, 
margine postico leniter simuato; scutello ante medium punctulato, parte postica elevata, rugulosopunctata; alis hyalinis, fuseeseenti-venosis; dorso abdominis fuscescenti, connexivo marginibusque scgmentorum pallidioribus; ventre sordide testaceo.-Long. corp. cum tegm. 413 ; lat. $114 \mathrm{~mm}$.

Bers, Anal, Soc. Cient. Arg. VIII, p. 265. 846 et Hem. Arg. p. 270. 346 (1879).

Esta bonita especie, característica por los nervios y las manchas blanquizcas de las alas superiores, fué descubierta por el Dr. Doerixg en Salinas Chicas.

\section{DELTOCEPIIALUS VENOSULUS Berg.}

Lix. II, Fig. 10.

Yas et Fem.: Albido-testacei, maculis quattuor obsoletis anticis, fascia media obliqua, medio interrupta, maculisque duabus aut quattuor posticis capitis, maculis obsoletis pronoti, punctis duobus scutelli, venis lineolisque transversis tegminum luteis vel laete fuscis, pronoto medio interdrm pedibusque semper nigro-maculatis; capite postiee subtilissime longitrorsum et antice distincte oblique striolato, margine antico subangulato-producto, oblique ascendente; fronte punctulata, magnam ad partem fusescenti, utrimque favido-striolata, ad apicem cum elypeo Alavido-alba; pronoto capite paullo longiore, obsolete mguloso, antiee laeviuseulo; seutcllo pone medium rugoso; tegminibus creberime fuscescenti-rctieulatis; alis subhyalinis; scgmentis dorsi abdominis rarissime medio offuscatis; femoribus distincte ct tibiis obsoletc nigro-maculatis--Long. corp. cum tegm. 6 ; lat. pron. 11.2mm.

Berg, Anal. Soc. Cient. Arg. IIII, p. 266. 348 et Hem. Arg. p. 271. 348 (1879).

Del mismo lugar y descubierta por la misma persona.

Esta especie se distingue de las demas congéneres por el mayor tamaño, por la márgen anterior de la cabeza ascendente y por las alas superiores reticuladas.

\section{TYPILOCYBA SALINARUM Berg.}

Fem.: Capite, fionte, pronoto, scutello, dorso abdominis femoribusque maximam partem saturate aurantiacis, vitta melia maculisque duabus antico-sublateralibus eapitis, lineolis obsoletis brevibus lateralibus frontis, vitta media pronoti scutellique flavido-albis, marginibus venisque tcgminum late viridibus icl glaucescentibus, pedibus, dimidio basali femorum excepto, viridibus; eapite subrotundato; ocellis distinctis, fulvis; fronte lineis duabus apiccm versus conjunctis obsolete fuscis ornata; pronoto antice obsoletissime albido-maculato, margine postico sat profunde sinuato; tegminibus areolis apicalibus? instructis, clavo venis destituto; alis vitreis.-Long. corp. cum tegm. 4; lat. pron. $34 \mathrm{~mm}$.

Berg, Anal. Soc. Cient. Arg. VIII, p. 269. 358 et Hem. Arg. p. 274. 358 (1879).

Tambien esta especie nueva fué recojida en Salinas Chicas. 
I V. DIPT T R A. (1)

NEMATOCERA.

Fam. CHIRONOMIDAE.

\section{CHIRONOMUS PROXIMUS E. Lch. A., n. sp.}

Few Thoraci virescenti, cano-pruinoso, vittis tribus ferrugineis; alis nudis, albis, nervulo transterso fuseo; pedibus virescentibus, tibiis articulisque basalibus tribus tarsorum fusco-terminatis, metatarso antico tibia ejusdem paris dimidio longiore; abdomine nigricanti, incisuris cinerascenti-albis. - Long. corp. 7 .; exp. al. $11 \mathrm{~mm}$.

Palpi fusci; antennae virescenti-tcstaceae, articulo ultimo infuscato. Thorax pallide virescens, cano-pruinosus; mesonotum vittis tribus ferrugineis, nedia dimidium antienn occupante, a linea obscuriore, postice latiore, subfusca et usque ad suturam scuto-scutellarem cxtcnsa, longitudinaliter divisa, lateralibus maculiformibus, postice attematis, dimilio postieo sitis; metanotum fermgineum vel fuscum, sulco nedio virescenti; pleurae parum fernginae; mesosternu piceum; alae nudae, albae, hyalinae, venis pallide testaeeis, nermulo transverso fusco; halteres flavidi; pedes pallide virescentes, albo-pubescentes, fomoribus infra parce albo-pilosulis, genibus levissime ferrugineo-tinctis, tibiarum atque tarsorum articulorum basalium trium summo apice fusco, corum articulis duobus ultimis infuseatis, tibiis anticis femoribus cjuslcm paris paululum brevioribus, metatarsis ejus dimidio longioribus. Abdoncn fuscum vel nigricans, ubique cano-scriceo-pruinosum et albo-villosum, marginibus posticis areum dorsalium 1-5 tcstaceis.

Un ejemplar muy destruido procedente de lasorillas del Rio Colorado. La descripcion la he hecho sirviéndome en parte de este y en parte de otro, cazado en Chacabuco por mi hermano.

Pcrtenece al grupo del Ch. plumosus (L.) Meig., del cual se encuentra bastantes especies en América. Difiere del Ch. brasiliensis Wied., del Ch. cristatus F. y del Ch. stigmatcrus SAY (Ch. glaucurus WiED.), especies amcricanas á las que se acerca mucho, por el color del abdómen, qne en cstas es, por lo ménos en los machos, amarillento rojizo; como no se ha descrito sinó el macho de la primera y de la última de estas espe cies, hay razon para sospechar, que la nuestra es simplemente el otro sexo de una de ellas, sin que á ello obste lo lejano de las comarcas en que respectivamente han sido encontrados, pues conocemos ya varios dípteros que se hallan esparcidos desde NorteAmérica luasta estos países.

(1) La parte diptérológica de esta obra ha sido preparada y redactada por mi amigo Exroqe Lrxí As insakizari, quien, ocupandose de algun tiempo a esta parte del estudio de los Dipteros que habitan en la Ropublica Argentina, y en posesion del material bibliografico necesario para ello, ha aceptado, á pedido mio, lib ejecucion de esta tarea. 
BRACHYCERA.

Fam. STRA TIOMYIDAE.

43. Nemotelus Fasciatifroxs E. Ler. A., n. sp.

Fen. = Nigra nitida; epistomate modice producto; antennis super basin cjus insertis; fronte fascia alba. medio interrupta, ornata; mesonoto abdomineque utrimque anguste flavescenti-limbatis; alis limpidis, venis pallide testaceis; halteribus flavescentibus, basi fusca; pedibus nigris, genibus extense tibiisque anterioribus omnino Alavo-testaccis, tursis flavescenti-albis.-Long. $5 \mathrm{~mm}$.

Caput nigrum, nitichem, sparsim punctulatum, punctulis brevissime piliferis, pilis flavescentibus: frons lata; epistoma productum, sed fronte multo breviore, subhorizontale, apice obtuso et leviter deorsum incurvo; frons antice, prope antenuas, utrimque triangulo transverso, elongato, eburneo, ornata; antennae piceae, articulo tertio interstitiis segmentorum albido-pruinoso, stylo . . . (deest); proboscis ut videtur retracta. Thorax niger, nitidus, ubique ut capite punctulatus et villosulus, mesonotum carinula laterali, ab humeris usque al alas extensa, sordide flevescenti-alba instruetum; alae limpidae, venis cellulaque subcostali pallide flavo-testaceis; halteres flavescentes, clava albida, basi fusca; pedes nigro-picei, albido-pubescentes, femorum tibiarumque posticarum apice nec non tibiis antic is et intermediis flavo-testaceis, tursis flavescenti-albis, unguibus piceis. Abdomen nigrum, nitidum, thorace parcius punctulatum et flavescenti-villosulum, segmentis 2-5 utrimque anguste favescenti-limbatis, ventre segmento secumlo macula media basali, transversa, sordide albida praedito.

Aseméjase al N. nigcr, de Chile, últimamente descrito por Bigot (Ann. Soc. Ent. Fr., s. 5, IX, p. 233, 3. I 879), pero este tiene las tíbias anteriores é intermedias testáceas sólo en la base y en el extremo, como las posteriores, y los tarsos pardos en el ápice, y, además, su descripcion no indica ni línea blanquizca en los lados del mesonoto, ni márgen amarillenta en el abdómen, caracteres que el autor señala en su especie siguiente (1. ruficomis BiG.).

Fam. oestridae.

4t. Rogenilofera grandis (Gúr.) Beric. BERG, Stett. Ent. Zeit., 268 (1876).

Sobre el Hesperomys flavesccns Waterh.

\section{Fam. MUSCIDAE.}

A. CALYPTERAE.

Subfam. SARCOPHAGINA.

45. SARCOPIHAGA FLAVIFRONS Mace.

S. flavifrons Mace., Dipt. exot., Suppl. 1, p. 191. 21 (18t6).-Buascr. in Gar, Hist. (hile, Zool., VII, p. 428. 1. lám. 5. fig. 4 (1852).

S. truncata Schr., Nov, Reise. Dipt., p. 814. 66 (1868).

Esta Sarcophaga, que entraría en el género Myophora R. D. (Ess. Myod. p. 327) 
si este fuese aceptado, es la mas comun en esta provincia; durante la primavera, acude en gran número á las flores del Ammi visnaga y otras Umbelíferas.

Macquart la describió, bastante imperfectamente por cierto, como del Brasil; BLANCHARd y Schiner la han señafado en Chile, de donde el Dr. Berg la ha traído últimamente; el Dr. DoERING recogió un ejemplar femenino durante la expedicion al R. Negro.

\author{
B. ACALYPTERAE.

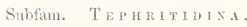

46. ACINIA ETFA Mace.

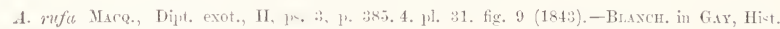
Chile, Zool., VII, 1. 460. 8 (1852).

Tephritis meleagris ScHux., Nov. Reise. Dipt., 1).272. 122 (1868).

Un espécimen, en nuy mal estado, capturado en una salina, pertenece á esta especie, hasta ahora hallada solamente en Chile.

\title{
47. AMETHYSA INTERMEDIA E. Lcir. A., n. sp.
}

A. Macquartii (Lrophora aenea, Macr.) et prophinque Schin. maxime affinis, sed differt prima a pedibus nigris et secunda a fascia obscura tertia alarum cum quarte s. apicali antice conjuncta.-Long. maris 3, feminae $\pm 1: \mathrm{mm}$.

Caput obsolcte albo-pruinosum; frons obscure fernginea, nigro-setosa; vertex epistomaque viridinigra, nitilla; antonnae ferrugineac, articulo tertio cum stylo fusco. Thorax virili-niger, leviter chalybescens, interdum parum auratus, obsolete albo-pruinosus, breviter nigro-sctulosus, nigrosetosus; pedes nigro-picei, nitidi, brevitor nigro-setulosi, femoribus anticis cxtus viresccntibus, trochanteribus genibusque perparum ferrugineis, metatarsis posterioribus testaceis; alae limpidae, venis fuscis, fusciis quatuor nigro-fuscis ornatae, prima subbasali, sucunda omnibus latiore, completa, inter basin et nervulum transversum primum sita, isto contigua, postice ampliata et multo dilutiore, margine postico alae cum sequenti anguste conjuncta, tertia quoque completa, nevulum transversum sccundum includcnte, al narginem costalem cum quarta anguste conjuncta, quarta apicali; halteres ferrugineis. Ablomen nigrum, nitidum, breviter nigro-setulosum.

Esta especie, de la cual tengo á la vista tres ejemplares, procedentes del Rio Colorado, se acerca mucho á las A. Macquartii y propinqua Schns., pero la primera ticne las patas de un pardo leonado", segun MACQUART, y en la segunda las dos últimas fajas alares no se unen en el borde anterior.

Fam. HIPPOBOSCIDAE.

48. ORNithonita STAallaxidis E. Len. A., n. sp.

Pieea, nitida; capite supra rubro-testaceo, utrimque carina depressa, nigro-setosa, posticcque spatio ocellari piceis; mesonoto lincola longitudinali flara; alis modicc ct uniformiter infumatis; femoribus infra stcrnoque virescentibus.-Long. $41.2 \mathrm{~mm}$. 
Caput supra rubro-testacenin, utrimque carina depressa, nigro-setosa, posticeque spatio ocelligero piceis, nitilis, infira sorlile virescenti-tcstacent; os nigvo-setosum, labro, bulbo rostrifero lobisque lateralibus albidis, his basi margineque externo palpisque piceis, nitidis, rostro flavescenti. Mesonotum angulis anticis productis, sulculo medio instructum, sutura satis profunda, medio interrupta, utrinque et postice nigro-setosum, picen, nitidum, humeris lateribusque sordide vivescentitestaceis, lincola media flara, in acersn paululatim ampliata guttulisque duabus subobsoletis, coloris humerorum, prope marginem anticum sitis, ornatum; scutellum piccum, nitidun, transversin striatum, sulculo medio, postice in depressionem latam dilatato, munitum, margine nigro-setosum; pleurae piceae, witide; stermu sordide virescenti-tcstaceum, nitidum; pedes picei, nigro-setosi, fenoribus infia coxisque ut stemo, sed illis virescentioribus, tarsis anterioribus quoque parum virescenti-testaceis, ungribus nigro-piceis; alae uniformitcr infumatae, sed hyalinae, venis piceis, costali nigro-sctulosa, basi-rirescenti; halteres fuscescentes, clava alba. Ablonen fiesco-virescens, nigro-setulosum et setosum.

Se asemeja bastante á la O. erythrociphala LEACH, y á la O. parza MACQ.; sin embargo, me decido á considerarla como diferente, pues en las descripciones de estas e pecies no se menciona la línea del mesonoto, que es bastante visible, y, ademas, LEACH llama amarillo (luteum ) el color del abdómen de la primera y Macquapt dice de las alas de la segunda que son un poco amarillentas?, sin indicar el color de humo que se observa en las de nuestra Ornithomyia.

Esta fú descubierta por el Dr. Doerixg, á mediados de Mayo, sobre una Synallaris [Bathmicerrus] patagonica (LAFR.) GRAT.

\section{IEPIDOPTERA.}

\section{Fam. pieridae.}

\section{PIERIS AUTODICE II.}

Burs., Descript. phys. de la Rép. Arg. V, p. 88, 10 (1878).

Del Rio Negro y del Fuerte Argentino.

Un individuo representa una variedad muy oscura, teniendo ciertas homologías con la Picris Demodice BLanch.

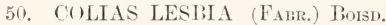

Burm., Descript. phys. de la Rép. Arg. V, p. 95 (18:8).

Un individuo del Cerro Blanco, dos leguas al N. del Fuerte Argentino. 


\section{i1. EUTEMA DEVA IOYн.}

Terias Agare (Fum Boisp., Bers.

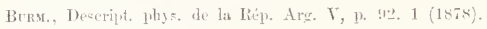

Estc lepidóptero fué traido de Salinas Chicas y corresponde perfectamente a ha individuoz colcccionados en Bucnos Aircs.

Fum. PSYCHIDAE.

52. OECETbCUS GEYERI Beri.

Brnm. Deseript. phys. do lin Reip. Arg. Y, p. 402. 2 (187x).

Dos habitáculos, que pertcneccn á la oruga de esta espccie, fueron encontrados en el valle del Rio Colorado.

\section{Fim. Saturniadae.}

53. DIRPIIL LATTA IBER, 11. -1.

1.ix. II, Fig. 11.

Ma-: Corpore pitis longis ochraceis vel lurilis dense restito, alis partm squanosis, sordide albulis; antennis sordide orfurnceis: eapite. pulpis pectoreque dense pilosis, ferc fulcis, pilis thoracis ad partem canesentibus; marginibus anterioribus segmentorum abdominis perparum infuscatis: margine costali alarum anticarum subtus obsolete flatido; pedibus luteis, femoribus valde villoso-pilosis, tibiis tarsisque pilis canis parce vestitis.-Long. corp. 20: long. alae ant. 28 mm.

Esta nueva especie, encontrada cn los saucedalcs del Rio Negro, cerca de la Balclieta, se distingue bien de las demas congéneres por las alas blanquizcas, que llevan pocas escamas y carecen de fajas ó líncas, y por el cucrpo muy vclludo, quc es de color ocre mas ó ménos, teniendo el abdómen las márgenes anteriores de los segmentos algo oscuros.

Fam. NOCTUIDAE.

\section{LEUCANIA EXTRANEA GEEN.}

Berc, Actas de la Acad. Nitc. I, p. 80. 26 et Bull. Soc. Fmp. des Nat. Yoscom. XLIX, 4, p. 216. $26(1875)$.

Fuć recogida cerca de Nueva Roma (Rio Sauce Chico). Esta especie cs muy comun en cl Rio Negro.

\section{PELAMIA PIIASIANOIIES GIEN.}

Berri, Actas de la Acad. Nac. I, p. 85.39 et Bull. Soc. Imp, des Nat. Moscou. XlJA, 4, p. 222. $33(1875)$.

De csta especic fué traido un individuo de Salinas Chicas. 
Anotacion.-Mi Pelania Tihuelcha es sinónimo de la Pelamia muica (Ferd. et Rogenh.). La sinonimia y bibliografía de esta especie es la siguiente:

Pelamia runiea (F. et R.).

Euclidia nuica Feld, et Rogesh., Nov, Lepid. Atlas Heteroc. Tab. CXVII, fig. 11 (1874): sine descript.

Euclidic Telurelcha Berg, Actas de la Acad. Nac. I, p. 84.32 et Bull. Soe. Imp. des Nat. Moscou. XLLX, 4, p. 221. 32 (1875).

Pelamia Tehuelcha Berg, Anal. Soc. Cient. Arg. IV, p. 205. 18 (1877).

Fam. GEOMETRIDAE.

\section{GLAUCOPTERYX TEPIDATA (GUEN.).}

Lix. II, Fig. 12.

Teplrosia undularia Blaxce, in Gix, Hist. de Chile. Zool. VII, p. 93.1 (1852).

Laventia tepidata Guen., Geom. II, p. 281. 1362 (1857). - Walk., List. Geom. p. 1188. 47 (1862).

De esta cspecie fueron coleccionados dos individuos en Nueva Roma.

Por la descripcion que da BLANCHARD, no es posible reconocer esta especie, habiendo estado muy mutilados los ejemplares que tenia. Mucho mas aceptable es la de GuEnÉ, quién cambió el nombre, por haber otra undularia en este género.

Los individuos recojidos por el Dr. DOFRING, son muy pequeños y han perdido un gran números de escamas; pero, comparándolos con un dibujo del Dr. Philippi y la descripcion de Guenée, resultan idénticos. Me tomo la libertad de publicar la figura hecha por el Dr. Philippi, para facilitar el reconocer esta geómetra y evitar descripciones largas. Solo debo advertir que los puntos oscuros de las alas posteriores faltan por completo en algunos individuos.

Fum. TINeIDAE.

57. LINDERA TESSELlatella BLANCH.

Berg, Actas de la Acad. Nac. I, p. 94. 48 et Bull. Soc. Imp. des Nat. Moscou. Xli, , 4, p. 236. 48 (1875)

Esta polilla muy comun en la Provincia de Buenos Aires al Sur, fué traida del Rio Colorado. 


\section{COLFOPTERA.}

Fam. CICINDELIDAE.

58. CICINDELA ATIATA DE.

DE.1., Spec. I. p. 86. To (1825).

De esta espccie fué traido un individuo muy mutilado de la Isla de Choelechoel.

Esta cicindela tiene una distribucion geográfica muy vasta, encontrándose desde el Brasil meridional hasta el Rio Negro en Patagonia. y ha sido observada en casi todas las provincias de la Rcpública Argentina, y enumerada por todos los viageros científicos, etc.

Fam. CARABIDAE.

\section{CALOSOMA BONARIENSE DEJ.}

DE.J., Spec: V, p. 560. 19 (18:1).

Un individuo del Rio Colorado.

Tiene tambien una distribucion muy ámplia y es mucho mas comun que la especie precedente. Todos los años, principalmente en cl mes de Noviembre, aparece este insecto en gran número en las calles de Buenos Aires, atraido por el pampero, despues de haber reinado una temperatura elevada. Sobre este tenómeno ya han tratado SteinheiL y Strobel (Atti della Soc. Ital. di Sc. Nat. XII, I, p. 240.-1869); Burmeister (Stett. Ent. Zeit. XXXIII, p. 227.-I872) y cl autor (Anal. Soc. Cient. Arg. V, p. 313.-1878 et Hem. Arg. p. 52.-1879).

\section{MIMOdronits nigro-FAsciatus (Sot.) Reed.}

Peed, Proc. Zool. Soc. 1874, p- 68.

Un individuo traido del Rio Colorade, corresponde bien á las descripciones dadas por Sor.IER (GAy, Hist. de Chile, Zool. IV, p. I35. I. lám. I, fig. 7 y 9.-1849), representando la variedad, en la que la mancha ó faja testácea sub-basilar de los élitros se extiende en el medio y en el borde costal hasta la base, encerrando una pequeña mancha alargada de la coloracion general de los élitros.

Anotitcion,--Solier habia puesto esta especie en el géncro Calleida, REeD la ha pasado al Mimodromius, é indica el cuarto artejo de los tarsos como "Sharply emarginate but not bilobed", y de acuerdo con nuestro individuo, miéntras que Chavioir propone la formacion de un nuevo género bajo cl nombre de Callidula (Ann. Soc. Ent. Belg. X1X, p. 109-1876), fundado 
principalmente en el cuarto artículo fortement bilobée. El ejemplar de CHAUdoIR ¿̨no representa talvez otra especie ó género?

61. ANISODACTTLUS CUPRIPENNIS (Gers.) Lac.

Lac, Gen. I, p. 279, nota 3 (1854).-Sterxir, Atti della Soc. ItaI. di Sc. Nat. XII, 1, p. 244. 25 (1869).-E. Lен. A., Nat. Arg. I, 10, p. 346 et 851 (1879).

Esta especie muy comun, que se halla con frecuencia en casi todas partes de la República Argentina, fué traida del Rio Negro, de la Sierra de Currumalan, del Fuerte Argentino, del Rio Sauce y Colorado, etc. Uno de los ejemplares es de un tinte negro-violáceo, coloracion que indica ya Steinheil, y que hemos observado tambien en Buenos Aires.

62. ?ANISODACTYLUS LAEVIS (CURT.).

Harpalus laevis Cunt., Trans. Lin. Soe. XVIII, p. 194. 28 (1839).

Poseo seis individuos de un Anisodactylus, originarios de Salinas Chicas, del Rio Colorado y de la Sierra de Córdoba, y coleccionados por el Dr. DOERiNG y por mi, que no corresponden bien á ninguna de las especies detalladamente descritas, y que se acerca mucho al Harpalus laevis CukT., procedente de la Patagonia meridional y de Santiago de Chile. Pero siendo la descripcion que da CurTIS, bastante superficial, no puedo resolver definitivamente la cuestion, hasta practicar el exámen del original ú obtener ejemplares originarios de los mismos lugares.

\section{SELENOPIIORUS MARGINIPILOSUS STEINH.}

StersH., Atti della Soc. Ital. di Se. Nat. XII, 1, p. 245.32 (1869).

Un individuo macho, traido de Salinas Chicas.

Corresponde bien á dos individuos que he recojido en la Banda Oriental del Uruguay, y á la descripcion de STeINHeIL, á la cual se debe agregar, que el pronoto tiene una línea media bien marcada y la parte posterior de la depresion latero-basilar, hasta la márgen, provista de puntos distintos.

Es buena especie, que no conoció Putzeys, cuando escribió su monografía de los Sclcnophorus de América (Stett. Ent. Zeit. XXXIX, p. 3 (1878).

64. FEROXIOHORPIA Striatula (Fabr.) Chatd. Chatd., Ano. Soc. Ent. Belg. XIX, p. 113 (1876).

Fué traiła en varios individuos del Rio Colorado y Salinas Chicis.

Esta especie es muy comun en el Brasil, Paraguay, en la Banda Oriental del Uruguay y en la República Argentina; yo la observé tambien en el Rio Negro en Patagonia. 
65. FeroniomorpHa moerens (Brulté) Chatd.

Feronia (Melanius) moerens Brulté in J'Orbusx, Voy. dans l'Amér. múrid. Vi, 2, p. 29.9. 104 pl. 3, fig. 7 (1) (1838).

Feronia Dejeanii Wateru., Am. and Mag. of Nat. Hist. VII, 1. 121. 4 (1841).

Omaseus moerens (itwur, et Hok., Cat. Cel. I, p. 312 (1868).

Platysna Dejeanii (iems. et Hak., (at. Col. I, p. 3 I8 (1868).

Feroniomorpla moerens Cirac1., Auu. Soe. Ent. Belg. XIX, p. 113 (1876).

Un individuo del Rio Negro.

Esta especie, que ha sido observada en Buenos Aires, y en el Baradero por los hermanos Lynch, por el Sr. (ix. Guenther y por mí, y que recojí tambien en el Cármen de Patagones en el año 1874 , es bastante variable en su tamaño, resultando la $F$. mocrens y F. Dejeanii como idénticas, distinguiéndose solo por las dimensiones.

Me he valido de los apuntes sinonímicos del Sr. Exrique Líscir, que resultaban conformes con las indicaciones de CHAUdoir.

\section{6it. Argutoridedes ablitus (Des.) Crato.}

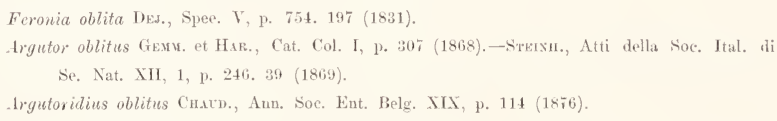

De esta especie fueron traidos dos individuos hembras de Nueva Roma y del Rio Negro.

Poseo en imi coleccion un individuo masculino, que recojí en la Banda Oriental del Uruguay, y que debe pertenecer á esta especie. STErnheIL ha recibido este Argutoridius de Buenos Aires, de Rio Cuarto, del Rosario y de Montevideo, de manera que tiene una distribucion geográfica bastante vasta.

\section{6i. ARgutoridits Ureguaicts Chaud.}

('имор, Anu. Soe. Ent. Belg. XIX, 1. 114 (1876).

Dos individuos de la Isla de Choelechoel.

Corresponden bien á la descripcion que da CHAUDolr, teniendo solo aún un cuarto punto en el tercer intérvalo, situado cerca de la segunda estría, mas ó ménos al principio del último quinto del élitro.

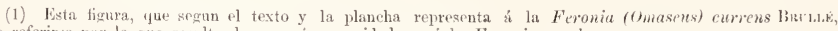
dobe referirse por lo que resulta de un eximen cuidadoso, i la Feroniomorpha moerens. 


\section{PLATiNus hineato-PUNCTUlatus (Dej.) Brulí..}

Berclé in D’Orbigny, Voy. dans l'Amér. mérid. VI, 2, p. 25.91 (1838).-Steinh., Atti della Soc. Ital. di sc. Nat. XII, 1, p. 247. 46 (1869).

Fué traido en varios ejemplares del Rio Colorado, recojidos el 19 y 20 de Mayo.

Este Platymus no es raro, y ha sido observado en Buenos Aires (STROBel y autor), Rio Negro y Salinas (D'ORBIGNy) y Montevideo (BRendel); se encontrará probabiemente en toda la República Argentina.

69. PlatyNus Brasiliensis (Dej.) Brulé.

Brellé in D'Orbigxy, Voy. dans liAmér. mérid. VI, 2, p. 24.89 (1838).

DejEan tenia esta especie del Brasil, D'ORBIGNy la recojió en Bolivia, los dos individuos que trajo cl Dr. Doering son originarios del Rio Colorado, donde fueron coleccionados el 20 de Nayo.

Anotacion.-Entre los Carábicos colescionados por el Dr. Doering, se encuentran dos especics del género Bembecidium, recojidas en la Laguna de Narra-Có, que no corresponden bien á ninguna de las señaladas en el Catálogo de Gemainger y Harold, ni á las que describe Steinheil. Siendo el estudio de estos pequeños coleópteros muy difícil sin un gran material de comparacion, los dejo ahora fuera de este trabajo, hasta otra oportunidad mas favorable.

\section{Fam. DYTISCIDAE.}

70. RIIANTUS VARIUS (Fabr.) Gems. et Har.

Gem. et Har., Cat. Col. II, p. 449 (1868).

De esta especie fueron traidos varios ejemplares, coleccionados en la orilla de la laguna de Salinas Chicas y en la Isla de Choelechoel.

Es bastante comun y ha sido observada hasta ahora en Montevidco, Buenos Aires, Patagonia (Rio Negro, Puertos Deseado y Famine) y en Chile.

\section{RiLANTUS mRroratus (Brulí) Gemm. et IIAr.}

Gema. et Har., Cat. Col. II, p. 449 (1868). - Sreish., Atti della Soc. Ital. di Se. Nat. XII, 1, p. 250. 61 (1869).-Sharp, Ann, Soe. Ent. Belg. XX, p. 116 (1877).

Dos individuos mutilados de Salinas Chicas.

Esta especie es, á lo ménos en Buenos Aires, mas comun que la anterior y ha sido observada en los mismos lugares y ademas en San Luis y en Mendoza por el Profesor STROBEL. 
Fam. HYDROPHILIDAE.

\section{TROPIsternts GLABER (IIbs'r) Sol.}

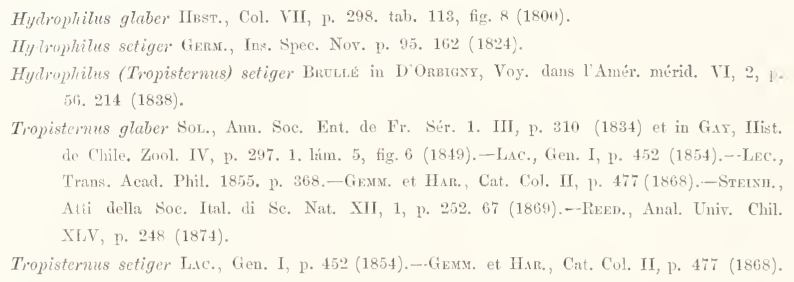

Tres individuos del Rio Colorado y Rio Negro (Choelechoel).

Este coleóptero acuático se encuentra frecuentemente en ámbas Américas, y ha sido observado en los Estados Unidos, en Mújico, en Chile, en el Brasil, en la Banda Oriental del Uruguay, y en la República Argentina, desde el Territorio de las Misiones antiguas hasta la Patagonia meridional y háeia el Oeste, hasta Mendoza.

Anotacion.-El Tropistcrnus setiger es sinónimo del T. glaber. Las pequeñas cerdas de los puntos de los élitros son muy rijidos, de manera que se pierden con facilidad, y solo por el empleo del microseopio se observa sus vestigios. E1 nombre $T$. sctiger, aúnque mas significafivo, debe ceder su lugar al de $T$. glaber, que tiene la prioridad.

\section{BEROSUS UNDATUS (FABr.) BRUllé.}

Pinclué in 1)'Orbigny, Voy. dans l'Amér. mérid. VT, 2, p. 59.222 (I838). - Stennh., Atti della Soc. Ital. di se. Nat. XII, 1, p. 253 . 72 (1869).

Un individuo muy mutilado, traido del Arroyo Guaminí, debe pertenceer á esta especie, que obtuvo FAbricius de la Patagonia y que fué observada por Stronel en la Provincia de Buenos Aires.

Fam. SILPHIDAE.

\section{NECROPIIORL'S CIILENSIS PHiL.}

Prul., Stett. Ent. Zeit. XXXII, p. 293, fig. 7 (1871).

De esta especie rara trajo el Dr. DOERING un ejemplar mutilado, que fué recojido muerto en Salinas Chieas, y que es aleo mayor en sus dimensiones que el ejemplar típieo, originario de Santa Cruz, en la provineia ehilena de Curico. 
Fam. SCARABAEIDAE.

\section{CANTIION PLICATIPENNIS BLancir.}

Canthon plicatipennis Branch. in D'Orbigny, Voy. dans l'Amér. mérid. VI, 2, p. 164. 517

(1838).-Harold, Col. Heft. V, p. 57 (1869).--Stersh., Atti della Soc. Ital. di Sc. Nat. XV, 5, p. 554. 102 (1873).

Canthon fractipes Harolv, Mou. der Gatt. Canthon, F. 101 (1868).

Un individuo de Salinas Chicas.

La especie es muy comun en el Cármen de Patagones, donde 'la coleccioné en gran número en el estiércol de caballo, á fines de Noviembre de IS74. Se halla tambien en Mendoza y Chile.

\section{PYTODERUS STROBELII (Sternh.) Bचra. (1).}

Orplnus Strobeli Sтеixh., Atti della Soc. Ital. di Sc. Nat. XT, 5, p. 546.117 (1873).

En el mismo número y del mismo lugar que la especie precedente.

El individuo típico de Steinheil fué recojido por Strobel in Bahía Blanca.

77. TROX PATAGONIOUS BLANCII.

HaroLd, Mon. der Gatt. Trox. p. 188. 6 (1872):-Burm., Stett. Ent. Zeit. XXXVI, p. 254. 3 et p. $264.5(1876)$.

Fué traido en tres individuos del Rio Colorado y de Olavarría.

Esta especie ha sido observada en los lugares siguientes: Montevideo, Rio Cuarto, Tandil, Bahía Blanca y Cármen de Patagones.

\section{TROX SUBEROSUS Fabr.}

Harold, Mon. der Gatt. Trox. p. 28. 54 et p. 119. 55 (1872).-Burm., Stett. Ent. Zeit. XXXVIT, p. 257.6 et p. $265.10(1876)$.

Esta especie, de la cual fué traido un ejemplar de Nueva Roma, tiene una distribucion geográfica muy vasta, encontrándose desde la Pensilvania hasta la Patagonia meridional, y ha sido observada en casi todas las provincias de la República Argentina.

\section{TROX AEGER Gú́r.}

Hanold, Mon, der Gatt. Trox. p. 29.61 et p. 132. 61 (1872).-Btra., Stett. Ent. Zeit. XXXVII, p. 259.8 et p. 266.28 (1876).

Un individuo de Olavarría.

(1) Las cnatro especies de escarabajos establecidas por el Dr. Bunxeister, representan nuevos géneros ó nuevas especies, descritas ya bace dos años, y que serin publicadas en breve, juntos con los demas Lamelicornios argentinos, en la obra: Description physique de la République Argentine. 
Este Trox ha sido observado en las Repúblieas del Perú, Oriental del Uruguay y Argentina; en esta última fué eneontrado en los lugares siguientes: Córdoba, Kosario, Paraná, Mendoza, Buenos Aires y Cármen de Patagones.

so. MYLOXENA VESTITA Bury.

LíM. II, Fig. 13.

E1 individuo que sirvió al Dr. Burmeister, para estableeer este nuevo género, fué reeojido por él en la Pampa oeeidental. El Dr. DoERING trajo tres ejemplares, que habia coleecionado al Sud-Oeste del Rio Colorado, donde los observó volando de noehe.

\section{S1. PACHRODEMA LCOCIDA BuRM.}

$$
\text { Lim. II, Fig. 14. }
$$

El ejemplar típico de esta nueva espeeie, fué eneontrado por mí en Patagonia en el año I874. El Dr. DoERING reeojió un individuo en Salinas Chieas.

\section{CYCLOCEPHALA PARVULA BURM.}

Lix. II, Fig. 15,

De esta nueva Cyeloceplaala fueron eoleeeionados dos individuos en Salinas Chieas. Los ejemplares típieos del Dr. Burmeister son originarios de la Banda Oriental.

\section{LIGYRUS BURMEISTERI STEINI.}

Sterse., Atti della soc. Ital. di Sc. Nat. XV. 5, p. 560. 133 (1873).

Dos individuos de Olavarría.

Esta espeeie es bastante eomun en la Provineia de Buenos Aires y en la Banda Oriental del Uruguay al Sur.

Frm. Buprestidae.

\section{Gen. Dactylomoder Cherrot.}

Lasionota Des., Cat. Ed. 3. p. 94 (1837); sine descript.

Dactylozodes Chevrol, in Silb, Rev. Ent. V, P. 79 (1838).--LaC., Gen. Col. IV, p. 56 (1857). Zemina Cast. et Gory, Mon. II, p. 1 (1838).-Lac., Gen. Col. IV, p. 55 (1857).

\section{D. QUADRIFASCIATA (MANNERIr.).}

Lasionota qradrifasciata Maxxerh., Bull. Soc. Imp. des Nat. Moscou. VIII. p. 1021 (1837).Gory, Mon. IV, p. 196. pi. 33, fig. 189 (1840).—-Gexм. et Har., Cat. Col. V, p. 1394 (1869)._-Burs., Stett. Ent. Zeit. XXXIII, 1. 375. 12 (1872). 
Lasionota qualricincta DE.s., Cat. Ed. 8. p. 94 (1837); sine descript.

Dactylozodes tetrazona Chevrol. in SiLb., Rev. Ent. V, p. 80 (1838). _-Gemis. et Har.. Cat. Col. V, p. 1395 (1869).

Zemina Dorbignyi Cast, et Gory, Mon. II, p. 3. pl. 1, fig. 2 (1838).-Binch. in D Orb GNx, Voy. dans l'Amér. mérid. VT, 2. p. 150. 474. pl. 9, fig. 8 (1843).-Brrm., Stett. Eut. Zeit. XXXIII, p. 375.13 (1872).

Zemina hirsuta Cast. et Gory, Mon. II, p. 4. pl. 1, fig. 4 (1838).

Zemina Brullei Cast. et Gorx, Mon. II, p. 4. pl. 2, fig. 5 (1838).

Zemina quadrizonata Buaxch. in D’Orbigny, Voy. dans l'Amér. mérid. VI, 2, p. 150. 475 (1838).—-Burs., Stett. Ent. Zeit. XXXIII, p. 375 (1872).

Dactylozodes Dorbignyi Geмm, et Hır., Cat. Col. V, p. 1394 (1869).

Dactylozodes hirsuta Gвмм, et Hır., Cat. Col, V, p. 1394 (1369).

Dactylozodes quadrizonata GемM. et Har., Cat. Col. V, p. 1395 (1869).

Dactylodes tetrazonus Bonu., Stett. Eut. Zeit. XXXIII, p. 375. 17 (1872).

De esta especie trajo el Dr. Doering muchos individuos, que fueron coleccionados cn las orillas de las Salinas del Sur, dondc se conscrvaban, muertos, cn bastante bucn estado.

Anotacion.-Los géneros Dactylozodes, Lasionota y Zemina, son idénticos, variando la forma y longitud de los tarsos en las difercntes cspecics y hasta en los individuos, $y$ existiendo formas transitorias.

Por el gran númcro de individuos que poseo de la Patagonia septentrional y de las Provincias de Buenos Aires, Mendoza y Corrientes, puedo observar tambien la variabilidad por lo que toca al tamaño, á la escultura y coloracion, resultando como idénticas todas las cspecies indicadas en la sinonimia, y que han sido establecidas en general por un solo ejemplar, sin exámen de los originales ó sin conocimiento de las descripciones ya existentes.

En cuanto al tamaño, son de $9 \mathrm{I} / 2$ hasta 22 milímctros de largo y dc $23 / 4$ á 6 milímetros de ancho cn la parte humeral. En su forma son, cn general, bastante convexas, pero hay tambien individuos algo aplastados, carácter que sirvió en partc á BLANCHARD para formar su Zemina quadrizonata.

La escultura de los élitros y dcl pronoto no da ningun carácter espccífico, sinó individual; cl surco pronotal falta por lo comun, cstá bicn ó solo ligeramente marcado, ó es sustituido por una especie de arruga en partc desvanecida, y la longitud y agudeza dc los dientes de la extrcmidad de los élitros es muy variable, como tambicn la mayor ó menor abundancia de vcllo cn las diferentes partes del cucrpo, que depende por otra partc, del estado dc conservacion del cjemplar.

La coloracion fundamental varia de un negro oscuro hasta un vcrdc violáceo metálico muy vivo; $y$ las fajas transversales son dc un tintc amarillo impuro, rara vez rojizo, y variables cn su anchura y forma; cn el mayor número de individuos hay cuatro fajas, algunos tiencn la cxtremidad de los 
élitros amarilla, representando una especie de faja, que es algunas veces bastante ancha, en otros está apénas indicada.

La mancha negra humeral, situada en la faja amarilla transverso-basilar de los elitros, es muy variable; ya es muy pequeña, puntiforme, ya de tamaño mediano, ó muy grande, dividiendo la faja casi en dos partes; á veces se une oblícuamente con la primera faja negra, separando la amarilla en dos manchas, una escutelar redondeada, otra marginal sub-triangular, como se observa en la figura citada de la Zemina Dorbignyi, y de acuerdo con la descripcion de la $Z$. quadrisonata.

No nos debe estrañar esta variabilidad, que ha sido ya observada varias veces en los Bupréstides (Vúase: Stett. Ent. Zeit. XXXVI, p. 86. - I875, etc.)

85. CHRTSOBOTIRIS RUGOSA CAs't. et G'ORY.

Bens., Stett. Ent. Zeit. XxxII, p. $380.26(\mathbf{1 8 7 2})$.

Uit Aidividuo mutilado de Salinas Chicas.

Tambien esta especie tiene una distribucion geográfica muy vasta, encontrándose casi w todas partes de la República Argentina, en la Banda Oriental del Uruguay y en Chile; al Sur desciende hasta el Estrecho de Magallanes.

Fam. ELATERIDAE.

S6. TIETERODERES RUFANGULUS (Grla.) Cand. Beru., Stett. Ent. Zeit. XXYTI, p. 268. 1 s et p. 273. 153 et 154 (1875).

De esta especie fueron coleccionados dos individuos cerca del Rio Colorado.

Anotacion-Estoy de acuerdo con el Dr. BuRmeister quién une el $H$. patagomus STEINH. con la especie en cuestion; la longitud del segundo artículo de las antenas y su relacion con la del tercero, da mas bien un carácter sexual que específico.

Fam. melanosomatidae.

\section{IIYLITHUS TENTYRIOIDES (LAc.) Gú́r.}

Steinf., Atti della Soc. Ital, di Sc. Nat. XV, 5, p. 575. 187 (1873). 一Bгrk., Stett. Ent. Zeit. XXXTI. 1. 461. 1 (1875).

Un individuo de Salinas Chicas.

Esta especie ha sido observada con frecuencia en San Luis, en Mendoza y en el Cármen de Patagones, donde se halla abajo de trozos de madera, de estićrcol seco, etc. 
89. SCOTOBIUS Miliaris (Billb.) Gemm. et IIar.

Gemu. et Har., Cat. Col. VII, p. 1857 (1870).-Buru., Stett. Ent. Zeit. XXXYT, p. 46.;. 10 (1875).

Esta especie, que tiene una distribucion mas vasta que la anterior, y que desciende tambien hasta el Rio Negro, fué traida por el Dr. Doeking de la Sierra de Currumalan.

\section{SCOTOBIUS OVALIS Guée.}

Bсrм., Stett. Ent. Zeit. XXXVI, p. 466. 15 (1875).

Fué traido en varios ejemplares del Rio Colorado y de Nueva Roma.

Lo he coleccionado en Córdoba, donde se hallaba con frecuencia, en el año 1875. El Dr. Doering lo encontró tambien en la Sierra de Córdoba.

90. NIUTELIA PLIOATIPENNIS LAC.

Brry., Stett. Ent. Zeit. XXXVI, p. 472. 24 (1875).

Un individuo de Médanos Colorados.

Es una de las Nictelias mas comunes, que tiene al mismo tiempo una distribucion muy vasta en la República Argentina, descendiendo hasta el Rio Negro en Patagonia.

\section{EPIPEDONOTA EBENINA (LAc.) SoL.}

Burм., Stett. Ent. Zeit. XXXVI, p. 477. 37 (1875).

Fué traida en un individuo mutilado de los Médanos de Carhué.

Se encuentra tambien con frecuencia en toda la Pampa desde San Luis hasta el Rio Santa Cruz, donde la coleccioné en el año 1874 .

\section{MITRAGENIUS ARANEIFORMIS CURT.}

Ber.a., Stett. Ent. Zeit. XXXVI, p. 481.45 (1875).

El Dr. Doering trajo un individuo de esta especie de Nueva Roma; yo la he recojido en un pendiente del Weddell-Bluff en Rio Santa Cruz, el 12 de Octubre de 1874.

\section{BLAPSTINUS PUNCTULATUS SOL.}

Bеrm., Stett. Ent. Zeit. XXXVI, p. 499. 75 (1875).

Cuatro individuos, que fueron rccojidos cerca del Rio Colorado, el ig de Mayo.

Este pequeño coleóptero es muy comun en la República Argentina, encontrándose desde Córdoba y Corrientes hasta el Rio Negro en Patagonia. 


\section{$-104$ \\ Fam. OPATRIDAE.}

El Dr. Doering ha recojido en el Rio Colorado dos especies del género Trichoton Hore, que no puedo determinar por falta de las obras que tratan del $T$. cayanense Hope (T. latum StUrm et T. rotundatum MuLs.) y del T. incisum BLANCH. Ninguna representa al T. rotundatum CuRT., specie que poseo de Mendoza.

Fam. epitragidae.

94. EPITRAgUS SCABRIPENNIS SteINit.

Steish., Atti della Soc. Ital. di Se. Nat. XV, 5. p. 576. 191 (1873).

Un individuo del Rio Colorado, que solo tiene 10,5 milímetros de largo, corresponde por lo demas á un ejemplar que he recibido del Sr. D. Federico Brachmann de Mendoza y que tiene las dimensiones que anota el autor, quien obtuvo el original tambien de Mendoza.

Fam. Cistelidae.

95. LOBOPOD PALLICORNIS (FABr.) OAsteln.

Castelx., Hist. Nat. des Ins. II, p. 242. 1 (1840).

De esta especie, que abunda casi en todas partes de la República Argentina y en el Brasil, fueron coleccionados por el Dr. DoERing varios individuos en el Rio Colorado, Nueva Roma y Salinas Chicas.

\section{Fum, MELOIDAE.}

96. CANTIIARIS DISPAR (Germ.) IIAAG-RirBg.

Tetraonyx dispar Gemm., Ins. Spec. Nov. p. 171 (1824).—-Gemm. et Har., Cat. Col. VII, p. $2146(1870)$.

Lytta dispar (ierm., Ins. Spec. Nov. p. 623 (1821).

Lytta vittigera Blaxer, in DrOrbigsx, Toy, dans l'Amér. mérid. VI, 2, 1. 200. tab. 15, fig. 7 (1838).- - Genu. et IInn., Cat. Col. VII, p. 215 (1870).

Cantharis dispar HAaG-Ririg., Deutsche Ent. Zeitschr. NXIII, p. 412 et Stett. Ent. Zeit. XL, p. $251(1879)$.

Un individuo muy mutilado del Rio Colorado. Poseo otro en buen estado, de Buenos Aires, que fué recojido por mi antiguo ayudante, el Ingeniero y Profesor D. EDUARDo Aguirre.

Anotacion.-La Lytta vittigera BLANcir. es idéntica con la Cantharis dispar (GERM.) HAAG-RTBG, representando solo una variedad, en la cual se unen las dos fajas sub-limbares y forman una faja arqueada ó semi-circular. 


\section{$-105$ \\ Fam. CURCUliodidaE.}

97. NAUPACTUS CIIORDINUS BomeM.

Naupactus chordinus Bonex. in Schoexn., Gen. et Spec. Curc. I, p. 573.9 (1833).

Naupactus suffitus Boнем. in Scноемн., Gen. et Spec. Curc. I, p. 573. 10 (1838).

De esta especie fueron traidos dos pequeños individuos del Rio Colorado. Ha sido observada ya varias veces en Buenos Aires.

Anotacion.-Boheman ha descrito el sexo masculino de esta especie bajo el nombre de Naupactus chordinus y el sexo femenino como Naupactus suffitus.

\section{NAUPACTUS LEUCOLOMA Bonem.}

Boнer. in Schoenh., Gen, et Spec. Curc. VI, 1, p. 62. 84 (1840).

Dos individuos muy mutilados de Salinas Chicas.

Este rincóforo tiene una distribucion muy vasta en el Brasil meridional y en las Repúblicas Argentina y Oriental. Lo he observado en casi todas partes que he tenido ocasion de visitar.

\section{NAUPACTUS DURiUS (Germ.) Bomem.}

Boнeм, in Senoexн., Gen. et Spec. Curc. VI, 1, p. 27. 38 (1840).

Fué traido un ejemplar de Salinas Chicas.

Esta especie no es rara en la Provincia de Buenos Aires y en la vecina República Oriental.

100. NaUpaCtus taexiatulus Berg, n. sp.

Líx. II, Fig. 16 .

Fem. : Parva, subelliptica, dense squamulosa, obscure grisea vol fisceseenti, vittis quattuor sat latis et maculis nonullis minutis albido-einereis ornata; capite fusceseenti, ad oculos albido-subviftato, apice metallico-squamoso, medio profunde et anguste canaliculato; antennarum scapo basin capitis attingente, rufo, parum pubeseenti, artieulis basalibus funiculi mis, vix puberulis, reliquis obscurioribus et puberulis, clava elliptica, cinerea; pronoto albido-quadrivittato, vitta laterali vitta submedia angustiore; clytris punctato-striatis, dense squamosis, striis octo al partem obtectis, vittis quattuor albidis ad basin angustioribus, apicem versus indistincte angustatis, vitta lat rali in stria septima et octava infuscata, interstitiis obscuris praccipue pone medium albilo-adspersis; corpore subtus cinereo-squamoso; fenoribus fuscis, parum squamosis et pubcrulis; tilits rufis, pubescentibus; tarsorum articulis basalibus rufis, caeteris obseurioribus. - Long. corp. $\tilde{\sigma}-6$; lat. pron. 112 , segm. sec. abdom. cum elytr. $2 \mathrm{~mm}$.

De esta especie, que ha sido observada tambien en Buenos Aires, fué traido un individuo femenino del Rio Colorado. 
Es bien característica por las cuatro fajas blanquizcas longitudinales, que llevan el pronoto y los élitros, y por los cuales tiene cierta scmejanza con el macho del Vaupactus leucolomo BOHEM.

\section{LISTRODERES COSTIROSTRIS GYLL.}

Listroderes costirostris GrL., in Schoenw., Gen. et spec. Curc. II, p. 277. 1 (1834).

Listroderes robustus Waterh., Proc. Zool. Soc. IX, p. 122 (1841).-Rlaxch. in GaY, Hist. de Chile. Zool. V, p. 341. 7. lím. 22, fig. 10 bis (1) (1851).

De csta especie, que es muy comun en la mayor parte de las provincias de la República Argentina, principalmente al Sur, descendiendo hasta el Estrecho de Magallanes, fueron coleccionados cinco individuos cerca del Rio Colorado.

Anotacion.-El Listroderes robustus WATERI. cs idéntico con el Listroderes costirostris GyLL. La pequeña faja blanquizca de los élitros no da ningun carícter espccífico: puede faltar por completo; está á veces apénas indicadaotras muy bien marcada y guarnecida de escamas oscuras. Lo mismo se ob. serva por lo que toca á la línea media del pronoto y las demas pequeñas manchas claras ú oscuras, que, formadas por una especie' de escamas, pueden desaparecer tambien con mucha facilidad.

\section{IILIPUS APIATUS (Oliv.) Schoenir.}

Schoesil., Gen. et Spec. Curc. VII, 2, p. 40, 21 (1843).

Tres individuos muy mutilados de Salinas Chicas.

Esta especie tiene una distribucion geográfica muy vasta; ha sido observada en los Estados Unidos y en Cayena. El gabincte de historia natural de la Universidad de Buenos Aires posee un ejemplar mutilado del Rio de Janeiro.

\section{Fam. CERAMbycidae.}

\section{Gen. ILalyeiducrius (2) Berg.}

(Novum genus Prionidarum.)

Caput longiusculum, antice paullo, postice vix angustatum, ante oculos in spinam subacutam productum. Oculi mediocres, supra satis, infra valde distantes.

Antemae 11-articulatae, corpore multo breviores; articulo $1^{\circ}$ subelongato et parum incrassato, articulo 20 minimo, $3^{\circ}-10^{\circ}$ fere aequilongis, laud longitudine decrescentibus, at contra $10^{\circ}$ caeteris nonnilil longiore, in mare longe flabellatis, articulo ultimo decimo plus quam duplo longiore, flabelliformi, obtuso-tetragono, basin versus attenuato.

(1) La figura 10 bis representa al Listroderes robustus, y no la figura 11, que pertenece al Listroleres chalceatus BцANCH.

(2) 'Ahu\%is-salis fodina, salinae; xfís -aries. 
Labrem minimum.

Mandibulac subhorizontales, mediocres, valde arcuatae, acutae, medio dcnte valido ct acutiusculo instructae Palpi (desunt).

Pronotum transvcrsum, capite paullo longius, longitudine plus quan dimidio latius, antice in totum levis simc, postice in medio leniter sinuatum, per ambitum modice marginatum, lateribus haud spinosis, indistinctc bisinuatis vel subcrenulatis.

Scutcllum mediocre, apice rotundatum.

Elytra corpore paullo breviora, coreacea, tricostata, valde dehiscentes, apicem versus admodum angustata, apice ipso hand spinoso.

Prosternum tuberculo rotundato et submarginato, coxas satis superante, instructum.

Pedcs mediocrcs; coxis validis, approximatis; femoribus infra minutissime spinosis; tibiis intus spinosulis, apice spinis duabus obtusis et calcaribus duobus mediocribus armatis; tarsorum anticorum articulis tribus basalibus apicem versus dilatatis, primo duobus sequentibus fere aequilongo, secundo sinuato, tertio bilobo.

Este nuevo género, establecido por un solo individuo macho, debe colocarse entre los géneros Rhipidocerus Westw. y Hicroplophorns BLANCH., de los cuales se distingue principalmente por la forma y estructura de las mandíbulas, del pronoto y de los élitros. Las antenas las tiene, mas ó ménos como el Rhipidocerns.

Es bien característico por lo que sigue: Los artículos de 3 á io de las antenas están provistos de un flabelo, siendo estos hácia la extremidad algo mas cortos y el último artículo está representado por un solo flabelo cuadrangular. Las mandíbulas son muy encorvadas y puntiagudas, con un diente bastante fuerte en el medio. El pronoto no posee espinas laterales, sinó dos muy ligeras sinuosidades, apazeciendo la márgen como algo crenulada, con ángulos medios muy desvanecidos. Los élitros, fine llevan tres costas, son coriáceos, muy dehicentes y angostados hácia el ápice, que tiene cul ángulo sutural apénas pronunciado. Las alas y el abdómen son mas largos que los élitro:

\section{IALYCIDOCRIUS PIILIPPII BerG, n. sp.}

\section{LAM II, Fig. 17.}

Mas: Niger, subopacus, subtilissime punctatus et granulatus, antennis fuscis, elytris luteis, apicem versus pallidioribus; capite atro, supra obsoletissime, infra distincte nitido-granulato, medio canaliculato, antice admodum impresso, clypeo excavato, mandibulis fortiter punctatis; antennarum articulis basalibus obscurioribus, flabellis obscure ferrugineis, pubescentibus, longitudine decrescentibus; pronoto atro, subplano, obsoletissime granulato et punctato, medio linea iongitudinali subobsoleto et hic illic depressionibus nomullis praedito; scutello nigro, leniter longitrorsum imprcsso, subtiliter granulato; elytris rugulosis, scabroso-punctatis, apicem versus decoloratis, costis duabus mediis ante apicem conjunctis, in unam excurrentibus, costa marginali post medium suberanescenti; alis sordidis, coste fusca; prostcrno distincte gramulato, mesosterno et metasterno in disco punctatis, ad latera obsolete gramulatis, granulis punctisque setigeris; abdomine fimbriato; pedibus valde punctatis et setigeris. Long. corp. 25; lat. pron. 7, meson. cum elytr. $10 \mathrm{~mm}$.

De este longicornio muy interesante trajo el Dr. Doering un individuo algo mutilado de Salinas Chicas. 
Anotacion.-Como testimonio de aprecio dedico esta especie al Sr. Dr. D. R. A. Philippi, Director del Museo Nacional en Santiago de Chile, quien conmemora hoy (Abril 26 de 1880 ) el dia quinquagésimo de su Doctorado.

Fam. CHRYSOMELIDAE.

104. METALLACTUS PATAGONICUS SEFFr.

Stfrr., Linn. Ent. XVI, p. 353. 52 (1866),-Bтrм., Stett. Ent. Zeit, XXXVIII, p. 67.59 (1877).

De esta especie muy variable en cuanto al número y extension de las manchas ó puntos negros, trajo el Dr. DoERING muchos ejemplares, que habia encontrado muertos en la orilla de la laguna grande de Salinas Chicas. Se halla ademas en Bahía Blanca Mendoza, Córdoba y en el Paraná.

\section{PIIAEDON BONARIENSIS BoHEM.}

Bonem., Freg. Eng. Resa, Ins. p. 175. 368 (1858).-Stá, Mon. Crysom. II, p. 320.9 (1868).

Varios individuos traidos del Fuerte Argentino y de Salinas Chicas, deben pertenener á esta especie. Son negros con excepcion de uno que es azulado, son bastante lustrosos, tienen la guarnicion roja del pronoto muy angosta y el vértice de la cabeza oscuro; el tinte rojo es muy vivo en las partes correspondientes.

Anotacion.-La determinacion de las especies del género Phacdon Latk. ofrece muchas dificultades $y$ pide gran material de comparacion de diferentes localidades.

La forma general. ¿' puntuacion de los élitros, la coloracion fundamental y la de la cabeza, ¿ ele los artículos basilares de las antenas, de la márgen pronotal y de las patas, etc., parece variable, y será en parte carácter sexual. El Museo Público posee ejemplares del interior, que pertenecerán al Phacdon semimarginatas LATR., y algunos de Mendoza, que se acercan, por su forma alargada y su coloracion de un azul vivo, al Phacdon cyanopterus Gurr. de Chile, de donde lo traje de Valdivia. Cuatro individuos que recojí en Córdoba, son unos azulados, otros verdosos, y parecen pertenecer al Phacdon bonariensis Bollew.

Es muy probable que algunas de las especies descritas no son sinó sinónimas, que solo se podria averiguar, teniendo un gran material de diferentes lugares.

106. ZYGOGRAMHA VIRGATA STÅ.

Sxi̊n, Öfv. Vet.-Ak. Förh. 1859. p. 318, 8 et Mon. Chrysom. II, p. 233.459 (1863).-Gexm, et Har., Cat. Col. NI, p. 3437 (1874).

De esta especie fué traido un individuo de Salinas Chicas, que corresponde á los que 
he recojido en Buenos Aires y que poseo de Tucuman. Se halla tambien en_el Brasil y en la vecina República Oricntal.

\title{
107. Disonicha interlineata Berg, n. sp.
}

\author{
Lín, II, Fig. 1x,
}

Mas et fem.: Ovales, nitidi, dense et obsolete punctulati, capitc, macula basali nigra excepta, antennis basin versus, pronoto, elytris, sutura vittaque media nigra, tcstaceo-interlineata, exceptis, pedibus, nec non marginibus apiceque abdominis, testaceis aut luridis, antennis apicem versus, scutello, pectore, !dorso abdominis discoque ventris infuscatis; capite tantum ad oculos profunde punctato et modice impresso, vertice parm convexo, macula postica nigra parva, lunari, mandibulis apice nigris, palpis apice fuscescentibus; antennarum articulis $3-11$ breviusculis; pronoto fere laevi, postice in medio levitcr impresso, antice parum angustato, postice antc scutellum levissime simuato, lateribus marginatis; scutello trigono, laevi, fere converiusculo, fuseo; clytris dense punctulatis, interdum ochraceis aut stramineis, sutura fere usque ad apicem nigra, vitta media nigra flavo-interlineate prope apicem abbreviata, aliquando lineis duabus angustis formente, seriebus duabus punctorum apul costam infuscatis, rarissine nigricantibus; ventre pedibusque flavido-sericeis, illo disco obscure fusco, his sorlide testaceis; femoribus tibiisque pcrraro apicem versus infuscatis.-Long. corp. 5-6 12; lat. part. post. pron. 1 3.4-2, ablom. exin elytr. $212-3 \mathrm{~mm}$.

De esta especie, quc parece ser nueva, trajo el Dr. Doering varios cjemplares de Salinas Chicas, del Fuertc Argentino y del Rio Colorado.

Es característica por la línea media longitudinal negra de los élitros, que está interrumpida en su medio por la coloracion general amarillenta, representándose aveces como dos angostas líneas unidas en la base. La sutura es tambien negra, pero esta coloracion no llega hasta la extremidad del élitro. En lugar de la faja negra cerca de la márgen externa se halla una infuscescencia.

\section{CAEPORIS STIGMULA (Gierx.) Des.}

Gемм. et Har., Cat. Col. XII, p. 3498 (1876).

De este coleóptero fueron traidos algunos individuos del Rio Colorado y de Salinas Chicas.

El ejemplar típico, que sirvió á (⿳亠丷厂ERMAR para establecer á csta especie, era originario de Buenos Aires, en donde la hemos observado tambien.

109. DIABRotiCA SPECIOSA (Germ.) DEJ.

Gemir. et Har., Cat. Col. XII, p. 3564 (1876).

Dos individuos del Rio Colorado.

Esta especie se halla con gran frecuencia en todas partes dc la República Argentina, en la Banda Oriental del Uruguay; en el Paraguay, y en el Brasil, encontrándose casi durante todo el año.

El esternon es en algunos individuos oscuro, cn otros amarillento. 
110. CHELYMORPIIA VARIABILIS BonEN.

Boнem., Mon. Camitl. II, p. 61.55 (1854). -Buru., Stett. Ent. Zeit. XXXI, p. 278. 31 (1870).

De esta especie muy variable fué traido un individuo de Salinas Chicas.

Este coleóptero se halla en muchas partes de las Repúblicas Argentina y Oriental, y tambien en el Brasil.

111. PHYSONOTA PROLIXA BoHEM.

Boнем., Mon. Cassid. II, p. 214. 23 (1854) et IV, p. 250. $30(1862)$.

Un ejemplar traido de Salinas Chicas, pertenece á la variedad, que tiene la parte inferior del cuerpo y las patas de color negro; la márgen del escudillo es de la misma coloracion.

Esta especie parece ser muy rara; este es el único individuo que ha sido recojido aquí, fuera de los ejemplares típicos que sirvicron á BOHEMAN para establecer á esta especie.

Anotacion.-Esta especie y la Phy'sonota sulcipennis BoHem. figuran en el género Mesomphalia en el Catálogo Coleopterorum de Gemurnger y v. HAROLD; al parecer introducidas allí erróneamente.

\section{Fam. EROTYLIDAE.}

112. MORPHOIDES BILINEATUS (Der.) Ginar. et HaR.

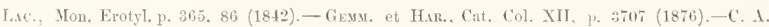
DoHrx, Stett. Ent. Zeit. XXXIX, p. 451.44 (1878).

Un individuo de Salinas Chicas.

He observado esta especie con frecuencia en la Banda Oriental del Uruguay, donde se halla, principalmente en el mes de Setiembre, debajo de piedras, de trozos de madera, etc. El Dr. Doering la trajo tambien de Entre-Rios y el Dr. Weyeneergit la ha coleccionado en Córdoba.

Fam. COCCINELLIDAE.

113. ERIOPIS CONNEXA (Germ.) Muts.

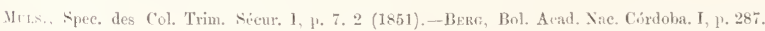
$1(1874)$.

De esta especie, que se halla distribuida por toda la América cuntral y meridional, descendiendo hasta el Estrecho de Magallanes, trajo el Dr. DoERING un ejemplar del Rio Colorado. La he observado en todas partes de la República Argentina, que he tenido la ocasion de visitar. 


\title{
114. COCCINELLA ANCORALIS Germ.
} $\operatorname{man}$.

Muls., Spec. des Col. Trim. Sécur. I, p. 94.3 (1851). - Bers, Bol. Acad. Yac. Cúrdoba I, p. 2*8. 4 (1874).

Tres individuos del Rio Colorado.

Esta especie tiene tambien una distribucion geográfica muy vasta, encontrándose con frecuencia desde el Brasil y Bolivia hasta el Rio Negro en Patagonia, donde la observé en el año 1974 .

\section{HYMTNOPTERA.}

\section{Fam. vESPIDAE}

115. POLYBIA ARGEYTTINA Berg, n. ep.

\author{
LiM. II, Fig. 19.
}

Mas et fem. : Tigri, parum sericci, maeulis duabus minutis frontis, striola postoculari, saepe margind postico pronoti, marginibus segncntorum primo secundoque ablominis, nec non apice coxarum anticarum, Alavis; capite thoracequc crebre punctatis; clypeo oblongo-hexagonali, sparsissime punctulato, angulis apicalibus sat acutis; mandibulis extus rufescentibus; antcmarum articulis basalibus interdum subtus rufis; pronoto haud spinoso; tegulis obscure fuscis; angulis spiniformibus mesonoti flavis; seutello longitrorsum impresso; metanoto dense punctato, impressione sublaevi; alis fuliginosis, costa cellulaque radiali rufescentibus aut violaceis; petiolo basi tenmi, pone medium incrassato, subcampanulato, margine flavo; abdominis segmentis omnibus dcnsc punctatis, sericeis.Long. corp. 13-15; lat. meson. $21 / 4-23,4 \mathrm{~mm}$.

Mas: Antonnis basi, subtus apiceque maximam partem rufescentibus; clypei angulis apicalibus valde productis, sat acutis; margine postico pronoti, macula parva epiner $i$ postscutclloquc, nec non margine segmenti secundi vcntris, flavis; potiolo supra pone medium impresso; segmento secundo abdominis fere aequc longo ac lato; femoribus apice tibiisque cxtus rufescentibus.

Fem: Antennarm articulo basali funiculi tantum subtus rufescenti; clypei angulis apicalibus parvis. obtusis; margine postico pronoti ncdio naculis duabus minutis ornato; postscutcllo margincque segmenti secundiabdominis subtus nigris; petiolo supra vix impresso; segmento secundo abdominis multo longiore quam latiore, post medium tiansversim impresso; pealibus nigris.

Esta especie, traida en dos ejemplares de Nueva Roma, pertenece á la III division de SAussure (Mon. Guêp. Soc. p. 183.-1853-1858), acercándose á la Polybia vicina y Polybia anceps SAUSS, de las que se distingue por muchos caracteres, sobre todo por la coloracion y escultura. Por otra parte, tiene mucha semejanza con la Polybia pygmaea (Fabr.) SAuss., de manera que podria ser tomada como variedad de esta especie, si los ojos no llegasen hasta las mandibulas, carácter que separa la tercera division de la cuarta, perteneciendo á esta última la Polybia pygmaea. 
116. Zetills (DIDYMOgASTRA) PAMPARtM Berg, n. sp.

Líx. II, Fig, 20.

Fem.: Nigra, antennarum scapo infra, funiculi articulo primo subtus et secundo omnino fere, maculis duabus parvis apicalibus clypei, pronoto snpra, tegulis, maculis duabus parvulis epiplenrae, scutello postscutelloque magnam ad partem, alis, abdominis segmentis primo lateribus apiceque et secundo basi, nee non pedibns, coxis basique femoribus exceptis, mis aut fulvis, abdominis segmento primo apice ipso et secundo basi petioli margineque apicali supra, laete flavis; capite thoraceque mule et scabroso-punctatis; clypeo perparum emarginato, angulis apicalibus subacutis; mandibulis bicarinatis, apice obscure rufis; mesonoto medio leviter longitrorsum impresso, carinis duabus mediis obsoletissimis, medio laevis, postice conjunctis, linea antica media laevi, parmo profunda, medio subcarinata; scretcllo antice nigro, medio longitrorsum impresso; postscutello postice rufo, rugoso-punctato; metanoto ruguloso-punetato, albido-villoso; alis, praecipue cellula radiali, violacemicantibus; abdominis segmonto primo rude punctato, apicem versus angustato, ante apicem parun coarctato, supra impresso, pone melium supra linea sublaevi instrueto, segmento secundo punctulato, subsericeo, petiolum distinctum, statim initio sparsin grosseque punctatum, postea deinceps laeve, formante, segmentis reliquis ventreque rude punctatis, puberulis; pedibus, praesertim tibiis tarsisque puberulis, femoribus mediis et posticis distinetc punctatis.-Long. corp. 16; lat. thor. $3 \mathrm{~mm}$.

Esta nueva especie fué descubierta por el Dr. Doering, en un individuo femenino, cerca del Rio Colorado.

Pertenece á la III division (Didymogastra) de SAUSS. (Mon. Guêp. Solit. p. I8.-I852), y es muy característica por la coloracion roja de los diferentes órganos indicados arriba, por el peciolo y el borde amarillo del segundo segmento abdominal, y siendo el primero bastante largo y notable en cuanto á su escultura.

\section{ODINERUS (PACHODYNERUS) ARGENTINUS SAUSS.}

SAưss., Rev. et Mag. Zool. Sér. 2. II, p. 56. 6 (1870).

Un individuo de Nueva Roma.

Esta especie se halla tambien en Buenos Aires, en Córdoba, en el Paraná y en la Banda Oriental del Uruguay. SAussure la habia recibido de Bahía Blanca, de donde le fué enviada por el Sr. ClaRAZ.

Anotacion.-Los tres individuos, que tengo en mi poder, corresponden perfectamente á la descripcion que da SAUSSURE, con excepcion de que los caracteres que enumera especialmente como pertenecientes al macho, son por lo contrario particulares de la hembra, así que debe haberse deslizado un error por parte del autor ó del cajista, al poner el signo correspondiente del sexo.

118. ODINERUS (PACIIODYNERLS) NigRICULUS BERG, n. sp.

Has: Antennis, corpore pedibusque nigris, tegulis al marginem favis, alis fuliginosis, violaceo-micantibus, apice pallidioribus; capite thoraccque crebre ct rude punetatis, perparum pilifcris; clypeo bre- 
tennarumque cxtremo scapi articuloque primo funiculi, rufescentibus; scutello medio longitrorsum levissime impresso; metanoto laevi, densissime pubescenti; abdomine irregulariter punctato, sericeo, marginibus segmentorum vix fuscescentibus; pedibus nigris, sericeis, geniculis tibiisque nigro-fuscescentibus, his parce setulosis.-Long. corp. 10; lat. thor. $23 / 4 \mathrm{~mm}$.

Aprovecho la oportunidad, para publicar esta nueva especie de Odynerus, que he recibido de Mendoza, de mi amigo el Sr. D. Federico Brachmann.

Es de fácil caracterizacion por la coloracion negra del cuerpo y de los diferentes órganos, con excepcion de la extremidad de las mandíbulas, del escapo y primer artículo del funículo de las antenas, que son rojizos. Tiene la parte externa de las tégulas amarilla, y las alas fuliginosas, con reflejos violáceos. El metanoto es sin puntuacion y muy pubescente.

\section{Fam. POMPILIDAE}

\section{PEPSIS ACICULATA TASCHB.}

TAscub., Zeitschr. f. d. gesammte Naturwiss. XXXIV, p. 29.6 (1869).-Bतrм., Stett. Ent. Zeit. XXXIII, p. 233. 3 (I872).

Un ejemplar del Rio Colorado.

Este himenóptero es bastante comun en la República Argentina, y desciende hasta el Rio Negro en Patagonia, donde lo observé en el año I874.

120. PRIONOCNEMIS HIRTICEPS TASCHB.

TAschв., Zeitschr. f. d. gesammte Naturwiss. XXXIV, p. 35.8 (1869). -BorM., Stett. Ent. Zeit. XXXIII, p. 235. 2 (1872).

Un individuo traido del Rio Colorado corresponde bien á la descripcion que da $\mathrm{TA}_{\mathrm{A}}$ SCHENBERG, con excepcion del escapo de las antenas, que no es rojo, sinó de la coloracion general, representando de esta manera una variedad.

El ejemplar típico en el Museo de Halle, ha sido recojido por el Dr. Burmeister en Mendoza.

\section{POMPILUS GASTRICUS SPin.}

SpIN. in $\mathrm{G}_{\Delta \mathrm{Y}}$, Hist. de Chile. Zool. VI, p. 380.6 (1851).-TAschr., Zeitschr. f. d. gesammte Naturwiss. XXXIV, p. 65. 41 (1869).-BurM., Stett. Ent. Zeit. XXXIII, p. 238.11 (1872).

De esta especie, que tiene una distribucion geográfica muy vasta, trajo el Dr. DoERING un individuo femenino muy pequeño de Carhué. 


\section{Fam. FGRMICIDAE.}

\section{CAMPONOTUS PUNCTULATUS MAYr.}

Marr., Annuar. della Soc. dei Naturalisti. Modena. III, p. 3. 1 et p. 19 (1) (1868).

Muchos ejemplares del Rio Salado.

Esta especie es muy comun en las Repúblicas Argentina y Oriental, hallándose con frecuencia en las Provincias de Buenos Aires hasta el Rio Negro en Patagonia, en San Luis, Mendoza, Córdoba, Catamarca, etc.

\section{CAMPONOTUS BONARIENSIS MAYR.}

Marr, Annuar. della Soc. dei Naturalisti. Modena. III, p. 4. 2 et p. 19 (1868).

De esta especie, que se halla en los mismos lugares que la precedente, y que es tambien muy comun, fueron traidos algunos individuos de Nueva Roma.

\section{ATTA LUNDII (Gú́r.) MaYr.}

Myrmica Lundii Guér., Voy. de la Coquille. II, 2, p. 206 (1838).

Atta Lundi Mayr, Annuar. della Soc. dei Naturalisti. Modena. III, p. 20 (1868).

Esta especie de hormiga, muy dañina á la horticultura y agricultura en general, la trajo el Dr. DofRing de los lugares siguientes: Rio Colorado, Azul, Salinas Chicas y Fuerte Argentino. Es muy comun en la parte austral de la América meridional.

\section{POGONOMYRMEX COARCTATUS MATR.}

Marr, Annuar. della Soc. dei Naturalisti. Modena. III, p. 12.10 et p. 20 (1868) et Terh. der zool.-bot. Ges. Wien. XX, p. $970(1870)$

Cuatro ejemplares del Rio Colorado y del Fuerte Argentino.

Esta hormiga la habia coleccionado el Prof. STRoBel en el Rosario, en el Rio Cuarto y en Bahía Blanca; yo la he recojido en Buenos Aires y en la Banda Oriental del Uruguay.

\section{POGONOMYRMEX RASTRATUS MaIR.}

Marr, Annuar. della Soc. dei Naturalisti. Modena. III, p. 13, 11 et p. 20 (1868) et Verh. der zool. bot. Ges. Wien. XX, p. 970 (1870)

De esta especie muy característica por la cabeza y el abdómen rojos, fueron traidos varios individuos del Rio Colorado, donde se encontraban debajo de piedras en las bar-

(1) Del trabajo del Dr. MAyr " Formicidae novae americanae collectae a Prof. P. de Strobet, " poseo -ilo el tiraje aparte, cnyas páginas cito. 
rancas del rio. Los ejemplares típicos que sirvieron para establecer esta especie, los recojió el Prof. Strobel en Mendoza, en la Pampa de Canota.

127. SOLENOPSIS (iEMINATA (FABr.) MAYR.

Mayr, Annuar. della Soc. dei Naturalisti. Modena. III, 1) 20 (1868) et Verh. der zool.-bot. Ges. Wien. XX, p. $996(1870)$.

Varios individuos de Nueva Roma.

Esta especie, que se halla casi en todas partes de la República Argentina, tiene ademas una distribucion geográfica vastísima, encontrándose en ámbas Américas, en Tahití, en Nueva Zelandia, en el Asia meridional y en Africa. 
. 


\title{
A RA C N I D O S
}

por

\author{
EDUARD0 LADISLA0 HOLMBERG
}

\section{PRELIMINAR}

El Dr. D. Adolfo Doering, miembro de la Comision Científica que acompañó al ejército del Sur, bajo las órdenes del General D. JuLio A. RocA, en sus marchas por la Pampa Meridional y por la Patagonia Septentrional, ha tenido la bondad de poner en mis manos una pequeña coleccion de Arácnidos, reunida por él en cumplimiento de la mision que se le encomendara. Las especies que la forman no son muchas, ni tampoco numerosos los representantes de cada una, lo cual se explica suficientemente, si se recuerda que la época en que la expedicion tuvo lugar no era la mas propicia para este género de adqui siciones; pero gracias á la amplitud del área de dispersion de algunas de dichas especies, de las cuales no pocas se encuentran tambien cerca de Buenos Aires, donde he coleccionado con más frecucncia, he podido hacer las descripciones teniendo á la vista ejemplares frescos, ó for lo ménos que no estan mutilados, defecto de que adolecen algunos de los que he recibido, por el movimiento á que se hallaban expuestos, en los utensilios de conservacion, durante las largas marchas á caballo.

Tan reducido número, y lo incompleto de nuestro conocimiento de la Aracnofauna de las regiones visitadas por la Comision, obligada á seguir á un ejército en operaciones, me impiden señalar los caracteres distintivos que este grupo de animales comunica á las comarcas en cuestion, por lo cual me abstendré de entrar en consideraciones respecto de aquellos.

Este trabajo es, pues, una simple contribucion para el conocimiento de la fauna aracnológica de los territorios meridionales de la República Argentina, á la que espero hacer seguir otra, conteniendo algunas especies recogidas en 1876 , en el Cármen de Patagones, 
por mi amigo el Ingeniero D. EDUARDO AGUIRRE, y una tercera sobre las reunidas en Chascomús, en 1878 , por mi amigo y compañero de tareas D. ENRique LvNCH ARriBÁLZAGA, algunas de las cuales, particularmente las del primero, han sido publicadas por mí en mi ligera reseña Arácnidos Argentinos, en 1876, señalando la localidad en que fueron halladas. La circunstancia de consignar aquí solamente las que ha coleccionado el Dr. DOERING, me impide hacer referencia á aquellas.

Despues de un prolijo exámen de las especies que motivan este trabajo, obtengo el siguiente resultado:

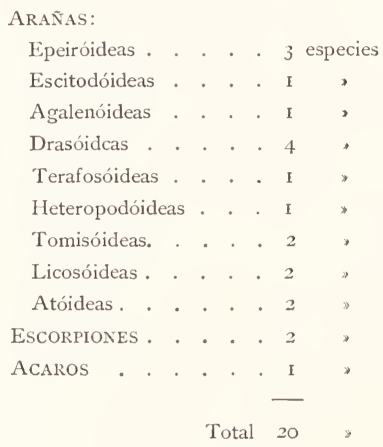

Las Epeiróideas venían representadas por 5 especies, todas ellas jóvenes; pero gracias á las circunstancias que consigno en la pequeña Nota latina despues de la diagnosis ó en las Observaciones, en seguida de la descripcion en castellano, mc ha sido dado reconocer cada una de ellas. La Argiope argentata (F.) C. L. K., no podía ofrecer duda alguna, porque es una especie bien caracterizada y porque la conozco en sus diversos aspectos; la Epeira lathyrina es la cspecie mas comun entre las que representan la familia en Buenos Aires, y aunque de la Epeira solitudinis, m., no venía sinó una hembra muy jóven, la minuciosa comparacion quc he hecho con los ejemplares de igual edad y otros adultos, que de Chacabuco me había enviado ántes mi infatigable amigo FÉLIX LyNCH Arribálzaga, y la adquisicion de un lindo ejemplar, hallado en Guaminí, por mi igualmente amigo Máxino Portela, me han permitido fundar la especie con ejemplares adultos. Otras dos de esta familia figuraban en la coleccion: una Cyrtophora y una Tetragnatha; la primera, en extremo jóven, podía dar lugar á errores, porque las espccies dc este género, en tal edad, se confunden fácilmente, por lo ménos las de Buenos Aires, y no queriendo contribuir, á sabiendas, á complicar el laberinto de la sinonímia, he preferido no 
publicarla, - y la segunda, jóven y muy mutilada, la he destruido totalmente, porque de todos modos era inútil. Prescindiendo, pues, de estas dos últimas, resultan 3 Epeiróideas, dos de las cuales eran ya conocidas, y una nueva (E. solitudinis $\mathrm{m}$.) que, al principio, creí fuera igual á la E. granadensis, ó á la E. Salìi Keys. (Beschr. n. u. wog. bek. Art. Orbit.-Isis, 1864, pp. 86 et 93 ), de las cuales, sinembargo, la separan caracteres acentuados.

Las Escitodóideas no vienen representadas sinó por una especie, ya publicada por mí en I876; mas como la descripcion fuera muy rápida y de ningun valor diagnóstico, he dado una nueva y minuciosa de ella.

Las Agalenóidcas no pueden presentar dificultades, haciéndose reconocer por la Tegenaria civilis, WALCK.

Las Drasóideas son cuatro especies, á las cuales he dedicado toda la atencion que podía, no quedando satisfecho del resultado de mis investigaciones, por esto: del Drassus australis, m., no he recibido sinó un ejemplar no adulto, algo destruido, que no he hallado cerca de Buenos Aires, ni ha sido tomado por mis colaboradores en parte alguna, $y$ que no he querido destruir más de lo que lo estaba;--no alcanzo á distinguir en él la oblicuidad de los ejes ópticos de los ojos medianos posteriores, lo cual tiene mucha importancia como caracter diagnóstico de este género;-- del Chiracanthium abnornte, m., no tengo completa seguridad, á pesar de llegar á este género segun la obra de L. KoCH, pero abrigo la sospecha de que esta especie se ha de hallar en Buenos Aires (y casi aseguraría que es la que en mis Arácnidos Argentinos señalé con duda como Clubiona amarantha WALCK.), en cuyo caso podré determinar fijamente su lugar sistemático ;-la causa de esta duda, por otra parte, es la falta completa de espinículas; la tercera especie es una Anyphaena (A. argentina, m.) muy comun en este país, pues la he hallado desde Buenos Aires hasta Salta y EduARDo Aguirre me la trajo en 1876 de Patagones; la cuarta pertenece al mismo género $y$ ha recibido el nombre de Anyplaena pampa, m., no estoy léjos de pensar que alguna vez la he visto en Buenos Aires.

Las Terafosóideas contienen una Eurypelma, que no he hallado descrita en las monografías de Ausserer, ni en los trabajos ulteriores de que he tenido noticia.

Las Heteropodóideas tambien se señalan por una rara especie, única que conozco del interesante género Thomisoides, Nic. (Sicarius, WALCK.).

Las Tomisóideas se caracterizan por dos arañitas, desgraciadamente jóvenes, la primcra de las cuales me despierta sérias dudas, al compararla con las especies bonaerenses congéneres.

Las Licosóideas no me han ofrecido dificultad alguna, pues las dos especies traidas por el Dr. Doering me son bien conocidas: la Tarentula poliostoma (C. KoCH) Keys. y la $T$. moesta, m., de la cual publiqué solamente el nombre en mi obra citada.

De las Atóideas no diré lo mismo que de la familia anterior, pues sus representantes siempre me han of recido sérias dificultades, careciendo de ejemplares bien detcrminados, esto es, p. ej., especies europeas, y sobre todo de una obra en la que los caracteres genéricos se hallaran bien definidos. Hoy, teniendo á mi disposicion la incomparable obra de 
THORELL, On European Spiders, que recien últimamente he podido conseguir, las dificultades se me desvanecen en gran parte, pues los dos Atidas que he recibido, constituyen, á mi juicio, un nuevo género, fundacion que no es de mi agrado, tratándose de esta familia.

Los EsCoRPIONES que he examinado, motivan dos nuevas especies, aunque una de ellas se asemeja mucho á una de las descritas por THORELl en sus Etudes Scorpiologiques (obra que debo á la extremada fineza del autor), pero que me parece presentar suficientes caracteres para separarse.

Los ACARos, finalmente, contienen un Trombidium. No teniendo á mi disposicion, fuera de l'Histoire naturelle des Insectes Aptères de IValckenaer y Gervais y Die Arachniden de C. L. Koch, sinó algunos trabajos ulteriores, exclusivamente dedicados á especies de Acaros del viejo mundo, me veo obligado á aceptar como guia al último autor, pues todavía no he podido conseguir las otras obras que me hubieran servido en el caso actual.

Un Ixodes mutilado, cuya procedencia se ignoraba, era el único representante del órden.

Reuniendo á las 20 especies significadas, la Cyrthophora, la Tetragnatha y el Ixodes, que no publico, resulta un total de 23 especies, recogidas por el Dr. Doering.

No es fácil consultar toda la literatura aracnológica á centenares de leguas de los centros científicos, ni es dado poderla reunir en poco tiempo, sin hacer sacrificios, no siempre posibles. A pesar de esto, creo que no me han faltado las obras esenciales, cuya enumeracion creo innecesaria, para escribir estas páginas. Las principales de WALCKENAER et GERvais, C. L. y L. Koch, Thorell, Keyserling, Simon, Ausserer, Taczanowski etc. se encuentran en mi poder, ó puedo consultarlas en la biblioteca del Museo de la Provincia, cuyo acceso me ha facilitado su sábio Director el Dr. BuRMeister. Gracias á esta circunstancia y á estudios mas prolijos, he podido formalizar mis trabajos, dedicándoles el corto tiempo que me dejan disponible otras obligaciones mas fundamentales.

Hago aquí mencion, más de una vez, de una obra mia, Arácnidos Argentinos, publicada en 1876 . En ella he dado á conocer cerca de cien especies Argentinas, en su mayor parte Arañas, cuyo estudio fundé en la obra de E. Sinon, Histoire Naturelle des Araignées (1864). No tenía pretensiones al publicar ese esqueleto de la Aracno-fauna Argentina, ni era tan ciego para desconocer los graves defectos de la obra que había seguido como modelo, ni tampoco las excelencias que ella tenía; pero, siendo autodidáctico, debía presentar mayor plasticidad, si puede admitirse la expresion, para aceptar, á pesar de todo, el caracter determinado por el modelo, sumision que debió desaparecer al llegar á las Salticiformes expresándome inconvenientemente contra el texto que había adoptado y reconociendo algo que, segun veo en la actualidad, tenía fundamento, pues la obra de THOrell, On European Spiders, arroja hoy un vivo resplandor sobre aquel crepúsculo en que me había envuelto la seductora enumeracion sistemática de Simon. 
Pido disculpa al leetor por lo que me es personal, pero ello se relaeiona con un libro de la familia de los eientíícos y en ninguna parte se eonsigna mejor un justifieativo que al frente de un trabajo que, si no puede servir de modelo, lleva por lo ménos impreso el sello del gran deseo que su autor ha tenido de haeer lo mejor que podía. Aquel primer ensayo es, y será durante mueho tiempo, la base de mis trabajos, no porque él sea bueno, sinó porque, despues de haber leido Recensio critica ete. y On Eurropcan Spiders el autor de los Arácnidos Argentinos tiene la obligacion de revisarlo prolijamente, deseribiendo las espeeies, en él señaladas, de tal manera que tengan eonsisteneia, eomo las del autor de aquellas dos obras. Con tal maestro, espera el discipulo atravesar el Rubieon, y ofreeer á sus eompañeros de tarea el resultado de una aetividad guiada por los prineipios de la verdadera eieneia, en cuanto podemos aleanzarla.

Al reeibir de parte del Dr. Doerıng tan señalada distincion eomo era el invitarme á tomar parte en la redaeeion del informe de la Comision Científica, he pensado que de ningun modo mejor podría manifestar mi gratitud que dedicando todo mi esfuerzo para el es. tudio pro'ijo de las siguientes especies, para la preparacion de las láminas que las ilustran, dirijiendo, al mismo tiempo, su traslado á las piedras, para suplir así la falta de práctica de nuestros artistas, en la eonfeeeion de un trabajo de cuyo género no todos los dias salen pruebas de las prensas litograficas de este país.

\section{A R A $\widetilde{N} A S$}

Fam. EPEIROIDAE.

Gen, Ar.giope, Sav, et Aud. (1825-27).

\section{ARgIOPE ARGENTAta (Fabricius), Koci.}

Líx. III, ff. $1,1 a, 1 b$.

Syn. :-(1798) Aranea argentata, FABr., Eutomol. system, II, p. 414, n. 27.

(1839) Argyopes argentatus, C. L. KocH, Die Arachiden, V, p. 38, pl. CLIV, f. 360.

(1876) $\Rightarrow$ D - E. L. Holmberg, Arácnidos Argentinos, in Anales de Agricultura de la República Argentina, T. IV.Separ. $4^{\circ}$, P. 19, n. 42 .

Nota-Exemplum juveneum hujus vulgarissimae speciei prope ripan "Rio Colorado», nidumque quoquè in Sierra de la Ventana collegit Dr. Doerixe.

Esta linda espeeie es abundantísima en la Repúbliea, á tal extremo que, en los eereados y bosqueeillos de Tueuman, p. ej., se eneuentra eon tanta freeueneia como el Pholcus phalangioides en los rineones de las habitaeiones humanas. En las otras eomareas que 
he visitado, esta Argiope ha aparccido siempre, exccpto, sin embargo, en Patagones, donde no.seria extraño que existicra, ya que su dispersion alcanza hasta las orillas del Rio Colorado.

No cstoy léjos de crecr que he visto cerca de mil individuos de esta araña, entre los cuales no se contaba un solo macho, ni tengo conocimicnto de que aracnólogo alguno lo haya obtenido ó descrito.

Respecto de la literatura y sinonímia relativas á esta especic, puede verse L. TACZANowski, Les Aranéides de la Guyane Francaise, pt. III, p. 261, n. 62, in Hor. Soc. Ent. Ros. IX, He agregado mi obra á la sinonímia esencial, porque cn ella, por vez primera, se extiendc á latitudes tan meridionales el área de dispersion de la especie, dispersion que aumenta algunos grados más, debido á la última adquisicion del Dr DOERING.

(ien. IApoirat (WALCK, 1805), THORELL (1869).

2. EPEIRA SOLITUdiNis, Honmberg, n, sp.

L.iM. III, $\mathrm{tf}, 2,2 a 2 b, \mathbb{d}$.

Fem. : Ep. cephalotorace latitudine longitudinis tibiae 1i. paris, longitudinem metatarsi 4i.paris rix superante, longituline longitudinis fomoris $4 i$. paris pedum, obscure fusco-subnigro margine griseo-fuscescenti-patlida, albo-piloso; mandibulis longituline latitulinis frontis obscure testaceo-fermyineis, apice obscuriorilns, maxillis lubioque testuceo-fermgineis, al basin nigricantibus, sterno nigricanti, fasciu longitudinali fermgineo-flavida vix aurantiaca; palpis pedbusque sordide flarido-ferragineis, nigro-amulatis et spinosis. ulbo-pilosis, quasi tomcntosis; abdomine oveto, antice rotundato quem postice latiore obscure fusco, pilis albis consperso; area dorsualis antica triangulis deobues latissimis irregularibus et posterius citte media amm versus sensim evanescenti et angustata albido-cinnamomeis; triangulis illis inter se et cum hae vitta conjunctis; area postica lineolis parvis transtcrsis vittae illae utrinque ejesdem coloris, maryimibus earundem eranescentibus; area dorsuali tota à linea undulata plus minusce intermpta, utrinune limituta, hac cum maculis subquadratis extus conjuncta cjusdem coloris, his antem à linea undulate per nimbram fuscam pallide punctatam separatis; figura palliela dorsuali plus minuste obscure fusco-prenctata rel maculata; parte antica lateribusque abdominis pallide cinnamomeo-prenctatis; mammillis fuscis aureola Hhwicanti circumdatis tribus lincis direryentibus subobsoletis hujns coloris ventre sordide fusco.

Nota-Dom. Félix Lxich Arribálzaga quatuor feminas hujus speciei, una adulta alteraeque juniores, in ('hacabucos (Prorincia Bonaërensi) primus collegit et amicissime dono mihi dedit; post eum individum feminem juniorem in sierra Pichi-Nabuida reperit Dr. A. Doening; ultimis diebus Dom. Míxuno Portela, in Guminis feminam alteram invenit.

\section{MEDIDAS DE LA HEMBRA}

Lougitud total . . . . . . . . $0.012 \mathrm{~mm}$. || Longitud de los palpos . . . . . 0.005 mm.

2) del cefalotórax ....... 0.005

Altura del tárax .......... 0.00275

Latitud de la frente . . . . . . . 0.002

3) del tórax. ........... 0.0045

Longitud del estermon. . . . . . . 0.0025

Iatitud dol id ......... $0,000^{\circ}$

\begin{tabular}{|c|c|}
\hline de la mandibula. . . . . . & $0.000^{\circ}$ \\
\hline 1 abdómen hasta & \\
\hline $\begin{array}{l}\text { hiladeras.... } \\
\text { abd, destle el aranzamie }\end{array}$ & 0.005 \\
\hline 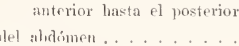 & \\
\hline
\end{tabular}




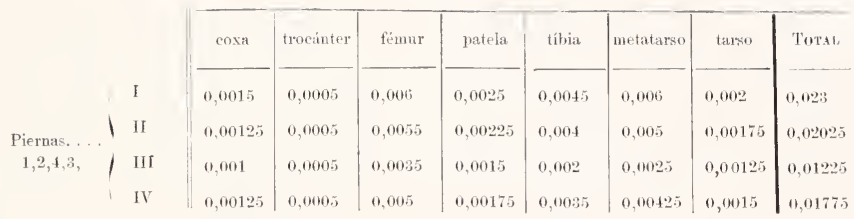

ForMA-El cefalotórax es de forma comun, esto es, cordiforme, truncado por delante, con los lados de la cabeza casi paralelos entre sí, apénas gradualmente mís separados en su union con los bordes del tórax, que son bien redondeado;, de tal modo que sus arcos, unidos por detrás y por delante, formarian un círculo; la parte posterior muy poco escotada; por arriba es convexo, con la bifurcacion bien marcada, en cuyo vértice se vé la foseta (fovea) poco profunda y cuyas irradiaciones apénas se señalan; todo él cubierto de pelos asentados, excepto en los costados, donde rozan los palpos, y en el cuadrado de los ojos centrales; es tan largo como el fémur del cuarto par, su anchura iguala á la longitud de la tíbia del primer par, superando apénas la longitud del metatárso del cuarto par. Los ojos están colocados en tubérculos poco prominentes; el grupo central forma un trapecio apénas mís ancho por debajo, pues una línea tangente al borde externo de los OMP (1), sólo dejaría hácia fuera un tercio de los OMA correspondientes, los cuales se encuentran en un plano muy poco más avanzado que aquellos; la distancia que separa entre ;sí los OMA es igual al diámetro de éstos y á la que média entre ellos y los OMP, separados entre sí tanto como su própio diámetro, que equivale, más ó ménos, á tres cuartos del de los anteriores;-mirando el animal de frente, los OMA se hallan separados del borde estomático tanto como su própio diámetro; los OL están separados del grupo central tanto como la mayor anchura de éste, hallándose tan próximos entre sí, que con dificultad se distingue la linea que los separa; ambos tienen casi un mismo diámetro, aunque el LP es aparentemente algo mayor, pues el LA es un tanto ovalado; el OLP se halla en un plano un poco más exterior que el OLA, de tal modo que un plano que pasara por la base de aquel, visto de arriba, sería secante de éste cerca de la tangente; un plano vertical, tangente por delante á los OMP, lo sería del mismo modo á los OLA y pasaría por detrás de los OMA; la fila anterior es casi recta, mirando el animal de adelante. El esternon es triangular cordiforme, muy poco mas largo que ancho, con una suavísima depresion transversal y pequeñas eminencias correspondientes á las coxas. El lábio es nítido y visiblemente más ancho que largo, con el borde libre formando un ángulo muy obtuso. Las maxilas, nítidas tambien, sub-cuadradas, más angostas en la base, convexas, de ángulos redondeados y con cerditas negras. Las mandibulas do-

(1) $O=$ ojo ; $\mathrm{YI}=$ medio ; $\mathrm{P}=$ posterior ; $\mathrm{\Lambda}=$ anterior ; $\mathrm{L}=$ lateral $;$ tanto en singular couro en plural, scgun lo determine el artículo. 
blemente largas que anchas, lustrosas, un poco gibosas por delante, cerca de la base, donde son mas anchas que en el ápicc, siendo tán espesas como la tíbia del primer par y prescntando rugosidades transversas poco marcadas; la tenaza es tan larga como la mitad de las mandíbulas. Los palpos y las piemas son de forma ordinaria, cubiertos de numcrosas espinículas que nacen, en su mayor parte, de tuberculillos poco prominentes, hallándose vertidos de pelos cortos y delgados. El abdoncn ovóidc, más largo que ancho, más ancho que alto, gradualmente más angosto hácia atrás, redondeado por delan1c visto de lado $\mathrm{y}$ de arriba, casi obtuso cerca de las hiladeras, fuertementc reclinado sobie el tórax, del cual cubre más de un tércio, se halla cubicrto de pclitos cortos y asentados. El cpiginio está constituido por una placa oval, transversal, un poco convexa, terminada por un apéndice cónico, un tanto deprimido, arqueado hácia abajo (tomando el conjunto del animal), esto cs, con la punta alejándose del vientre; tanto la placa como su apéndice prescntan rugosidades transversales, siendo todo de un color pícco claro, con dos manchitas oscuras cn el disco, una á cada lado; estas manchitas están rodeadas de cerdas cortas, negras y blancas, siendo de este último color otras que se encuentran en la banda media, y que convergen dirigiéndose al apéndice. Separándolo del abdómen, el órgano aparece en el microscópio con cl aspecto que presenta la fig. 2 b (Lám. III), esto es, el cpiginio rugoso $(c)$ visto de atrás, con su aṕndice $(c)$, y un ancho tabique $(t)$ que separa las dos abcrturas vulvales ( $\left.i^{\prime}\right)$; cste tabique se cnsancha en su contacto con el epiginio, y un poco atrás de los hoyuclos se dilata bastante;- esta porcion parece que asienta sobre el vientre; - á cada lado de la parte más estrecha del tabique, se ven dos eminencias transversales ( $m$ ) que, al parecer, son ménos elevadas que d tabique en la porcion que se unc con ćl, son algo arqueadas con la convexidad hácia atrás; en su extremidad, por debajo, cnvian una crestita arqucada $(c r)$ que vá á tcrminar, dirigiéndose hácia la opuesta, cerca de la base del tabique, penctrando allí cis la cavidad de la vulva; por dentro de esta crestita nace otra que baja más aún y que, arqueándose, pasa cerca del tabique y luego termina debajo de la cminencia transversal; de csta segunda cresta nace otra pequeña, formando así todo lo que puede distinguirse en el interior de la vulva. Las hiladeras son muy cortas, apúnas salientes.

\section{ESPINAS DE LAS PIERNAS.}

I par: Fémur arriba 1,2,2,2,2, adclante 1.1.1.1., atrás 1.1.1.1.1., abajo: dos filas, la anterior de 9, la posterior de 12. Putela ariba 1.1. (1. 1.1. en la pierna derecha), adelante 1. 1., atrás 1.1. Tíbia amiba 1.1.1.1., adelante 1.1.1.1.1., atrús 1.1.1., abajo 2.2.2.2.2.2.2. Metarso arriba 1., adelante 1., atrás 1. abajo $2,2,2,2,2,2$.

II : Fémur arriba 1.2, 2. 2.2., adelante 1. 1.1.1.1., atris 1.1.1., abajo: dos filas, la anterior de 9, la posterior de 8. Patela arriba 1.1., arlelante 1.1., atrás 1. 1. Tíbia arriba 1. 1.1.1., adelante 1.1.1.1.1., atrís 1.1.1., abajo 2.2.2.2. Netatarso ariba 1., adelante 1., atrás 1., abujo 2.2.2.2. 2

III : Femur ariba 1.1.1., adelante 1.1.1.1., atrais 1.11. (casi superiores), abajo: 2 filas, la anterior de 4, la posterior de 5. Patela amiba 1,1., adelante 1, 1, atrás 1, 1, Tíbia arriba 1,1. 
adelante 1. 1 1., atris 1. 1., abajo 2. 2. 2. Metatarso arriba 1. 1., adelante 1. 1., atrás 1., abajo 2. 2. 2. 2.

IV * : Fémur arriba 1. 1. 2., aulelente 1. 1. 1., abajo 1. 1. 2. Patela arriba 1. 1., adelante 1. 1., atrás 1. 1., Tibia arriba 1. 1. 1., adelante 1. 1. 1., atrás 1. 1. 1., abajo 2. 2. 2. 2. Metatarso arriba 1. 1., adelunte 1. 1., atris 1., abajo 2. 2. 2.

Color-El cefalotórax, cubicrto de pelos blancos, es de un eolor moreno oscuro algo rojizo, siendo más pálido en la region inter- y circumocular y en el occipucio, ó sea ésta la parte posterior de la cabeza, comprendida inmediatamente entre la bifurcacion; la márgen externa, tanto de la cabeza como del tórax, de un tinte amarillento agrisado claro. listemon moreno oscuro, cubierto de pelos esparcidos del mismo color, y con una banda media, más angosta hácia el peciolo; amarillento-ferruginosa, casi anaranjada. Mandibulas amarillento-ferruginosas, algo parduzcas, con los lados y el extremo cscuros, casi morenos, siendo pardorroja la tenaza con base morena. Nlaxilas y lábio lustrosos, de un color amarillo ferruginoso y con la base pícea. Palpos amarillentos ferruginosos claros, más oscuros en los últimos artículos, siendo parduzco el ápice del fémur en el dorso, el dorso y el ápice de la patela y casi eompletamente la tíbia y el tarso; están eubiertos de pelitos blancos, entremczclados de pardos en los últimos artículos y de espiniculas negruzcas. Piernas de un tinte súcio amarillento-ferruginoso, irregularmente lavado de pardo en las coxas, en el trocánter y en la articulacion fémoro-trocanteriana, incluyendo la extrema base del fémur, un anillo irregular en el medio de éste, y otro más oscuro en su extremidad patelar; las patelas tienen parda la base y la extremidad, siendo ésta más oscura; del mismo eolorson la extrema base de las tíbias, un anillo al fin de su primer tercio y todo el último; los metatarsos y tarsos, más ferruginosos y oscuros que el resto, muestran, especialmente los primeros, tres anillos pardos en sus dos primeros tercios, que se funden en el eolor general, y su ápice, así como el de los tarsos, tambien pardo fundente; las piernas se hallan cubiertas de pelitos blancos, que se vuelven parduzcos y aún morenos en los dos últimos artículos; las espinículas pardas nacen en manchitas del mismo color en el fémur, en la patela y en la tíbia. El abdómen pardo oscuro, cubierto de pelitos blancos, algo sedosos; el área dorsal anterior presenta dos triángulos muy anchos, blancus acanelados (?), que ocupan los dos quintos del dorso; ellos no tienen una forma bien definida, pues sus ángulos laterales son algo redondeados, y los lados algo eurvos hácia adentro; el primer triángulo tiene el ángulo anterior redondeado y dentro de él una manchita pardo-rojiza, ovalada, transversa, una estría del mismo eolor en eada expansion lateral y dos puntitos en el borde posterior, apénas mas separados de la porcion de eonfluencia del siguiente triángulo; en el centro de éste se vé una manchita irregular, angulosa y euatro puntos (::) hácia adelante de ella, todo pardo; en el borde posterior de este segundo triángulo, nace una banda longitudinal del mismo eolor, que se atenúa y desvanece gradualmente, hasta llegar al comicnzo del último quinto; á poco más de un milímetro de su nacimiento tiene, á eada lado, una rayita transversa, siendo eortada en su mitad posterior por cinco rayitas, transversas tambien, - esta banda, asi como las rayas costiformes que en ella nacen, está salpicada de pun- 
titos pardos; a cada lado de csta figura dorsal hay una línca ondulantc, que, cn su primera porcion, sc intcrrumpe cn la emincncia de cada una de las tres primcras onclas entrantes, correspondicndo las tres primeras ondas salientes á los ángulos laterales de los triángulos yá la primera raya transversa; despucs corre casi paralela, habiéndose aproximado á la opuesta, estando entónces unidacon las rayitas transversas; hácia fuera y ocupando el cspacio abierto que forman las tres primeras ondas entrantes, se encuentran, á cada lado, tres manchas rombiformcs, claras tambien, separadas antcriormcnte de la línea ondulante por una raya pardo-oscura, y del seno mismo de la onda por un oscurccimiento irregular, pardo, de puntos oscuros mas ó menos conflucntes, donde se destaca uno claro, bien redondo; hay detrás de cllos como el comienzo de un cuarto rombo, pcro apcnas se definc por una manchita clara; - la línca ondulante parece continuarse anteriormente por una fila de puntos que sc dirige casi transversalmente hácia la línea média, vinicndo á terminar al lado de la porcion anterior del primcr triángulo dorsal. La parte anterior del abdómen y los costados, estan cubiertos de puntos ó manchitas de color claro, hallándose tan próximos en las inmediaciones del peciolo, por arriba, que forman un limbo claro á la porcion oscura que lo rodea; en csa parte clara, los pclitos están tambien mas próximos. Las hiluderas, la áulva y las placas pulnonales son píceas, éstas con el bordc más claro y las primeras circundadas de una aureola amarillenta, casi anaranjada, nó continua, formada como de pigmento y destacándosc sobre un fondo píceo,-ella envía hícia adelante dos rayas del mismo color, quc limitan el vientre pardo-oscuro, pero casi perdidas, esto cs, bastante difusas, así como una rayita média, colocada entre la vulva y las hiladeras; algunos pelitos negros, dispersos en los costados y en el vientre, completan la vestidura del abdómcn.

OBservaciones.---Parece que esta especic abarca, en su dispersion, un área considerable, pues los ejemplares quc he recibido proceden de Chacabuco, Guaminí y Pichi-Mahuida, siendo de estc último punto de donde trajo cl Dr. DoERING un ejemplar muy jóven que comparé con los de igual edad que me había enviado FÉLIx LrNCH del primero. En El Naturalista Argentino, T. I, p. 338, he hecho referencia á una araña descubierta por mı en el Partido del Pilar, en Marzo de 1878 , mas, como no conservo los ejemplares que cacé, no puodo decidir si es la misma, aunque abrigo vchementcs sospechas de que lo sea, cn cuyo caso, el dibujo claro del abdómen es blanco y nó pallidé cinnamoneus como digo en la diagnosis, como es blanco el de otras especies muy semejantcs, si algunas no son la misma, que se encuentran esparcidas por toda la Rcpública, y cuyo color se transforma en acanelado pálido por la accion del alcohol, Así, las Epeiras granadcnsis y Salci del Conde de Keyserling, que son muy próximas á la nuestra, y de la cual se distinguen fácilmente, dcben tencr dibujo blanco tambien. Nuevas investigaciones nos darán á conocer lo que haya al respecto. Entretanto, no vacilo en adelantar la siguiente conjetura, fundada en recuerdos mas ó menos fijos: la especie se halla difundida por toda la República, teniendosu foco en las regiones tropicales y modificando su celda y relaciones de ésta con la tela segun el medio que la rodea. Sospecho que la vestidura de pelos 
blancos del dorso abdominal, en el animal fresco, es más espesa, disimulando un tanto lo vivo de los dibujos.

\section{EPEIRA LATHYRINA, Holmberg.}

syn.: (1875) El). Luthyrina, Hocm, Descriptions et notices à Arachides de la Ripublique Argentine in Periódico Zoológico, T. 1, p. 282, Pl. VI, f. 1.

(18i6) "Arienidos Aigentinos in An, de Agric, de la Rep. Arg. T. IV.... Separ. $4^{\circ}, p+16, \mathrm{n}, 36$.

(18:8) Ep. monteridensis, Kexserdixg, Spinnen aus Uruguay u. einig. andn. Geg. Amerikas, in Verhandl, der k,-k, zool,-bot. Ges., Wien, T. XXVII, P. 571, Lim, XIV, ff. 1-2.

Jora.-Feminam immaturam prope ripam Rio Negro invenit Dr. Doenixc.

La larga descripcion que he dado de esta especie, me autoriza á reclamar la prioridad, nó por hacer cuestion de ésta, sinó porquc, de no aceptar aquella, tendríamos que desconocer muchas de los autores, que pasan por suficientes. Sin embargo, debo declarar que, aunque mi descripcion dá prioridad al nombre, la del Conde Kexsertivg tiene la excelencia.

Fan, SCYTODOIDAE

Giem. Soytodos LATREILLE (1804) v. THoR.

4. SCYTULES MACULATA Holmberi.

LÁx. III, ff. $3,8 a, 3 b, \mathbb{d}$.

Syn. : (1876) Siytoda maculata, Hozmb., Arác. Argent.. in An. de Agrie. de la Rep. Argent., Tom. IV. Separ. $4^{\circ}$, p. 3 , n. 1 .

Fem.: Sc. cephalothorace, cuja longitudo longitudinem patellae + tibiac 3i. paris acquat, pedibusque rufescenti-testaceis, his annulis maculisque nigris eel obscure brumeis, illo notutione palluda $\boldsymbol{T}$-formi med io a linea obscura longitudinaliter divisa onnato, margine obseurc maculato, lineola undulata prope maculas marginales et reliquo dorso, plus minus a testaceo irrorato, obscure brumco; man. dibulis fermgineis macula antica vel dorsuali nigra; abdomine griseo-flarido-fuscescenti, fascia media ex maculis graiculatis constituta, scriebus transersis punctorum alternantibus, lateribus centreque manulis, strigis punctisque conspersis nigricantibus; palporum apice duobus apendicibus breribus, cglindraceis, parm arcuatis, extremitate vix incrassatis; unguicula infora 1i: paris umidentata, 4i. paris bidcntate (?); aperturis meac separatis, subrotundatis, marginatis.

Mas: Coloribus formaque feminac, pedibus autem longioribus et proportionaliter gracilioribus, cephalothorace longitudinem tibiae 3i. paris non attingchtc, palporm articulo apicali elongato, gracile, ad basin incrassato, subtus emarginato, brelbo copulationis ad basin incrassato, dcinde conico-elongato, graciliusculo, apicem cersus scnsim dilatato, depresso, carinato, apendicibus duobus unguiformibus apicc ipso ct ante eosaltero minore instructo.

Nota - Individum femineum unicum immaturum hujus vulgarissimae araneae a Dre. Doerse in Paso de Pachecos (Rio Colorado) repertum (nune detritum) emm exemplis phribus collectione mea servatis lustrari r-1 his noxam dexeriptionem speciei feci. 


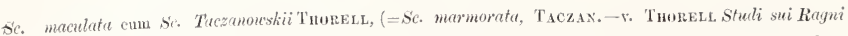
Mulesi e Papmani, II, p. 160) affinis esse videtur, differt autem, iuter aliquos characteres, longitndine pedum formaque conjunctoris; magis cum Sc. globulu, XIC. (Fand Chil.), a qua parum differt, nisi figurae imperfectae fuissent, affinis est; si figuram sol am feminae et Tab. II, sine partibus anatomiae maris neque uensuris dedisset auctor pro ea verisimiliter babuissem, differentia autem bulbi maris, longitudinis pedum picturaeque abdominis pro diversa specie habere me ducunt.

\section{MEDHDAS DE LA HEMBRA}

Longitnd total. ......... $0.008 \mathrm{~mm}$... Latitnd del esternon . . . . . 0.0015 nim.

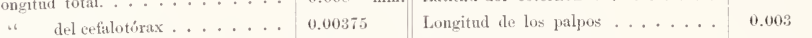

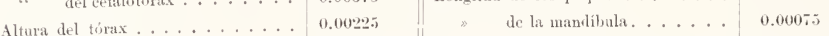

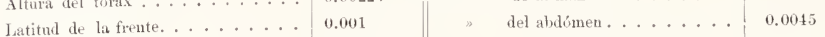

" del túrax ......... 0.003 "... "

Longitud de esternon ....... $0.002 \quad$ Latitud del id ..... . . . . 0.0035

\begin{tabular}{|c|c|c|c|c|c|c|c|c|c|}
\hline & & $\operatorname{cox} a$ & troctinter & fémur & patela & tíbia & metatarso & tarso & TotaL \\
\hline \multirow{4}{*}{$\begin{array}{r}\text { Pieruas.. } \\
1,2,4,3 .\end{array}$} & I & 0,001 & 0,0005 & 0,0055 & 0,001 & 0,0065 & 0,0075 & 0,00125 & 0,02325 \\
\hline & II & 0,001 & 0,0005 & 0,005 & 0,00075 & 0,005 & 0,00575 & 0,001 & 0,019 \\
\hline & III & 0,00075 & 0,0003 & 0,001 & 0,00075 & 0,003 & 0,0035 & 0,001 & 0,0138 \\
\hline & IV & 0,001 & 0,00005 & 0,0015 & 0,001 & 0,0045 & 0,00475 & 0,00125 & 0,0175 \\
\hline
\end{tabular}

\section{MEDIDAS DEL MACHU}

Longitud total .......... $0.0085 \mathrm{~mm} . \mid$ Lougitud del copulador. . . . . . 0.00125 mm.

„ del cefalotórax....... 0.0035

Altura del tórax ................. 0.002

Latitud de la freute......... 0.001

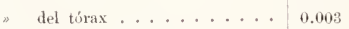

Longitud de los palpos. . . . . 0.003

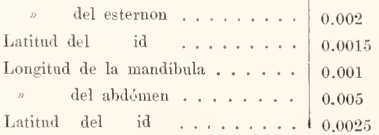

\begin{tabular}{|c|c|c|c|c|c|c|c|c|c|}
\hline & & & & & & & & & \\
\hline & & $\cos a$ & trocinter & fëmur & patela & tíbia & metatarso & tarso & Total. \\
\hline & I & 0,0011 & 0,0005 & 0,0095 & 0,001 & 0,010 & 0,0013 & 0,0014 & 0,0365 \\
\hline Piernas... & UI & 0,001 & 0,0005 & 0,007 & 0,001 & 0,00675 & 0,0085 & 0,0011 & $0,025,85$ \\
\hline & III & 0,00075 & 0,0003 & 0,005 & 0,0008 & 0,0044 & 0,005 & 0,001 & 0,01725 \\
\hline & IV & 0.001 & $0,000.5$ & 0,007 & 0,001 & $0,006 \mathrm{i}$ & 0,007 & 0,00125 & 0,02875 \\
\hline
\end{tabular}

DESCRIPCTON DE LA HEMBRA

Forma.-El cefalatórax es oval, giboso en la parte posterior, más largo que ancho, más ancho que alto, tan largo como la patela+la tíbia del tercer par de piernas, tan ancho coms el largo de la tíbia del misms, inclina lo hácia adelante, en curva suave, 
más violenta hácia atrás, no alcanzando, sin embargo, á reclinarse sobre el abdómen, con el epístoma muy poco avanzado y truncado, apénas escotado visto de arriba, y cuyos ángulos descienden un poco, y presentan sobre ellos una depresion; lleva pelos cortos $y$ rígidos desde la cima de la giba, por el dorso, hasta el epístoma; estos pelos se hallan colocados en séries más ó ménos regulares y nacen en tuberculitos pequeños. Es muy suavemente ondulado en los bordes, en correspondencia con las piernas; los costados son más inclinados, casi rectos, sin pelos. Los ONI ó $\mathrm{A}$, redondos, muy juntos, pero visiblemente separados, distan del borde epistomático tanto como su propio diámetro; se hallan situados en una pequeña eminencia, de tal modo que su borde de contacto está más arriba que el borde externo, viniendo á tener así sus bases oblicuadas; los dos pares de OP se hallan, entre sí, más distantes que de los $\mathrm{OA}$, en un tuberculillo análogo, son tambien redondos, el anterior apénas mayor que el posterior; los planos de sus bases son casi verticales en ángulo recto, el primero mira hácia adelante y afuera, el segundo hácia fuera y atrás, apareciendo por arriba una porcion, como un triángulo horizontal, del tuberculillo que los lleva. Esternon oval, truncado por delante, redondeado por detrás, con cuatro eminencias á cada lado, correspondiendo á las cuatro coxas, esto es, opuestas á ellas, separadas por depresiones, donde se escota muy poco el borde,- - es un tanto lustroso, como las coxas, y lleva algunas cerditas esparcidas. Lábio trapeciforme, más ancho en la base, donde parece soldado con el esternon, del cual lo separa una depresion fuerte; es redondeado en su borde libre, convexo en la mayor parte de su extension, con el borde anterior y parte de los laterales marginados, cubierto de cerditas esparcidas y frangeado en el ápice. Marilas mas largas que anchas, se juntan por delante del lábio, al cual contornean, de tal modo que su borde de union es un poco más corto que el largo del lábio;-son convexas en el sentido de su longitud y en su dilatacion, se dilatan en la base, y así, su conjunto, viene á tener casi el mismo contorno que el lábio; tambien se hallan cubiertas de pelitos ó cerditas esparcidas. Mandíbulas oblícuas hácia abajo, un poco estrechadas en la base, despues de la cual se dilatan suavemente por fuera para volverse á. estrechar cerca de la extremidad; son cilindro-convexas, pero su convexidad es más marcada cerca del borde interno, cubiertas de cerditas, al parecer más finas que las que se observan en las maxilas y en el lábio. Palpos cortos, el último artículo más largo que el penúltimo, y más estrecho, engrosado en la base (v. Lám. III); en el ápice presenta dos uñuelas transformadas en apéndices rígidos, cortos, cilíndricos, poco arqueados hácia abajo, truncados y apénas mas anchos en el ápice; los pelos que los circundan son plumosos, y aún me ha parecido distinguir que las barbillas son verticiladas. Los apéndices no son tan largos como en la Dictis striatipes L. Косн (Die Arachn. Austr. p. 294, pl. 24, ff. 5 y 6) sinó tanto como el diámetro del último tercio del artículo palpal en que se encuentran. Pier. nas largas, delgadas, siéndolo más gradualmente el metatarso, con ocho filas equidistantes de cerditas arqueadas hácia la extremidad de los miembros. El primer par (varios indivíduos observados) lleva dos uñuelas grandes, pectinadas, la anterior con dos filas de dien- 
tes, una de las cuales no parece salir de un lado de la otra, sinó que ambas filas tienen una insercion scmcjante, como resultaría si dobláramos una tira de papel y reeortáramos á un tiempo los dos bordes unidos; no he podido contar sinó ocho dientes en cada fila;la uña posterior (nó la inferior) tiene los dientes más grandes, más paralelos, siendo el apical el mayor y más divergente, - he contado diez; la uñuela inferior (aftcrkralle de los autores alemanes) tiene su extremidad larga, aguda y casi en ángulo recto con el lomo,- - detrás de ella hay un diente como de dos quintos de su longitud, y más hácia la base un lóbulo redóndeado. El cuarto par lleva dos uñuelas unipeetinadas (varias observaciones), los dientes son más espaciados y más cortos, siendo el apical el más largo y divergente; - incluyendo éste, he contado ocho dientes en la anterior, y, en el mismo easo, sicte en la posterior; la uñuela inferior es muy pequeña, con tres dientes cortos, contando cl extremo (una observacion segura, las otras imperfeetas); los pelos que las rodean plumosos como los del palpo y algunos ensiformes, algo arqueados, dentados en sierra, eomo en las Epeiróideas etc, El abdómcn es globuloso, un tanto oval, siendo más largo que ancho, apénas más angosto por detrás y un poco saliente, sin violencia, en la region de las hiladeras. La vulva consta de dos aberturas muy separadas, redondeadas, marginadas de sustancía quitinosa. Las hiladeras son muy eortas, apénas salientes.

COLOR.-El cefalotórax es de un color testáceo más ó ménos agrisado, tornándosc ocráceo en los ejemplares conservados en alcohol; sobre dieho fondo predominan diversas manchas de color pardo-rojizo oseuro, que no siempre conservan una disposicion idćntica, pues sus bordes son más ó ménos regulares unas veces y otras bien limitados por contorno limpio, pero siempre obedecen, no obstante sus modifieaciones, al tipo específico. Por esta razon me veo obligado á prescindir de lo que he dieho en general sobre el fondo, para poder definir mejor la distribucion del claro y del oscuro, y, para simplifiear, diré oscuro cuando se trate del pardo-rojizo oscuro indicado, y claro en el otro caso. En el borde del tórax, y correspondiendo á cada coxa, se vé una manchita oscura, más ó ménos regular; unas veces, ęstas manchitas están separadas, otras, se hallan reunidas por una linea muy fina, en cuyo caso puede deeirse que el extremo borde del tórax cs oseuro, con ampliaciones háeia arriba, en las porciones correspondientes á las coxas. De la parte anterior, hácia la altura de los palpos, naee una línea oscura, ondulante, que termina cerca del borde posterior, pasando por encima de las manchas narginales, á las cuales corresponden sus ondas ascendentes, y estando separada de cllas por el fondo claro. Hácia arriba de esta línea, y en contacto eon ella, se presenta otra de color claro, que nace en el ángulo de la boca, pasa al lado de la frente, á la cual limita, y dirijiéndose hácia atrás separa al dorso oscuro de la línea ondulante mencionada; esta banda clara se estreeha y dilata alternativamente, de tal modo que sus ampliaeiones coineiden con las concavidades de la línea ondulante, y las correspondientes del borde, onduloso tambien, del dorso oscuro; en otros términos, el borde del eolor oscuro del dorso es ondulante, y sus ampliaciones coinciden eon eada mancha del borde toráeico; entre éstas y aquel corre la línea oscura ondu- 
lante y como sus ondas son opuestas á las del borde del oscuro del dorso, resulta de aquí la forma de la banda clara. Hácia adelantc de los ojos anteriorcs hay una lúnula clara, transversa, de concavidad posterior y muy ténuc; los tres grupos de ojos están circundados de negro, especialmente hácia atrás; de la parte que corrcsponde al grupo antcrior, nace una banda más rojiza que se dirije hácia atrás, en cuya linea media suclen verse dos lineolas claras, muy finas, soldadas á vcces, y á cada lado otra más ó ménos acodada, clara, con ángulo hácia la línca media; la banda rojiza, despucs de habcrse dilatado un poco, sc cstrccha cn la mayor gibosidad del tórax, y á veces sc corta, pero en cste punto ya sc aclara, desccndiendo, gradualmente más dilatada, por el declive postcrior. A cada lado de dicha banda mcdia sc vé una mancha clara formada por una línea paralela y cn contacto con la banda media, y dos ampliacioncs hácia fucra, la anterior marcadamentc cuadrangular y mayor que la posterior ménos bien contorneada;-podría darse una idca de csta mancha ó dibujo claro, diciendo que parece una $\boldsymbol{T}$, cortada longitudinalmentc por la banda mcdia. La porcion que circunda esta figura clara cs casi negra; algunos puntitos claros sc observan á veces sobre cl resto dd color oscuro del dorso. Esternon testáceo, con bordes laterales, ampliaciones oblicuadas de éstos, correspondicndo á las coxas y puntitos más ó ménos grandes de color oscuro. Lábio testácco rojizo, con el borde antcrior algo parduzco. Maxilas del color del lábio, con una línea oscura que pasa á lo largo cn contacto con la insercion del trocanter palpal. Naudtbulas rojizas, algo parduzcas, con una mancha triangular, negra, en el dorso. Palpos ocráceos, con puntitos y pequeñas manchas oscuras. Coxas ocráceas, con el ápice moreno, casi negro; el resto de las piernas del misno color quc las coxas; fímures con puntos, manchas más ó ménos irregulares y anillos de color oscuro, éstos, generalmente, completos ccrca de la patela; la patela igualmente manchada, con cspecialidad á los lados; las tíbias con cuatro anillos oscuros, bastante regularcs, el primero en la basc, cl último en el ápice y alternándosc con los de color ocráceo que los separan; los metatarsos tienen cuatro anillos semejantes, pero muy apagados, siendo el basal el que mejor se define generalmente, Abdómen gris testáceo parduzco con una banda media, dorsal, de manchitas oscuras, alargadas, apareadas, divergentes hácia atrás, cada par scparado por una série de puntos paralclos á aquellas y que se destacan sobrc la parte de fondo claro que media entre cada par de manchas, $y$, á los lados, manchas irregularcs que alternan con puntos dispcrsos y séries de estrias dcl mismo color oscuro; en el vientrc, las manchas están ménos aproximadas, habiendo una de cllas entre el pcciolo y la vulva, =las márgenes de las aberturas de ésta y las hiladeras de color rojizo. Pelos del dorso del cefalotórax negros, - los del resto del cuerpo parduzcos, más ó ménos claros.

\section{Descripcion det Macho.}

Fonus.-Fuera de las diferencias sexuales y de las que resultan de la proporcionalidad de las medidas consignadas, el macho no difiere esencialnente de la hembra en cuanto á os caracteres generales de su estructura. Comparando, sin embargo, las medidas absolutas 
de ámbos sexos entre sí, se observa que el macho cs apénas mas largo, lo cual depende de quc la medida de la hembra ha sido tomada en ejcmplares que ya habian pucsto sus hucvos, antes de cuyo acto el abdómen es más largo, como lo he hecho notar en la página I28. El cefalotórax, cn cl macho, es proporcionalmente algo más bajo que en la hembra, sicndo su longitud mucho menor que cl largo de la patela + la tíbia del tercer par, y aún más corto que la misma tíbia, y su ancho igual á la mitad de la longitud de la tíbia dcl cuarto par. Los OP, por otra parte, sc hallan colocados en tubérculos un tanto mayorcs. En las maxilas me la parccido notar una pequeña depresion transversa al comenzar el último tcrcio; e; muy suave y poco scnsible. La otra diferencia se obscrva en la longitud de las mandibulas, $=\frac{8}{4}$ de $\mathrm{mm}$. cn la hembra y $\mathrm{I} \mathrm{mm}$. en el macho; pero rcconozco ahora que depende del estado de los órganos, pues con frecuencia se nota en ellos algo como un avanzamicnto, sicndo acompañados por los tcjidos blandos de la base, que toman cntónccs el aspecto de líbios internos, y, midiendo un ejemplar, en el que no se laya verificado tal cosa, desdc el ápicc de la mandibula hasta el borde del clipeo, hay una pequeña difercncia de poco valor. Las picrnas son absoluta y relativamente más largas que en la hcmbra, como pucde rcconoccrse comparando las figuras y las mcdidas; las uñuelas no presentan otra difcrencia notable que la de scr la inferior del cuarto par igual á la corrcspondientc dcl primero. Los palpos (v. Lám. III) son cortos y gruesccillos; el último artcjo, ó sea el tarsal, grucso en la basc, se cscota para recibir cl bulbo, lucgo sc adelgaza bastante, para tcrminar un tanto fusiformc y cubierto dc pelitos; el bulbo recuerda la figura de una ccbolla: grueso y redondcado en la base, se cstrecha luego y, en su último tércio, se dilata irregularmentc; examinándolo dcl lado extcrno, mucstra, en su parte gruesa ó basal, dos líneas curvas, transversas, más oscuras quc el cucrpo fcrruginoso, y quc corresponden á débilcs aristas, muy especialmentc la más distante de la base, sc arquean hácia cl ápicc por debajo $\mathrm{y}$, corriendo más ó ménos paralelas, forman una crcstita no muy filosa que contornea un poco la porcion extrema del bulbo por fuera, y termina cn un gancho muy encorvado hácia fuera y muy agudo; hácia arriba de esta cresta, nace otra más clcvada y más filosa, que tambien rcmata en otro gancho no tan bien arqueado como el externo, pcro más ancho, y sostcniendo como un filo ó lámina filosa adherida á él y de sustancia ménos opaca; finalmente, hácia adentro y un poco ántes del ápicc mismo, se encuentra otro ganchito ancho, cón lámina filosa y de borde un tanto desigual.

COLOR,-Ninguna difcrencia digna de mencion existe en el macho; lo único que podría recordarse, quizá, cs que la porcion oscura dcl dorso, en la que sc encuentra la figura característica, es ménos manchada de claro, teniendo más rojiza ó más bicn no tan oscura la partc que se halla ccrca de la línea ondulante.

Observaciones.-El único ejemplar (una hembra jóven) cazado por el Dr. Doering en las orillas del Rio Colorado (Paso de Pachcco) ha sido prolijamente comparado por mí con los que conservo cn mi coleccion, y no he hallado diferencia alguna que me autoricc á sospechar que no se trate de la Scytodes maculata, debiendo advcrtir que cl abdómen de 
aqucl se hallaba en mal estado de conservacion. Esta espccie no es escasa en la Provincia de Buenos Aircs, pues la he recogido no sólo cn los alrededorcs de la capital, sinó tambien en el Baradcro y en otros puntos. En la Sicrra Chica de Córdoba, ccrca del Pan de Azúcar, encontré, á principios de Encro de 1877 , una hembra adulta. Vivc con predileccion en parages húmedos y oscuros, bajo piedras, ladrillos ó troncos de árboles. Tiende hcbras finísimas cn un corto espacio, á mancra dc Tcridio, y hace la mortecina cuando se la toca; mas luego echa á andar con lentitud. Su capullo, junto al cual pcrmanece hasta la eclosion de los huevos y primer tiempo de la vida juvenil de sus desccndicntes, cs esférico, de unos 3 ó $4 \mathrm{~mm}$. de diámetro, blanco nívco y de seda un tanto floja. Cuando reposa en cl suelo, cste animal suele tomar una actitud que rccuerda la de un Tomisida: oblicuando los fémures hácia atrás, dá la flexion natural, cn mayor ó menor grado, á los otros artículos de las picrnas. En la corta noticia que de ćl he dado (loc. cit.) digo lo siguientc: s el animal adulto, quc hemos visto repetidas veccs, ticne un color lilácco.» No es esto precisamente, sinó más bien un cierto viso morado, que el animal pierde $\mathrm{cn} \mathrm{cl}$ aguardiente. Las medidas quc consigno en dicha obra son falsas para la gcneralidad de los ejemplares que tengo actualmente; pcro rccuerdo que la figura fué hecha copiando una hembra muy grandc, que no sé dóndc está ahora. Al trasladar el dibujo mio al trozo de madera en que debía grabarse fué bastante modificado, como todos los otros, lo que hizo que suspendiera los dibujos, ya que se habian de intcrpretar del modo que lo han sido.

Réstame ahora comparar la especie con una muy inmediata, de la cual no hice referencia en 1876 cuando publiqué los Arácnidos Argentinos, por no entrar en consideracioncs que no pucdo rchusarme á haccr ahora. Me reficro á la Scyt. globula de NiColet (Fanna Chilena, Arancidas, T. III, p. 347, Atlas Lám. 2, ff. I y 2). Dcbo dcclarar que, á pcsar de las diferencias que encuentro comparando mis ejemplarcs con las figuras citadas (NICOLET, en cierto modo, ha dibujado los Arácnidos de Chilc mejor que lo que los ha descrito), no tengo ciega confianza cn la estricta diversidad dc ambas especies, ó más bicn, son tan próximas, que sc vacila hasta el último momento en scpararlas. Comenzando por la diagnosis, encuentro que puede aplicarsc, entrc otras especies, á la Sc. marmorata, L. KocH (Arach. Australiens) á la Sc. Tacwanoruskii Thorell ( = Sc. marmorata TACZ.,-v. p. 128), á la Sc. maculata m. etc. Prescindiendo de aquellas, á las cuales pucde rcferirse tambien, en gran parte, la descripcion de Nicolet, tomaré en cuenta sólo la última, y recordaré que lo que dice de la mancha torácica del macho $\ldots . . . .$. imitando un yerro de alabarda, de un amarillo metálico brillante, » 10 he observado tambien en la Sc. maculata, pcro nó en el vivo, sinó cn el conservado en alcohol. Diríase que la cutícula dorsal se hubiera levantado, y, al evaporarse el alcohol (pucs recien entonces es que se observa) una ténue capa de aire le dicra el brillo dorado, como se nota en algunas especies de Coleóptcros, en particular una Cassida (sens. lat.) de este país, ó las manchitas de oro de las crisálidas do Lepidópteros diurnos, etc. Esto lo he observado tambien en una hembra, pero jamás en el vivo, de lo cual deduzco, como así tambien de la circunstancia de señalar e ojos amari- 
llos, á algunos Atidas oscuros, que describió cjemplares conscrvados en alcohol (ignoro los antccedentes de los Arácnidos descritos por dicho autor-no sé si GaY se los llevó, ó si él los cazó, como podría sospecharse por las palabras de Simov-Hist. Nat. des Ar--más de una vcz repetidas- . . . . rapportées du Chili par M. Nicolet»). Dcjando esto á un lado, preguntaré, ’̨es «el corsclete glabro»?-los «puntos negros muy pequeños y levantados ¿no sostienen una cerda corta? Ias patas «como glabras» ¿no presentan ocho filas de pelos bien visibles? ó describía á veces á la simple vista, en cuyo caso difícilmcnte habría distinguido los puntos levantados del corseletc? ó cran «como glabras» para la descripcion y tenian bastantes pelos para la lámina? y «en fin, el lábio, las quijadas, el estcrnon y las ancas son glabros..... 》-no lo creo, á no ser que fueran "como glabros» ó que los pelos hubieran desaparccido por el movimiento, en el utensilio de conservacion, lo que ez frccuente, en cuyo caso vale más no decir nada al respecto; « una manchita morena ocupa el medio del esternon"--la hay hácia adclante del medio cn la Sc. maculata, pero ésta las tienc mas grandes y más ó ménos unidas en los bordes, lo cual no sc scñala en la Sc. globula ; «y otra mayor cn la extremidad anterior de las ancas»-si «anterior"significa aquí «inferior», coincide con la Sc. maculata, cuyas coxas tienen el ápice negro, sobre todo por debajo.

La corta descripcion de la hembra conviene con nuestra especie en un todo, respccto dc la coloracion, excepto la placa extcrnal quc, en la Sc. maculata es manchada, no siéndolo en la Sc. globula. La discrepancia considerable que existc cntre las medidas del macho y de la hembra de esta última especic, me hace sospechar, ya que las hembras son siempre mayorcs que los machos, hasta donde alcanza mi conocimiento, que el autor se valió de un macho adulto $\mathrm{y}$ de un hembra jóven. Por ésto descarto la hembra para la comparacion, y tomando las medidas del macho, cncucntro una diferencia tan notable entre los de ambas especies, que no puedo aceptarla como individual. Más aún, la relacion entre la longitud del cefalotórax de la Sc. globula es á la longitud del primer par de piernas como I á 12, sin contar quizá con la coxa y cl trocánter, mientras que en la Sc. maculata, contando con ambas piczas, es como i á io. Finalmente, suponiendo quc’el palpo del macho de Sc. globula csté bien dibujado, las pocas diferencias resaltan comparando con la figura que doy en la Lám. III, como es bicn visible la del dibujo del dorso abdominal, por no mencionar la figura pálida caractcrística que adorna el ccfalotórax de la mayor parte de las especies de Scytodes. 
Fam. AGALENOIDAE.

Gen. Texenaria (Latreille, 1804) Westring, 1861.

5. TEgenaria Civilis (Sundevale? 1831) Walchevaer 1837.

Syn,:-(1831) Agelena eivilis, Sexderali, Svenska Spindlarnes ete. Acta Holm. p. 127. 2.

(1837) Tegenaria eivilis, Warck. Hist. Nat. des Ins. Apt., T. II, p. 7. Atl. pl. XVI, f. 1 (et aut. plur.).

(1876) $\gg$ \#. L. Holvв., Arac. Arg.-Separ. p. 15, n.30.

Nora. Feminam singulam ad «Carhué eaptam vidi.

Repetiré, á propósito dc la parte que me toca dc la escasa literatura que cito, con motivo de esta cspecic, lo que he dicho refiriéndome á la Argiope argentata. No abrigo la mínima duda en cuanto á la determinacion cspecífica, pucs la he hecho por KocH (Die Arachniden ViI, p. 37, ff. 618-619), Walckenaer (ut supra), Westring (Araneae Svecicac, p. 307) y, tomando cn cuenta lo que dice THorell (Recensio critica, p. 36), he consultado CLERCK, Svenska Spindlar (p. 76). Ignoro de qué manera trata THorell csta espccie en su obra Remarks on synonims \&, pero, atcniéndome á la litcratura de que dispongo y comparando la sinonímia consignada por Thorell, Westring, Simon, Walckenaer y Koch, parece que fué Sundevall quicn dió á esta Tegenaria cl nombre específico que lleva.

De cualquier modo que sea, esta especie no cs solamente el tipo del género (segun THorell), es el tipo dc las especies cuya sinonímia copian muchas vcces los autores sin cxaminar préviamentc la vcrdad de los hechos, prestando fé ciega á lo primcro quc encucntran (ego olim quoque); así, con Simon, he rcfcrido cl género Tegenaria á WalckeNakr y nó 'á LATreille (Arac. Arg. p. 15) y, en cuanto á la cspccie, me contentaba entónces con tener seguridad de la determinacion. Hoy, despues de cinco años, pucdo confirmar plena y satisfactoriamente ésta con los mismos cjemplarcs femeninos que tenía, debiendo agregar que he cazado mas tarde cl macho y quc corresponde exactamente á lo que de él dicen los autores.

Respecto de la cita que hice de Martin de Moussy, persisto, en parte, cn lo que dije entónces, pues, hasta ahora, entre más de ciento cincucnta ejcmplares de Tegcnaria civilis, que he tenido cntre manos, no había uno solo que ni rcmotamente pudicra refcrirsc á la $T$. domestica. Verdad es que este último nombre específico lo dió LiNeo á la $T$. civilis, pcro no cran los conocimicntos zoológicos de Moussy como para penctrar cn cstas honduras dc la cspecialidad, y hoy, á pcsar de tanto tiempo transcurrido y de habcr cruzado oblícuamente la República sin cncontrarla, creo quc Moussy, con su determinacion específica, sólo quiso significar nó Aranea domestica L. sinó Araneae domesticae. 
Fam. DRASSOIDAE.

Gen. Drassus (Walckexaer 1805); L. Koch, 1866.

\section{DRASSUS AUSTRALIS IIolmb., n. sp.}

Mas: Dr. cephalothorace longitudine longitudinem patellae plus tibiae 4i. paris vix supcrante, quasi aequante, nigro-piceo, sub-micante, foveis radiantibus lateribusque brevitcr parceque nigro-piloso; mandibulis latitudinem frontis paullo longioribus, supra piccis, intus vel facie orali unguiculaque ferrugineis, stemo cum pedibus (articulis duobus ultimis cxccptis), maxillis labioque piceis, his apice testaceo, femoribus nigricantibus, ultimis intus obscure virili-cyaneo micantibus, patellis pedum omnium ad basin obscure mfis, metatarsis piceo-fcrugincis, tarsis testaceis fuscescentibus; palpis tcstaccis articulo ultimo (mare immaturo) magno, ovoide conico, a supra lanccolato a latcre quasi semicirculari; abdomine fuligineo, laminis trachcarum testaceis, mamillis piceis.

Nota.-Marem haud adnltum prope ripam "Rio Colorarlo» a Dre. Doerivg inventum examinavi.

\section{MEDIDAS DEL MaCho Jóven.}

Longitud total . . . . . . . . . . . . . . $0.0055 \mathrm{~mm}$. 0.0015 Longitud del esternon .

* del cefalotórax....... 0.0025

Altura del id ........ 0.00125

Latitud de la frente.......... 0.0005

, del túrax .......... 0.00175

Longitud de los palpos. . . . . . 0.003

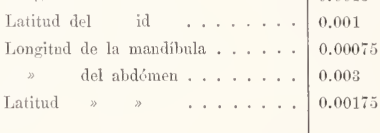

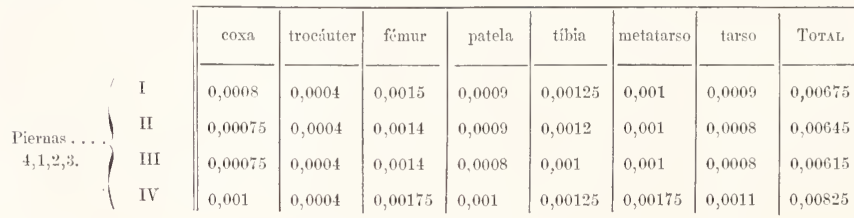

DESCRIPCION DEL MACHO.

ForMA.-Cefalotórax cordiforme, imperccptiblemente más largo que la patela +la tibia del $4^{\circ}$ par, álgo más ancho que la mitad del largo, muy estrechado por delante, donde es truncado, pero con los ángulos redondeados, finamente marginado, apénas escotado por detrás, con los costados redondeados, el dorso casi recto elevándose un poco hasta el comienzo del último tercio, donde es convexo para formar el declive posterior y presenta la foseta longitudinal, lustroso, sin serlo mucho, con finísimos pelos en las depresiones radiantes y cn los costados, teniendo algunos esparcidos irregularmente en el resto. Los OA en línea arqueada con la convexidad hácia arriba, de tal modo que una línea tangente al borde inferior de los OMA sería secante de los OLA, dejando hácia arriba el cuarto superior de éstos; los OMA se hallan tan scparados uno de otro como su propio diámetro, y casi conflucntes con los OLA, quedando el borde infcrior de éstos tan distante del bordc del clípeo como I $\frac{3}{4}$ de su propio diámetro; los OLA son como $\frac{1}{4}$ ma- 
yores que los OMA,- los OP en línea curva, de tal suerte que una línea tangente al borde posterior de los OLP, pasaría por el centro de los OMP; los OMA forman casi un cuadrado con los OMP, de los cuales están más cerca que del borde del clípeo, pero los OMA estan apćnas más léjos de los $\mathrm{P}$ que éstos y que aquellos entre sí; los OLP son apénas más grandes que los OMP, siendo las respectivas proporciones casi como en la fila anterior ( 1 ); los $\mathrm{OP}$ se hallan equidistantes, y una línea ántero-posterior que pasara por la base de los OLP, sería tangente á la convexidad externa de los OLA. Esternon cordiforme, más largo que ancho, algo ampliamente deprimido en el medio, y con pelitos esparcidos. Labio tan largo como la mitad de las maxilas, casi cuadrado, sub-nítido, con pelos esparcidos en su cara libre y algunos más aproximados y más largos en el borde anterior. Maxilas lo mismo, un tanto angulosas en la union de sus bordes, convexas fucrtemente en su mitad basal, despucs de la cual se vé la depresion transversa, un poco oblicuada hácia el lábio. Mandíbulas cónicas, un poco gibosas por delante cerca de la base, truncadas en el ápice, con algunos pelitos largos en su cara libre, y con la uñucla tan larga como el ancho de la base de aquellas. Palpos cubiertos de pelos esparcidos, más largos que en el ccfalotórax,-su fémur más corto que el último artículo, el $3^{\circ}$ muy corto, el $4^{\circ}$ más angosto en la base que en el ápice, donde se ensancha mucho para sustentar el último, grande, de contorno lancéolado, visto de arriba, más redondeado en la base que en cl ápice, donde es un poco agudo, casi semicircular visto de lado. Picrnas bastante robustas con cspinículas (2); las uñuelas del $2^{\circ}$ par fucrtemente arqueadas, con 5 dientes pectiniformes, casi rectos, ménos largos que la parte no pectinada de la uñuela. El abdómen oval oblongo, apenas muestra algunos pelos en su base.

Color.-Cefalotórax y apéndices adyaccntes de color píceo oscuro, con pelitos negros; el lábio y las maxilas con borde testáceo; las mandibulas en su cara interna y su uñucla fcrruginosas; las picrnas con fémures mas oscurecidos, los del último par con cicrto reflejo subido verde azulado; las patelas dc un color rojo subido, oscuro en la base por arriba; los metatarsos píccos rojizos, los tarsos testíceos un poco parduzcos; el abdómen es fuliginoso, con las placas traqucales testáceas cubiertas de pelitos negros y las hiladeras píceas.

OBservaciones. - El único ejemplar de que he podido disponer, es un macho jóven, al cual no le faltaba probablemente sinó la última muda, porque examinando el artejo de los palpos que caracteriza su sexo, se von diseñadas en su interior ciertas líneas ó nubéculas ferruginosas, apénas perceptibles, que quizá responden á los contornos del órgano enserrado por el tegumento juvenil. Lo he adscrito al géncro Drassus porque á éste se llega scgun ia tabla dicotómica de L. KocH en su obra Die Arachnidcn-Familie der Drassiden, p. 2, coincidiendo tambien con los caracteres que atribuye al género, cn la p. 76 de la misma

(1) Los OMP me han parecido visiblemente oblongos, pero, ni con lentes poderosos ni con microscopio he podido distinguir la oblicuidad particular de sus ejes, pues parece como si las córneas sobresalieran apéuas.

(2) El ejemplar se halla bastante estropeado y no me atrevo, por lo tanto, á determinar la distribucion de las espinículas por temor de seũalarla falsamente. La figura que doy cn la Lámina III, contiene las que he podido distinguir. 
obra, y siguiendo el sistema de Thorell (Conf. On Europcan Spiders) coloco entre paréntesis el nombre de WaLckenaER, pues la circunstancia de dar éste al género Drassus mayor amplitud, segun lo consigna por otra parte Trorell en su obra citada, p. I47, lo que es por demas evidente, por la desmembracion que de dicho género hizo $\mathrm{C}$. KocH (Ucb. etc.), se hace manifiesto que no corresponde proceder de otro modo. El nombre de WALCKENAER no se halla entre paréntesis en la obra de THORkLL, pero sí la fecha, lo cual atribuyo á error de imprenta ó á lapsus calami, no correcto en la crrata. Inútil me parece recordar que tambien se llega á Drassus segun la sinopsis que este último autor nos da en su magistral obra citada, y que, tomando en cuenta los caracteres que luego consigna en los comentarios, no se puede adoptar otro género. Por último, examinando la Tabla analitica de las especies del género Drassus (v. L. Koci, op. c. p. 78), se llega á Dr. loricatus, especie exótica cuyas diferencias (v. L. K., ibid., p. 131) con la nuestra resaltan despues del más lijero exámen comparativo. La importancia del Drassus australis, por otra parte, es momentánea, por estar fundada la especie en un indivíduo jóven. La esperanza de ulteriores adquisiciones en el territorio conquistado me determina á sospechar que mi especie se describirá más tarde en su estado adulto, $\mathrm{y}$, si he dado del juvenil una descripcion tan detallada, es para que sea mejor reconocido, aunque bastara la diagnosis que coloco al frente.

LÁß, III, ff, $4,4 a, \&$

Gen. Chixacanthium C. L. Коси, 1839.

v. L. Косн, op, c., et T. Thorell, On Eur. Sprul.

7. CHIRACANTHIUM ABגORME, Honms, n. sp.

$$
\text { Lír. III, ff, } 5,5 a, d \text {. }
$$

Fem.: Ch. cephalothorace obseure fuscescenti-nufo posteriora versus sensim pallidiore, nitidiusculo, longitudine longitudinem patellue plus eam tibiae 4i. paris vix superentc, latitudine quasi dimidium longitudinis aequante, ovalis, antice posticeque truncato hic cmarginato, leviter maryinato, capite clevato a thorace depressione separato, foeca brevi, lincari, palp is pedibusque nefescenti-testaceis vel subfuscescenti-ochraceis, anterioribus quatur horum reliquis robustionibus (aculeis desnent?), unguiculis tarsorum parum denticulutis; ablomine fuscescenti-griseo, ventre palluliore, dorso serie media dimidio postico e fasciis coloris wentris transecrsis antrorsum geniculatis constituta lineolaque longitulinali cjuslem coloris dimidio antico ornato, reliquo dor:so lateribusque abdominis striolis $x c l$ punctis pallidis conspersis, vulea ad partem nufescenti-fusca, mammillis breribus pallide testaceis.

Noтa.-Feminas tres atultas et marem immaturnm (nnne detritum) in Sierra de la Ventanas invenit Dr. DoERING.

\section{Medidas de LA HeMirRa.}

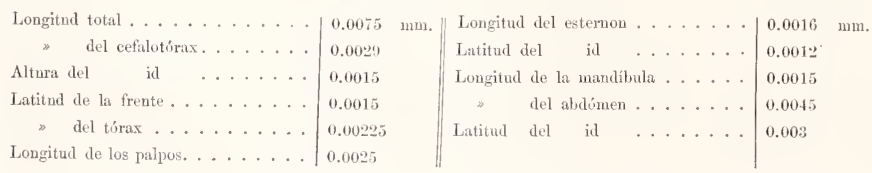




\begin{tabular}{|c|c|c|c|c|c|c|c|c|c|}
\hline & \\
\hline & & $\cos a$ & trocínter & fémur & patela & tíbia & metatarso & tarso & TOTAL \\
\hline \multirow{4}{*}{$\begin{array}{r}\text { Piernas .. } \\
1,4,2,3 \text {. }\end{array}$} & I & 0,001 & 0,0004 & 0,00225 & 0,001 & 0,0019 & 0,0015 & 0,001 & 0,00905 \\
\hline & II & 0,0008 & 0,0004 & 0,00175 & 0,0009 & 0,0015 & 0,00125 & 0,0008 & 0,00735 \\
\hline & III & 0,0007 & 0,0003 & 0,0015 & 0,0008 & 0,0011 & 0,00125 & 0,0006 & 0,00625 \\
\hline & IV & 0,0009 & 0,0004 & 0,00225 & 0,0008 & 0,00175 & 0,002 & 0,00075 & 0,00885 \\
\hline
\end{tabular}

FORMAS-Cefalotórax lustroso, oval, suavemente arqueado en los costados, truncado por delante, con curva no muy saliente, siendo allí inclinado en curva hácia el clípeo, un poco emarginado por detrás, un tanto marginado, superando apénas su longitudl a de la patela+la tíbia del $4^{\circ}$ par reunidas, casi tan ancho como la mitad de su largo, tan alto como el ancho de la frente, con la cabeza elevada, descendiendo posteriormente en curva contínua con la del tórax, más fuertemente inclinada en los costados donde la separa del tórax una depresion bastante ancha, que hace descender el borde, para de aquí elevarse oblícuamente á formar el clípeo, con el que se une sin presentar ángulo, detrás de cuya depresion se ven las impresiones radiantes; la foseta es lineal, corta, se halla inmediatamente detrás de la cabeza, en el comienzo del último tercio dorsal; el clípeo suavemente emarginado, mirando el animal de adelante, con algunos pelos porrectos ó subporrectos en la frente. Los OA forman una fila apénas convexa hácia arriba; los OM, separados entre sí y del borde del clípeo tanto como su propio diámetro miran hácia adelante y se hallan colocados en una pequeña eminencia convexa; los $\mathrm{OL}$ casi un quinto más pequeños que los $\mathrm{OM}$, miran un poco hácia abajo y apénas hácia fuera, se hallan de los OM un tercio más cerca que éstos entre sí, una pequeña eminencia cuyo declive une por fuera á los OLA y P les sirve de asiento; los $\mathrm{OA}$, vistos de arriba, forman una línea un poco recurva; los OP, mirados del mismo modo, se presentan en línea recta, son equidistantes, de igual tamaño entre sí y comparados con los LA, los OMP forman con los OMA un trapecio muy poco más ancho por detrás, se hallan entre sí más distantes que de los OMA, de los cuales distan tanto como éstos entre sí; los OLP distan tanto de los OLA, como de los MP, su base está en un plano casi vertical, y su eje se dirije lateralmente y algo hácia atrás, el plano de su base dirijido hácia adelante, pasaría tangente ó por fuera de los OLA. Esternon oval, corto, algo convexo, truncado por delante, con pequeñas escotaduras correspondientes á las coxas, un poco agudo por detrás y vestido de pelitos muy finos. Lábio tan largo como ancho, un poco convexo, con los bordes laterales redondeados, truncado por delante, donde es más estrecho, así como en la base. Maxilas doble más largas que el lábio, muy poco convergentes, redondeadas por delante, con pelillos cortos en la parte interna de este borde, un tanto estrechadas en la base, y convexas á lo largo. MTandibulas tan largas como el ancho de la frente, cilindro-ovóideas, gibosas por delante en su primer tercio, un tanto más estrechas en el ápice, con algunos pelillos esparcidos y cerditas; su gancho corto y robusto.-Palpos delgados con muy pocos pelitos, siendo éstos más abun- 
dantes en el último artejo euya uñuela sin dientes es más corta que el diámetro de dieho artejo. Picmas de regular tamaño; las cuatro anteriores más robustas que las posteriores; carecen completamente de espinículas y no he hallado los funtos de inscrcion probable, por euya causa he dado á esta especie el nombre de abnorme. Sus uñuelas ocultas entre el penacho de pelos eseamosos pueden verse en la Lámina III; su mitad apical no lleva dientes eomo la mitad basal, pero muestra estrias particulares que recuerdan ciertas sierras cuyo nombre no tengo presente en este instante; las uñuelas del primer par, cuyo penaeho no he representado, tienen euatro dientes rectos y las del euarto par einco irregulares; de este último he representado en la Lámina un pelo espatuliforme del penacho y un pelo plumoso de la escópula. Abdómen ovóide, oblongo, algo más aneho en la parte posterior y un poco reclinado sobre el tórax. El cpiginio (que parece cn cierto modo no corresponder á indivíduos adultos) eonsta de dos pequeñas erestas que se aproximan en su parte anterior y al unirse por una barra transversa, envian otra crestita hácia atrás, que al terminar se dilata, siendo muy finamente estriada á lo ancho; en la parte posterior de las ramillas nace un arco que se dirige hácia adelante, estando aquí más separado del opuesto que en su orígen posterior; hácia adelante del extremo de cada uno, se vé un pequeño óvalo, que tiene toda la apariencia de abertura vulvar y un poco háeia fuera se observa una eminencia redondeada poco conspíeua. Esta disposicion me hace sospechar que falta todavía á mis ejemplares una muda de piel, porque teniendo cl epiginio, bajo el microscopio, todas las apariencias de relieves y fóveas acentuadas, nada de ello, exceptuando las crestitas posteriores, corresponde á lo que se presenta examinando esta parte con una lente de regular aumento (de I5 á 20 diámetros) y sólo deja ver que todas aquellas partes anteriores se hallan cubiertas por el tegumento. Las hiladcras eortas, sin llegar á ser en roseta; las inferiores tienen su artejo basal en extremo corto y el apical mastóideo, un poco más largo que ancho; las superiores tienen su artejo basal como las otras, y el apieal, muy poco más largo y delgado que el eorrespondiente de las inferiores, es cilíndrieo.

COLOR.-El cefalotórax un poeo más pálido cn su parte posterior, es pardo-rojizo oscuro, así como las mandíbulas, las maxilas y el lábio; el estcrnon es pardo, siendo algo más pálido en su parte central y posterior. Palpos y picrnas de un color amarillo ferruginoso, siendo las últimas muy poco oscuras en la base. El abdómen de color parduzco, lleva en la línea media una raya pardiclara que se bifurca al llegar al eentro del dorso abdominal; hácia atrás de ella una série como de 5 á 6 rayitas transversas, acodadas hácia adelante y tanto ménos cuanto más se acerean á las hiladeras, al propio tiempo que se vuelven más cortas; el resto de la parte oscura del abdómen cstá salpicado de numerosos puntitos pardiclaros, color que tambien corresponde al vicntrc, que se muestra muy poeo amarillento en la base, esto es, en las placas traqueales y mayor porcion de la region del epiginio, color que tambien tienen las hiladeras; las partes más conspicuas del epiginio son pardo-rojizo-oseuras.

OBSERVACIONES - El animal que motiva este trabajo se distingue muy particularmente 
de las otras especies por earecer de espiníeulas en las piernas, lo que no puedo atribuir á su falta actual, pues ni siquiera he hallado los vestigios ó depresiones en que se encuentran cuando las hay. Su effalotórax careec de pelos, aunque los tiene en el clípeo. Sus uñuelas tarsales se asemejan poeo á las del tipo que accpta Thorell (p. 145), el Ch. mutrix, pero coineide eompletamente en lo relativo á los penaehos. A pesar de todo esto, no he ereido fundada la formacion de un nuevo sénero, que otros, con mayor aeopio de materiales quizá se atreverian á erear. Es el primer Chiracanthinm que he visto y sinembargo no me permitiría dudar de que lo he adscrito bien á su género, eon las salvedades que indico.

Gen. Anyphacha, Sendeval, 1880.

จ. L. Косн, op. c., 1866, etc.

8. ANYPIIAENA ARGENTINA HoLmb. n. sp.

Lis. III, ff. $6,6 a, \&$.

Fem.: An. parum grisescenti-pilosa, cephalothorace cordiformi-ovali, fronte parum latiore quam in medio thoracis, longitudinem patellae plus tibiae 4i. paris longitudine vix superante, sat alto, convexo, margine postica parum emarginato, fuscescenti-testaceo; forea, lineolis radiantibus prope foveam obsoletis et ante marginem vittam longitudinalem irregularem formantibus fuscis; mandibulis longitudine thoracis altitudinem vix minoribus, pallide rufescenti-piceis, unguicula piceo-rufescenti; oculis anticis serie recta, externis majoribus, mediis inter se plus quam ab illis disjunctis; palpis pedibusque pallide fuscescenti-flavidis, his tibiis apicem versus sensim atque articulis ultimis fuscescentibus, illis ultimis; maxillis colore mandibularum apice pallido veluti labio fusco; sterno colore pedum utrinque fusco-vel nigro-punctato, punctis prope coxas; abdomine ob-ovato (id est postice latiore) depressiusculo, tertio antico vitta media fusca à lineola pallida longitudinaliter divisa, postice utrinque in fovcolis macula parva expansa ubi lineola fusccscentiabbreviata, subobsoleta anteriora versus currente partumque divergente utrinque saepe nascitur; pone vittam illam scriem irrcgularem macularum geniculatarum, punctos conspersos tertio postico quasi confuentes videtur; lateribus vitta fusca cum irroratione tertii postiei confuent"; ventre utrinque scrie irregulari punctorum obscuriorum; plica transversa pone medium ventri; mammillis pallide testaceis.

\section{MEDIDAS DE LA HEMBRA}

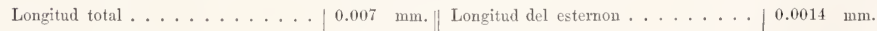

, del cefalotórax ...... 0.003 Latitud del id ...... 0.001

Altura del tórax.......... $0.0015 \quad$ Longitud de la mandíbula . . . . 0.00125

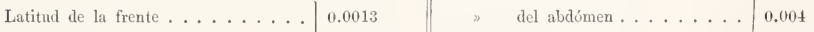

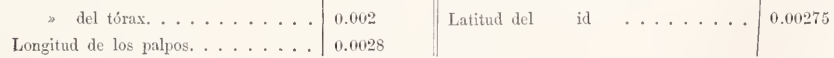

\begin{tabular}{|c|c|c|c|c|c|c|c|c|c|}
\hline & & \\
\hline & & $\operatorname{cox} a$ & trocánter & fémur & patela & tíbia & metatarso & tarso & Total \\
\hline \multirow{4}{*}{$\begin{array}{c}\text { Piernas... } \\
4,1,2,3 .\end{array}$} & I & 0,0008 & 0,0004 & 0,0022 & 0,0012 & 0,0017 & 0,0015 & 0,001 & 0,0088 \\
\hline & II & 0,0008 & 0,0003 & 0,0022 & 0,0012 & 0,0015 & 0,0014 & 0,001 & 0,0086 \\
\hline & III & 0,00075 & 0,0002 & 0,0019 & 0,0008 & 0,0012 & 0,0013 & 0,0008 & 0,00695 \\
\hline & IV & 0,0009 & 0,0005 & 0,0025 & 0,001 & 0,0018 & 0,002 & 0,0009 & 0,0096 \\
\hline
\end{tabular}


Nota.-Individua á Dre. Doerixg in eSierra de la Ventanas et "Paso de Pacheco» (Rio Colorado) reperta tres feminae sunt, duo adultae unaque junius. Exemplos plurimos ì me usque ad provinciam "Salta" et ab Edtardo Agcirre in "Carmen de Patagones» et amicis alteribus provincia bonä̈rensi collectis cum illis accuratissime comparavi.

Oculorum serie antica recta Anyph. Argentinam ad Anyphaenas "gracilis» et "pectorosa» (v. L. Косн, pp. 195-198) approximat: ì prima vulva, ì secunda abdomine picto vulvaque differt. Anyph. maculatipes Keyseriaxg (v. Keys. Spinnen aus Lruguay, iu Verh. derk.-k. Zool.-bot. Ges., Wien. XXVII, p. 603, Lám. XIV, fig. 23, 1878) An. Argentinae picturis valde similis, parum is vulva, aculearum dispositio, aculorum serie antica recta discrepat.

Forma.-Cefalotórax oval cordiforme, muy poco más largo que la patela más la tíbia del 4 par de piernas, por delante apenas mayor que la mitad del ancho del tórax, redondcado anteriormente, de tal manera que parece que el tórax sc continuara sin interrupcion, lateralmcnte, con la cabeza, pero los ángulos del clípeo se expanden un poco hácia fuera, de tal modo que el frente, por debajo, vicne á ser más ancho que por arriba; mirando cl animal de lado, no se observa ningun ángulo marcado, su dorso es poco convexo, suavemente inclinado hácia adelante, donde forma la convexidad anterior, y, por detrás, el declive torácico, en ángulo de $45^{\circ}$, muestra apénas su union con el dorso, siendo en curva muy débil; de adelante, el cefalotórax es más fuertemente convexo, y aunque nin. guna arista sc señala, se vé que los flancos son más inclinados que posteriormente; el borde del clípeo es convexo, y sus ángulos descienden un poco; el borde posterior es débilmente escotado, y los laterales son redondeados, de tal suerte que, uniendo los arcos por detrás y por delante constituirían un óvalo corto; los costados de la cabeza, de arriba, son casi paralelos, pero se nota que divergen un tanto para confundirse con los costados, habiendo una depresion detrás de las mandibulas, que corrcsponde á la bifurcacion; la foseta es alargada y las impresiones radiantes no son muy fucrtes pero bien visibles, siéndolo ménos al acercarse al borde, finamente ondulado; sc halla cubierto de pelitos asentados, al través de los cuales se distingue el tegumento lustroso; en la parte anterior se ven algunos más gruesecillos y lcvantados, habiendo cuatro, particularmente, como cerdas, en el borde del clípeo, que se dirigen, arqueándose, hácia adelante. Los OA se encuentran colocados en línea recta, de modo que una tangente al borde inferior lo sería á los cuatro; los OMA, cuyos ejes son divergentes, se hallan distantes entre sí tanto como la mitad de su diámetro, y del borde del clípeo tanto como el tercio de éste, que equivale á unos dos tercios del de los OLA, de los cuales se encuentran tan ccrca, que difícilmentc se distingue cl cspacio que media entre ellos; la tangente al borde superior separa un segmento de los OLA equivalente á su diferencia con los OM, éstos un poco más avanzados que los OL; el borde posterior dc los $O P$ es recto, y su fila más ancha que la anterior, de tal modo quc un plano ántero-posterior que pasara por la base del OLP, dejaría hácia adentro al I.A, cuyo tamaño ticnc, con débil difcrencia, y del cual se encuentra tan scparado como un tercio, más ó ménos, dc su diámetro; los OMP corresponden, en su posicion, al cspacio que mc- 
dia entre los OA, M y L, y su tamaño cs apénas mayor, al parecer, que el de los OMA, de los cuales se encuentran tan separados casi tanto como el diámetro de los OL entrc sí, algo más que su propio diámetro, siendo un tanto menor cl espacio que distan de los OLP. Estcmon oval, poligonal, nítido, un tanto convexo, cubierto de finos pelos, con pequeños hundimientos en los cspacios intercoxalcs. Lábio convexo, casi tan ancho como largo, redondeado por delante, con la base algo mas ancha en su union con el esternon, tan largo como la mitad del de las maxilas, midiendo desde la base hasta el ángulo ántero externo; las maxilas convcxas, casi paralelas, con el borde antcrior oblícuo hácia adentro, un poco dilatadas y redondeadas por fuera y hácia arriba en la extremidad, gibosas en la base y cubiertas, como el lábio, de pelos esparcidos. Mlandíbulas cilindro-ovóideas, cubiertas de pelillos, robustas, fuertemente convexas por delante cerca de la base, con sus bordes latcrales casi paralelos, pero estrechadas en la base, siendo doblemente largas que anchas y su doble ancho igual al bordc del clípco; la uñnela muy lustrosa, robusta, algo más larga que el ancho de la mandíbula, con una depresion imperceptible, cerca de la basc, en su cara externa. Los palpos casi tan largos como el ccfalotórax, están vestidos de pelos cortos y csparcidos, pero muy aproximados en el extremo, donde ocultan la uñuela delgada, recta, encorvada suavemente en la extremidad, y finamente dentada en su borde infcrior; Ilevan escasas espinículas cn su fćmur y algunas scdas tactiles (fiihthaare). Las piernas se hallan igualmente cubiertas de pelitos finos y cortos y de espinf́culas cuya distribucion scñalo lucgo (exceptuando las de los mctatarsos III y IV, por hallarse en ellos muy irregularmente esparcidas, razon por la cual, sin duda, no las señalan tampoco L. KocH, ni KEYSERLING en sus obras); las escópulas se componcn de pclos que se engrosan en el extremo, dcbajo dc las uñuelas, junto á éstas hay algunos más largos que cllas y que parecen tercbriformes; las escamas del manojo son largas, muy anchas en la extrcmidad y truncadas oblícuamcnte, pero con bordc redondeado, su longitud sobrcpasa á la de las uñuclas, las cuales son cortas, robustas, con el lomo recto, y fuertcmente arqucadas cn la extremidad, la cual, cn su borde cortantc, lleva las mismas estrías oblicuas mencionadas á propósito del Chiracanthium abnorme; la interna ticne 16-18 dientes, largos, paralelos, muy finos y tanto más grucsos cuanto más se accrcan á la extremidad, siendo tambien éstos los que se hallan más scparados, pues los próximos á la basc, al parccer, se tocan, quedando apénas libre su ápicc; la externa ticnes 8-9 dicntes más robustos y más scparados. En una palabra, todo ello coincide casi completamente con las palabras de Thorell á propósito del tipo del géncro Anyphacna (Eur. Spid. p. 144). Hc representado en la Lámina III el tarso izquicrdo del $1^{\text {er }}$ par de la espccie que me ocupa, suprimiéndole numerosos apéndices para mayor claridad. El tarso del $4^{\circ}$ par presenta los mismos caracteres, pero la extremidad de las uñas se prolonga algo más, y, en cuanto á los dientes, he contado 16 y 8 respectivamentc. El abdómen ob-ovado, algo deprimido, y más ancho en su último tercio, un poco reclinado sobre el tórax, siendo aquí levemente truncado; se halla vestido de pelos asentados, más finos y nó tan espesos en el vientre. El epiginio es oblongo, poco marcado en su porcion 
anterior; en la posterior presenta como una placa doble más ancha que larga, en la cual se distingue el borde posterior ampliamente escotado; en la línea media existe una ranura más profunda y más ancha hácia atrás, donde se confunde con el borde posterior; esta ranura divide la placa en dos cradriláteros irregulares, cada uno de los cuales lleva un disco oscuro y algo prominente y que dista de cada lado del cuadrilátero casi tanto como el ancho de la ranura á la altura de la línea transversa ideal que uniera sus centros; el borde posterior de dicha placa se halla separado, por una profunda ranura transversa, de una crestita igualnnente transversa y que forma como el lábio posterior de la abertura vulvar; por otra parte, el epiginio se halla vestido de pelitos finos. El pliegue transverso (plica transversa) se halla colocado un poco hácia atrás del medio del vientre. Las hiladeras no presentan nada particular.

\section{Espinas de las pierias.}

I par: Fémur arriba 1.1.1, adelante 1.1. (háeia el extremo, muy aproximadas y la línea que une sus bases oblícua). Tíbia abajo 2.2.2. Metatarso abrijo 2.

II „ : Fémur arriba 1.1.1., adelante 1. Tibia abajo 2.2.2. Metatarso abajo 2 (en la base).

III " : Fémur arriba 1.1.1., adelante 1., atrús 1. Patela atrás 1. Tíbia adelante 1.1., arriba 1., atrás 1.1., abajo 1.1.2.

IV „ : Fémur arriba 1.1.1. () adelante 1, atrás 1. Patela atrás 1. Tíbia arriba 1., adelante 1.1., atrás 1.1., abajo 1.2.2.

CoLor.-El ccfalotórax vestido, como el rcsto del cuerpo, de pelillos agrisados pálidos, es de un color testáceo parduzco más oscuro en la cabeza, donde tambien toma un cierto tinte rojizo, siendo pardos los ángulos anteriores; la fóvea es parda; en algunos ejemplares envía hácia adelante dos lineolas finas, paralelas y aproximadas; las impresiones radiantes son apénas más oscuras que el fondo; á cierta distancia de los bordes laterales corre una línea irregular, tambien parda, que se amplía hícia arriba en. cada impresion y que termina desvanecida, descendiendo por la arista obtusa del metanoto. Los ojos están más ó ménos circundados de negro. El estemon es testáceo, con una manchita pardo-oscura en cada impresion lateral. El lábio es pardi-negro con el ápice claro. Las maxilas son ferruginosas con cerdas negras hácia fuera y pelillos claros en el borde anterior. Las mandibulas son ferruginosas parduzcas, más oscuras en ei ápice y en la ranura, su gárfio rojizo cs casi negro; además de los pelillos claros llevan cerditas negras. Palpos y picrnas de un color testáceo ó gris amarillento, siendo gradualmente hácia el ápice de un color parduzco-rojizo; los fémures son manchados de pardo por debajo y las tíbias presentan tambien algunas manchitas esparcidas ménos visibles en las patelas; las espiniculas son casi negras, así como los tuberculillos en que nacen. El abdónncn es de un color gris pálido; en su mitad anterior corre une banda longitudinal media, de color pardo-chocolate, generalmente dividida incompletamente á lo largo por una lineola pardi-clara; esta banda, en su extremidad posterior, que está antes del medio del abdómen, tiene una mancha á cada lado, manchas que

(") 1 ejemplar presenta 1.1.1.1.1. en la pierna izquierda. 
corresponden á las impresiones mayores y que con frecuencia envian hácia adelante una estriola que va á unirlas con las correspondientes impresiones menores que se encuentran dclante de cllas y en las que no pocas veces se observa una manchita. La banda queda, pues, interrumpida, pero, hácia atrás de clla, parece continuarse con una sćrie de manchas acodadas hácia adelante, que tiencn más ó ménos ramas y que, cn cl tercio posterior, se confunden con numerosas manchitas confluentes, todas pardas, como cl resto de los dibujos; á cada lado y naciendo casi á la misma altura que la banda média, hay otra un poco más fina que se dispcrsa entre las manchas posteriores confluentes; la acompañan algunos puntitos esparcidos, particularmente hácia el vientre, en el cual hay dos sérics más ó ménos regulares de cllos, que nacen hácia fuera de las placas traqueales y que, limitando el vientre, terminan cerca de las hiladcras; éstas son de color tcstáceo.

ObSERVACIONES. - Esta espccie se encuentra probablemente en toda la República. Abundante en Buenos Aires, donde se la suele hallar bajo la corteza desprendida del Eucalypthus \&, en su celda semitransparente, no escasea tampoco en las otras comarcas que he visitado, desde las Provincias del Norte hasta la Patagonia, de donde me trajo EdUARdo AguiRre, hace algunos años, diversos ejemplares que hc comparado con los mios y con los que ha puesto cn mis manos el Dr. DoERing, procedentes de la Sierra de la Ventana y de las orillas del Rio Colorado. A pesar de esto, sólo conozco cl macho jóven, que sólo difiere de la hembra por sus caracteres sexuales. Así que lo encuentre adulto, lo cnviaré, junto con diversos ejemplares fcmeninos, al SR. Conde de Keyserling, que ha publicado, en las Actas de la Sociedad Real é Imperial zoológico-botánica de Viena (ut supra), una especie (A. maculatipes, Keys.) de Montevideo, á la cual sc asemeja tanto mi $A$. Argentina, que casi me siento inclinado á creer que se trata de la misma. Sin embargo, y esto podría dcpender de la manera de observar, discrepan un tanto por los ojos, cl epiginio y la distribucion de las espinículas de las piernas.

\section{ANYPHAENA PAIPA, Holme. n. sp.}

$$
\text { LAs. III, ff. } 7,7 a, \& \text {. }
$$

Fem.: Cephalothoracis forma ut in specic praecedentc, colore pallirle fuscescenti-testaceo nec non'palpi, pedes, stermum, maxillae (hae ino apice nigrae) labrumque, hoc sensim al basin obscuriore; mandibulae fuseiores, apice unguilaque fusco-rufis; cephalothoracis dorso fuscano-trivittato, vitta media magnam ad partem obsoletiuserda, dimidio antico ex lineolis duabus subparallelis et arl partem posticam foveolae conflucntibus constituta; vittis lateralibus ab impressionibus radiantibus intermptis; abdomine pallidiore albo-vestito; vittis deabus ad marginem anticam nasecntibus, dcin sensim convergentilus abdominis extremitate postica conjunctis; spatio triangulari elongato pallido inter cas vittam fuscam quam abulominis centrum quasi attingit dimidio antico fert; abdominis lateribus alteram vittam fuscam postcriora versus in striolis dispersam quoque videtur; ventre punctis nomullis conspcrso; mammillis pallidis apice fusco.

Noта.-Individuum femineum ì Dre. Doerung in proximitate «sierra de la Ventana» inventum lustravi. 


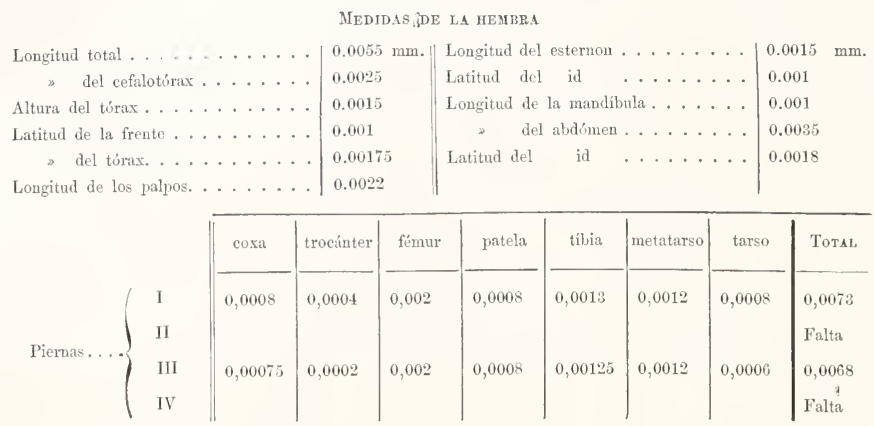

FORMA,Las únicas difercncias esenciales que, á mi juicio, pueden tomarse cn consideracion, comparando las formas de la A. pampa y de la A. Argentina, están en los ojos. $\mathrm{Al}$ parecer, en la $A$. pampa, los $\mathrm{OA}$ son más iguales y el espacio que separa los MA es apcnas mayor que cl que media entre el OMA y el OLA. Las cuatro cerdas que cxisten en la frente de la otra no las he visto en ésta. En el cjcmplar que examino, faltan las piernas de los pares II y IV, pero, en los otros, las espinículas no se distribuyen exactamente del mismo modo que en la A. Argentina. El epiginio consta de una placa lcvantada, cubierta de pelos, más ó ménos triangular, muy poco escotada posteriormente, con dos óvalos cortos, gruesamente estriados, de color píceo rojizo, quc se destacan sobre el color claro, semejante al dcl vientre; la distancia que mcdia entre ambos es como dos tercios de su diámetro. Las uñuelas son muy semejantes á las de la especie anterior, pero son proporcionalmente más cortas en su parte recta, y sus dientes tambien más cortos, más obtusos, en número de 6 en la externa y de 12 en la interna; las escamas espatuliformes no son tan anchas, ni tan grandes como en la A. Argentina.

\section{ESPINAS DE LAS PIERXAS.}

I Par: Fémur arriba 1.1.1, adelante 2 (en el extremo). Tibia abajo 2.2.2. Metatarso abajo 2.

II $\nsim$ : Falta,

III " : Fémur arriba 1.1.1., arlelante 2, atrás 1. Patela atrás 1. Tíbia adelante 1.1., arriba 1, atrás 1.1., abajo 1.1.2. Metatarso como en la especie anterior.

IV * : Falta

Color.-Cefalotórax, piernas, palpos, lábio y maxilas de color tcstáceo parduzco claro; el primero lleva una banda delgada longitudinal en la línea media dcl dorso, parduzca, compucsta en su mitad anterior de dos lineolas sub-paralclas muy poco marcadas, que se uncn en una hácia atrás dc la fóvea, sicndo csta partc posterior más oscura; á cada lado, ántes dcl borde latcral, se vé otra formada como de manchitas interrumpidas, colocadas cn los es- 
pacios que median entre las impresiones radiantes y que, á los lados de la eabeza, es ménos oscura, pero más contínua; el lábio gradualmente algo más oscuro hácia la base; las maxilas con el extremo ápice negruzco. Las mandíbulas muy poco más oscuras que el color general, con el ápice y el gárfio de color ferruginoso parduzeo. Las piernas, poco más oscuras gradualmente hácia la extremidad, llevan manchitas pardas en el fémur, patela y tíbia. El abdómen, cuyo tegumento es del color del cefalotórax y que se halla velado por numerosos pelillos cenicientos acostados háeia atrás, presenta dos líneas pardas oscuras, como todas las figuras que se encuentran en el resto, y que, naciendo en el borde anterior, convergen hácia atrás, para unirse completamente en la extremidad posterior; el espacio encerrado por estas líneas es de color pálido; su mitad anterior lleva una línea media, parda, que ocupa como 2 [5 de la longitud del abdómen y la posterior se muestra como una série de pequeños triángulos; las líneas convergentes de que nos ocupamos son un tanto interrumpidas y ménos visibles en la mitad anterior; el resto del abdómen, ménos el vientre, presenta numerosos puntitos oscuros y estriolas cortas, muy particularmente en los costados, háeia atrás, en los cuales naee una banda oscura que, despues de recorrer I [3 de su longitud, se dispersa en numerosas estriolas dirijidas hácia atrás; en el vientre se encuentra uno que otro puntito aislado. Las hiladeras muy pálidas, tienen el extremo ápice parduzco.

OBSERvacion,--El ejemplar de que me he valido para fundar esta especie, fué hallado por el Dr. Doerivg cerca de la Sierra de la Ventana.

Fam. THERApHOSOIDEAE.

Gen. et subgen. Eury pelma (Koch) Adsserer (1871).

10. EURYPELAIA DOERINGII, HoLme., n. sp.

Líx. III, ff, $8,8 a, \&$.

Has: Euryp. fusca, nufescenti-pilosa; cephalothorace tibin patellaque fi. paris simul sumptis longiore, longitudinem femoris 1i. paris subattingcnte; longiore quam latiorc; fronte, maxillis, mandibulisque rufo-finbriatis, mandibularum unguicula nigra, nitida, supra ad basin apiceque intense rufa; bulbo rufo nigroque picto, piriformi, apice terebrato, elongato, acuto, depresso, carimula postica mope madium longitudinis munito; postice, prope basin, imprcssionc irregulari instructo; mammillis gracilibus tarso quarto brevioribus; unguiculis tarsorum brevibus, partm brevissimeque denticulatis, is primi paris una in medio 5 dentata, quarto 2-dentata; pedibus lineolis pallidis ut in speciebus nommellis hujus generis.

NoтA - Marem adultum alterumque immaturum prope "Rio Negro" in Pampa mesopotamica Dr. Doerixe collegit (vide p. 25).

\begin{tabular}{|c|c|c|c|}
\hline \multirow{3}{*}{ Longitud total . . . . . . . . . } & \multicolumn{2}{|c|}{ Medidas del Macho. } & \multirow[b]{2}{*}{0,006} \\
\hline & $0.030 \mathrm{~nm}$. & Longitud del esternon. . . . . . . & \\
\hline & 0.013 & Latitud máxima del id. . . . & 0.005 \\
\hline de la cabeza hasta la foseta. & 0.009 & Longitud de la maxila . . . . . . . . & 0.005 \\
\hline S anterior ... & 0.008 & del copulador. & 0.0035 \\
\hline cabeza \{ posterior. . . & 0.009 & del abdómen. . & $0.017 \quad$ ? \\
\hline del tórax . . . . . . . & 0.0115 & Satitud del & 0.009 \\
\hline Longitud de la mandíbula . . & 0.0075 & Longitud de la hiladera mayor. . . . . & 0.0065 \\
\hline de la tenaza (su cnerda) & 0.006 & menor. . . & 0.0015 \\
\hline
\end{tabular}




\begin{tabular}{|c|c|c|c|c|c|c|c|c|c|}
\hline & & $\operatorname{cosa}$ & trucínter & fémur & patela & tillia & metatarso & tarso & Total \\
\hline & I & 0.0055 & 0.0015 & 0.0135 & 0.0065 & 0.011 & 0.011 & 0.006 & $0.055^{\prime}$ \\
\hline & II & 0.0055 & 0.002 & 0.013 & 0.006 & 0.009 & 0.0105 & 0.006 & 0.052 \\
\hline That & III & 0.005 & 0.002 & 0.0115 & 0.005 & 0.009 & 0.0105 & 0.006 & 0.049 \\
\hline & IV & 0.005 & 0.00175 & 0.013 & 0.0055 & 0.01125 & 0.0135 & 0.008 & 0.058 \\
\hline Palpos: & & (maxila) & 0.00275 & 0.008 & 0.004 .5 & 0.0075 & - & 0.0025 & 0.024 \\
\hline
\end{tabular}

Descripcion det Macho.

Forma.-Cefalotórax más largo que ancho, levemente escotado por detrás, ;con la cabeza bastante clevada, bien scparada del tórax por la bifurcacion, algo más estrecha en la frente y convexa; la foseta corta, apénas convexa hácia atrás; impresiones radiantes bien marcadas; cubierto por arriba de muy cortos pelos más ó ménos asentados, una fila de ellos en la línea media y una fimbria cn el borde anterior. El tubérculo ocular, delante del cual hay algunas cerditas rígidas, es alto, sobretodo cn su parte anterior y media, muy poco más ancho que largo; los OMIA separados entre sí algo más que su diámetro y otro tanto de los OLA; éstos apenas mayores que aquellos. Los OMP muy cerca de los LP y más pequeños que los MA; situados en la canaleja que forma la emincncia longitudinal media dcl tubérculo. Estcrnon oval, poligonal, con pelos esparcidos. Lábio cuadrangular, un poco más largo que ancho, truncado por delante, granulado en la truncatura anterior. Mandibulas robustas, más largas que el ancho de las dos reunidas; el gancho grueso, casi tan largo como la mandibula, y ensanchado en la base. Maxilas doblemente largas que anchas, granuladas en la base, con cl ángulo ántero-interno saliente y agudo. Palpos de forma comun; el bulbo más largo que el artículo tarsal, piriforme, terminado en punta aguda, larga, comprimida y contorneada y que hácia atrás y por fuera lleva otra arista pequeña que queda como en el tercio medio de la longitud del bulbo; cerca de la base y por detrás hay una fuerte depresion irregular. Piemas relativamente largas y delgadas; la tíbia del primer par lleva dos fucrtes ganchos: el interno doble más corto que el externo; los cuatro fémures anteriores son arqueados hácia adelante y un tanto comprimidos, el dcl tercero recto y cilíndrico; el del cuarto par comprimido y arqueado hácia atrás; llevan filas de espinas cn todas sus piezas, menos en los tarsos; no he podido ver ninguna en el fémur del primer par; se hallan vestidas de pelos cerdosos mas ó menos largos y el tegumento mismo parece como cubicrto de pelos en extremo finos y apretados; los fémures, por debajo, tienen pelos largos, sueltos, dirigidos hácia abajo; las escópulas son muy angostas y en su extremidad redondeada sobresalen algunos pelitos en forma de pequeño pincel; las uñuclas tarsales son cortas, finas, encorvadas, escasas de dentículos, de los cuales he contado, en 
su tercio medio, cinco en una uña del par I, y 2 cn otra del par IV. El abdómen (mal conservado en el ejemplar de que me he valido) parece más largo y delgado que cl ccfalotórax; las hiladeras muy finas y más cortas que el tarso IV.

ColOR.-El color general de esta Eurypelma es pardo, siendo algo más claras las líneas quc con frecuencia, y así en este caso, adornan los palpos y piernas en las especies de cste género; los pelos largos que ella presenta son más claros y rojizos, tirando al rubio oscuro; la fimbria anterior de la cabeza, asícomo las que adornan los bordes de la ranura mandibular y $\mathrm{cl}$ interno de la maxila son de un tinte rojo de ladrillo, ménos intenso en la primera. El gancho mandibular es negro, con la basc y el ápice de un rojo oscuro intenso; tambien es negro el bulbo genital, cuya ancha dcpresion posterior es roja, color que se extiende por dentro contorneando la parte grucsa y llega á la cara anterior; los pelitos apicales finos, apretados y cortos del ápice de los metatarsos, son pardiclaros, los ganchos tibiales son negros; las espinículas pardas oscuras.

Obsfrvaciones,-Esta especic ha sido hallada por el Dr. Doering cerca del Rio Negro. Repito aquí sus palabras, consignadas en la pígina 25, en las Observaciones generales sobre la fauna del Territorio conquistado.-Region entreriana de la Patagonia Septentrional.- Entre los Arácnidos llama mucho la atencion una especie de Mygale (Eurypel$m a, s$. str.) que se halla en abundancia extraordinaria sobre la mescta, entre los matorrales de jarilla. Viven en tubos verticales construidos cn cl suelo, de 2 á 5 decímetros de hondura. Ellos están tapizados por un tejido scdoso, y llevan una tapa ó puerta móvil, resistente, un poco convexa en la parte inferior y fija al tubo por uno de los puntos dcl borde, por medio de cierta cantidad de hilos, tal cual se observa en la $M$. caementaria de Europa, y otras muchas especies de la misma familia. En algunos sítios, el suelo parece perforado por estas habitaciones, que tienen, desde un diámctro reducido, hasta el de 2 centímetros ó más.

La Eurypelma Doeringii es muy próxima de la Eur. striatipes, AUSSERER (Verh.der k.-k-zool. bot. Ges. T. XXI, p. 212, IS7I), de la cual se distingue, principalmentc, por la forma del bulbo (Tf. I, f. I6). Conviene cxactamente con los caracteres que AUSSERER (op.c., p. 208) señala al género Eurrypelma; pero presenta una pequcña difcrencia con el sub-género del mismo nombre (p. $2 \mathrm{II}$ ), donde dice el autor: "Tarsen und Metatarsen mit mässig breiter...... Seopula.s No es así, exactamente, cn mi especie, en la cual la escópula es muy angosta y coincide más bien con lo que en lo misma página dice de la del sub-género Ilomoconma: "Scopula sehr dicht, aber sehmal.s La refiero al sub-géncro en que la he colocado, por parecerme que ese solo carácter no es suficiente para alejarla de él, máxime cuando queda excluida de Homoeomma por tener los OMA casi doble mayores que los OMP. 


\section{Fam, HETEROPODOIDEAE.}

Gen, Thomisoidos, Nicolet, 1849.

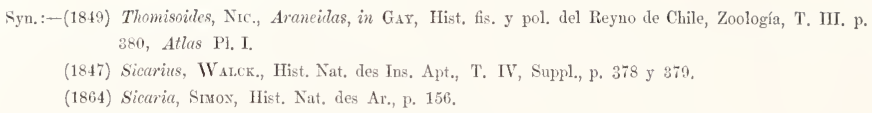

Ante todo descartcmos la parte que toca á Simon. Aunque este autor ha publicado su libro en 1864, no ha consultado sinó la obra citada de WaLckenaEr y GervaIs (1847), pues dice que el géncro no es conocido sinó por las láminas que Nicolet ha publicado en la Historia de Chile, siendo así que estc autor ha dado cl texto cn el tomo citado (1849), quince años ántes de la publicacion de la His. Nat des Arancides (i864).

En cuanto al uso que WALCKEnAER ha hecho de las figuras de Nicolet, no me pa. recc propio, ni acertado; lo primero porque, no significando en parte alguna, á lo que alcanza mi conocimiento, cómo llegó á sus manos esa lámina, podría suponcrse ó que la reeibió como un regalo privado de GAY ó de Nicolet, ó que, animado por el deseo de no dejar sin incluir en su obra especies interesantes, hizo uso de aquella, cualquiera que hubiera sido su procedencia, pues no aleanzo á eomprender cómo NicoleT, p. cj., podía autorizarlo á publicar sus especies, dándolc solamente las figuras y nó los tipos, todo lo cual, dada la alta autoridad de dos naturalistas como WVALCKENAER y GERVAIS (porque bien podría haber sido éste, que tambicn tomó parte cn la publicacion de los Arácnidos chilenos), autorizaría á cualquiera poco cscrupuloso á publicar especies de las cuales sólo encontrase la lámina en preparacion en casa del grabador, lo que, no mediando el consentimicnto dcl autor, sería algo parccido á un rapto literario; en cuanto á lo scgundo, esto es, que no sea acertado, vamos á ver porqué.

E1 nombre de Thomisoides, fundado por NicoLeT, cs perfectamente trivial, pues sólo rccuerda cl carácter fisionómieo de la familia (sens. lat.) á que pertenece cl género de que nos ocupamos, y no vco por qué razon lo cambió Walckenaer por el de Sicarius, que significa ascsino, nombre quc, en todo caso, se rcficrc á un carácter comun á todo el órden, lo cual presta al nombre mayor trivialidad, es eierto, pcro que no tiene más fundamento que el que había recibido ántes. Si para cambiar el nombre de Thomisoides se invocara su semcjanza con el de la familia, me hallaría más dispucsto á aceptar esta razon, pero de ningun modo la que da WALCKENAEk, que le niega cse aspecto como genérico y se lo acepta como cspecífico. Este autor, por otra parte, parece que no ha tenido los ejemplares á la vista y que sólo se ha guiado por la Lámina I, aludida, pues todo lo que dice, y aún los caracteres genéricos sc funda cn las figuras.

Scguramcnte las especies de este género reclaman un nuevo exámen más prolijo que el que de ellas ha hecho Nicolet, pcro podría avcnturarse, entrctanto, la sospecha de que WALCKENAER ha procedido con demasiada precipitacion, refundićndolas todas en una 
sola (Sicarius thomisoides), ejemplo que sigue Simon (I), lo que no puedo aceptar, por no haber hallado en las figuras, ni en las descripciones, un fundamento positivo para semejante union, pues las unguículas tarsales y los ojos, por ej., las diferencian suficientemente, sospechando más bien que no sería improbable el que se fundaran dos géneros inmediatos, en cuyo caso, aceptándose el nombre de Thomisoides, propondría se le refiriera una parte de las especies del actual género, reuniéndose la otra bajo el de Sicarius. NICOLET mismo, en la página 352, forma una primera seccion del género, denoninándola Piriformes, y una segunda, Rugosas, en la página 353. Desgraciadamente, al caracterizar la Seccion I, ha dejado en el texto graves errores, como por ejemplo, respecto de la longitud relativa de las piernas, diciendo: "Las patas del primero y del segundo par son de igual longitud, las del cnarto un poco más cortas y las del segundo! mayores que todas.» Esta repeticion del $2^{\circ}$, sin mencionar el $3^{\circ}$, deja cludas respecto de lo que ha querido decir, pues, al dar las medidas, en la descripcion de cada una de las especies, les señala, segun la longitud absoluta, esta relativa:

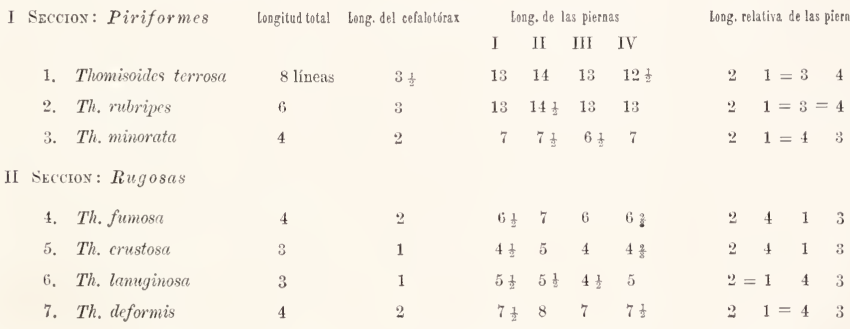

Por estos datos, se vé que la longitud de las piernas no caracteriza las secciones, pues la especie núm. 3, sec. I, las tiene lo mismo que la especie núm. 7 , sec. II; que en la sec. I no hay dos que la tengan igual, y que en la sec. II, sólo la tienen dos (núm. 4 y 5). Ei exámen de las precedentes relaciones numéricas, por otra parte, permitirá al lector darse cuenta del valor taxonómico que, en este caso, pueden tener las mencionadas medidas. Despues de ésto, se comprenderá que el error ántes señalado no se puede ni se necesita corregir, pues, aunque Nicolet ha querido decir, para caracterizar (en parte) la seccion I, que las piernas de los pares I y III son de igual longitud, ésto no es exacto para la $3^{\text {a }}$ especie. De cualquier modo, resulta que el $2^{\circ}$ par siempre es el más largo, pudiendo, por mi parte, confirmar ésto, pues la prolija medida de la longitud relativa de las piernas de un Thomisoides ( 2 ejempl.) traido por el Dr. DoERING, me dá por resultado: 2,1,4,3,

(1) Sırox señala esta especie de "Brasil y Chile». No sé dónde, ni quién la menciona del primero de estos dos paises. 
como en muchas Hetcropodóidcas ó Filodromóideas. WALCKEnaEr entretanto, midiendo quizá las figuras, obtuvo que: "La premicire paire cst la plus longue ", lo que no es exacto.

El género Thomisoides presenta, seguramente, un grande interés bajo el punto de vista del método.

WALCKenaer, siguiendo su sistema artificial, fundado en el número de ojos, lo colocó entre las Discleras, Segestrias, etc, por tener solamente scis, pero no se escaparon al gran aracnólogo francés sus verdaderas afinidades, pues dice (p. 378) lo siguiente: * N. Nicolet a nommé ce genre Thomisoide parce qu'en effet par ses mâchoires inclinées sur la lère, par ses pattes étalíes latéralement, par les formes courtes et ramassées de son corselet ct de son abdomen il a beaucoup danalogie avec les Thomises; mais par ses pattes peu inćgales entre elles il se rapproche cncore plus des 'Philodromes; par la grandeur des invidns dont il se compose, et par son faciès it rappelle le genre Olios".

Nicolet, en el texto de la obra aludida, sigue el sistema general de WALCKENAER, colocando su nuevo género del mismo modo que el maestro, á quien no cita al respecto, pero reconoce tambien en qué familia debería colocarse, si se hubiera de seguir un método natural.

Thorell ( On Eut. Sp.pp. 29, iri, et r7o), con motivo del número de ojos, hace mencion tres veces de este género, manifestando tambien, de paso, la sospecha de que estas arañas sean realmente Tomisóideas (con sus dos tríbus, no separadas aún como familias, Philodrominae y Thomisinac). Este eminente aracnólogo, por otra parte, parece inclinarse á aceptar (p. III) el nombre de Sicarius, pues luego agrega, entre paréntesis, el que le había dado Nicolet; en la página i70, no es tan decisivo, pues dice solamente e Sicarius, WALCK. or Thomisoides Nic.s, como ya lo había hecho ántes, p. 29, y se adhiere á la opinion del fundador del género en cuanto á referirlo á la familia aludida, rechazando la de Sinon que lo coloca entre sus Clothéeiens esto es, un Teridiforme, lo cual no puede aceptarse.

Las opiniones de los tres autores que he citado, y, más que todo, los caracteres mismos del género, me obligan á colocarlo definitivamente en la familia Heteropodoidac, entre los géneros Heteropoda y Selcnops. El material de que dispongo no me permite entrar en consideraciones sobre la organizacion de las diversas especies; sin embargo, espero que la descripcion que luego doy del Thomisoides que he recibido, servirá como un conjunto de datos que se utilizarán más tarde, cuando el género sea bien estudiado. Siendo necesario caracterizarlo bien, es mejor no hacerlo hasta haber reunido cierto número de especies. Entretanto, describo minuciosamente la única que poseo. 
11. THOMISOIDES RUPESTRIS, HoLmb, n. sp.

Lім. IT, ff. $9,9 a, \mathbb{R}$.

Fem. : Th, brerissime appresseque grisescenti fusco-vestito, ccphalothorace cordiformi, aeque longo atque lato marginibus rotundato, antice posticeque truncato, hic fronte duplo latiore, longitudine longitudinem femoris 4i.paris acquante, longitudincm tibiac ejusdem superante, forca lata, leviter carinato et gramulato ubi impressiones radiantes in alteribus speciebus reperiunter; satis concexo, obscure rufo, postice pallidiore et sensim ferrugineo; capite posticc subgibboso, lateribus subparallelo; clypeo alto, fere druplo latiore quem altiore; oculis lateralibus anticis reliquis majoribus; nundibulis, maxillis, labio (hoc ad apicem pallidiore ) palporumque articulis ultimis cephalothorace obscurioribus; mandibulurum unguicula rufa; stcruo, pedibus palporumque femore lutcscenti-ferrugineis; pedibus octo sericbus spinulurum irestructis; unguiculis longis, gracilibus, parallelis, panm arcuatis, sine denticulis. Abdominc sparsim seriatinuqu sctoso sice spinuloso; mammillis brevissimis, pilis numerosis perconditis.

Nota.-In sierra Pichy-Mahuidas Dr. Doerisa speciem reperit.

\section{MEDIDAS DE LA HEMBE.I}

tongitnd total .......... $0.015 \mathrm{~mm} . \|$ Longitud de la mandibula . . . . $0.002 \mathrm{~mm}$.

\& del cefalotórax........ 0.0065

de la cabeza (hasta la foseta). 0.0045

Latitud de la id ..................... 0.0025

" del tórax. ........... 0.0065

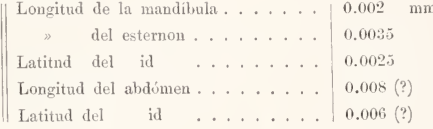

\begin{tabular}{|c|c|c|c|c|c|c|c|c|c|}
\hline & & eoxa & trocánter & fémur & patela & tibia & metatarso & tarso & Total \\
\hline \multirow{4}{*}{$\begin{array}{c}\text { Piernas. } . \\
2,1,4,3\end{array}$} & I & 0,00225 & 0.0005 & 0.0065 & 0.0025 & 0.006 & 0.0045 & 0.00325 & 0.0255 \\
\hline & II & 0.0025 & 0.0005 & 0.007 & 0.00275 & 0.006 & 0.0045 & 0.003 & 0.02625 \\
\hline & III & 0.002 & 0.0005 & 0.0065 & 0.0025 & 0.005 & $0.00 t$ & 0.0025 & 0.023 \\
\hline & IV & 0.00225 & 0.0005 & 0.007 & 0.0025 & 0.005 & 0.0045 & 0.002 .5 & 0.02425 \\
\hline Palpos. & & - & 0.00025 & 0.00175 & 0.00075 & 0.001 & 一 & 0.00175 & 0.0055 \\
\hline
\end{tabular}

Fopma.-Cefalotórax cordiforme, convexo, tan largo como ancho, en la frente un poco más ancho que la longitud de la mandíbula y doble que aquella en el borde posterior casi recto; la cabeza un poco gibosa en la parte posterior; la fóvea ancha, como una abolladura; las irradiaciones no son impresas sinó prominentes y como formadas por granulillos umbilicados, un poco espaciados, y tendidos sobre una carena delgada; la cabeza se halla bien separada del tórax por una ancha impresion, teniendo otra longitudinal en la línea media, así como algunas filas de gránulos, como los anteriores, que tambien se encuentran esparcidos en otros puntos del tórax, ademís de los señalados; estos gránulos no parecen ser setígeros, pues no hay uno solo que presente tales apéndices; el tegumento, irregularmente denudado en mis ejemplares, se muestra lustroso, fina y esparcidamente puntuado, mientras que las otras partes, donde el animal parece estar súcio con tierra, se ob- 
serva la resolueion de esta aparieneia en pelitos muy cortos, espareidos como la puntuacion mencionada, lo que hace sospechar que cubre todo el dorso, y entremezclados con una espeeie de polvo que, más que otra cosa, parece tierra muy fina; los bordes levemente marginados, llevan eerdas cortas, arqueadas; el clipco es ancho, muy poeo saliente, espareidamente puntuado y granuloso, lleva una impresion transversa un poco ántes del borde, el cual es ligeramente eonvexo visto de arriba, y un poco, hácia abajo, mirado de adelante. Los dos OM son apénas oblongos, miran háeia adelante y muy poco háeia arriba y hácia fuera, se hallan entre sí tan separados eomo la mitad de su diámetro y del borde del clípeo muy poco más que de los OL; una línea tangente á su borde inferior, separaría el tercio superior del OLA; éste visiblemente mayor que aquellos, se encuentra en el ángulo sólido de la eabeza, mira hácia adelante y un poco hácia fuera, siendo más saliente $\left(^{*}\right)$ que los OM; el OLP, mira hácia fuera y muy poeo háeia arriba y hácia atrás, tiene el tamaño de los OM y dista del LA tanto como el diámetro de éste; un plano ántero-posterior que pasara tangente al borde externo del OLA, dejaría hácia fucra, pero tocándolo casi, al OLP, colocado á la misma altura que los OM, en relaeion al plano horizontal, y por lo tanto más alto que el LA. Estos tres grupos se hallan colocados en anchas eminencias, de modo que, á cada lado del grupo central, se vé algo deprimida la arista que el clípeo forma con el plano superior de la cabeza. Estcrnon casi circular en el espacio encerrado por las coxas, pero un poco ampliado cerca del lábio, poligonal á causa de aquellas, y muy hundido cerea de éste; se halla cubierto de pelitos muy cortos y de algunas cerditas á los lados, su borde posterior es tan ancho como el anterior, pues las bases de las coxas IV, distan entre sí tanto como las coxas I. Lábio la mitad más largo que aneho, cilindro-convexo, de bordes laterales paralelos, redondeado en el anterior, pcro levemente truncado, donde lleva pelitos más apretados que los de su cara libre. Maxilas poco más largas que el lábio, al cual contornean arqueándose, se unen easi delante de él, son convexas en el sentido de su longitud y presentan una pequeña depresion cerca de su ápice y del borde labial. Mandibulas verticales, más cortas que el ancho de la frente, casi cilíndricas, y apénas ovóideas, truncadas en el ápice, cubiertas de cortos y finos pelos, habiendo algunos más gruesos que coronan la truncatura; su gancho robusto y arqueado, no alcanza el ancho de la mandibula, y presenta en la base, y correspondiendo á su eoncavidad, un grucso tu_ bérculo redondeado. Los palpos cortos y robustos no tienen ni vestigios de uñuela; su último artejo, tan largo como el fémur, es cónico, y termina delicadamentc redondeado, tiene hácia abajo y á eada lado una fila (abajo 2? ) de cêrdas más gruếsas y mayores que los pelillos que visten la casi totalidad del palpo. Las piernas parecen prismáticas, muy particularmente en las tibias y metatarsos, debido ésto á la circunstancia de tener 8 filas de espinículas cortas entremezcladas con otras más largas, sobretodo en los metatarsos; de estas filas, se hallan colocadas cuatro en el fémur, por arriba, y cuatro por abajo, apareadas á cada lado, de 
modo que las caras antcrior y posterior del fémur son las más anchas, y llcvan algunas cerditas más cortas é irregularmentc esparcidas; dichas filas se aproximan más en las patelas, estando casi equidistantes en las tíbias, metatarsos y tarsos, y entre sus espacios se ven numcrosos pelitos; las tíbias en el ápice, por debajo, tienen una corona de cerditas; las uñuclas son largas, delgadas, arqueadas desde la base, carecen completamente de dicntes, y se hallan tan juntas y paralelas que sólo se vé una mirándolas de lado, y su distancia, miradas de arriba, es como el cspesor de su lámina (v. Lám. IV). El abdómcn (*) parece quc hubiera sido oval, esto es, más largo que ancho, un poco truncado por delante y que las hiladeras hubiesen cstado un poco ántcs del ápicc rcdondeado, pero ignoro si era dcprimido (lo que supongo); llcva gránulos como los del cefalotórax y en ellos espinículas csparcidas cn séries más ó ménos regularcs, todo él vestido de pelitos en extremo finos y cortos. Las $h i$ laderas (4) muy cortas, completamcnte ocultas por numerosísimos pelos finos y más largos que el vestido abdominal.

Color.-Todos los pelos son de color parduzco-agrisado, como tcrroso. Respccto de los tegumentos, el color varía: así, el cefalotórax, los últimos artejos de los palpos y las uñuclas, rojo oscuro, caoba, más claro y ferruginoso en la parte posterior del primero. El estcmon, todas las piczas de las fiemas y el fémur de los falpos, ferruginosos amarillentos; las mandibulas, las maxilas y el lábio cuyo borde anterior es claro, de un rojo más oscuro que el del cefalotórax; el gancho mandibular rojo vivo. El abdómen del color general de los pelos.

Observaciones. - Los dos ejcmplares que he estudiado fucron cazados en la Sierra Pichy-Mahuida. Las observacioncs que he hecho á propósito del gćnero valgan para la especie, que no he podido adscribir á ninguna de las de NiCOLET.

\section{Fam, THOMISOIDAE.}

Gen. Misumena (Latr. 1804) Thorнl. 1870.

12. MISUMENA EXANTHEMATICA, Hoцmв, n. sp.

Lis. IV, ff. $10,10 a, \&$.

Mas?: M. omnino scriatim ct sparsim obscure sanguineo-punctata sive gramelatu, gramulis nigro-unisetigeris, cephalotorace circa $1 / 6$ longiore quam laviore, subfuscescenti-tcstaceo, fronte obscuriore, utrinque obscure fusco-vittato; pedibus anticis subfuscescenti-tcstaccis quoque; abdomine pedibusque posticis anticis paulo pallidioribus, illo vittis duabus e pigmento albo constitutis, antice posticeque (id est prope petiolum et mammilles) conniventibus, in medio separatis, alteraque media dorsuali ejusdem coloris pone medium dorsi, retrorsum sensim angustata, granulis majoribus sanguineis seriatim dispositis utrinque in structa, ornato.

Nota.-Exemplum singulum hujus specici prope ripam Rio Colorado» D1: Dosnuxg collegit.

(\%) No atribuyo mucha fijeza á los caracteres que puedo tontar de esta parte. Los dos ejemplares no ve nian eu aguardiente, sinó en papel, de tal modo que el ahdómen se ha secado, y deformato al arrugarse; pero, si mi expericncia en estos easos puede servir como un apoyo para abrir opinion, diré que recuerda mucho, actualmente, lo que sucede con las especies de Hetcropada (Olios, Ocypete) en el misiuo caso. 


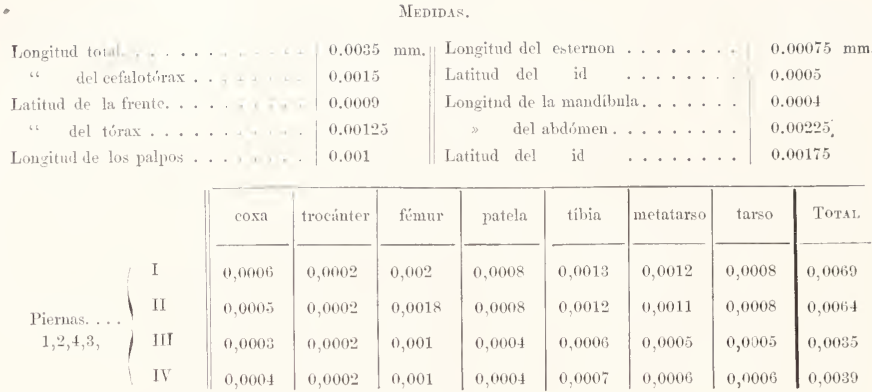

FORMA.-Cefalotórax más corto que el fémur del par I, casi tan largo como la tíbia del mismo, circular, cordiforme, casi recto por delante, bien redondeado en los costados; su corte transverso casi semicircular mirado de adelante; casi plano mirándolo de lado, siendo bien marcada la inclinacion posterior oblícua; el clípeo á la altura de los OMA, doble más alto que el diámetro de éstos, ligera y anchamente escotado, con un ligero reborde, retiránclose en curva suave por debajo de los OL; salpicado de gránulos setf́geros, de los cuales deben recordarse, principalmente, uno que se encuentra entre los OMA, dos detrás de ellos y uno hácia fuera de cada OMP; estos gránulos se encuentran tambien en el abdómen y en los miembros. Los $\mathrm{OA}$ en línea recurva, equidistantes, de igual tamaño; un plano horizontal tangente al borde inferior de los OLA pasaría por el medio de los OMA; la distancia que separa á unos de otros es casi igual al doble de su diámetro; los OP en línea tambien recurva, más ancha que la anterior, un plano vertical tangente al borde anterior de los OLP dejaría por delante á los OMP, siendo casi tangente á su borde posterior; se hallan equidistantes, aunque los OM parecen un tanto más aproximados entre sí, y forman un trapecio con los OMA; un plano vertical tangente al borde interno del OLA cortaría en dos partes iguales la distancia que média entre el OMP y el L.P; los OP son de igual tamaño, siendo su diámetro como de dos tercios del de los anteriores; los OL se encuentran en una eminencia comun oblícua; el eje óptico del OLP se dirije hácia fuera, hácia atrás y muy poco hácia arriba. El esternon es triangular con una ligera depresion junto al lábio; las bases de las coxas anteriores se hallan separadas entre sí cuatro veces más que las de las posteriores cuya separacion es como la mitad del diámetro transverso de la coxa; las coxas del par I se hallan entre sí un poco más próximas que las del II. El lábio más largo que ancho, convexo, con una leve impresion média transversa, es un poco estrechado en la base y termina en punta obtusa. Las maxilas convexas, visiblemente gibosas en la mitad basal, son levemente convergentes, irregularmente redondeadas en el ápice y sobrepasan sólo por un cuarto de su propia longitud á la del lábio. 
Mandibulas verticales, cónicas, truncadas, un poco gibosas en la base; como los otros órganos de la boca y cl esternon sc hallan vestidas de pelitos esparcidos. Palpos cortos y robustos, con pelillos y espinículas ( v. Lám. IV.);--como carecen de uñuela, supongo deben corresponder á un macho jóven, tanto más cuanto que no encuentro epiginio. Picrnas con gránulos setígeros y espinículas no muy bien caracterizadas; las uñuelas tarsalcs como cn la especie siguiente, pero la punta es más larga, más acentuadamente estriada y forma un ángulo más marcado con el lomo; les he contado 7 á 8 dientes, gradualmente mayores. El abdómen oval, corto, poco más largo quc ancho, truncado por delante, rcdondeado por detrás, deprimido, y adornado dc numerosos gránulos setígcros, cuya distribucion se señala lnego, con motivo del color. Hiladeras muy cortas, las inferiores cónico-mastóidcas más gruesas que las supcriores.

CoLOr.-El cefalotórax, las picrnas antcriores y órganos bucales de color testáceo dćbilmente parduzco, más oscuro en la frente; á cada lado de él, incluyendo cl ojo externo de la scgunda fila, nace una ancha banda parda oscura que termina casi en cl ángulo postcrior; cstas bandas corrcn paralelamente, prescntando cada una, al comcnzar su último tercio, cn el declive torácico, una pcqucña ampliacion angular dirijida hácia adcntro. El abdémenn, así como las piernas posteriores, dc un color apénas más claro que el resto, teniendo el primero dos bandas blancas que naccn juntas cn la partc anterior, y que, scparándosc, ocupan la parte cxtcrior y lateral del dorso, dcbilitándose extrcmadamente cn los costados mismos, y yendo á terminar en las hiladeras; estas bandas no tienen un borde interno rcgular, pues presentan débiles ampliacioncs, siendo las más accntuadas dos que se cncuentran en la mitad anterior; la mitad posterior del cspacio que separa cstas bandas está ocupada parcialmente por otra banda blanca, más ancha anteriormente quc hácia atrás, porque se atcnúa poco á poco, sin llegar á fundirse con las otras ccrca de las hiladcras; á los lados, ella se encuentra scparada de las mayores por una línea dcl color testíceo dcl abdómen. (*) Estas bandas están formadas por un pigmento blanco, cncerrado en una red bicn visible de color testácco, de tal modo quc cllas presentan, nó un conjunto jerfcctamente contínuo, sinó en forma de tejido areolar. En la base de las mandíbulas y lá́cia arriba del ángulo bucal se ven puntos muy próximos de color carmin, puntos que tímbicn se presentan cn las picrnas, donde se hallan colocados en líneas más ó ménos re§ulares ó esparcidamente, acarminándose en ciertas porcioncs, pcro muy poco, el tegumcnto mismo, sobrctodo en la base y ápice de las tíbias dc los dos pares anteriores, donde, por otra parte, los puntitos rojos se encucntran más confluentes; en el tórax son mas escasos, predominando cn las bandas oscuras; cn el abdómen aparecen los mayores, cuya distribucion corresponde á las depresioncs ó tubcrculillos análogos de otros Xisticos, tilles como las cspecies: Xysticus cincreus y graecus, etc., ff, 290 y $29 \mathrm{I}$ respcctivamcnte,

( ) Tambien podría expresarse el carácter general de la coloracion del dorso del abdómen, diciendo que es blunco, y que, en su mitad anterior, presenta una mancha testricea de bordes recortados, la cual envía láeia atris dos lineas poco convergentes del mismo color. 
de la grande obra de HAH y Kucl: ; - asi, en la miad anterior del espacio que separa las bandas blancas laterales, se obsertan seis grandes, ocupando los ángulos de un hexágono imaginario, cuyos lados anterior y posterior fueran los más cortos; en el centro de este hexágono, hay dos puntos más pequeños, formando asi una fila transversal con los del segundo par, miertras que entre los del primero se observa un puntito muy pequeño; en la segunda mitad, ocupando las dos lineas que separan la banda blanca media de las Laterales, aparecen tambien puntos de los mayores, apareados, cuyos dos primeros están apenas monos siparados que los del segundo del hexágono; lus siguientes se hallan algo más aproximados; hácia el borde anterior del abdómer se observa una fila de puntos mínimos, que ra a confundirse con los de los costados, donde aparecen en no escaso número y de diversos tamaños. Todos los pelos, cerdas ó espiniculas, así como las uñas, de color negro ó pardo.

OBSERTACIONES. - El único ejemplar de que me he valido fué cazado por el Dr. DoERISG cerca de las riberas del Rio Colorado. Como lo he hecho notar, á propósito de los palpos, creo que esta especie debe estar fundada en un macho jóren, pues las hembras de otras Nisumanas que he visto, no carecen de uñuela en esa parte. El color rojo de los granulos setigeros de todo el cuerpo, $y$ que me ha invitado á bautizar la especie con el nombre de exanthemativa, se ha desianecido poco á poco en el alcoho', y, á juzgar por casos análogos, no serna dudoso que ellos fueran pardos en vez de rojos en el vivo,-en tal caso, no seria ménos exacto el nombre.

Ge- Diaea. Thorell 15-

13. DIAEA CHLOROPHILA. Holsв, n. sp.

Líx. T., ț. 11,11 t. 5 .

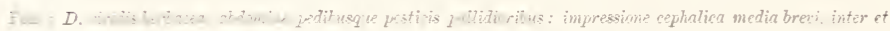

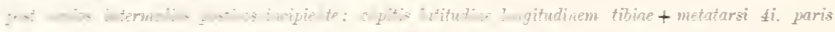

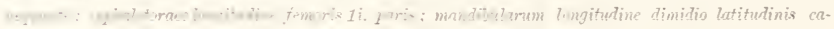

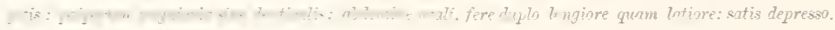

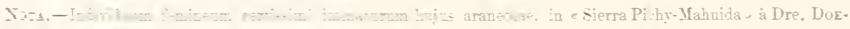

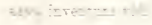

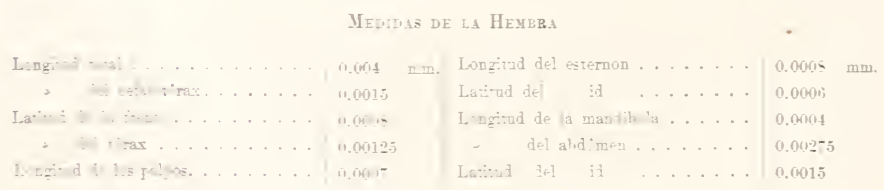




\begin{tabular}{|c|c|c|c|c|c|c|c|c|c|}
\hline & & $\cos 3$ & trocsinter & $\therefore-\operatorname{sur}$ & patela & tibia & metatarso & $\tan =$ & Tora: \\
\hline & I & $0.000 \mathrm{~s}$ & 0.0002 & 0.0015 & 0,$000 ;$ & 0.001 & $0,000=5$ & 0.0005 & $0,6014=5$ \\
\hline iernas & $\Pi$ & 0,0003 & $0,000:$ & 0.0014 & (0. & 0.00 & 0.00075 & 0.00005 & D.poites \\
\hline $1,2,4,3$ & III & 0,00025 & 0.00015 & 0.00055 & "1. enot & $0, \mathrm{COH}_{1}:$ & 0. 60025 & $0 . \cos 25$ & $400: 55$ \\
\hline & $\mathrm{IV}^{-}$ & 0.00025 & 0.00015 & 0.0002 & $0.0004 t$ & 0,005 & $0,000,3$ & 0.0003 & $\therefore .002=$ \\
\hline
\end{tabular}

FORMA. - El cefalotórax un poco cnangostado hácia adelante, casi circular, apénas más largo que la patela + la tíbia - el metatarso del cuarto par de piernas, tan largo como el fémur del primer par, muy poco más largo que ancha, truncado por delante, bien redondeado en los lados, suaveniente escotado en el borde posterior; presenta una impresion que nace entre los dos OMIP y que casi se desianece al aproximarse á la forea o foseta torácica; la cabeza es visiblemente gibosa á cada lado del orıgen de dicha depresion; las impresiones radiantes bastante desranecidas, habiendo una de ellas que nace en la parte posterior de la foseta $y$ que es ancha y redondeada; la bifurcacion es muy marcada, siendo todo el ccfalotórax relativamente deprimido. Mirando de lado el cefalotórax, es recto, destacándose muy poco las eninencias post-oculares; el declive posterior es violento, pero visiblemente redondeado; mirándolo por delante se ve que su dorso es casi plano, pero se redondea suavemente en los declives laterales; el clipro es recto en su corte y en el ángulo que forma con el plano dorsal, tan alto como el diámetro de los O.M.A, pero á los lados se retira arqueándose hácia atrás, por debajo de los OL.A, inclinándose un poco en esta parte para confundirse con el declive lateral del tírax. Los OA forman una linea poco convexa hácia abajo; el diámetro de los OLAt es doble que el de los ONLA, y la distancia que separa á todos algo mayor que el diámetro de los OL.A. Los OP estan situados en una fila más ancha que la anterior; ella es muy convexa hácia adelante, de tal modo que una línea tangente al borde anterior de los OLP, dejarı muy adéante á los OMP, y otra tangente al borde interno de los OLP, pasarıa por fuera de los OLA. El diametro de los OMP es igual al de los OMLA y el de los OLP es algo menor que el de los OLA; ellos están casi equidistantes entre si, porque los O.IP estan muy poco más próximos el uno del otro que de los OLP, de modo que los OALA forman un trapecio con los correspondientes posteriores; el OLA forma con el LP y el MP un triángulo escaleno, siendo la distancia que separa á los dos OL igual á la que media entre ambos OMIP; el OLP mira hácia atras y un poco hảcia fuera, hallandose colocado en una eminencia comun con el LA. Esternon oval, casi plano, más estrecho en la parte posterior que en la anterior, estando las piernas posteriores, entre sí, tres veces más cerca que las bases de las anteriores. Labio tan largo como ancho, casi triangular, con bordes redondeados. Mlaxilas convexas, redondeadas en el ápice, casi unidas delante del labio. 3landiobulas nuy cortas, casi oróideas, truncadas y dirigidas hácia atrás, lleran algunos pelitos esparcilos como los utros órganos bucales y el esternon. Palpos muy cortos, con pelitos esparcidos; la uñuelta 
corta, muy ancha en la base, desde donde se encorva hasta el ápice; algunos pelitos plumosos la rodean. Piemas escasas de pelos y de espinículas, llcvan tres ó cuatro pares de éstas en las tíbias y cuatro pares en los mctatarsos: las uñuclas son fuertes, con base muy ancha, muy arqueadas despues de ella, con cinco dientes fuertes en la externa y cinco cn la interna, gradualmente mayores; la parte apical, no dentada, es mucho más larga quc el último diente, y ella no sólo cs estriada (como cn Chiracanthium) en su borde filoso, sinó tambicn en la porcion que ocupan los dientes (una sola observacion muy clara del par II). El abdómen es oval, casi doble más largo que ancho, truncado por dclantc, redondeado por detrás y bastante deprimido; sus impresiones punctiformes, apénas visibles, parccen distribuidas como en la cspecic anterior y no llcva dibujo alguno característico; las hiladeras son muy cortas, mastóideas.

Color. - El color general es vcrde herbáceo, más claro en los dos pares posteriorcs de piernas y cn cl abdómen que cn cl resto;-pero ha cambiado por completo en el alcohol, quedando testáceo cn las partes verdes más oscuras, y más claro donde lo era tambien el verde (*).

Fam, LycosoId AE.

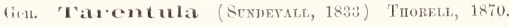

14. Tarentula poliostoma (C. L. Косн) Kexserling.

Syn. :-(184x) Lycasa (Tirantule) poliostoma, C. L. Kocir, Dir Arach. T. XIV, p. 152, Lám. 494, f. 1379

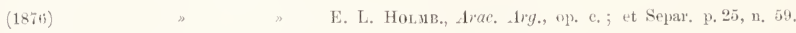

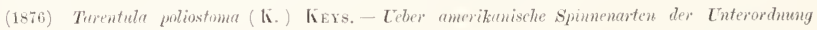
Citigradae, in Yerh, d. k, -k, z.,-b. Gese, Wien, T. XXII, P. 64:3, Lám. 7 , f: 24 .

NoтA. Feminam singulam hand alultam hujus speciei per totau Argentinam dispersam prope Rio Negros rollegit Dr. DoERINa.

Esta espccie, bien conocida por los trabajos de KOCH y de KEYSERLING, se encuentra en casi toda la República, muy particularmente cn la region oriental y en la vecina del Uruguay. No siendo una de las Arañas Argentinas que yo he dado á conocer, me abstengo de publicar la descripcion de la hembra, muy semejantc al macho y difícil de confundir. El ejemplar muy jóven que me entregó el Dr. DoERıNG, lo había cazado éste cerca del Rio Negro.

(·) El Dr. Doerrase es quien me ha comunieado verbalmente estos datos relativos í los colores del animal vivo, de tal modo que no podrá disceruirse en las colecciones si no se estudia bajo el punto de vista de la estrinetura y de la proporcionalidad de las medidas, agregándose, alemís, el inconveniente de ser un indivíduo júven el que se me ha comunicado para estudiar. 
15. TARENTUla MoEsta, Holmberg.

L.r. IV, ff. $12,12 \alpha, \&$,

Syn. : (1876) Lycosa (Turantula) moesta, Ноцмв, Arae. Arg., loc. cit.--Separ. p. 26, n. 65.

Nота-Feminam immatnram prope "Rio Colorado" repertam cum individuis numerosis proximitate "Bnenos Aires» et in "Las Conchas" collectis comparavi.

Me parece innecesario describir minuciosamente esta especie, pues ella se parece tanto á la Tarentula Thorellii, Keyserling (op. c. p. 650, Lám. VII, f. 28 ) que basta señalar las diferencias para dar una idea de ella. Espero se me permita, en este caso, modificar mi plan de descripciones, adoptando el de Keyserling, para que resalten más las diferencias y las semejanzas con la especie en cuestion.

Conservo entre mis papeles una larga y prolija descripcion que hice, tres años ha, de la especie denominada por mí, en los Arácnidos Argentinos, Lyc. (Tar.) moesta (*) valiéndome de un hermoso ejemplar femenino, recien cazado en los alrededores de Buenos Aires por mi muy caro amigo ENrique Lynch ArribálzagA, quien me lo entregó vivo. Por temor de alterar su coloracion, lo maté atravesándole el tórax con un alfiler fino, y describiéndolo enseguida. Advierto ésto, porque los doscientos ejemplares de mi coleccion no conservan esa fijeza de dibujo que consigno en mis apuntes, carácter que, si bien no tan seguro como la estructura, no por ésto puede ni debe descuidarse en lo mínimo.

Medidas.-Numerosos ejemplares de mi coleccion coinciden con todas las medidas que Keyserling da de la hembra de su T. Thorellii. A veces la diferencia es de 2, 3 ó 4 décimos de milímetro en piezas largas como el fémur, pero se encuentran muchos ejemplares que no tienen sus dos fémures del mismo par de igual longitud etc., como ya lo he hecho notar, p. ej., en la pág. I48, á propósito de la Eurypelnna Doeringii, y como lo he observado en la especie que actualmente me ocupa.

COLOR.-Conforme, pero debo advertir que, en mi especie, las bandas no son amarillas, ni hay pelos de este color en el cefalotórax. Lo que de la T. Thorellii dice KEyserLING "gelb», es gris acanelado claro en la $T$. moesta. La banda media no es "schmal» sinó, más bien, ancha, gradualmente mayor despues de los ojos posteriores y se estrecha luego en medio del declive peciolar para dilatarse más aún enseguida, lleva tres líneas finas, longitudinales, negras; las bandas laterales son ondeadas con las convexidades hácia arriba ; hay finas lineolas negras en las impresiones radiantes, y las bandas claras parecen finamente bordadas de negro, con especialidad la parte posterior de la banda media. Las piernas no tienen realmente anillos ni dibujos notables, sinó manchas desvanecidas que les dan un cierto aspecto viperino. En cuanto á la coloracion del abdómen, ella concuerda con la de la $T$. Thorellii, pero la mia tiene algo más, que Kerserling no menciona en la suya, por cuya razon me parece más acertado copiar integra la descripcion que hice en presencia del animal fresco: «El abdómen es pardo, más claro y gris acanelado en el

(*) En esta obra sólo dí el nombre y la longitud del animal. 
vientre; en la parte completamcnte anterior cs canela rojizo claro, donde se dcstaca una figura que nace un poco arriba del peciolo, compuesta de cuatro ramas negras, radiantes, que divcrgen dos hácia arriba, y dos hácia los costados, de manera que parece que el color canela rojizo claro formara los limbos de estas rayas. Tanto es así, que el limbo interno de las dos ramas supcriores, corre hácia atrás, para desaparecer al fin del primer quinto de la longitud abdominal. Por dentro de estas rayas claras, nacen dos líncas negras, muy finas, que alcanzan hasta el cxtremo del segundo quinto, dando cada una, hácia fuera, una lengüeta; allí se interrumpen para reaparecer en el centro del dorso, bajo el aspecto de un acento circunflejo, pequeña figura á la que sigue un triángulo más pequeño aún, detrás del cual, pero nó junto, se percibe un punto ó bandita negra; tres manchitas de puntos negros muy finos parecen continuar las ramas negras superiores (V) del extremo anterior y que semejan bandas muy interrumpidas en su curso á cada lado de la banda media, se aproximan cerca de las hiladeras y se envian ramitas recurrentes. La porcion ántero-lateral dcl abdómen presenta puntos claros, esparcidos, que disminuyen hácia el medio.»

Forma.-El ccfalotórax concuerda casi completamente con el de la T. Thorcllii. Los ojo3, sinembargo, discrepan un tanto. Así los $\mathrm{O} \Lambda$ distan algo más del borde del clípeo que de la scgunda fila; los OMA distan entre sí tanto como dos tercios de su diámetro y de los OLA tanto como un tercio del diámetro de éstos. Los de la segunda fila, más ancha que la primera, se hallan cntre sí tan separados como tres cuartos de su diámetro; los de la fila posterior miran bilateralmente y algo hácia arriba, y su distancia, medida desde su borde superior ó interno, es casi igual al ancho de la segunda fila; de las demás partes, cuya semejanza es indiscutible, sólo haré algunas ligeras observaciones. El lábio es visiblemente cscotado por delante,-aunque, en verdad, dice de él KeyserLing: «ziemlich gerade». Del estcrnon de mi especie no podría decir que es oval, sinó tan largo como ancho, casi circular. Las picrnas de los pares I y II tienen sus espinas distribuidas del mismo modo que en la especie que me ocupa y en cuanto á los pares III y IV, doy aquí su armadura :

III. par: Fémur arriba 1.1.1., adelante 1,1., atrás 1.1.1. Patela adclente 1., atrás 1. Tíbia arriba 1.1., adelante 1.1., atrás 1.1., abajo 2.2.2. Metatarso adelante 1.1.1., atris 1.1.1, abajo 2.2.2.

IV. " : Fémur arriba 1.1.1., adelante 1.1, atrás 1. Patela adelante 1.1., atrás 1. Tíbia arriba 1.1., ade lante 1.1., atrás 1.1., abajo 2.2.2. Metatarso adelante 1.1.1., atrás 1.1.1., abajo 2.2.2.

\section{Medidas deL MACHo}

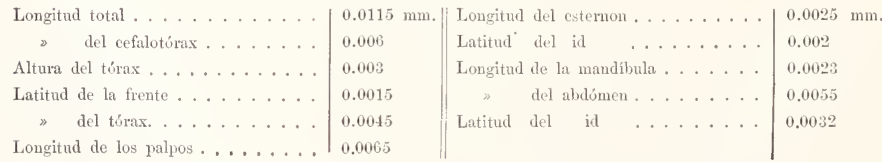




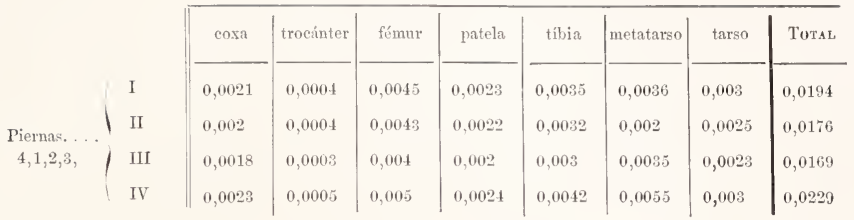

Forma.-El cefalotórax proporcionalmente es más estrecho en la frente con relacion al ancho del tórax que en la hembra, y la proporcion de su ancho á su largo como $3: 4$. Todas las partes son absolutamente más cortas que en la hembra. Las mandíbulas no son tan gibosas. Los palpos (v. Lám. IV.) son muy poco más largos que el cefalotórax. Las piemas son dirijidas muy á los lados, tanto que el animal, sacado del aguardiente, tiene el aspecto de una Heteropodóidea.

COLOR,-En general puede decirse que todos los colores son más pálidos que en la hembra, y, en particular, puede señalarse mayor abundancia de estrías radiantes claras cerca de la banda marginal del cefalotórax.

\section{Espinas de las pierkas.}

I par : Fémur arriba 1.1.1., adelante 1.1. ( $\left.\dot{0}_{2}^{2}\right)$ atrás 1.1.1. Tíbia adelante 1.1., atrás 1.1., abajo 2.2.2.

II $\infty$ : Fémur arriba 1.1.1., adelante 1.1. ú 1.1.1., atrás 1.1. Patela adelante 1., atrás 1. ó 0 . Tíbia arriba 1.1. ó 1. ó 0., adelante 1.1., atrás 1.1, abajo 2.2.2.

III s : Fémur arriba 1.1.1, adelante 1.1., atrás 1.1.1. 6 1.1.1.1. Patela adelante 1., atrás 1. Tíbia arriba 1.1., adelante 1.1., atrás 1.1., abajo 2.2.2. Metatarso adelante 1.1.1., atrás 1.1.1., abajo 2.2.2.

IV " : Fémur arriba 1.1.1., adelante 1.1., atrás 1. Patela adelante 1.1., atrás 1. Tíbia arriba 1.1., adelante 1.1., atrás 1.1., 6́ 1.1.1, abajo 2.2.2. Metatarso adelante 1.1.1., atiás 1.1.1., abajo 2.2.2.

ObServaciones.-Esta especie es, sin duda, una de las más comunes en la Provincia de Buenos Aires, muy particularmente en la ribera del Plata y de sus afluentes paranenses; vive con predileccion entre las acumulaciones de yerbas, hojas y ramas secas que, en sus inundaciones, depositan estos rios sobre las playas, ó bien bajo los troncos ó bajo las piedras en puntos á donde no alcanzan las aguas. Cuando éstas vuelven á subir, desalojan de sus húmedas moradas á la triste (moesta) Tarántula, que corre entónces en inmensas bandadas hácia los puntos libres del desborde. Una vez me mandó Oliverra César, de Las Conchas, un frasco que contenía cerca de doscientos ejemplares, entre los cuales venian algunos machos. Comprendí en el acto que había habido inundacion en ese punto, lo que me fué confirmado mas tarde por mi corresponsal. Siendo tan abundante en todo el Delta, sería muy extraño que no abundara tambien en la vecina República del Uruguay, de donde no la ha recibido el Conde de Kexyserling, quien señala á Nueva Granada como pátria de la $T$. Thorcllii. El ejemplar jóven que me trajo el Dr. Doering fué cazado cerca del Rio Colorado. La manera de vivir de la $T$. moesta difiere completamente de la de las $T$. poliostoma 
(K.) Krxs., y pampeana, Holmb., que habitan en un tubo de varios ccntimetros, practicado en suclo duro, pero ignoro si por ellas ó por otros animales.

Fam, ATTOIDAE.

Cuando escribía la Introduccion de este trabajo, un año há, pensaba sériamente en la fundacion de un nuevo género para dos lindas arañitas de $4 \mathrm{I} / 2$ milímetros la una y de 3 I 2 la otra, que el Dr. Doering habia cazado en la Sierra de la Ventana, y que no formaban parte de ninguno de los géneros que me eran conocidos; pero hoy, despues de exa. minarlas con más prolijidad aún que entónces y considerando que no he podido completar todavía mis elementos bibliograficos, relativos á la familia á que pertenecen los dos ejemplares únicos que he recibido; y que uno de los caractéres mas importantes en que hubiera de fundarsc el nuevo género es la carencia de clípeo, por llegar hasta su borde los ojos medios antcriores, carácter que, por su novedad en ejemplares adultos y su frecuencia en los jóvcnes, como puede recordarlo cualquiera que haya observado, p. ej., los del género Enophrys, por el tamaño de los animales, por la distribucion del pelage y la desproporcion cntre los clementos de éste y aquel, por la fisonomía juvenil de los cjemplares y por su exígua representacion numérica,-he juzgado más prudente reservar la publicacion del nuevo género para cl dia en quc, contando con todos los elementos indispensables, pueda confiar cn la excelcncia de una descripcion no destinada á engrosar las filas de una sinonímia ya dcmasiado complicada por desgracia. Dicha fundacion podría disculparse tratándose de una region de difícil acceso, pero no de aquclla en que vive cl prcsunto nuevo género.

\section{ESCORPIONES}

Fam, TELEgONOIDAE.

fien, Bothxiurus, (Peters, 1861), Thorell, 1877

16. BOTHRIURUS VITTATUS (Guéris, 1830) Thoreli, 1877.

v. Thorelu Etudes scorp. \& Sobre algunos Arácridos de la República Argentina in Boletin de la Acad, de Cienc, de Córdoba-18i8.

Nota-Exemplum singulum haud duhie immaturum prope "Paso de Pacheco, Rio Colorado" sub lapidas riparias collegit Dr. DOERIsG.

La falta de ejemplares jóvencs, ya que nó de adultos, y la de casi todas las obras en que esta cspecie sc halla tratada, me obliga á aceptar, por el momento, la sinonímia establecida para ella por THORELl y á considerar como á indivíduo jóven al pequcño Bothriurus que lia puesto en mis manos cl Dr. Doering, quien lo había cazado en el «Paso de Pa- 
checo» (Rio Colorado). Sospecho, sinembargo, que una buena série de ejemplares frescos del Bothriurus vittatus, tal como lo entiendc THORELL, tiene que arrojar mayor claridad que la quc hasta ahora nos guia en la interpretacion de csta especie, tan fácil de conocer, en apariencia, y tan difícil en realidad. Mas tarde, cuando haya reunido el material necesario, emprenderé un estudio de todos los Escorpiones que conservo y someteré á la critica el resultado de mis invcstigaciones.

Gen. Corcophonius, (Pet.) Thorel., 1877.

v. Thorell, Etudes scorpiologiques, Milan, 1877 , pp. 83 \& 178 (Extr. de las Aetas de la Sociedad Italiana de Ciencias Naturales).

\section{CERCOPHONIUS BRACHYCENTRUS, ThORELL.}

LÁM. IV, ff. $13,13 a, \&$.

Syn.: (1877) Cercophonius brachycentrus, Tuone1,I, op. cit. p. 180.

Nora-In eodem loco eum specie praecedente.

Esta es la especie de la cual digo en la introduccion (p. 120) que se parcce mucho á una de las descritas por el Dr. Thorell. No había estudiado entónces tres cjemplares que conservaba en mi coleccion, cazados por el Dr. D. CÁrLos Berg en Santa Cruz (Patagonia Meridional) durante su viage al Sur del Continente y que me regaló hace algunos años. Al clasificarlos ahora, encuentro que no pueden separarse del Corcophonius brachycentrus, á pesar dc algunas diferencias que con su descripcion presentan. El ejemplar, ó mas bien los ejemplares, que Thorell rccibió del Dr. Weyenbergh, procedian de San Juan, los de Berg de Santa Cruz y el de Doering del Rio Colorado, punto intermcdio de la extensa region habitada por esta especie.

\section{ACAROS}

Fam, TROMBIDIOIDAE

Gen, rrombianum, (F.) Косн.

18. TROMBIDIUM DESERTICOLA, Holais. n. sp.

Lás. IV, ff. 14, 14a, \&,

Tr. purpurascens, pedibus pallidioribus, articulo ultimo primi paris praecedente breviore; abdomine postice rotundato; thoracogaster antice foveolis duabus subrotundatis of pone eas alteram transtersam; abdomine foveolis quatuor in quadratum dispositis, pone impressionem thoracicam.

NoтA.-Individum unicum in Paso de Pacheco repertum, nunc studio detritum, sed collectione mea servatum, vidi, 
Medidas

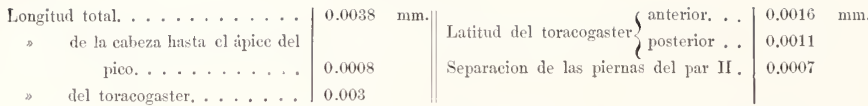

El único ejemplar que he recibido de esta especie sólo ha podido servirme para trazar los dibujos de la Lámina IV, que darán á conocer casi todo lo que de él he podido averiguar. Los pelos del dorso son bastante cortos y un tanto rígidos, los de las piernas son plumosos (Lám. IV, f. 14 i). El color general cra acarminado, y las piernas más pálidastodo lo cual se ha desvanecido en el alcohol en que se ha conservado.

\section{Explicacion de LAS Láminas III y IV.}

\section{LÁ MINA III.}

Fig. 1. Argiope argentate (F.) Kосн

$\begin{array}{ll}1 a & \Rightarrow \quad \Rightarrow \\ 1 b & \Rightarrow \\ 1 & c\end{array}$

Fig. 2. Epeira solitudinis Howan.

$\begin{array}{ll}2 a & \Rightarrow \\ 2 b & \# \\ 2 c & \Rightarrow \\ 2 a & \Rightarrow\end{array}$

Fig. 3. Scytodes maculata HoL эв.

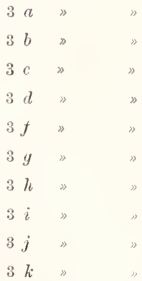

Fig. 4. Drassus australis HoLmb.

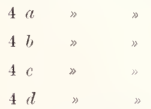

Fig. 5. Chiracanthium abnorme HoLdis. epiginio.

eapullo cubierto.

deseubierto.

huevo.

la hembra 21

palpo.

tarso I.

epiginio.

* de atris.

hembra 21.

tamaño natural.

palpo.

" su ápiec con los apéndices.

nũnelas del par I.

" " $\mathrm{IV}$.

vulva,

macho 21 .

su palpo.

ápice del bulbo.

tarso I.

macho jóven.

tamaño natural.

jalpo, anmentado.

» tamaño natural.

uñuelas del par II.

hembra 31 .

tamaño natural.

ápice del palpo. 
nũuelas del par I.

$\begin{array}{lll}5 e & \Rightarrow & \\ 5 d & \# & \\ 5 e & \Rightarrow & \Rightarrow \\ 5 f & \# & \Rightarrow \\ 5 g & \#\end{array}$

Fig. 6. Anyphaena Argentina HoLsв.

\begin{tabular}{|c|c|}
\hline $6 a$ & , \\
\hline $6 b$ & D \\
\hline $6 c$ & 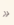 \\
\hline $6 d$ & N \\
\hline $6 e$ & 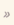 \\
\hline $6 f$ & ", \\
\hline
\end{tabular}

Fig. 7. Amyphaena pampa HoLms.

$7 a$ »

Fig. 8. Eurypelma Doeringii Ноцлв.

$\begin{array}{ll}8 & a \\ 8 & b \\ 8 & c\end{array}$ " \#

y $\Rightarrow$ IV

apéndice espatuliforme del penacho.

pelo.

epiginio.

hembra,

palpo.

2 su ápice.

uñuelas del tarso I.

pieza espatuliforme del peuacho

pelo.

epiginio.

hembra.

epiginio.

macho $1[1$.

palpo.

bulbo por fuera,

nũicela del tarso I

IV.

\section{LAMINA IV.}

Fig. 9. Thomisoules mipestris HoLaB.

$\begin{array}{llll}9 & a & \# & \\ 9 & b & \# & \text { \# } \\ 9 & c & \# & \text { \# } \\ 9 & d & \# & \text { \# }\end{array}$

Fig. 10. Misumena exanthematiea HoLmB.

$10 a, 2$,
$10 b$
$10 c$
$10 d$

Fig. 11. Diaea chlorophile HoLmB.
$11 a \gg n$
$11 b \%$,
$11 c$ p

Fig. 12. Turentula moesta HoLms.

\begin{tabular}{|c|c|}
\hline $12 a$ & $"$ \\
\hline $12 b$ & 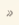 \\
\hline $12 c$ & » \\
\hline $12 d$ & $"$ \\
\hline $12 e$ & $D$ \\
\hline $12 f$ & $\nu$ \\
\hline $12 g$ & 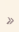 \\
\hline
\end{tabular}

hembra.

ojos.

boea (lábio y maxilas).

palpo.

uñuelas .

macho jóven.

tamaño natural.

palpo.

uñuelas del tarso 1 .

》 $\gg$ II.

hembra.

» tamaño natural.

palpo,

uñuela del tarso II.

hembra $1 / 1$.

palpo.

uñuelas del tarso I.

" $\Rightarrow$ IV

epiginio.

macho.

palpo de lado,

, de abajo. 
Fig. 13. Cercophonins brachycentrus ThoneLL, tamaño natural

$\begin{array}{lll}18 a & \Rightarrow \\ 13 b & \Rightarrow \\ 13 c & \Rightarrow\end{array}$

Fig. 14. Trombition deserticola HoLmB.

$14 a$
$14 b$
$14 c$
$14 d$
$14 c$
$14 f$
$14 g$
$14 h$
$14 i$

aumentado á $2[1$.

palpo.

vesícula.

tamaño natural.

aumentado $7_{[} 1$.

palpo.

mandíbula

piernas I y II.

uñuelas par I.

» II.

3) III

" IV.

un pelo de las piernas

Nota - En momentos de imprimir estc pliego, preparado desde fincs de Enero, pero cuya impresion se ha detenido por contener la explieaeion de las Lúminas Araenolígicas, reeibo la obra de M. Eugène Simox Araehnirles de France, en la cual encuentro algo que tiene relacion con especies publieadas en este trabajo:

$1^{\circ}$ La Tegenuria civilis, Walck. (p. 185), llevarí, para M. Sumon, el nombre de T. domestica (op. c. II, 73). Comparando la sinonímia que $d h_{1}$ tanto de ésta, como de la $T$. ferruginea (p. 65) me inelinaría $\dot{t}$ aceptar; con Thorell, el de T. Derhami (Scop.) Thor. para la especie que nos ocupa. Por otra parte, seguu el mismo Simon, IValckenaer precedió á Sundevall por 30 años respeeto del es pecífico cirilis.

$2^{\circ}$ Las mismas razones que podría invoear para aceptar aquet nombre, son las que parece haber aceptado M. Sinox al suprimir el de Ttrentula como genérico cntre las Lycosoidae, reservándolo para el g. Phrymus, por ser aquel más antiguo (III, 233).

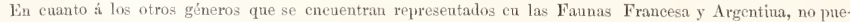
den ser motivo, en este momento, de observacion algua. Mis especics están demasiado detalladamente deseritas para que no puedau servir a la crítica. 


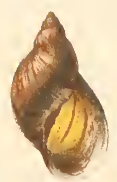

Fii, /

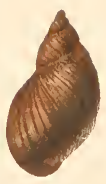

Ii, I"
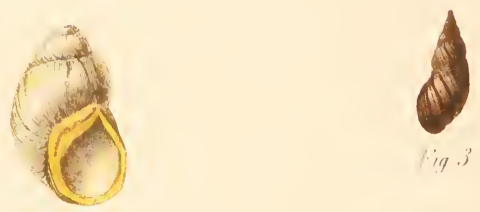

fiil 4

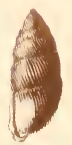

liig. 6

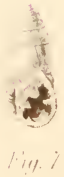

13

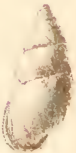

limi l' 


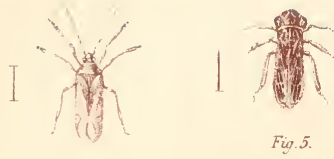

Fo. 4

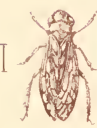

Fig. 8.

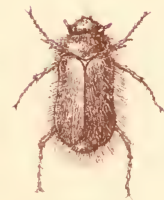

Fig. 13
1 的

Fin. :

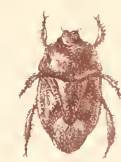

Fig.

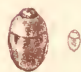

Fì. 2
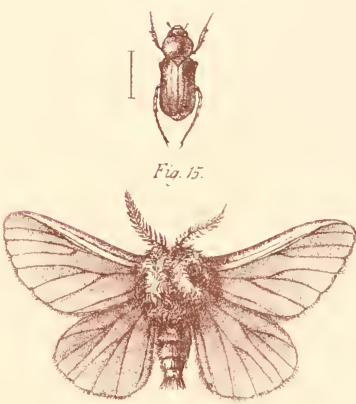

Fig. II.

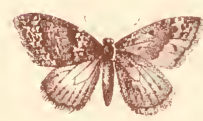

Fig. 12

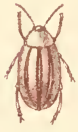

Fia. 19

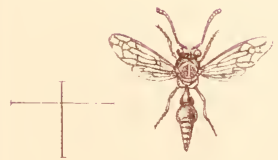

Fig. 19
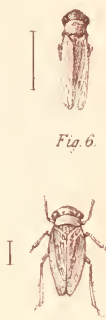

Fig 9

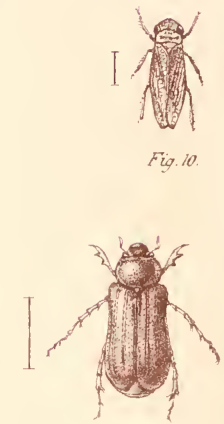

Fira. 14

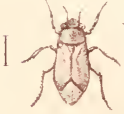

Fig. 3.

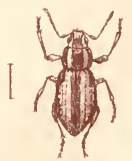

Fig. 16
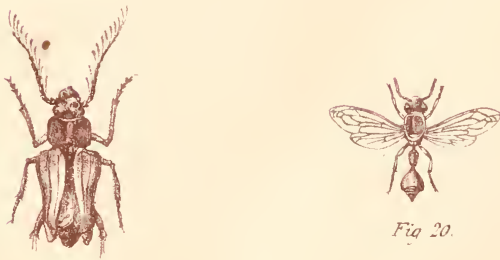

Fia 20 
Mrivingos 70)(0LO):I.1

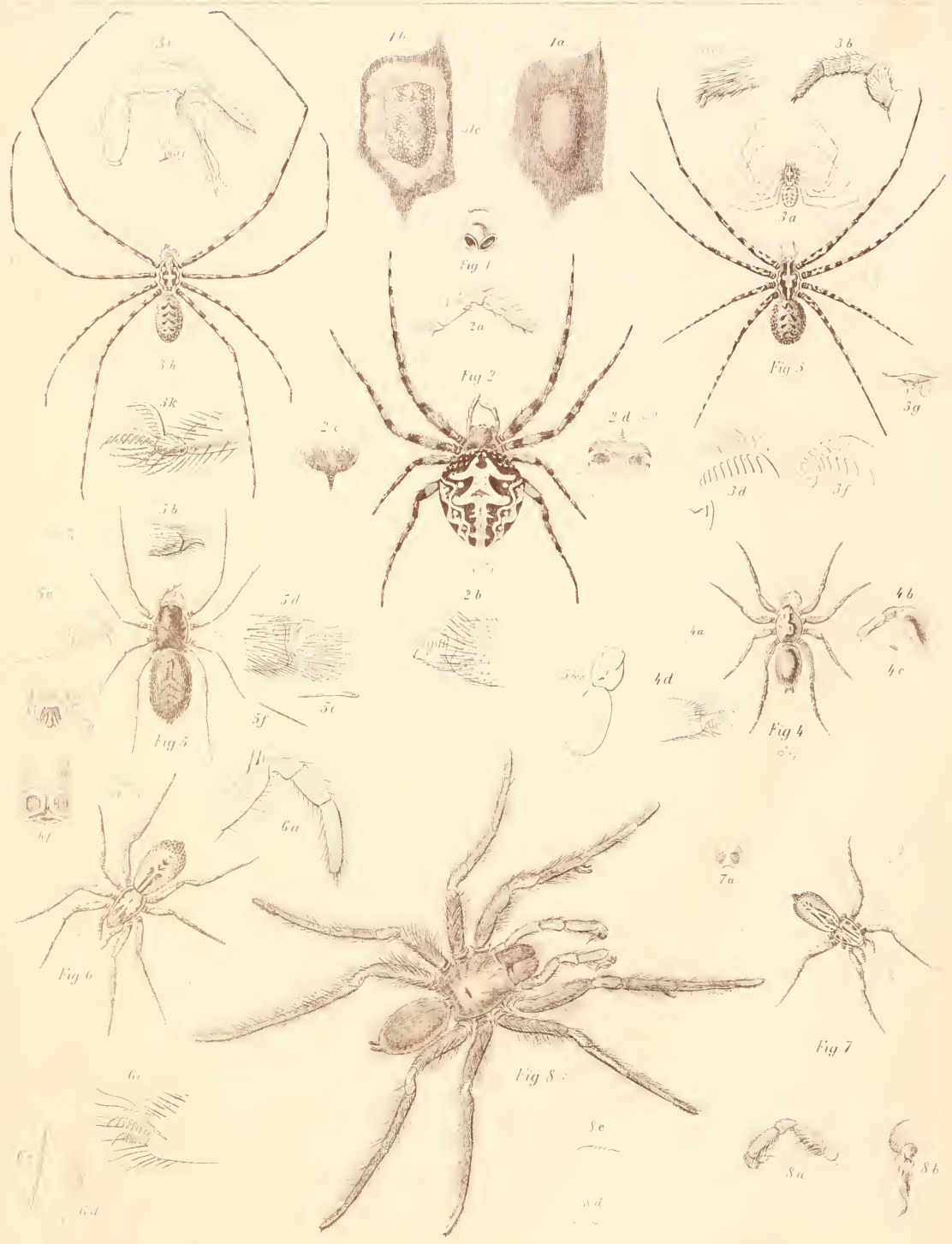




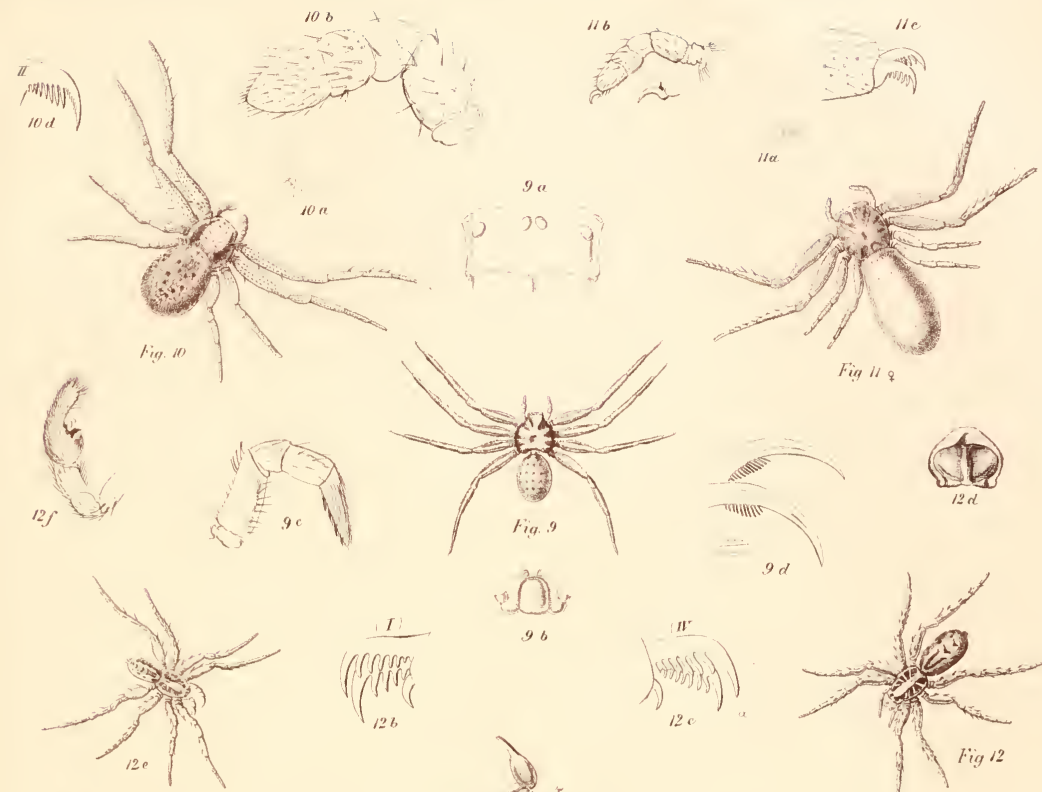

(1).
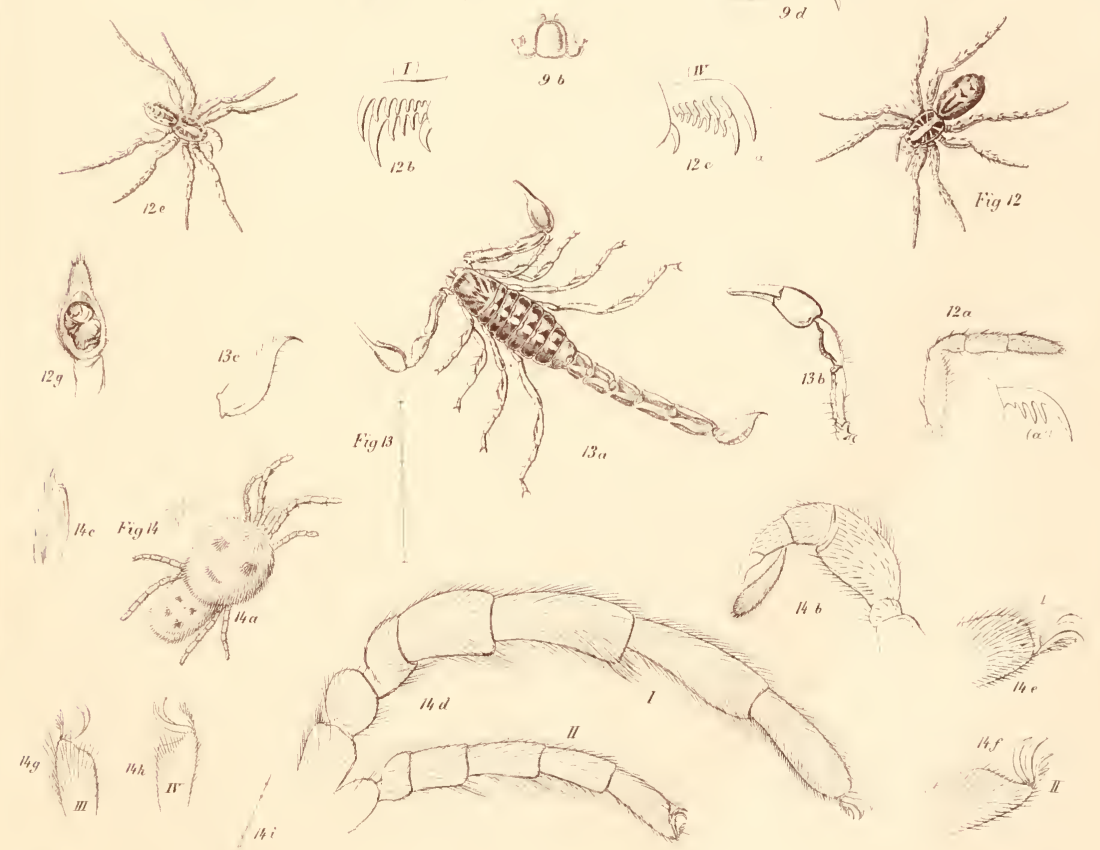

$\left.14 \mathrm{~g}\right|_{\text {III }} 14 \mathrm{~h}$
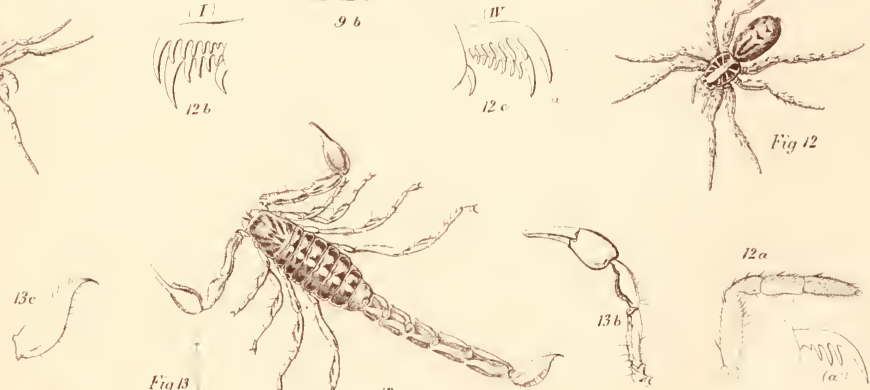
Figl 3

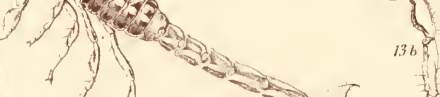

$\int(\alpha)$
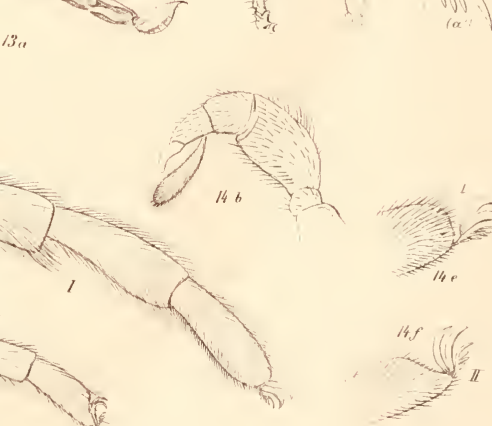

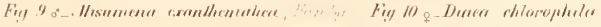

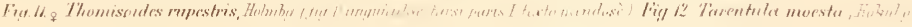

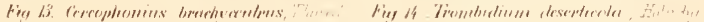





\section{ERROREE TIPOGRÁFICOS}

\begin{tabular}{|c|c|c|c|c|c|}
\hline Piging & lillea & & & Dive & Léase \\
\hline 24 & 7 & (de abajo & & Balcheta & Clichinat. \\
\hline 25 & $\because$ & & & pasada & parada \\
\hline$s$ & . & $($ id & ) & ne & de \\
\hline 27 & 7 & ( id & ) & remueve & renueva \\
\hline 28 & 15 & & & tija & tifa \\
\hline 29 & 10 & & & ancas & ansas \\
\hline 30 & 5 & & & Plunorbis & Planorbis \\
\hline 32 & 17 y 18 & & & en tauto & tanto en \\
\hline 45 & 7 & & & it la cual es easi & á la cual es \\
\hline 45 if 47 & & & & Harigularis & flavogularis \\
\hline$\therefore 1$ & 14 & & & de la balcheta» & del Chichinal \\
\hline 63 & 3 & id & ) & levigata & laevigata \\
\hline 66 & 2 & & & ealcarent & caleareus \\
\hline " & 9 & ( id & ) & it al márgen & í la márgen \\
\hline 81 & 16 & ( il & ) & roturedato & rotundato \\
\hline "s & 8 & id & ) & untidos & hundidos \\
\hline 82 & 14 & ( in & ) & 24 & 24 bis \\
\hline 84 & 1: & ( id & ) & conservaba & conservó \\
\hline 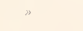 & 12 & ( id & ) & alguna & ninguna \\
\hline 88 & 4 & & & PROATMLA & BONAERENSIS \\
\hline " & 16 & & & contem & hortem \\
\hline$\therefore$ & 9 & iil & ) & primera & segunda \\
\hline 89 & 9 & id & ) & Havescens & griseo-flants \\
\hline & 1 & it & ) & suprímase toda la linea, menos & "Esta Saronplatga \\
\hline 90 & 1 & & & id "si este fuese aceptad & $10 \%$ \\
\hline , & $1: 3$ & ( il & ) & isto & hoe \\
\hline 97 & 1 & & & PLNCTULATLS & PUNCTATLS \\
\hline 98 & 19 & & & rijidos & rịjidas \\
\hline $10 i$ & 3 & & & colomo & coloma \\
\hline $1+1$ & 14 & & & parum plus & parum (sólo en algunos números). \\
\hline 142 & 5 & & & serie & series \\
\hline 16.5 & + & id & ) & alteram transwersan & altera transversa. \\
\hline
\end{tabular}





\section{PLAN DE LA OBRA}

Esta obra aparecerá en cuatro entregas, con las siguientes materias:

\section{Entrega I. ZOOLOGIA (ha aparecido).}

Por el Dr, D. Adolfo Doering, con la colaboracion de los Drs. D. Cárlos Brrg y D. Eduardo L. Holmberg y de D. Enrique Lynch Arribálzaga.

Introduccion, por D. A. Ebelot.

1. Observaciones genera'es sobre la fauna del territorio conquistado, por el Dr. D. Adolfo Doering.

2. Enumeracion sistemática de las especies observadas durante la expedicion.

a. Vertebrados, por el mismo.

b. Mroluscos id.

c. Insectos. Por el Dr. D. Cárlos Berg y D. Enrique Lynch Arribálzaga.

d. Arácnidos. Por el Dr. D. Eduardo L. Holmberg.

$$
\text { Entrega II. BOTANICA (aparece ahora). }
$$

Por el Dr. D. P. G. Lorentz y D. Gustavo Niederlein.

$$
\text { Entrega III. GEOLOGLA, (próxima á aparecer). }
$$

Por el Dr, D. Adolfo Doering.

I. Formaciones eruptivas y primitivas.

A. Las serranías de la Pampa oriental.

1. El sistema dela Cadena del Tandil.

2. El sistema de la Sierra de la Ventana.

B. Las serranías de la Pampa Occidental.

a. Serranías al Sur del paralelo $37^{\circ}$ 1. S.

1. La Sierm de Pichi-Mahuida.

2. " " "Choique-Mahuida.

3. " " " Lihué-Calel.

4. " " " Calen-Có.

5. " " " Luan-Mahuida.

b. Serranias al N. del paralelo $37^{\circ}$ I, S.

1. La Sierra de Currú-Mahuida.

C. Las serranias de la precordillera.

1. La Sierra de Cochi-Co.

2. " " "Luan-Có.

II. Formacion terciaria.

III. Formacion cuaternaria.

IV. Formaciones modernas.

1. Los terrenos del Sur.

2. Las aguas saladas.

3. " " dulecs.

\section{Rutrega IV, DIARIO DE LA COMISION CIENTHFICA.}

Por el Dr. D. P. G. Lorentz y el Dr. D. Adolfo Doering, con la col, de D. Gustavo Niederlein.

1. De Buenos Aires á Carhué.

2. De Carhué al Rio Colorado.

3. En el valle del " "

4. ". " " " " Negro.

5. Desde el Nauquen lasta Mendoza, por D. Gustavo Niederlein. Apéndice. 




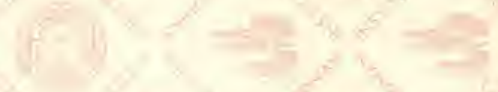

14
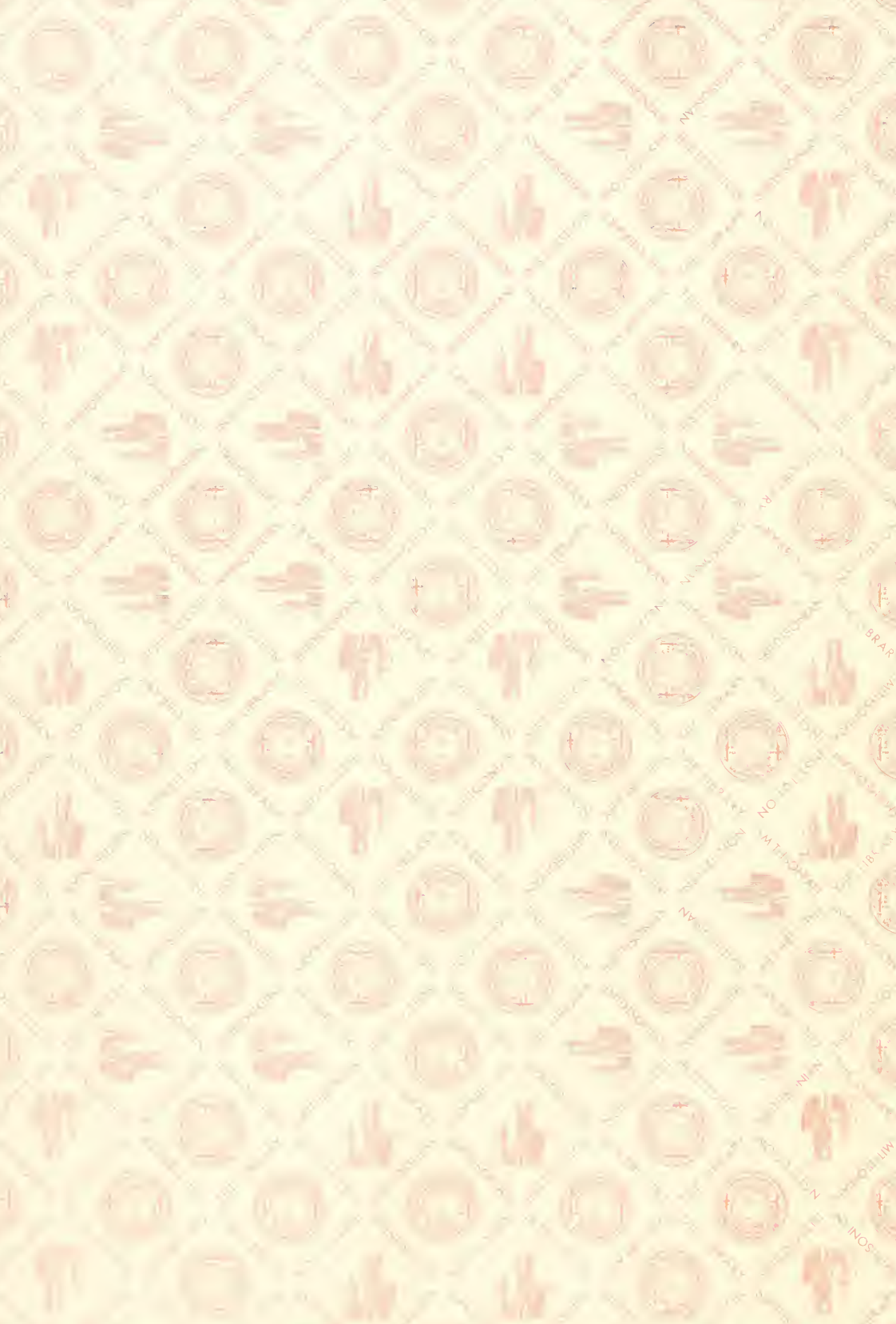

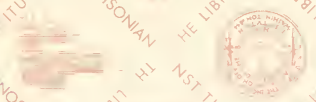

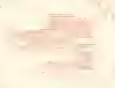

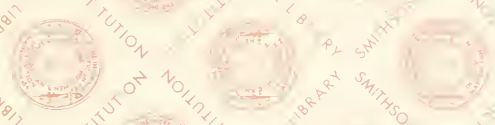

迹
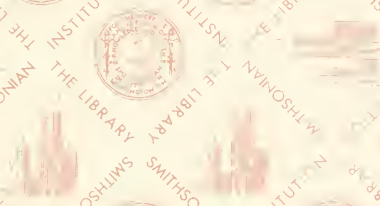

$\left(\begin{array}{c}3 \\ -1\end{array}\right.$
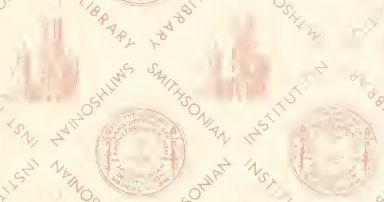

the

its

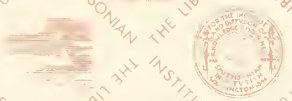
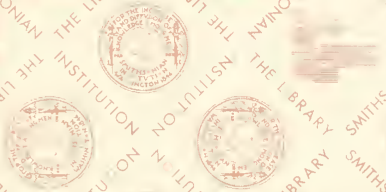

$=$
$=-1$
$-=$
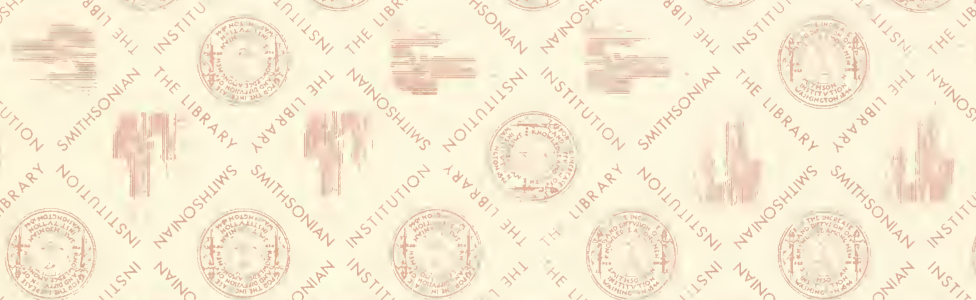

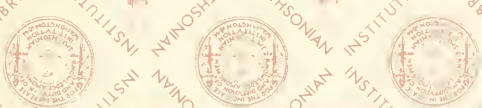

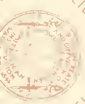

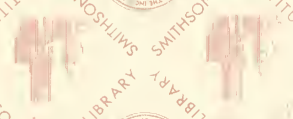

$=$

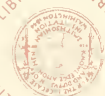
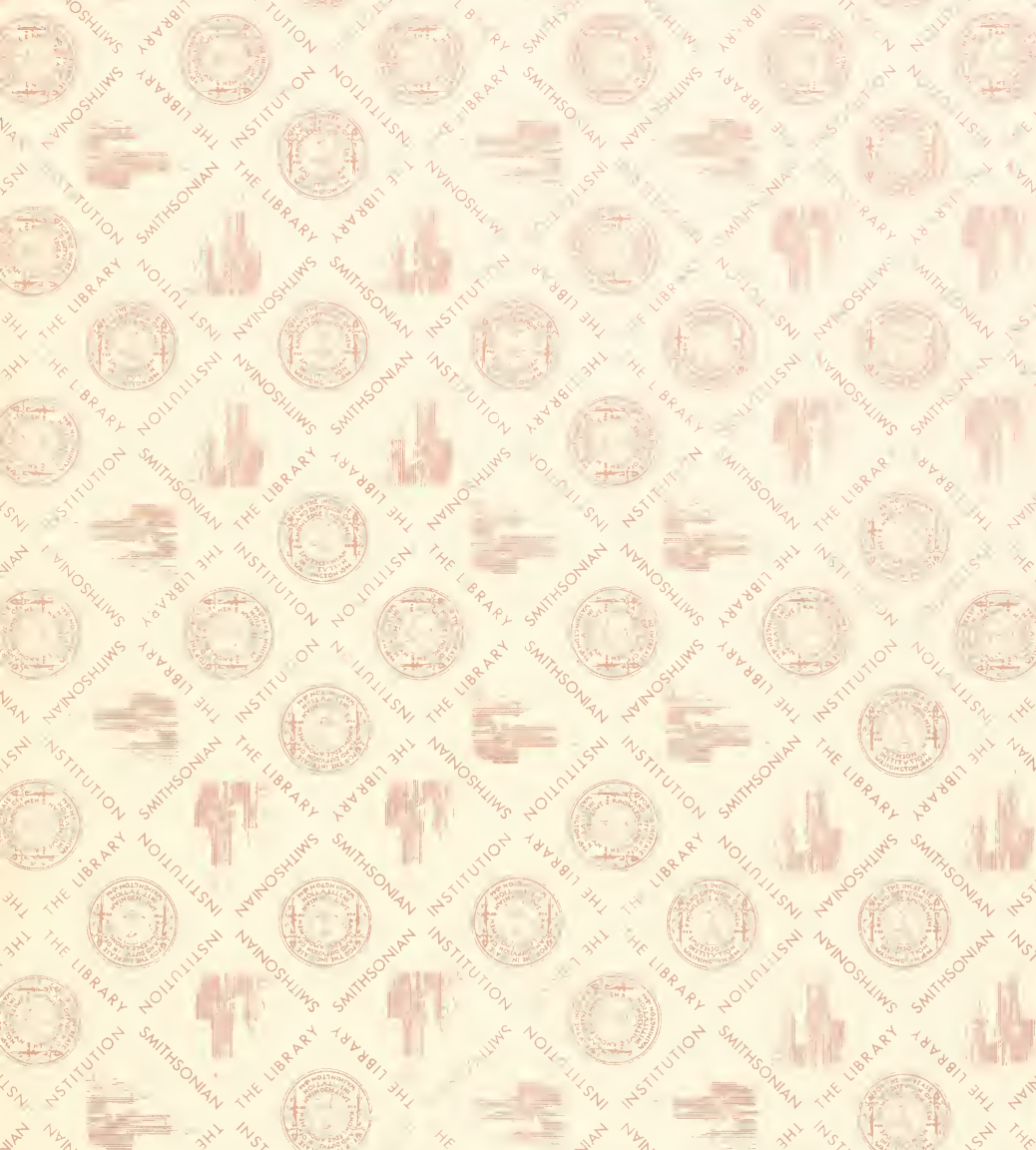

$x_{1}^{2}=$
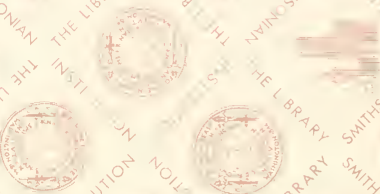

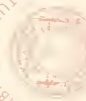
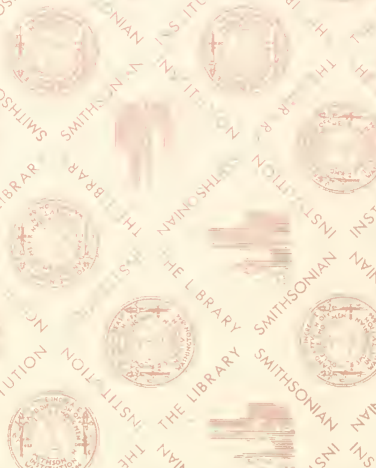

$\left.(4)^{2}\right)^{3 / 2}=$

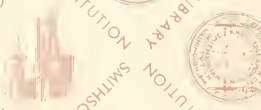
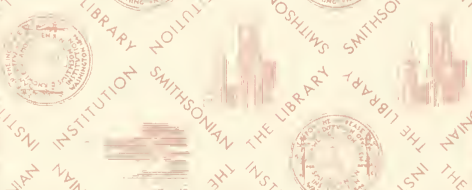

if
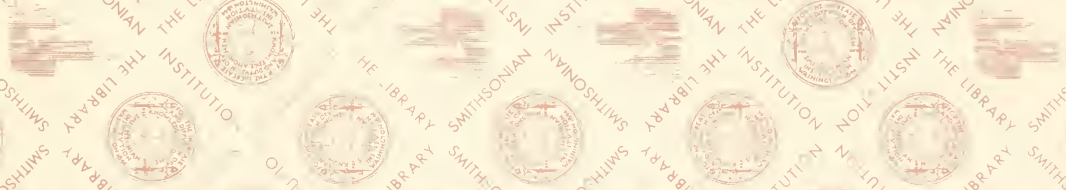

$={ }^{2}=11$
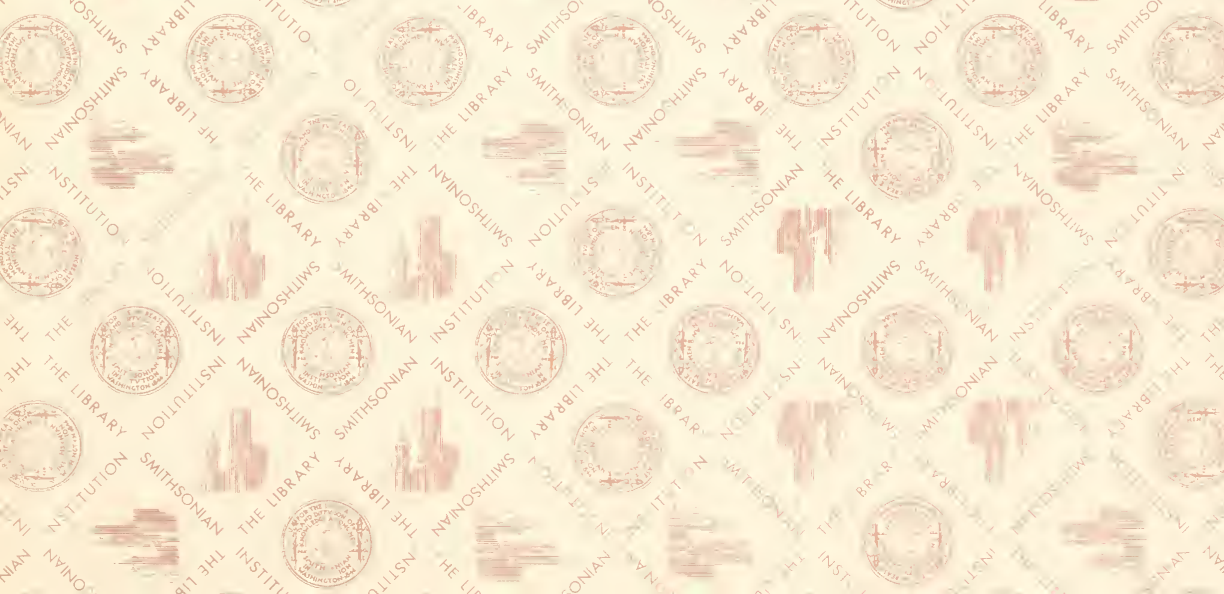
